M0017142SR

7548949

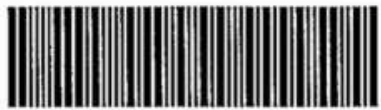

UNIVERSITY OF SURREY LIBRARY 
The quality of this reproduction is dependent upon the quality of the copy submitted.

In the unlikely event that the author did not send a complete manuscript and there are missing pages, these will be noted. Also, if material had to be removed, a note will indicate the deletion.

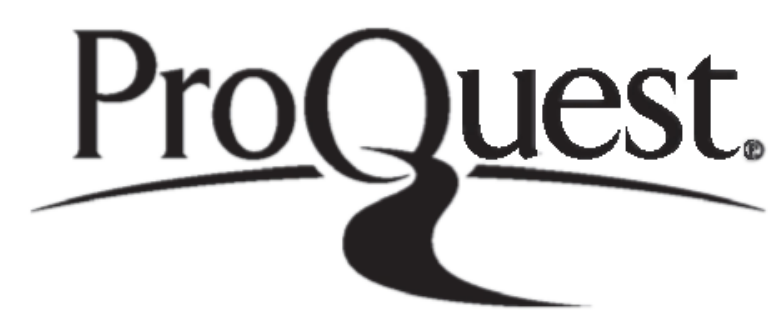

ProQuest 10130509

Published by ProQuest LLC (2017). Copyright of the Dissertation is held by the Author.

All rights reserved.

This work is protected against unauthorized copying under Title 17, United States Code Microform Edition () ProQuest LLC.

ProQuest LLC.

789 East Eisenhower Parkway

P.O. Box 1346

Ann Arbor, MI 48106 - 1346 


\section{Sulphur Doped Silicon Light Emitting Diodes}

\section{Sotiria Galata}

Submitted for the degree of Doctor of Philosophy (Ph.D.) from the University of Surrey

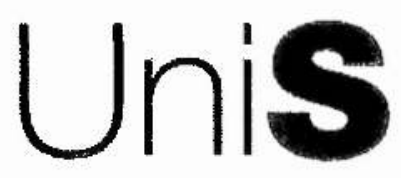

Advanced Technology Institute,

School of Electronics and Physical Sciences, University of Surrey,

Guildford, Surrey, GU2 7XH, UK

February 2005

(C) S Galata 2005 


\section{ACKNOWLEDGEMENTS}

I would like to thank sincerely my supervisor Prof. K. P. Homewood for his continuous guidance, encouragement, advice and support throughout the progress of my research. I extent my gratitude to Dr. M. Lourenço for her generous guidance regarding the experimental part of my work.

I would also like to thank Dr. R. Gwilliam, Dr. M. Milosavljevic, Dr. P. Hydon and Dr. S. Ahmed for their suggestions and several interesting discussions.

I would like to express my gratitude to Prof. R. Webb and Prof. B. Sealy for their encouragement and for providing me with the necessary fundings.

My appreciation goes to the computer staff members, Mr D. Patto and Mr B. King for their technical support.

I would like to thank my parents Fragiskos and Irini and my brother Petros Galatas, for their constant moral and financial support and for having faith in me. Finally, I would like to thank Dr. A. Kesidis for his continuous moral support and patience with me.

Guildford, December 2004 


\begin{abstract}
In this thesis light emission from sulphur related impurity in silicon has been reported. Although, sulphur related luminescence from silicon has been stated since the 1980 's, no room temperature luminescence has been achieved and no compatible devices that can be integrated to the silicon technology have been invented.

Photoluminescence and electroluminescence experiments were made on a set of samples implanted with only with sulphur at doses ranging from $10^{11}-10^{14} \mathrm{~S} \mathrm{~cm}^{-2}$ at 30 $\mathrm{keV}$, annealed at $1000^{\circ} \mathrm{C}$ or $1100^{\circ} \mathrm{C}$ for $10 \mathrm{~s}$ and on another set of samples implanted with sulphur as above and further implanted with boron at $10^{15} \mathrm{~B} \mathrm{~cm}^{-2}$ at $30 \mathrm{keV}$, further annealed at $950^{\circ} \mathrm{C}$ for $1 \mathrm{~min}$.
\end{abstract}

The experiments revealed two major emissions at $1129.5 \mathrm{~nm}(1.0997 \mathrm{eV})$ which is due to the $\mathrm{Si}$ TO phonon assisted transition and at $1363 \mathrm{~nm}(0.9097 \mathrm{eV})$ which is due to sulphur related impurities. Variable temperature experiments were done at both PL and EL experiments. From the EL variable temperature measurements, it was observed that the two main lines were shifting towards longer wavelengths with the increase of temperature. Sulphur emission was present at room temperature with low intensity compared to the silicon emission which was more dominant at room temperature. Of great interest was the effect of power on silicon and sulphur emission. It has revealed a sublinear and a superlinear behaviour for the sulphur and silicon integrated intensity respectively with the increase of the injection condition, which can be attributed to the saturation of sulphur related levels responsible for the $1.33 \mu \mathrm{m}$ emission at the high excitation levels.

A model of the diffusion of sulphur concentration after the annealing treatments was presented, introducing the two cases of perfect reflection and perfect loss from the samples surfaces. Finally a model explaining our PL and EL power dependence experiments was provided which showed that there are two major radiative routes via the silicon and the sulphur that take place, which are competing at each other along with a non-radiative route coming from the sulphur-related level. Our model describes the trends in our experimental data well. Finally, the energy related to the sulphur peak quenching was calculated to be $32.2 \pm 1.4 \mathrm{meV}$. 


\section{CONTENTS}

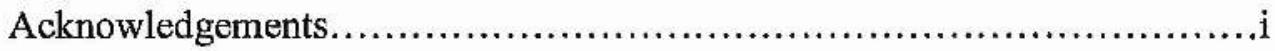

Abstract......................................................................

Contents..............................................................

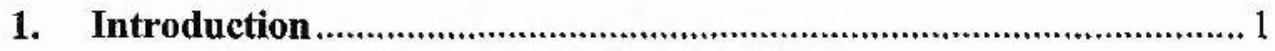

1.1 Introduction - Light Emission from Silicon ................................... 1

1.2 Sulphur related luminescence ....................................................... 3

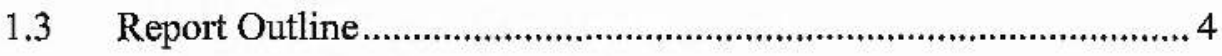

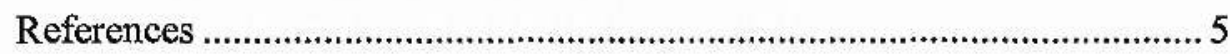

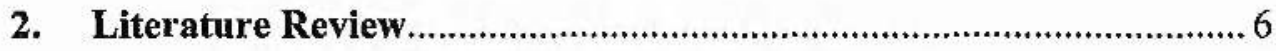

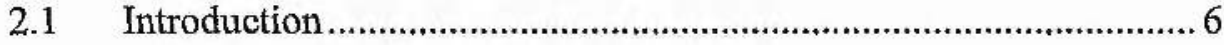

2.2 Light Emission from Silicon based Materials ................................ 6

2.2.1 Porous Silicon............................................................................... 7

2.2.2 SiGe Alloys and Superlattices ............................................ 10

2.2.3 Iron Disilicide ................................................................. 13

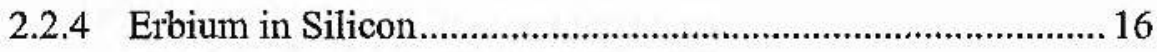

2.2.5 Defect and Dislocation related Luminescence ...................... 19

2.2.6 Dislocation Engineering Luminescence .................................22

2.2.7 Isoelectronic Impurities .....................................................24

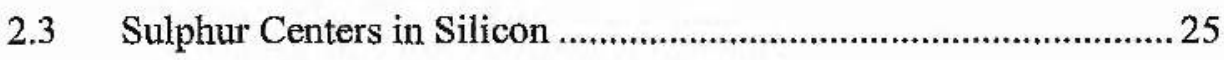

2.3.1 Light Emission from Sulphur Doped Silicon .......................25

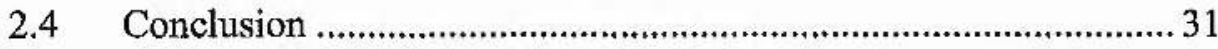

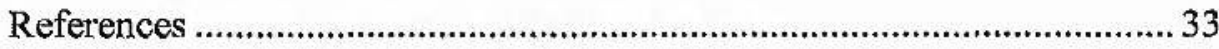

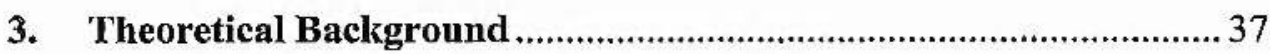

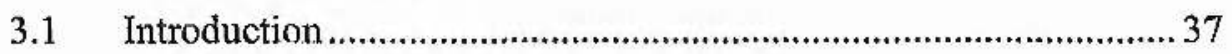

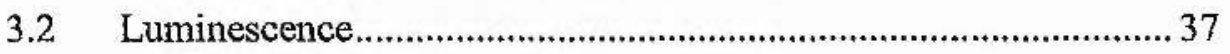

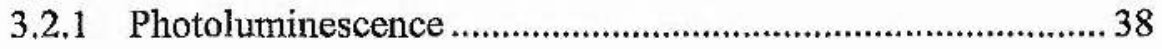




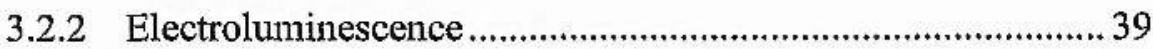

3.3 Silicon - an Indirect Band Gap Material ......................................... 40

3.4 Intrinsic Luminescence in Silicon................................................... 42

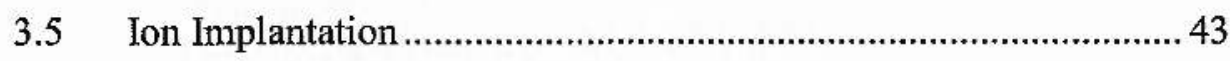

3.6 Defects in Silicon .......................................................................... 46

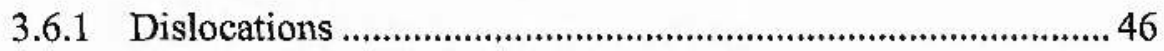

3.7 Light Emitting Diode (LED) ……………….................................. 49

3.7.1 External Efficiency - Calculation of the Extraction Efficiency $\eta_{\mathrm{e}}$ and the Detector Collection Efficiency $\eta_{\mathrm{D}} \ldots \ldots \ldots \ldots \ldots \ldots . . . . . . . . . . . . .50$

3.8 Proposed Model for our Sulphur-based Light Emitting Device .... 57

References

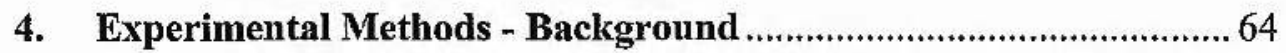

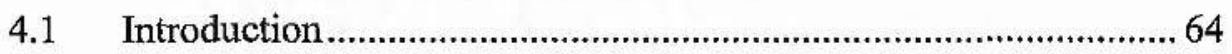

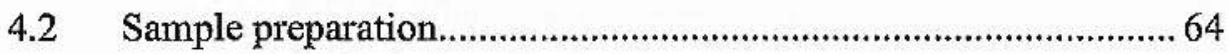

4.3 Light Emitting Diode (LED) Fabrication.......................................... 65

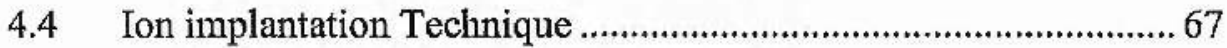

4.5 SIMS - Secondary Ion Mass Spectrometry ……………….............69

4.6 Photoluminescence Spectroscopy ...................................................71

4.7 Electroluminescence Spectroscopy ………………......................... 74

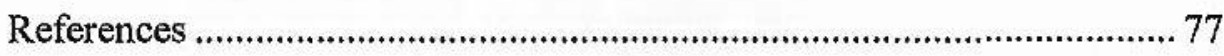

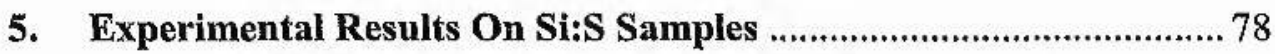

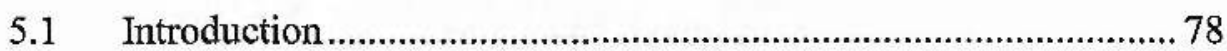

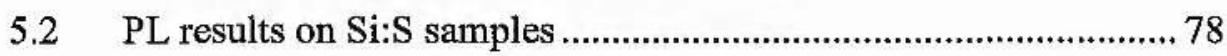

5.2.1. PL variable temperature measurements.................................... 78

5.2.2. PL variable power measurements ........................................... 98

5.3 EL results on Si:S samples.......................................................... 108

5.3.1. EL variable temperature measurements.................................. 108

5.3.2. EL variable current measurements ........................................ 129

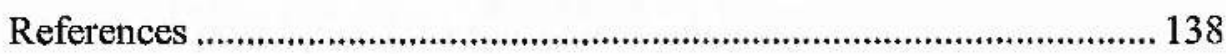

6. Discussion On Si:S Samples …………….....................................139

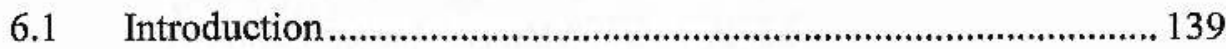


6.2 Discussion on PL results from Si:S samples.............................. 139

6.2.1 Peak positions and thermal quenching ............................... 140

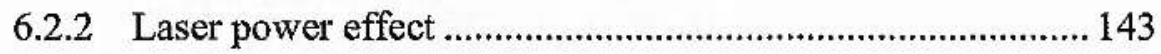

6.3 Discussion on EL results from Si:S samples …......................... 145

6.3.1 Peak positions and thermal quenching .............................. 146

6.3.2 Current dependence ............................................................ 147

6.3.3 Effect of implantation dose and annealing conditions.......... 149

6.3.4 Explanation of results and modelling of sulphur diffusion .. 153

6.3.5 Model explaining the power and current dependence

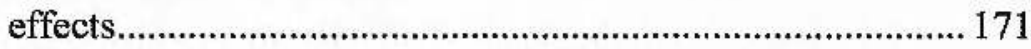

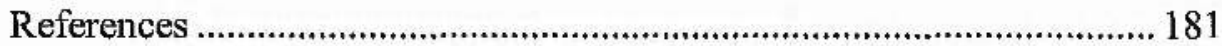

7. Conclusions And Recommendations for Further Work ................. 182

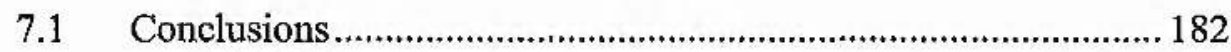

7.2 Recommendations for further work ......................................... 183 


\section{INTRODUCTION}

\subsection{Introduction Light Emission from Silicon}

Silicon is the most fundamental material in the semiconductor technology. This is due to its excellent electronic properties in terms of high-density functionality, its low cost and its wide availability still in nature. Because it is easy to handle and manufacture, more that $95 \%$ of the semiconductor devices fabricated are based on silicon. Furthermore, the big trend of the last 20 years in optoelectronics to incorporate optical devices such as lasers and detectors, optical modulators, LEDs and waveguides within the established silicon microelectronics industry has led to heavy investment in silicon based technology. Much of this work is being carried out with group III-V semiconductors such as GaAs and InP, whose optical properties are well suited to such devices. However, the fabrication of these alloys on a silicon substrate is difficult and expensive because there are not many resources left from these materials for many more years and also it involves toxic processing with regard to the silicon technology. Therefore the desire to use silicon material for such devices is overwhelming and continuing.

Although $\mathrm{Si}$ is technologically superb for electronic applications in terms of integration control and cost, its main problem is that it is an indirect band gap semiconductor and, therefore emits light very feebly. In order to overcome this problem a lot of money has been invested in materials science engineering. There has been a tremendous development in growth over the last decade in a wide variety of materials systems and techniques. In the semiconductor field, techniques, such as ion implantation are used in order to introduce atoms into the surface layer of solids modifying their properties. Such techniques can result in alteration of the electronic and optical properties of bulk materials. These techniques are being applied here in order to overcome the weak light emission in silicon. 
The computer processor power and speed is growing exponentially over the years. This has been achieved by integrating more and more transistors on chip due entirely to decreasing transistor size which is decreasing, yielding significant reduction in cost per bit. Although the operating speed of the microelectronic devices is increasing, there is a limitation due to 'the interconnect' [1]. Metallic contacts are being used so far to interconnect the increasing number of transistors on a single chip. On the other hand, the time delay associated with electron transport in the metallization does not decrease. Therefore, there will be a point where the computer chips will not keep getting faster. A solution to this problem could be the replacement of some of the metallic interconnects with optical ones on a chip [2]. In addition to this, a silicon based light emitter would be the ideal solution because it will lead to faster chips at lower cost.

Significant progress has been made to such an extent that bright light emitting devices are now being produced from silicon. Different approaches have been used in order to achieve light emission from Si. Those approaches differ in the material used and its preparation, in the material properties and theory and operation, as well as the device fabrication and properties. In particular, some of the most important techniques which have been used in that direction are listed below:

- Dislocation engineering in silicon

- Impurity centres in silicon

- Iron disilicide

- Rare earth doping in $\mathrm{Si}$

- Silicon nanostructures

- Porous Si

- Atomic layer superlattices

All the above techniques try to minimize the cost of fabrication, to increase the efficiency of the LED devices and finally to become as compatible with ULSI technology as possible, making them more commercially viable. 
A very promising technique which has been reported quite recently is the defect controlled luminescence from silicon. This technique was not very popular among researchers because dislocations are generally considered to be damaging to device performance in crystalline $\mathrm{Si}$. W. L. $\mathrm{Ng}$ et al. [3] reported electroluminescence and photoluminescence from dislocated $\mathrm{Si}$ at room temperature. The dislocation loops were introduced into silicon by ion implantation of Boron. The room temperature EL spectrum had the main peak at 1,160 $\mathrm{nm}$ and the external quantum efficiency that was achieved at room temperature was estimated to be in the order of $2 \times 10^{-4}$. V. V. Kveder et al. [4] and E. O. Sveinbjörnsson [5] reported also room temperature electroluminescence from Si containing threading dislocations. The dislocation layer though was formed differently using high power laser melting and the external power efficiency of the D1 line electroluminescence at room temperature was estimated to be in the order of $10^{-6}[5]$, which is lower than W. L. $\mathrm{Ng}$ et al. [3] reported.

\subsection{Sulphur related luminescence}

The interest in sulphur related luminescence has emerged after a report from T. G. Brown and Hall [6] and consequently from P. L. Bradfield et al. [7]. They observed that from sulphur related centres isoelectronic bound excitons could be activated with photoluminescence emissions near $1.3 \mu \mathrm{m}$ and $1.5 \mu \mathrm{m}$. The importance of isoelectronic impurities lies in their ability to bind excitons, resulting in efficient radiative recombination of electrons and holes. These reports stated high quantum efficiencies up to $5 \%$ at low temperatures but with no emission at room temperature. This rather high quantum efficiency suggests this centre may be interesting especially if it is combined with the successful dislocation engineering [3]. Moreover, a Si:S light emitting diode (LED) could be a new route towards the silicon optical emitter. 
This study aims to continue the work on a practical based light emitting diode. This will be achieved by introducing dislocation loops into $\mathrm{Si}$ and in particular additional impurities, such as sulphur, under a range of implant and process conditions.

\subsection{Report Outline}

In this chapter the subject has been introduced. In chapter 2 , is presented a literature review on the light emission from silicon based materials and defect related luminescence. The experimental theory along with the theory of defects induced by ion implantation and sulphur impurities and a calculation of the extraction and detector collection efficiency of our devices is presented in chapter 3. In chapter 4 will be shown the experimental techniques used for the formation, growth and characterisation of the sulphur dislocation-rich samples. The experimental results of the above samples will be presented and discussed in chapters 5 and 6 , respectively and finally in chapter 7 , the conclusion on our results and recommendations for the future work will be given also. 


\section{References}

[1] L. Pavesi, J. Phys. Condens. Matter 15 R1169 (2003).

[2] M. A. Lourenço, W. L. Ng, G. Shao, R. M. Gwilliam and K. P. Homewood, SPIE Proceedings 4654, 138 (2002).

[3] W. L. Ng, M. A. Lourenço, R. M. Gwilliam, S. Ledain, G. Shao and K. P. Homewood, Nature 410, 192 (2001).

[4] V. V. Kveder, E. A. Steinman, S. A Shevchenko and H. G. Grimmeiss, Phys. Rev. B 51, 105020 (1995).

[5] E. Ö. Sveinbjörnsson and J. Weber, Appl. Phys. Lett. 69, 2686 (1996).

[6] T. G. Brown and D. G. Hall, Appl. Phys. Lett. 49, 245 (1986).

[7] P.L. Bradfield, T. G. Brown and D. G. Hall, Appl. Phys. Lett. 55, 100 (1989). 


\section{LITERATURE REVIEW}

\subsection{Introduction}

Silicon is the most fundamental material of integrated circuits because of its ability to support high-density electronic functionality. Silicon has a band gap $(\sim 1.12$ $\mathrm{eV})$ that is ideal for room temperature device operation and an oxide $\left(\mathrm{SiO}_{2}\right)$ that provides the necessary processing flexibility to place $10^{8}$ and more devices on a single chip. The high level of integration has resulted in high speed device performance ultimately limited by the interconnect propagation delay between devices. The integration of optical interconnection with silicon microelectronics could be used in order to overcome this limit to the speed problem. This has stimulated significant effort towards developing silicon-based optoelectronics components.

Unfortunately, silicon is a poor light emitter because of its indirect band gap structure. Therefore, many remarkable efforts have been reported recently by various groups in order to overcome the indirect band gap limitation. Those efforts make use of porous silicon, $\mathrm{SiGe}$ alloys and superlattices, iron disilicide, erbium impurity doping, defect and dislocation related luminescence, isoelectronic impurities and finally sulphur impurity doping which is also the main part of the thesis. A review of the relevant literature is presented in this chapter.

\subsection{Light Emission from Silicon based Materials}

In this section, the different attempts for light emission from silicon which have been mentioned in the introduction will be reviewed. 


\subsubsection{Porous Silicon}

Porous silicon was discovered in 1956 by Ulrich [1]. It is formed by electrochemical etching in an HF solution under an anodic current. The remaining deep and narrow pores form arrays which generally run perpendicular to the $\mathrm{Si}$ surface. Using specific etching conditions pores could be made measuring nanometers across and micrometers deep.

In 1984 C. Pickering et al. [2] reported PL from high and low resistivity porous silicon (PS) films in the deep red-near infrared at $4.2 \mathrm{~K}$. The interest for porous silicon increased after a report from L. T. Canham [3] in 1990. Canham demonstrated that when porous $\mathrm{Si}$ is further etched in HF for hours after preparation, it emits bright red light under illumination with blue or UV light. (In Figure 2.1 is shown the room-temperature PL as observed by Canham). This luminescence emission was attributed to silicon quantum wires, which have a larger band gap than bulk crystalline Si because of the quantum confinement of the carriers, resulting in a widening of the band gap.

M. Koós et al. [4] in 1993 observed a PL blue shift in PS with increasing excitation intensities at $80 \mathrm{~K}$ and at room temperature. They also observed that by increasing the excitation intensity further, the PL intensity saturated, but the blue shift was not observable in this range. This behaviour was explained by a nanoparticle model in which the absorption and also the PL take place in the independent individual particles. A. Nakajima et al. [5] demonstrated that porous Si contains Si microcrystallites with sizes ranging from 3 to $20 \mathrm{~nm}$ randomly distributed; knowing the concentration of these structures, the emission of the porous $\mathrm{Si}$ was attributed to three-dimensional carrier confinement in the unlinked $\mathrm{Si}$ microcrystals, rather than to the threadlike structures. 


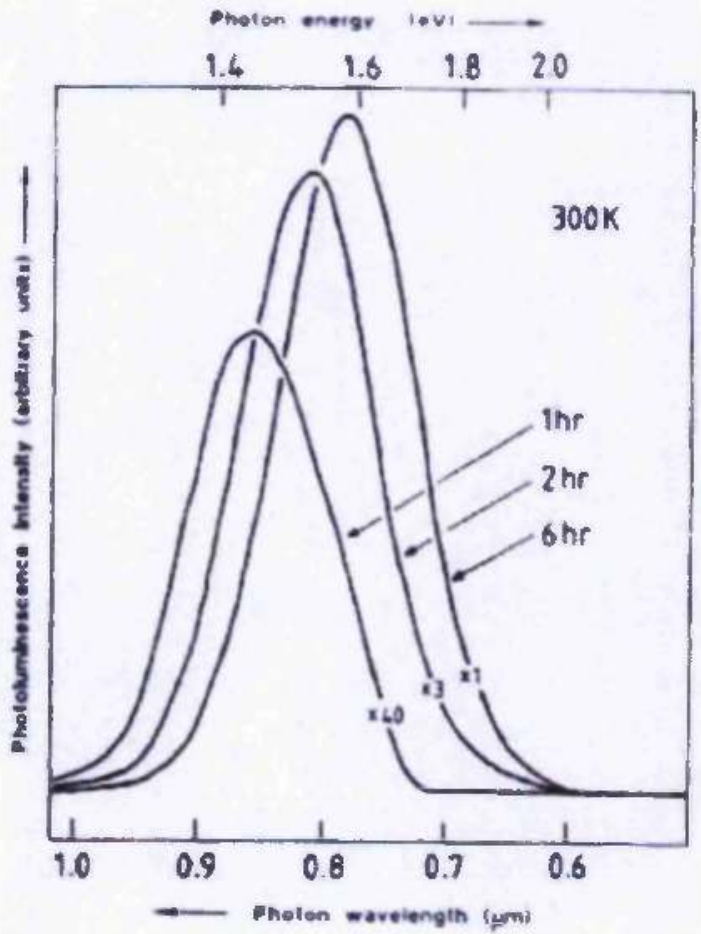

Figure 2.1 Room-temperature photoluminescence from an anodized $\mathrm{p}^{-}$wafer after immersion in $40 \%$ aqueous HF for the times indicated. Spectra were taken with $200 \mathrm{nW}$ unfocused $5145 \AA$ laser excitation incident on the sample in air and amplified by the relative gains indicated. (After L. T. Canham [3]).

W. L. Wilson et al. [6] detected visible (red) PL in isolated and perfectly passivated Si quantum dots with $50 \%$ quantum efficiency at low temperature. They observed that porous $\mathrm{Si}$ is not made of perfectly isolated and passivated quantum dots and therefore nonradiative recombination took place, at a reduced rate. D. J Lockwood $[7,8]$ attributed the red emission in PS due to confinement in Si nanocrystallites and the blue PL, which was produced from oxidation of PS to originate from the small $\mathrm{c}-\mathrm{Si}$ core region. In addition, he noted that the $\mathrm{PL}$ in porous silicon is very sensitive to the chemistry of porous Si production and treatment [7].

A few years ago it was reported $[9,10,11,12]$ that porous Si LEDs could be integrated to into Si microelectronic devices in order to provide an addressable LED display [10] (see Figure 2.2). Also demonstrated was PL and EL at room temperature, although with low quantum efficiencies. L. Tsybeskov et al. $[11,13]$ 
achieved silicon band-edge photoluminescence and electroluminescence at room temperature with a photon energy of $1.1 \mathrm{eV}$. The external quantum efficiency for the PL was estimated to be better than $10^{-3}$ in samples prepared by high temperature oxidation of porous silicon. The PL spectrum peak was shifted and became broader as the temperature was increased. In the temperature region from $12 \mathrm{~K}$ to $50 \mathrm{~K}$ the PL peak revealed a small shift towards shorter wavelengths and at temperatures greater than $70 \mathrm{~K}$ the PL peak was shifted to longer wavelengths. This emission was believed to be due to $\mathrm{Si}$ band edge radiative recombination and to originate from large silicon clusters within a nonstoichiometric silicon-rich oxide (SRSO) matrix. The EL was only weakly dependent on temperature and measurable with a current density of $<10 \mathrm{~mA} / \mathrm{cm}^{2}$. After etching of their LED device, there were revealed nearly spherical, densely packed Si grains of around $100 \mathrm{~nm}$ diameter which were observed by atomic force microscopy (AFM). The carrier transport mechanism was believed to be field-assisted tunneling [12].

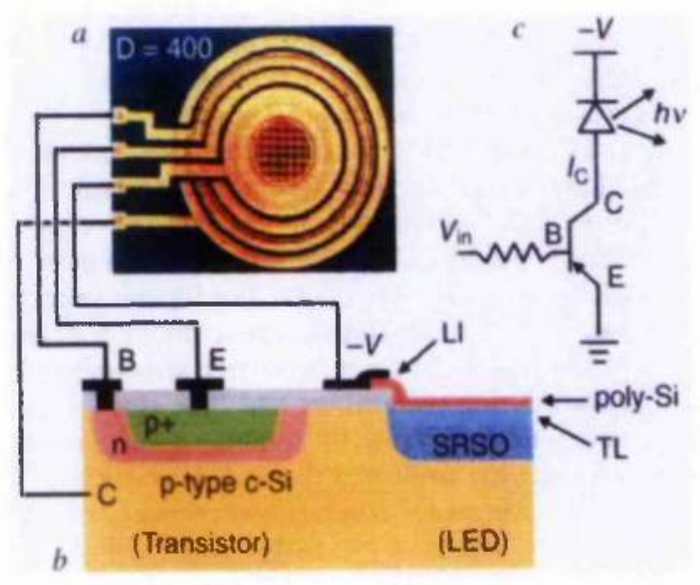

Figure 2.2 Micrograph of an integrated LED porous $\mathrm{Si}$ LED/ bipolar transistor device operational at room temperature, plan view (a), along with the cross section (b) and the equivalent circuit (c). The LED is in the middle of the structure and has a $400 \mu \mathrm{m}$ diameter light- emitting area. Partial oxidation of porous $\mathrm{Si}$ in a dilute oxygen ambient has produced Si nanoclusters within an oxide matrix - Si-rich Si oxide (SRSO). (From Hirschman et al. [10]).

The first published report of high efficiency was in the pulsed mode of operation only [14]. The reported EL quantum efficiency was $\sim 0.16 \%$ under pulsed 
conditions which corresponds to an internal quantum efficiency as high as $2.3 \%$. The above device has severe limitations on its repetition rate and its lifetime. Also, it has poor diode I-V characteristics with ideality factors of $>10$. Quite recently, L. Pavesi et al. [15] reported light amplification from quantum dots in a silicon dioxide matrix. Net optical gain was seen in both waveguide and transmission configurations, with the material gain being of the same order as that of direct-bandgap quantum dots. The observations were explained using a model based on population inversion of the radiative states associated with the $\mathrm{Si} / \mathrm{SiO}_{2}$ interface.

\subsubsection{SiGe Alloys and Superlattices}

Alloying of $\mathrm{Ge}$ or $\mathrm{C}$ with $\mathrm{Si}$ allows modification of the electronic band structure, where the energy gap may be varied with alloy composition and strain [16]. Electroluminescence and photoluminescence have been observed from $\mathrm{Si}_{1-\mathrm{x}} \mathrm{Ge}_{\mathrm{x}}$ in both single layer and superlattice form with increased intensity compared with $\mathrm{Si}$ [17], as shown in Figure 2.3. The strong broad peak seen in PL and EL at $0.89 \mathrm{eV}$ at $4.2 \mathrm{~K}$ was found to have internal quantum efficiency of $\sim 0.5 \%$ [17] and is typical of results obtained from similar studies $[18,19,20]$.

The recombination mechanism varies depending on the alloy layer thickness and perfection. J. S. Sturm et al. [18] studied the band-edge luminescence from strained SiGe quantum wells grown on $\mathrm{Si}$. They suggested that at liquid-He temperatures the PL is due to shallow bound excitons, whereas at higher temperatures free-exciton luminescence was dominant. In this report, the higher temperature which was used for the experiments was $60 \mathrm{~K}$. L. C. Lenchyshyn et al. [19] attributed the photoluminescence process to the recombination of excitons localized at random alloy fluctuations. This luminescence saturated at very low excitation densities (around $100 \mu \mathrm{W} \mathrm{cm}$ cm $^{-2}$ ), it has very long decay times (>1ms) and high quantum efficiency at low excitation. The temperature which was used for the above experiments was $2 \mathrm{~K}$. It was concluded that high PL quantum efficiency for 
the SiGe system could be achieved by effectively eliminating the nonradiative channels, rather than increasing the radiative rate.

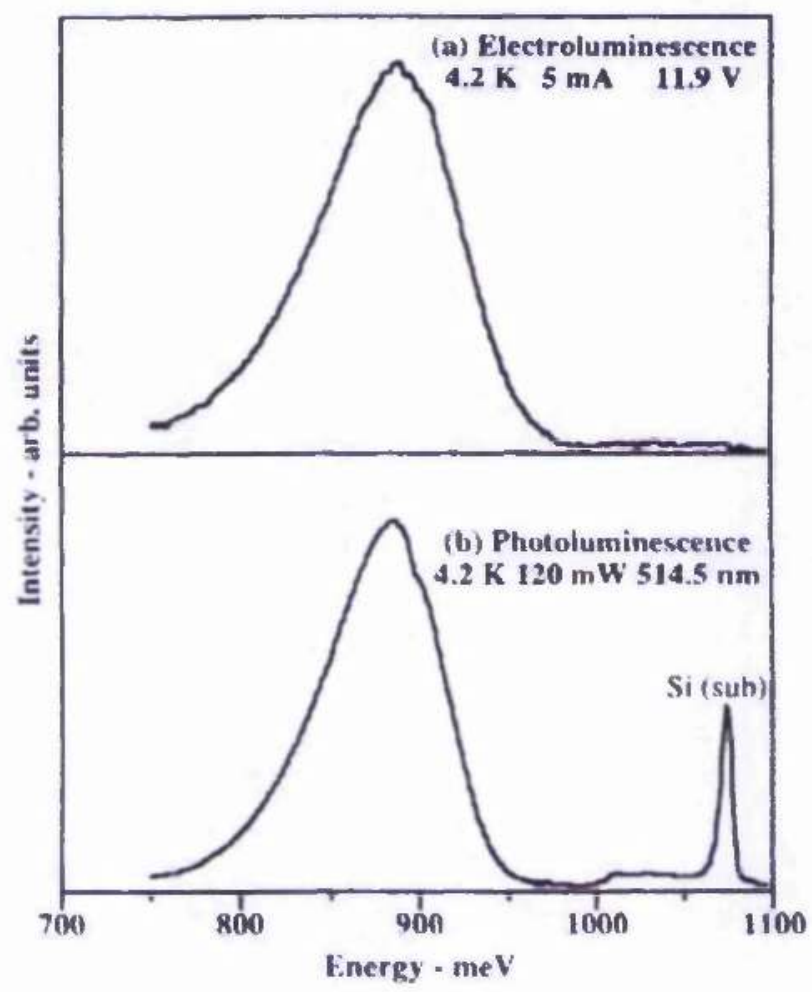

Figure 2.3 Broad EL and PL from a $\mathrm{Si}_{0.82} \mathrm{Ge}_{0.18}$ p-n heterostructure at $4.2 \mathrm{~K}$. A sharper emission line from the Si substrate is also evident. (After Rowell et al. [17]).

J. -P. Noël et al. [20] and N. L. Rowell et al. [21] attributed the origin of the broad PL band from thick, fully strained layers of $\mathrm{Si}_{1-\mathrm{x}} \mathrm{Ge}_{\mathrm{x}}$ alloys grown by molecular beam epitaxy (MBE) to interstitial-type features (platelets) smaller than $\sim 1.5 \mathrm{~nm}$ and in densities up to $7 \times 10^{8} \mathrm{~cm}^{-2}$. It was observed that when the alloy layer thickness was greater than 4-10nm, depending on $\mathrm{x}$ and the growth temperature, a strong PL band was evident. Thinner alloy layers revealed phonon-resolved PL originating from shallow dopant bound excitons, similar to bulk material but shifted in energy due to strain and quantum confinement. The luminescence experiments were taken from $2 \mathrm{~K}$ up to $77 \mathrm{~K}$ [20]. 
Room temperature EL at $1.3 \mu \mathrm{m}$ has been reported from Q. Mi et al. [22] for $\mathrm{Si}_{1-\mathrm{x}} \mathrm{Ge}_{\mathrm{x}} / \mathrm{Si}$ quantum wells. The EL was attributed to band-edge carrier recombination and its EL peak intensity increased linearly with forward current up to $1700 \mathrm{~A} / \mathrm{cm}^{2}$. The internal quantum efficiency was estimated to have a lower limit of $2 \times 10^{-4}$. The $1.3 \mu \mathrm{m}$ intensity was found to be relatively insensitive to temperature from $77 \mathrm{~K}$ to room temperature, whereas the silicon luminescence increased relative to the one originating from the $\mathrm{Si}_{1-\mathrm{x}} \mathrm{Ge}_{\mathrm{x}} / \mathrm{Si}$ wells. Also, it was suggested that a minimum band offset was required for the design of an effective room-temperature luminescent device.

J. Engvall et al. [23] also demonstrated room temperature EL in the region of 1.3-1.7 $\mu \mathrm{m}(0.70-0.95 \mathrm{eV})$ from a strain-adjusted $\mathrm{Si}_{6} \mathrm{Ge}_{4}$ superlattice. The observed EL was reported to originate both in transitions over a recombination centre $(0.77$ $\mathrm{eV})$ and in band-to-band recombination processes $(0.88 \mathrm{eV})$ in the strained-layer superlattices. H. Presting et al. [24] in 1996 observed EL and PL in the near infrared $(\lambda \sim 1.3 \mu \mathrm{m})$ from $\mathrm{Ge} / \mathrm{Si} / \mathrm{Ge} / \mathrm{Si}_{1-\mathrm{x}} \mathrm{Ge}_{\mathrm{x}}$ quantum well diodes grown on $<100>\mathrm{Si}$ by MBE. The strength of the spectra, although not fully understood, was linked to states localized at the interface. The external quantum efficiency for the EL was estimated to be $10^{-7}$ at room temperature. Quite recently, L. Vescan and T. Stoica [25] reported room-temperature EL from diodes with strained $\mathrm{Si}_{0.80} \mathrm{Ge}_{0.20}$ and for diodes with $\mathrm{Ge}$ islands in the active region. The current density which was used was $250 \mathrm{~A} / \mathrm{cm}^{2}$. The internal quantum efficiency which was obtained was $\sim 10^{-4}$ for the strained LEDs and $\sim 10^{-5}$ for the diodes with the islands.

The main problem of the above devices is their poor efficiency at room temperature. 


\subsubsection{Iron Disilicide}

Although metallic silicides have been of great interest to the semiconductor industry for some time, more recently a large amount of research has been directed to the semiconducting (beta) phase of $\mathrm{FeSi}_{2}\left(\beta-\mathrm{FeSi}_{2}\right)$. The main reason for the interest in $\beta-\mathrm{FeSi}_{2}$ is reported properties of a direct band gap in the region of $0.87-0.89 \mathrm{eV}$, which makes it a potentially useful material for incorporating in to silicon-based light emitting devices $[26,27]$.

There has been a lot of discussion about the direct or indirect nature of band gap of $\beta-\mathrm{FeSi}_{2}$. Ab initio band gap calculations performed by $[28,29]$ have shown the minimum band gap to be indirect, with a slightly larger direct band gap. Other reports though $[26,27,30$,$] supported the view that the minimum band gap is direct.$

Dimitriadis et al. [31] studied polycrystalline iron disilicide thin films which were prepared by furnace annealing of electron-beam deposited iron layers. PL measurements were taken at liquid helium temperature $(1.8 \mathrm{~K})$ to thin films grown on single crystal substrates at temperatures of $800{ }^{\circ} \mathrm{C}, 850{ }^{\circ} \mathrm{C}$ and $900{ }^{\circ} \mathrm{C}$. PL measurements indicated that the luminescence of the $0.84 \mathrm{eV}$ originated from the silicide. No PL of the substrate was found in the samples that show luminescence at $0.84 \mathrm{eV}$. It was also illustrated that at high growth temperature $\left(900^{\circ} \mathrm{C}\right)$ the spectrum consisted only of the three bands $(0.84,0.809$ and $0.790 \mathrm{eV}$ ), (different phonon replicas), which suggested it belonged to one recombination process. When the growth temperature was decreased to $850{ }^{\circ} \mathrm{C}$ a new additional recombination line appeared which was very sharp compared with the three bands. At $800{ }^{\circ} \mathrm{C}$ the additional recombination line was broader.

D. N. Leong et al. [32] reported PL at $10 \mathrm{~K}$ and $80 \mathrm{~K}$ from samples containing precipitates of $\beta-\mathrm{FeSi}_{2}$ which have been fabricated using ion beam synthesis. A dose of $5 \times 10^{15}$ of $\mathrm{Fe}^{+}$ions was implanted at $200 \mathrm{keV}$ into n-type single crystal $\mathrm{Si}(100)$ wafers with a resistivity of $10-20 \Omega \mathrm{cm}$, followed by subsequent 
annealing at $900{ }^{\circ} \mathrm{C}$ for 18 hours. Comparative PL measurements using excitation energies above and below the silicon band gap energy allowed the identification of the origin of the luminescence. Suitable short and long wavelength pass filters together with a $3 \mathrm{~mm}$ thick silicon filter were used in order to eliminate the excitation above the silicon, room temperature, band edge, thus allowing only the silicide to be directly excited. To prevent the possibility that the emission might be caused by the excitation of a silicon defect below the band edge, the above experiments were repeated with samples in which dislocations had been deliberately introduced. The results indicated a dramatic quenching of the PL when the Si filter was introduced for the samples with the defects. No such quenching was observed for the sample containing the $\beta-\mathrm{FeSi}_{2}$ precipitates. These results showed that the luminescence emission observed at $1.5 \mu \mathrm{m}$ can be attributed to band edge related emission from the $\beta-\mathrm{FeSi}_{2}$.

In 1997 Leong et al. [33] reported the first EL from Si layers containing precipitates of $\beta-\mathrm{FeSi}_{2}$ and demonstrated the fabrication of a Si/ $\beta-\mathrm{FeSi}_{2}$ LED device. The approach used was by incorporating direct band gap $\beta-\mathrm{FeSi}_{2}$ into a conventional silicon $\mathrm{p}-\mathrm{n}$ junction diode, in the recombination region adjacent to one side of the depletion region, in order to provide a route for direct radiative recombination. EL measurements took place at $80 \mathrm{~K}$ revealing a strong emission at $1.54 \mu \mathrm{m}$. They also depicted the temperature dependence of the EL signal from $80 \mathrm{~K}$ to room temperature. The EL signal reduced with increasing temperature but could be still seen clearly at room temperature. The peak energy of the EL shifted slightly towards lower energies with increasing temperature, as expected from a band-edge related emission.

Another evidence for the origin of the $1.54 \mu \mathrm{m}$ luminescence from $\beta-\mathrm{FeSi}_{2}$ has been reported by C. Spinella et al. [34]. Iron was implanted into n-type silicon wafers at $350 \mathrm{keV}$ and $250{ }^{\circ} \mathrm{C}$, at fluences ranging between $1-5 \times 10^{15}$ ions $/ \mathrm{cm}^{-2}$, followed by annealing at $800{ }^{\circ} \mathrm{C}$ for up to 24 hours. Cross sectional TEM measurements of the samples showed the presence of three bands where $\beta-\mathrm{FeSi}_{2}$ 
precipitates with different morphologic characteristics are situated (strained and relaxed $\beta-\mathrm{FeSi}_{2}$ precipitates and residual extended defects). These bands are centred at different depths from the surface. A sharp PL peak was measured at $1.54 \mu \mathrm{m}$ at 17 $\mathrm{K}$. That peak remained unchanged when the region containing the small precipitates was removed, using Ar sputtering. In contrast, that peak was fully suppressed when the large precipitates region was removed and a high concentration of extended defects remained in the samples. This was interpreted as showing, the main source of the $1.54 \mu \mathrm{m}$ luminescence to be the large unstrained precipitates.

T. Suemasu et al. [35] obtained room temperature EL from a Si-based LED with $\beta-\mathrm{FeSi}_{2}$ active region. The $\beta-\mathrm{FeSi}_{2}$ was formed by reactive deposition epitaxy (RDE; deposition of $\mathrm{Fe}$ on a hot $\mathrm{Si}$ ) and developed the formation technique of $\mathrm{Si} / \beta$ $\mathrm{FeSi}_{2}$ balls/Si structures by molecular beam epitaxy. The EL was increased superlinearly with increase of the injected current density as shown in the inset of Figure 2.4. The peak wavelength was at $1.6 \mu \mathrm{m}$. The explanation that was given for their result was that in the low current density region, most of the bias current flows through non-radiative recombination centers. So, it was concluded that when the current through the defect levels saturates, the bias current begins to contribute to the radiative recombination and therefore EL output was obtained, as shown in Figure 2.4. $\mathrm{PL}$ was also observed at $77 \mathrm{~K}$ but not at room temperature. 


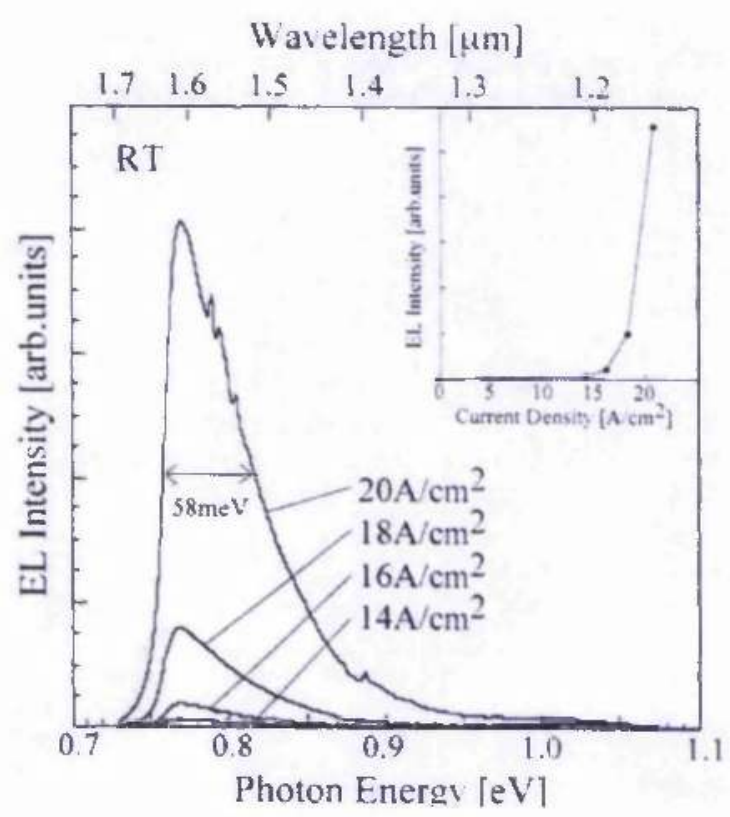

Figure 2.4 EL spectra measured at room temperature under several forward bias currents. The inset shows the injected current density dependence of the integrated EL intensity. (After T. Suemasu et al. [35]).

\subsubsection{Erbium in Silicon}

Erbium is a rare earth metal and emits light at the same wavelength independently of the host. It behaves like a trivalent atom and has the ionic configuration of $4 \mathrm{f}$. It is known that, for free ions, intra- $4 \mathrm{f}$ electric dipole transitions are strictly forbidden by the parity rule. When a rare earth atom is placed in the crystal it is subjected to several forces, which are absent for the free ion, due to interaction with neighbouring ions through molecular orbital interactions.

Since the first report of Er-doped Si luminescence at $1.54 \mu \mathrm{m}$ and at $20 \mathrm{~K}$ from H. Ennen et al. [36] (Figure 2.5), several reports have been published on the luminescence of $\mathrm{Er}$ in $\mathrm{Si}$. B. Zheng et al. [37] reported the first room-temperature sharp line EL at $1.54 \mu \mathrm{m}$. The LED device was built by implantation of a high dose of $\mathrm{P}$ into B-doped CZ-Si wafers in order to form the $\mathrm{n}^{+} / \mathrm{p}$ junction. The back sides of 
the wafer were boron implanted and after annealing, spatially overlapping Er and O were implanted within the bulk $\mathrm{p}$ region. Further annealing followed by photolithographic and etching procedures was performed in order to make the $\mathrm{Al}$ contacts.

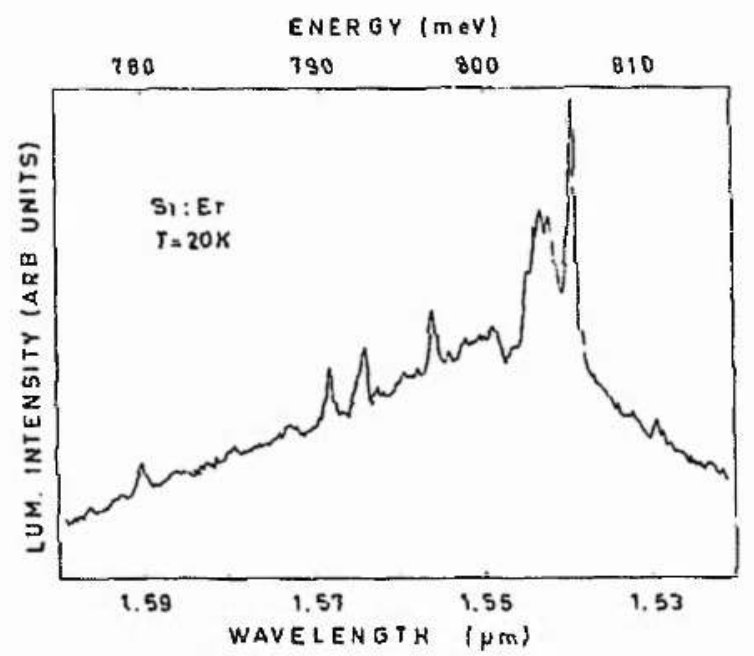

Figure 2.5 20-K luminescence spectrum or Er-implanted and annealed Si. The half-width of the intense line at $1.53904 \mu \mathrm{m}(805.6 \mathrm{meV})$ is $3.4 \mathrm{~cm}^{-1}$. (After H. Ennen et al. [36]).

The EL was observed at both $100 \mathrm{~K}$ and room temperature [37]. A sharp luminescence linewidth $(\sim 100 \AA)$ at $1.54 \mu \mathrm{m}$ was produced at both $100 \mathrm{~K}$ and room temperature and no line shift of the peak wavelength with temperature was observed, consistent with the $\mathrm{Er}^{+3}$ intra- $4 \mathrm{f}$ shell transition. $\mathrm{The}^{\mathrm{E}}{ }^{+3}$ peak $\mathrm{EL}$ intensity changed with temperature though, as shown in Figure 2.6. From $100 \mathrm{~K}$ to $200 \mathrm{~K}$, the EL intensity decreased with an activation energy of approximately $17 \mathrm{meV}$. Above 200 $\mathrm{K}$ a steeper decay with activation energy of about $200 \mathrm{meV}$ occurred. The decrease of the EL intensity was attributed to the reduction in the number of the optically active $\mathrm{Er}^{+3}$ centres. 


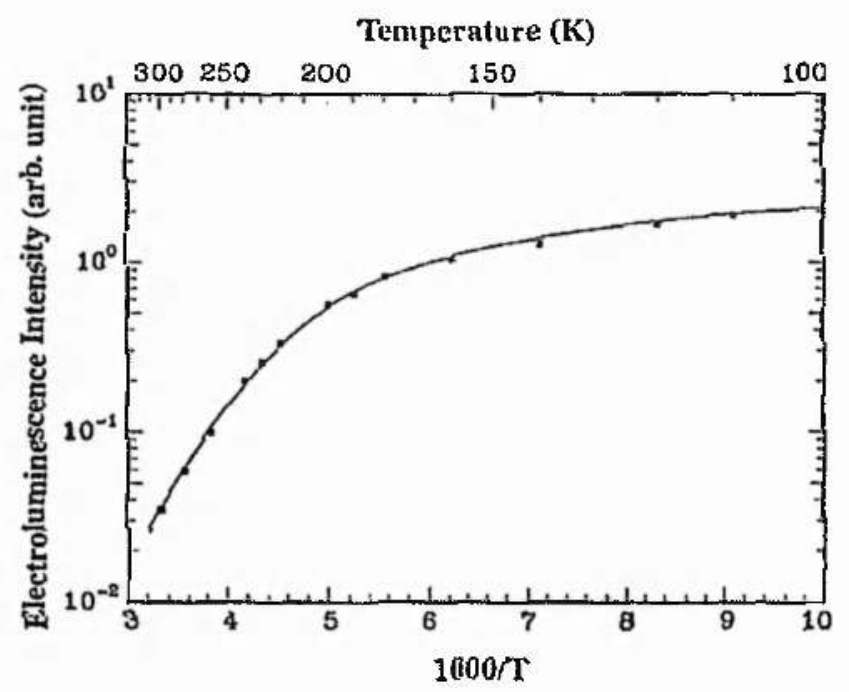

Figure 2.6 Temperature dependence of the $\mathrm{Er}^{+3}$ electroluminescence peak intensity $(\lambda=1.54$ $\mu \mathrm{m})$. (After B. Zheng et al. [37]).

Room-temperature EL was also measured by Chun-Xia Du et al. [38] from a Schottky-type LED on Er-doped Si layers grown by molecular beam epitaxy. Again, from the temperature dependence of the normalised intensity of the EL at $1.54 \mu \mathrm{m}$ was observed that for temperatures above $200 \mathrm{~K}$ the EL was decreasing linearly in a logarithmic scale with the decrease of $1 / \mathrm{T}$. Room-temperature PL at $1.535 \mu \mathrm{m}$ was obtained from W. L. Ng et al. [39] from Er-doped thin-film Si layers prepared by laser ablation and annealed at $450^{\circ} \mathrm{C}$. It was revealed from the PL measurements that the Er luminescence is significantly excited via the silicon band edge. The temperature dependence of the peak $(1.535 \mu \mathrm{m})$ PL intensity revealed that the quenching of the luminescent intensity between $80 \mathrm{~K}$ and $300 \mathrm{~K}$ was about a factor of 2.5. This observation of the intense PL with the low thermal quenching up to room temperature was connected with the presence of a low concentration of residual defects. 


\subsubsection{Defect and Dislocation related Luminescence}

Although tremendous research has been done on light emission from Si based on nanostructures like porous silicon, few researches were focused on the defect related luminescence from $\mathrm{Si}$. This may be due to the fact that dislocations are generally considered to be damaging to device performance in crystalline Si. Several investigations in the past years have documented that dislocations in silicon give rise to characteristic photoluminescence (PL) spectra below the band edge. Drozdov et al. $[40,41]$ were the first to show in 1976 that four lines are related to dislocations which they labelled as D1 $(0.812 \mathrm{eV}), \mathrm{D} 2(0.875 \mathrm{eV}), \mathrm{D} 3(0.934 \mathrm{eV})$ and D4 $(1.000$ eV). Those lines were introduced by deformation. A few years later in 1983, M. Suezawa et al. $[42,43]$ measured the intensities of the PL lines D1 through D4 and also of the background component as a function of temperature. All of them became weaker as the temperature was raised. Such behaviour for the D1 through D4 lines could be attributed to transitions between shallow levels $\left(\mathrm{E}_{\mathrm{i}}=4-7 \mathrm{meV}\right)$ and deep levels $\left(\mathrm{E}_{\mathrm{g}}-\mathrm{E}_{\mathrm{i}}-\mathrm{hv}\right)$ in the forbidden gap. They studied the influence of the impurities, of the annealing, of the deformation temperature and of the dislocation 'morphology' on the D1 through the D4 lines. They concluded that impurities and point defects do not play a vital role in the recombination processes and that dislocation themselves are the active recombination centres but dangling bonds are not involved. Finally they concluded that D1 and D2 are probably related to geometrical kinks on the dislocations.

A couple of years later in 1985, a similar study by Sauer et al. [44] showed that the lines D1/D2 and D3/D4 are related to the presence of "relaxed" dislocations which have been frozen in under low-shear stress (Figure 2.7). They reported that these lines appear as pairs mostly because of their identical stress response. Moreover, they suggested that although D1/D2 lines are emitted by tetragonal centres which are randomly distributed over all equivalent orientations, they cannot be considered as the most characteristic optical proof of the dislocations. So they suggested that they might originate in deformation-induced point defects located in 
the strain region of the dislocation. The same authors proposed for the D3/D4 lines that they have either triclinic symmetry or, if the symmetry is higher, are preferentially aligned in the lattice. Again the temperature dependence of the D1 through D4 lines showed a very weak PL signal for the higher temperatures (above $100 \mathrm{~K}$ ) and no PL for above $200 \mathrm{~K}$.

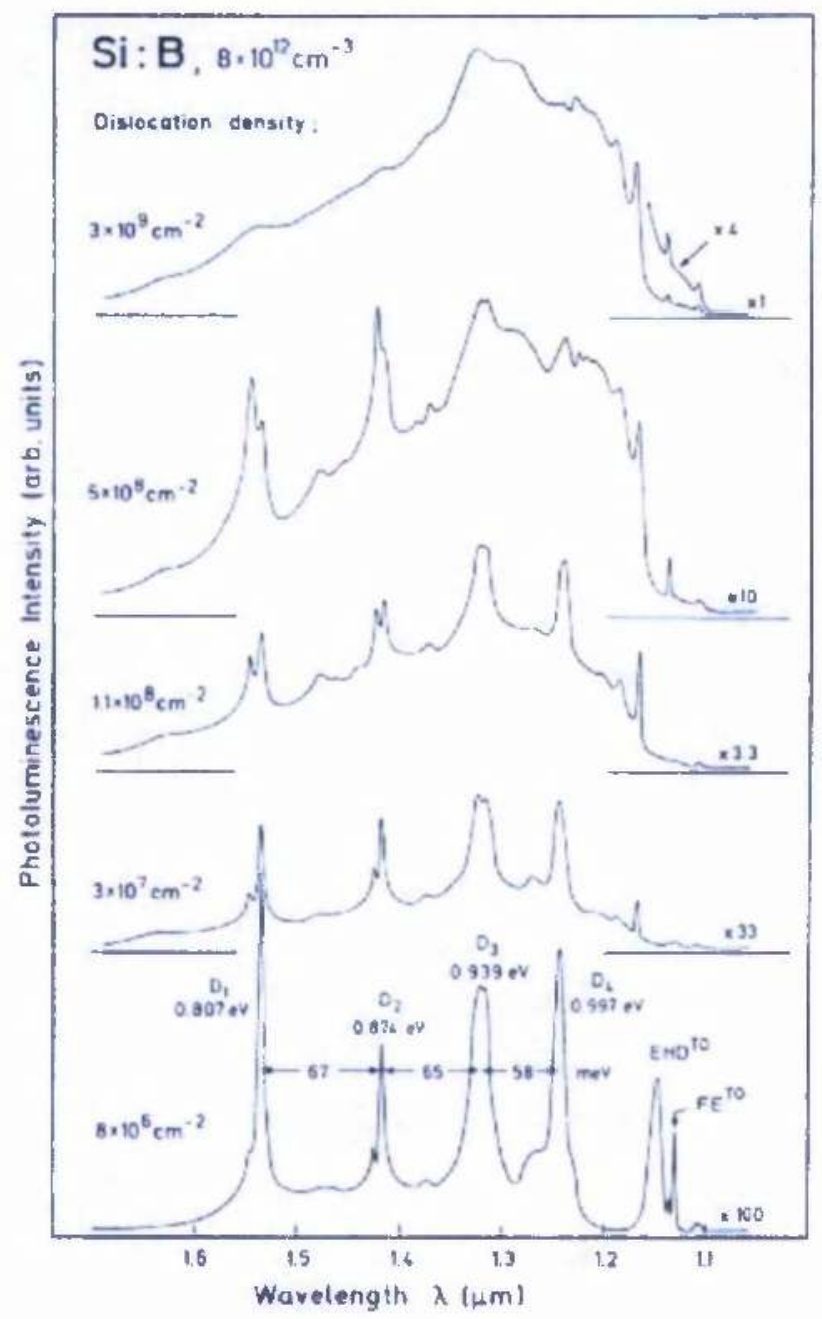

Figure 2.7 Photoluminescence spectra from samples deformed at $650{ }^{\circ} \mathrm{C}$ along [213] to various dislocation densities as indicated. Bath temperature $4.2 \mathrm{~K}$, resolution $\Delta \lambda=2 \mathrm{~nm}$, excitation by $647 \mathrm{~nm}(\approx 1.92 \mathrm{eV}) \mathrm{Kr}$ laser line. (After Sauer et al. [44]).

Many years later in 1995, V. V. Kveder et al. [45] reported a faint EL and PL at room temperature from boron doped plastically deformed floating zone (FZ) 
silicon. They observed an exponential decrease of luminescence with temperature for $\mathrm{T}>200 \mathrm{~K}$. They attributed this to the fact that the recombination of electrons and holes at centers, responsible for the D1, D2, D3 and D4 luminescence, is not the main recombination channel but there are some other nonradiative recombination centres where the recombination of free carriers takes place mainly via them, especially at high temperatures. They finally assumed for their samples that the above nonradiative recombination centers are either located at some other dislocations or generated by point defects in the vicinity of these dislocations and they are not at the dislocation segments which give rise to the D1, D2, D3 and D4 luminescence.

In 1996, E. Ö. Sveinbjörnsson and J. Weber [46] reported a dislocationrelated electroluminescence at room temperature peaked at a wavelength of $1.6 \mu \mathrm{m}$ corresponding to the D1 line. The dislocations were produced by the use of a high power laser which melted the surface of the float-zone grown boron doped silicon wafers. After recrystallisation the dislocation layer was created at depths of $5-10 \mu \mathrm{m}$ below the surface layer. The external efficiency (light power out / electrical power in) for their LED at room temperature was estimated to be of the order of $10^{-6}$. In this report was also observed silicon band to band emission but without an estimation of the external efficiency of this emission.

In 1998 E. A. Steinman and H. G. Grimmeiss [47] wrote a report about dislocation-related luminescence properties of silicon. They observed that after annealing their plastically deformed samples at $450{ }^{\circ} \mathrm{C}$ for $66 \mathrm{~h}$ there was a considerable decrease of the D2 line and an appearance of two new broad emission bands around 0.778 and $0.85 \mathrm{eV}$. They also exhibited that the relative intensity of the $0.778 \mathrm{eV}$ line increased with increasing temperature; this property though was shown only for temperatures below $120 \mathrm{~K}$. The temperature dependence of the integrated intensity of the dislocation-related PL showed a decrease of the intensity with increasing temperature. Again those results were shown only for temperatures which were not exceeding $100 \mathrm{~K}$. 


\subsubsection{Dislocation Engineering Luminescence}

Quite recently in 2001, a novel LED device from W. L. Ng et al. [48] was reported. They exhibited EL and PL from dislocated Si containing dislocation loops at room temperature. The dislocation loops were introduced into silicon by ion implantation of boron. Boron was implanted into silicon both as dopant to form a p-n junction, and also to introduce dislocation loops (Figure 2.8).

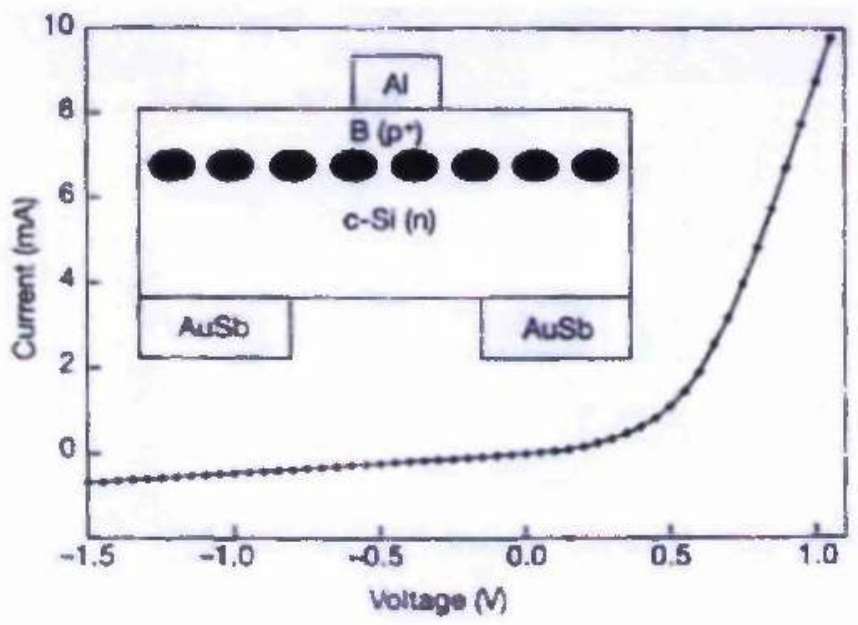

Figure 2.8 The current-voltage plot for the device measured at room temperature. Inset, a schematic of the light emitting diode (LED) device. The top and bottom contacts are formed by $\mathrm{Al}$ and $\mathrm{AuSb}$ respectively. The infrared light is emitted through the window left in the bottom contact). (After W. L. Ng et al. [48]).

Boron was implanted into a $\mathrm{CZ}$ n-type silicon substrate of 2-4 $\Omega \mathrm{cm}$ resistivity. Subsequent anneal at $1000{ }^{\circ} \mathrm{C}$ for 20 minutes was performed to form the dislocation loops and to activate the boron dopants. A diagram of the device is shown in the inset of Figure 2.8. The same picture also depicts the current-voltage measurements which were made between the back and the front contacts in order to check that the device is behaving like a diode.

The authors demonstrated that the dislocation loops introduce a local strain field in three dimensions that can modify the band structure of silicon in so that the silicon itself can be used to provide spatial confinement of the charge carriers in 
three dimensions. So by confining the carriers at specific areas, the radiative recombinations between the carriers are being enhanced, leading to light emission from silicon. In Figure 2.9 is illustrated the EL spectra as a function of temperature, at a forward current of $50 \mathrm{~mA}$. The low-temperature EL spectrum from the device revealed the main Si peak at $1130 \mathrm{~nm}$ shifting to $1160 \mathrm{~nm}$ with a full-width at half maximum of $80 \mathrm{~nm}$ at room temperature.

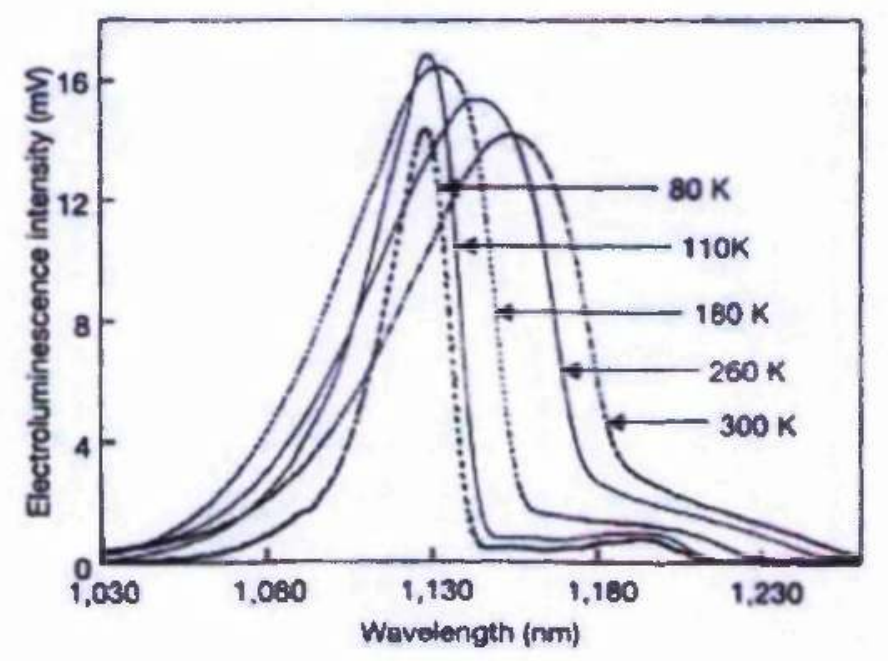

Figure 2.9 Spectra of the electroluminescence intensity against wavelength at various temperatures. The device was operated at a forward current of $50 \mathrm{~mA}$ for temperatures. (After W. L. Ng et al. [48]).

The external quantum efficiency of the above device was estimated to be $(2.0$ $\pm 0.1) \times 10^{-4}$. In Figure 2.10 is depicted the temperature dependence of the integrated EL, clearly shown the increase of the integrated EL intensity with the increase of temperature. Also depicted is the increase of the integrated PL intensity with the increase of temperature, indicating that the temperature dependence is intrinsic to the recombination. 


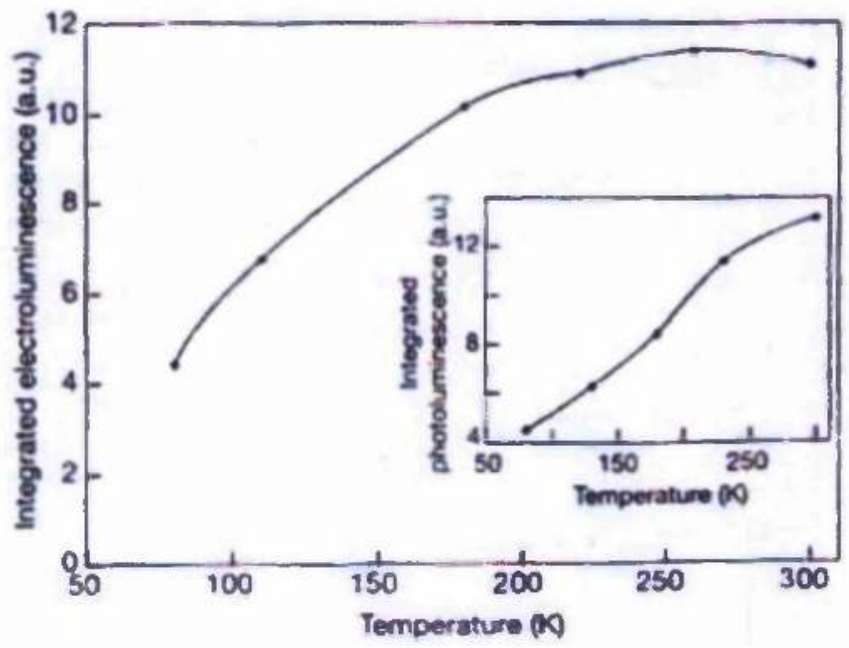

Figure 2.10 A plot of the integrated intensity as a function of measurement temperature. Inset, a plot of the integrated photoluminescence intensity as function of temperature. The solid lines are provided as a guide to the eye. The photoluminescence was excited by the 488 $\mathrm{nm}$ line of an argon laser at a power of $150 \mathrm{~mW}$. (After W. L. Ng et al. [48]).

\subsubsection{Isoelectronic Impurities}

An isoelectronic impurity is isovalent with the host crystal. Examples of substitutional isoelectronic atoms for $\mathrm{Si}$ could be any other element in the same IV group, i.e. $\mathrm{C}, \mathrm{Ge}$ and $\mathrm{Sn}$ may be used to substitute $\mathrm{Si}$ without influencing the number of valence electrons. They do not influence the carrier density in the conduction or valence bands and therefore have a weak influence on the conductivity. An isoelectronic impurity is not always a simple atom substitution. A multiple-atom complex, if it is in a configuration with no dangling bonds, may also be isoelectronic. In practise, a defect is regarded as isoelectronic if the threshold for ionisation is comparable to the band gap energy. Therefore, for most temperatures, the isoelectronic impurities add no free carriers to the host. The total number of free carriers may be reduced though, through confinement in the short range potential, but the electrical conductivity will not be increased in total. 
Isoelectronic impurities doped in $\mathrm{Si}$ bind free excitons in $\mathrm{Si}$, which can increase the probability of electron-hole recombination due to spatial confinement of the particles. The resulting recombination energy may appear as light or disappear through phonon generation and other nonradiative decay channels [49]. Isoelectronic bound exciton emission in $\mathrm{c}-\mathrm{Si}$ was first observed by M. A. Vouk and E. C. Lightowlers [50] and identified as such by G. S. Mitchard et al. [51] in 1979. Mitchard et al. were the first to report observation of lines with lifetimes of about $200 \mu \mathrm{s}$ at $20 \mathrm{~K}$ in silicon samples doped with indium. Those long lifetimes were connected to the radiative lifetime for the indium bound exciton and was suggested that those lines were due to excitons bound to isoelectronic centers in silicon. The temperature dependence of the ratios of intensity and the difference in decay times attributed to the fact that the lines were all due to transitions from initial states on different centers.

The study of isoelectronic impurity centres has been expanded to other elements apart from $\mathrm{C}, \mathrm{Ge}$ and $\mathrm{Sn}$, such as $\mathrm{S}, \mathrm{Be}$ and $\mathrm{Se}[52,53,49]$ but without much success at high temperatures. Till present, efficient room temperature emission from isoelectronic impurity based EL devices has not been observed.

\subsection{Sulphur Centers in Silicon}

\subsubsection{Light Emission from Sulphur Doped Silicon}

Early photoluminescence experiments from sulphur-doped silicon samples took place from J. Weber and C. Holm [54] in 1984. They revealed three luminescence lines, at $1.1439 \mathrm{eV}$ and its phonon replica at $1.0858 \mathrm{eV}$, and at 1.1150 $\mathrm{eV}$. They suggested that these lines resulted from the recombination of excitons bound to two different centres. From the thermal ionisation energy of the $1.1439 \mathrm{eV}$ line they concluded that it corresponds to excitons bound to the sulphur donor levels. 
An important report from T. G. Brown and D. G. Hall [53] in 1986 demonstrated PL from sulphur-related impurity in crystalline silicon. The luminescence spectrum consisted of two major peaks, one near the wavelength $\lambda=1.32 \mu \mathrm{m}(0.94 \mathrm{eV})$ and the other near $\lambda=1.5 \mu \mathrm{m}(0.83 \mathrm{eV})$ (see Figure 2.11$)$. The low energy peak was more dominant at low temperatures reaching its maximum intensity at $35 \mathrm{~K}$, whereas the high energy component was increasing from $40 \mathrm{~K}-70$ $\mathrm{K}$ persisting up to $\mathrm{T} 170 \mathrm{~K}$. This emission was identified as bound-exciton luminescence from sulphur-related isoelectronic impurities in silicon. That was also supported by the long lifetimes ( $>1 \mathrm{~ms}$ ) exhibited at low temperatures and the high deactivation thermal energy of $\sim 139 \mathrm{meV}$. In addition, it was further suggested that the sulphur was directly involved in the defect. The external efficiency for the $1.3 \mu \mathrm{m}$ peak was valued in the $2-5 \%$ range. However, the PL intensity and lifetime of the bands decreased rapidly with increasing temperature, possibly due to exciton dissociation and competing nonradiative recombination processes.

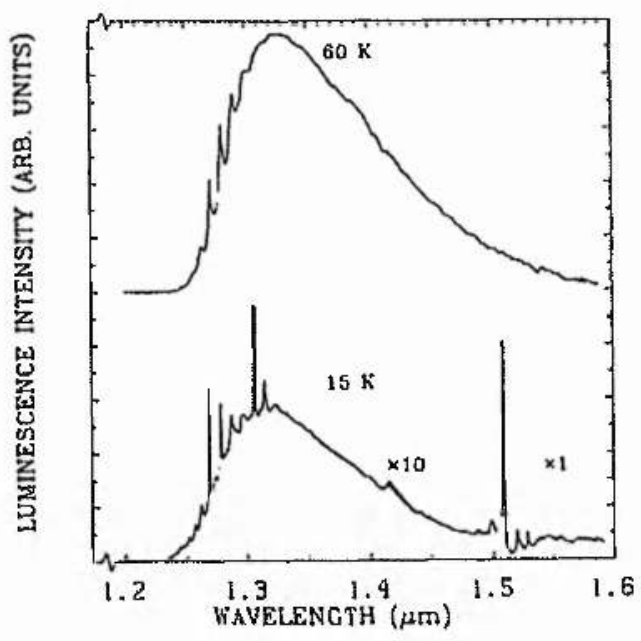

Figure 2.11 Photoluminescence spectrum of $\mathrm{Si}: \mathrm{S}$ at $\mathrm{T}=60 \mathrm{~K}$ (top) and $\mathrm{T}=15 \mathrm{~K}$ (bottom). (After T.G. Brown and D.G. Hall [53]).

Subsequent reports from the same group [55] examined the dependence of the intensity of the sulphur emission upon sulphur concentration using Czochralski silicon samples implanted with sulphur at an energy of $200 \mathrm{keV}$. Their results showed that the luminescence intensity of $\lambda=1.32 \mu \mathrm{m}, \mathrm{T}=80 \mathrm{~K}$, varied linearly with 
concentration up to the point at which concentration quenching appears (Figure 2.12). They suggested from the linear dependence that each sulphur complex contained only a single atom rather than a pair of sulphur atoms and they proposed the involvement of oxygen. Also, the quenching occurred for sulphur concentrations exceeding $10^{17} \mathrm{~cm}^{-3}$ in ion implanted samples.

Electroluminescence from a sulphur-related impurity complex in a p-n junction formed in epitaxial silicon was also reported from the same group [56]. The EL signal exhibited the same temperature behaviour as the PL signal which persisted up to $\sim 150 \mathrm{~K}$. They found an external efficiency associated with the EL of $0.2-0.5 \%$.

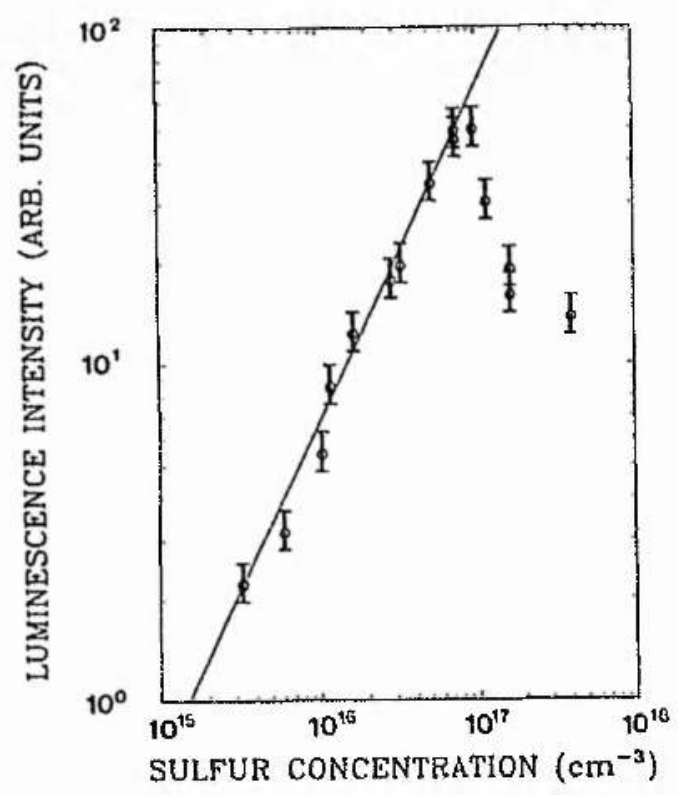

Figure 2.12 Photoluminescence intensity vs sulphur concentration at wavelength $1.32 \mu \mathrm{m}$ and temperature T=80 K for ion-implanted and annealed Si:S. (After T. G. Brown et al. [55]).

Beckett et al. [57] identified zero phonon lines from two luminescence systems, which they labelled as $\mathrm{S}_{\mathrm{A}}$ and $\mathrm{S}_{\mathrm{B}}$, each of which displayed two transitions, one forbidden but dominant at low temperatures ( $968.2 \mathrm{meV}$ for $\mathrm{A}, 812 \mathrm{meV}$ for $\mathrm{B}$ ) and a second higher energy one at $977 \mathrm{meV}$ for $\mathrm{A}$ and at $821.9 \mathrm{meV}$ for $\mathrm{B}$, dominant at higher temperatures ( $\mathrm{T}>15 \mathrm{~K}$ ) (Figure 2.13). From far infrared absorption 
spectroscopy they showed that that the lowest excited state for each was composed of a deeply bound hole and an electron Coulombically bound by $65.28 \mathrm{meV}$ for $\mathrm{A}$ and $66.21 \mathrm{meV}$ for $\mathrm{B}$. They concluded that these values indicate a binding centre that with its central-cell potential can be attractive for both holes and electrons.

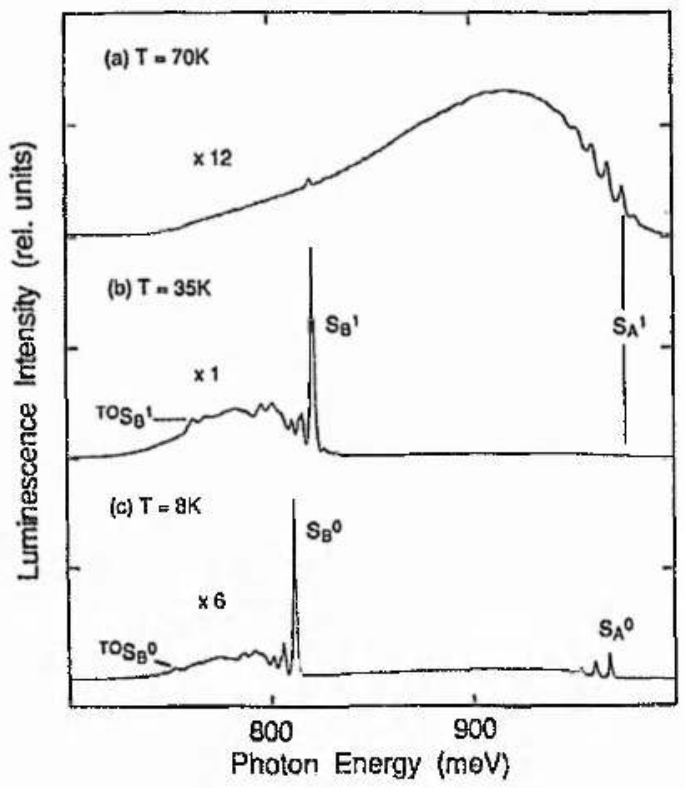

Figure 2.13 Low-resolution, wide-spectral-range photoluminescence spectra showing large scale features at 8, 35 and $70 \mathrm{~K}$. (After D. J. Beckett et al. [57]).

A similar study from M. Singh et al. [58] identified from the decay of isoelectronic bound excitons (IBEs) zero phonon lines at $812.04 \mathrm{meV}$ and $968.30 \mathrm{meV}$, which they labelled as $\mathrm{S}_{\mathrm{B}}{ }^{0}$ and $\mathrm{S}_{\mathrm{A}}{ }^{0}$ respectively at $\mathrm{T}<10 \mathrm{~K}$. At higher temperatures they identified higher energy zero-phonon lines at $822 \mathrm{meV}$ and $977.1 \mathrm{meV}$, which they labelled as $\mathrm{S}_{\mathrm{B}}{ }^{1}$ and $\mathrm{S}_{\mathrm{A}}{ }^{1}$ respectively (Figure 2.14). They suggested that the two iso-electronic bound exciton systems are due to two metastable configurations of the same defect. Also, they reported that the system could be optically excited from one configuration to another at $\mathrm{T}=4.2 \mathrm{~K}$. From Zeeman $\mathrm{PL}$ measurements they showed that the two zero-phonon lines of each iso-electronic system are transitions from an isotropic $\mathrm{S}=1$ spin triplet state (the lower energy zero-phonon line) and an $\mathrm{S}=0$ spin singlet state (the higher energy zero-phonon line). 


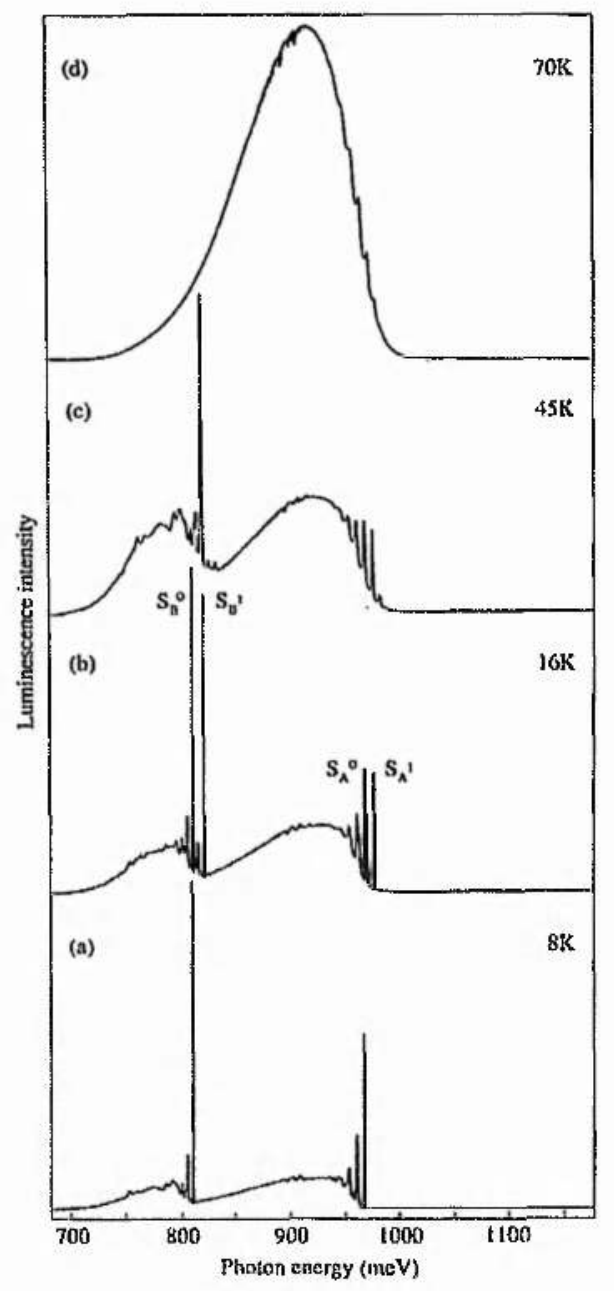

Figure 2.14 The PL spectra of a thermally quenched Si:S sample at (a) $T=8 \mathrm{~K}$, (b) $\mathrm{T}=16 \mathrm{~K}$ showing the two zero phonon lines (ZPLs) of each system, (c) $\mathrm{T}=45 \mathrm{~K}$ and (d) $\mathrm{T}=70 \mathrm{~K}$ showing the $1.32 \mu \mathrm{m}$ band which exhibits high radiative efficiency. (After M. Singh et al. [58]).

A later report from P.M. Mason et al. [59] described the sulphur-related defect in its two configurations, $\mathrm{A}$ and $\mathrm{B}$, as of triclinic $\left(\mathrm{C}_{1}\right)$ symmetry, consisting of an impurity atom with nuclear spin $I=3 / 2$, presumably copper, incorporated with one or more sulphur atoms. This conclusion took place by resolving the hyperfine structure of the defect from the optically detected magnetic resonance (ODMR) spectra. They also suggested that the defect is a deep donor with two configurations between which it can cycle under optical excitation or thermal recovery at cryogenic temperatures. Finally they concluded that the luminescence from this defect 
originates from a transition from its neutral excited effective-mass state to its ground deep neutral donor state for either configuration.

A general comment concerning the above reports is that the observed sulphur emission took place at low (cryogenic for some cases) temperatures.

The electrical and electronic properties of sulphur in silicon were studied in the early 80 s $[60,61]$. From thermal emission and Hall-effect measurements two main centres were found which were named as sulphur $I$ at 0.18 and $0.38 \mathrm{eV}$ and sulphur II at 0.32 and at $0.53 \mathrm{eV}$ and a third one, sulphur III, at $0.08 \mathrm{eV} \mathrm{[60].} \mathrm{The}$ sulphur centres I and II were assumed to be double donors. Finally, an early report in 1959 from R.O. Carlson et al. [62] revealed also two deep donor levels at 0.18 and $0.37 \mathrm{eV}$ from Hall-effect measurements. They also produced solubility and diffusion coefficient data for sulphur in silicon (Figure 2.15).

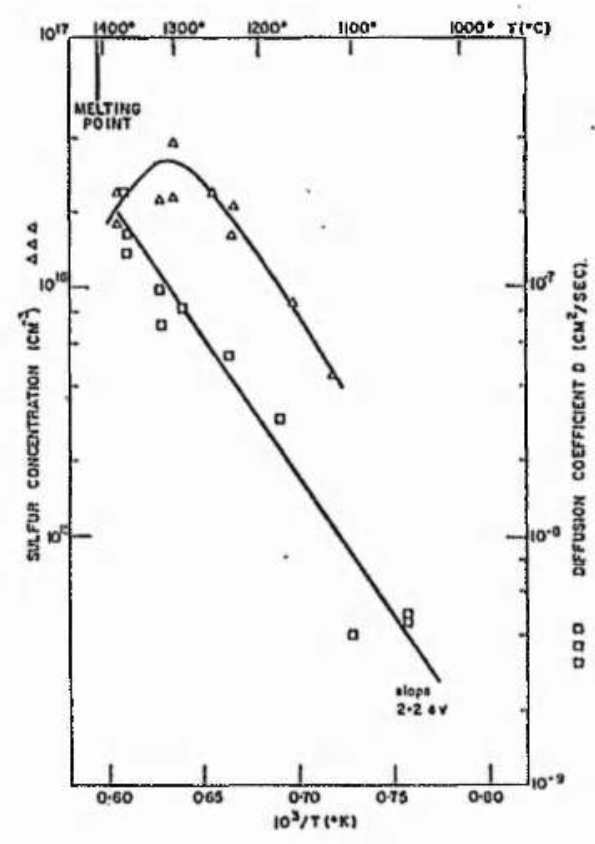

Figure 2.15 Solubility and diffusion coefficient of sulphur in silicon as determined from electrical measurements. (After R. O. Carlson et al. [62]). 


\subsection{Conclusion}

In this chapter, light emission from silicon has been reviewed. Different approaches have been used in order to overcome the indirect band gap of silicon which limits the light emission. For example, the use of porous silicon was one amongst the efforts proposed from many research groups but with low quantum efficiencies at room temperature [9-12]. Furthermore, devices consisted of porous silicon which had high quantum efficiencies were difficult to prepare and repeat and had poor I-V characteristics [14]. Other groups used SiGe alloys and superlattices in order to emit light from $\mathrm{Si}[18,19,20]$ with internal quantum efficiencies of $0.5 \%$ at low temperatures $(<100 \mathrm{~K})$. Room temperature EL and PL was reported from SiGe superlattices $[23,24,25]$ with also quite low external quantum efficiencies of $10^{-7}$ [24].

Emission at $1.54 \mu \mathrm{m}$ has been reported from the beta phase of $\mathrm{FeSi}_{2}\left(\beta-\mathrm{FeSi}_{2}\right)$ $[32,33,34]$. Again, the above emission was observed at low temperatures ( $\leq 80 \mathrm{~K}$ ) and was very weak at room temperature. Erbium in silicon was another approach used in order to emit light from silicon. Room temperature EL and PL has been reported $[37,38,39]$ with $\mathrm{EL}$ decreasing linearly in a logarithmic scale at temperatures above $200 \mathrm{~K}$ [38].

Dislocation related EL and PL $[45,46]$ at room temperature was reported with external quantum efficiency in the range of $10^{-6}$ [46]. The use of dislocation loops was one of the most promising techniques used so far, applied in Surrey University, in order to extract light from silicon [48]. PL and EL was measured at room temperature and the external quantum efficiency was estimated to be in the region of $10^{-4}$. The use of the sulphur impurity added to silicon is studied in order to expand the successful method of the dislocation engineering, as has been proposed by W. L. $\mathrm{Ng}$ et al. [48]. Sulphur's known peaks are in the region of $1300 \mathrm{~nm}$, as reported from T. G. Brown [53]. Thus, the aim of this report is to shift the emission to longer wavelengths, apart from the one due to silicon (1129.5 nm) and to observe 
if the photoluminescence will be enhanced with the combination of the dislocation engineering and the sulphur impurity. 


\section{References}

[1] A. JR. Uhlir, Bell Syst. Tech. 35, 333 (1956).

[2] C. Pickering, M. I. J. Beale, D. J. Robbins, P. J. Pearson and R. Greef, J. Phys.C, 17, 6535 (1984).

[3] L. T. Canham, Appl. Phys. Lett. 57, 1046 (1990).

[4] M. Koós, I. Pócsik and É. B. Vázsonyi, Appl. Phys. Lett. 62, 1797 (1993).

[5] A. Nakajima, Y. Ohshima, T. Itakura and Y. Goto, Appl. Phys. Lett. 62, 2631 (1993).

[6] W. L. Wilson, P. F. Szajowski, L. E. Brus, Science 262, 1242 (1993).

[7] D. J. Lockwood, Solid State Comm. 92, 101 (1994).

[8] D. J. Lockwood and Ai Guo Wang, Solid State Comm. 94, 905 (1995).

[9] P. M. Fauchet, J. Lumin. 70, 294 (1996).

[10] K. D. Hirschman, L. Tsybeskov, S.D. Duttagupta \& P. M. Fauchet, Nature 384, 338 (1996).

[11] L. Tsybeskov, K. L. Moore, D. G. Hall and P. M. Fauchet, Phys. Rev. B, 54, 8361 (1996).

[12] L. Tsybeskov, S. P. Duttagupta, K. D. Hirschman, and P. M. Fauchet, Appl. Phys. Lett. 68, 2058 (1996).

[13] L. Tsybeskov, K. L. Moore, S. P. Duttagupta, K. D. Hirschman, D. G. Hall and P. M. Fauchet, Appl. Phys. Lett. 69, 3411 (1996).

[14] J. Linnros and N. Lalic, Appl. Phys. Lett. 66, 3048 (1995).

[15] L. Pavesi, L. Dal Negro, G. Mazzoleni, G. Franzò and F. Priolo, Nature, 408, $440(2000)$.

[16] T. P. Pearsall, Prog. Quant. Electr. 18, 97 (1994).

[17] N. L. Rowell, J. -P. Noël, D. C. Houghton and M. Buchanan, Appl. Phys. Lett. 58, 957 (1990). 
[18] J. C. Sturm and H.Manoharan, L. C. Lenchyshyn and M. L. W. Thewalt, N. L. Rowel, J. -P. Noël, and D. C. Houghton, Phys. Rev. Lett. 66, 1362 (1991).

[19] L. C. Lenchyshyn and M. L. W. Thewalt, J. C. Sturm, P. V. Schwartz and E. Prinz, L. Rowel, J. -P. Noël, and D. C. Houghton, Appl. Phys. Lett. 60, 3174 (1992).

[20] J. -P. Noël, N. L. Rowell, D. C. Houghton, and A. Wang, D. D. Perovic, Appl. Phys. Lett. 61, 690 (1992).

[21] N. L. Rowell, J. -P. Noël, D. C. Houghton and A. Wang, L. C. Lenchyshyn and M. L. W. Thewalt and D. D. Perovic, J. Appl. Phys. 74, 2790 (1993).

[22] Q. Mi, X. Xiao and J. Sturm, L. C. Lenchyshyn and M. L. W. Thewalt, Appl Phys. Lett. 60, 3177 (1992).

[23] J. Engvall, J. Olajos and H. G. Grimmeiss, H. Presting, H. Kibbel and E. Kasper, Appl. Phys. Lett. 63, 491 (1993).

[24] H. Presting, T. Zinke, A. Splett, H. Kibbel, M. Jaros, Appl. Phys. Lett. 69, 2376 (1996).

[25] L. Vescan and T. Stoica, J. Luminescence 80, 485 (1999).

[26] M. C. Bost and J. E. Mahan, J. Appl. Phys. 58, 2696 (1985).

[27] Z. Yang, K. P. Homewood, M.S. Finney, M.A. Harry and K. J. Reeson, J. Appl. Phys. 78, 1958 (1995).

[28] N. E. Christensen, Phys. Rev B 42, 7148 (1990).

[29] R. Eppenga, J. Appl. Phys. 68, 3027 (1990).

[30] M. C. Bost and J. E. Mahan, J. Appl. Phys. 64, 2034 (1988).

[31] C. A. Dimitriadis, J. H. Werner, S. Logothetidis, M. Stutzmann, J. Weber and R. Nesper, J. Appl. Phys. 68, 1726 (1990).

[32] D. N. Leong, M. A. Harry, K. J. Reeson and K. P. Homewood, Appl. Phys. Lett. 68, 1649 (1996).

[33] D. Leong, M. Harry, K. J. Reeson and K. P. Homewood, Nature 387, 686 (1997).

[34] C. Spinella, S. Coffa, C. Bongiorno and S. Pannitteri and M. Grimaldi, Appl. Phys. Lett. 76, 173 (2000). 
Chapter 2-Literature Review

[35] T. Suemasu, Y. Neghishi, K. Takamura and F. Hasegawa, Jpn. J. Appl. Phys. Part 2, 39, L1013 (2000).

[36] H. Ennen, J. Schneider, G. Pomrenke and A. Axmann, Appl. Phys. Lett. 43, 943 (1983).

[37] B. Zheng, J. Michael, F. Y. G. Ren and L. C. Kimerling, D. C. Jacobson and J. M. Poate, Appl. Phys. Lett. 64, 2842 (1994).

[38] Chun-Xia Du, Wei-Xin Ni, K. B. Joelsson and G. V. Hansson, Appl. Phys. Lett. 71, 1023 (1997).

[39] W. L. Ng, M. P. Temple, P. A. Childs, F. Wellhofer and K. P. Homewood, Appl. Phys. Lett. 75, 97 (1999).

[40] N. A. Drozdov, A. A. Patrin, V. D. Tkachev: Pis'ma Zh. Eksp. Teor. Fiz. 23, 651 (1976); Sov. Phys. JETP Lett. 23, 597 (1976).

[41] N. A. Drozdov, A. A. Patrin, V. D. Tkachev, Phys. Stat. Sol, (b) 83, K137 (1977).

[42] M. Suezawa, Y. Sasaki and K. Sumino, Phys. Stat. Sol. (a) 79, 173 (1983).

[43] M. Suezawa and K. Sumino, Phys. Stat. Sol. (a) 78, 639 (1983).

[44] R. Sauer, J. Weber and J. Stolz and E. R. Weber, K. -H. Küsters and H. Alexander, Appl. Phys. A 36, 1 (1985).

[45] V. V. Kveder, E. A. Steinman, S. A. Shenchenko, and H. G. Grimmeiss, Phys. Rev. B 51, 10520 (1995).

[46] E. Ö. Sveinbjörnsson and J. Weber, Appl. Phys. Lett. 69, 2686 (1996).

[47] E. A. Steinman and H. Grimmeiss, Semicond. Sci. Technol. 13, 124 (1998).

[48] W. L. Ng, M. A. Lourenço, R. M. Gwilliam, S. Ledain, G. Shao and K. P. Homewood, Nature 410, 192 (2001).

[49] L. C. Kimerling, K. D. Kolenbrander, J. Michel and J. Palm, Solid State Phys. 50, (1997).

[50] M. A. Vouk and E.C. Lightowlers, J. Lumin. 15, 357 (1977).

[51] G. S. Mitchard, S. A. Lyon, K. R. Elliot ant T. C. McGill, Solid State Comm. 29, 425 (1979). 
[52] G. Davies, Phys. Rep. 176, 83 (1989).

[53] T. G. Brown and D. G. Hall, Appl. Phys. Lett. 49, 245 (1986).

[54] J. Weber and C. Holm, J. Appl. Phys. 56, 3518 (1984).

[55] T. G. Brown, P. L. Bradfield and D. G. Hall, Appl. Phys. Lett. 51, 1585 (1986).

[56] P. L. Bradfield, T. G. Brown and D. G. Hall, Appl. Phys. Lett. 55, 100 (1989).

[57] D. J. S. Beckett, M. K. Nissen and M. L. W. Thewalt, Phys. Rev. B 40, 9618 (1989).

[58] M. Singh, E. C. Lightowlers and G. Davies, C. Jeynes and K. J. Reeson, Mater. Sci. Eng. B 4, 303 (1989).

[59] P. W. Mason, H. J. Sun, B. Ittermann, S. S. Ostapenko, and G. D. Watkins, L. Jeyanathan, M. Singh, G. Davies and E. C. Lightowlers, Phys. Rev. B 58, 7007 (1998).

[60] S. D.Brotherton, M. J. King and G. J. Parker, J. Appl. Phys. 52, 4649 (1981).

[61] H. G. Grimmeiss, E. Janzén, and B. Skarstam, J. Appl. Phys. 51, 4212 (1980).

[62] R. O. Carlson, R. N. Hall and E. M. Pell, J. Phys. Chem. Solids 8, 81 (1959). 


\section{THEORETICAL BACKGROUND}

\subsection{Introduction}

In this chapter will be provided the theory of photoluminescence and electroluminescence. Also will be described the light emission of silicon, a brief description of ion implantation and the defects in silicon. In addition, a review on the operation of LEDs and a calculation of the extraction efficiency and the detector collection efficiency of our LED will be provided and finally, a proposed model for our sulphur-based LED will be also given.

\subsection{Luminescence}

When electron-hole pairs are recombined in a semiconductor or when excited carriers return to their initial states, light can be given-off by the material. This general property of many semiconductors to emit light is called luminescence. For example, semiconductors with direct band gaps emit light strongly. According to the excitation mechanism, luminescence can be classified into the following categories: The most common technique is photoluminescence, where the carriers are excited by absorbing photon energy (usually from a laser source) and the light that is resulting is due to the recombination of the excited carriers. If the excitation of carriers occurs due to the introduction of current into the sample (carrier injection) then the resulting luminescence is referred to as electroluminescence. 


\subsubsection{Photoluminescence}

When a semiconductor absorbs light from a source (usually from a laser) with photon energy greater than the band-gap energy of the semiconductor material, the electrons are excited to the conduction band, creating holes at the valence band. When an electron-hole pair recombines radiatively, it emits a photon which is of characteristic wavelength of the material. If it is a direct recombination rather than a recombination via a defect level, this photon energy is equal to the band-gap energy of the material (band-to-band recombination). This direct recombination is a fast process because the mean life-time of the electron-hole pair is around $10^{-8} \mathrm{~s}$ or less [1] and the recombination occurs at the same rate as the generation, so for each photon absorbed one photon is emitted.

The most common transitions that take place in photoluminescence experiments are the band-to-band transition, impurity-band, donor-to-acceptor and excitonic transitions. From all the mentioned transitions, the band-to-band is the one which takes place at higher temperatures (from $80 \mathrm{~K}$ to room temperature). For indirect band gap materials, such as silicon in our case, the band-to-band transition is very unlikely to happen (or if it does happen with very low probability) because it needs the energy of a phonon to conserve the momentum. The transition which is more dominant and is what we actually see as our main peak at the photoluminescence spectrum is the TO phonon assisted band-to-band transition at $1.13 \mu \mathrm{m}$ and the TO phonon replica assisted band-to-band transition at $1.19 \mu \mathrm{m}$. The latter one has much lower probability to occur than the main one, so is seen in the photoluminescence spectrum as a small peak close to the main one.

Another dominant transition that is observed in our samples, is due to recombination of bound excitons at isoelectronic sulphur-related impurities in silicon at $1.3 \mu \mathrm{m}$, as described in Brown et al. [2]. This transition is represented as a broad peak compared to the Si TO phonon assisted one. The sulphur-related isoelectronic centre has the same valence atoms as $\mathrm{Si}$. Therefore, bound excitons can be bound to 
this centre which behaves neither as a donor nor an acceptor. In addition, since the time needed to capture a free exciton (capture lifetime) is more than $10^{-6} \mathrm{~s}$, which is much smaller than the typical exciton lifetime (less than $10^{-9} \mathrm{~s}$ for pure crystal) [3], the sulphur-related impurity captures efficiently bounds excitons. Once the bound excitons are localized at the impurity site, it is easier to recombine radiatively in Si in a direct-emission process without the participation of a phonon.

Photoluminescence spectroscopy is a powerful technique for investigating both intrinsic electronic transitions and extrinsic electronic transitions taking place via impurities and defects in semiconductors. Therefore, it can be used to detect and identify impurities, defect complexes and also to measure the band gap of semiconductors. The photoluminescence technique will be described in more detail in the following chapter, chapter 4 (section 4.6).

\subsubsection{Electroluminescence}

In electroluminescence, electrical energy is applied in order to generate photon emission in a solid. In light emitting diodes (LEDs), the energy of the carriers can be increased by applying a forward bias to the pn junction. Under forward bias, the majority carriers from both sides of the junction are injected to the other side of the junction, where they are then the minority carriers causing an increase of the minority carrier population. As the excess minority carriers diffuse away from the junction they recombine with the majority carriers giving off light, which is of characteristic wavelength of the semiconductor involved (band-to-band transition). This process is called injection electroluminescence. Most of the recombination occurs from carriers which are in an area close to the junction. However, some of the minority carriers may diffuse further away from the junction and therefore the recombinations can take place in an area away from the junction. 
The transitions which take place in our electroluminescence experiments are the same as the ones involved at the photoluminescence experiments, as described in previous section (section 3.2.1). Thus, from the electroluminescence experiments on our sulphur doped silicon LEDs, the major transitions observed are the Si TO phonon-assisted band-to-band transition at $1.129 \mu \mathrm{m}$, its phonon replica at $1.190 \mu \mathrm{m}$ and the isoelectronic bound exciton at the sulphur-related impurity at $1.3 \mu \mathrm{m}$.

\subsection{Silicon - an Indirect Band Gap Material}

The property that largely determines if a semiconductor emits light by bandto-band recombination is the direct or indirect nature of its band extrema. In Figure 3.1 is shown the band structure of Ge, $\mathrm{Si}$ and GaAs. The energy is plotted as a function of the carrier wave vector, $\mathbf{k}$, since the band diagram based on interatomic distances and the internal potential energy distribution depends on the direction in the crystal. The carrier wave vector is proportional to its linear momentum by the relation $\mathbf{h k}=\mathbf{p}$.

GaAs is a direct band gap semiconductor because the linear momentum of an electron is the same at the bottom of the conduction band and the top of the valence band. A direct transition between the two states is achieved by emission of a photon of energy $\mathrm{E}_{\mathrm{g}}$. The rate of such intrinsic, direct transitions in $\mathrm{GaAs}$ is fast due to the short radiative lifetime. Silicon and Germanium have an indirect energy gap because the lowest point in conduction band occurs away from high symmetry points near the $\mathrm{X}$ point at the Brillouin zone boundary, $\mathrm{k}\left(\mathrm{VB}_{\max }\right) \neq \mathbf{k}\left(\mathrm{CB}_{\min }\right)$. Electronic transitions between the two states can occur only with a simultaneous change in momentum by absorption or emission of a lattice phonon with large momentum. Generation of heat is, therefore, intrinsic to the relaxation process in indirect gap materials. The required simultaneous involvement of a phonon and an electron reduces the likelihood of the intrinsic optical transition in silicon because of the long radiative lifetime. Exciton 
recombination and recombination via impurity centers and defects provide direct transition paths for bound carriers, as it was previously mentioned.
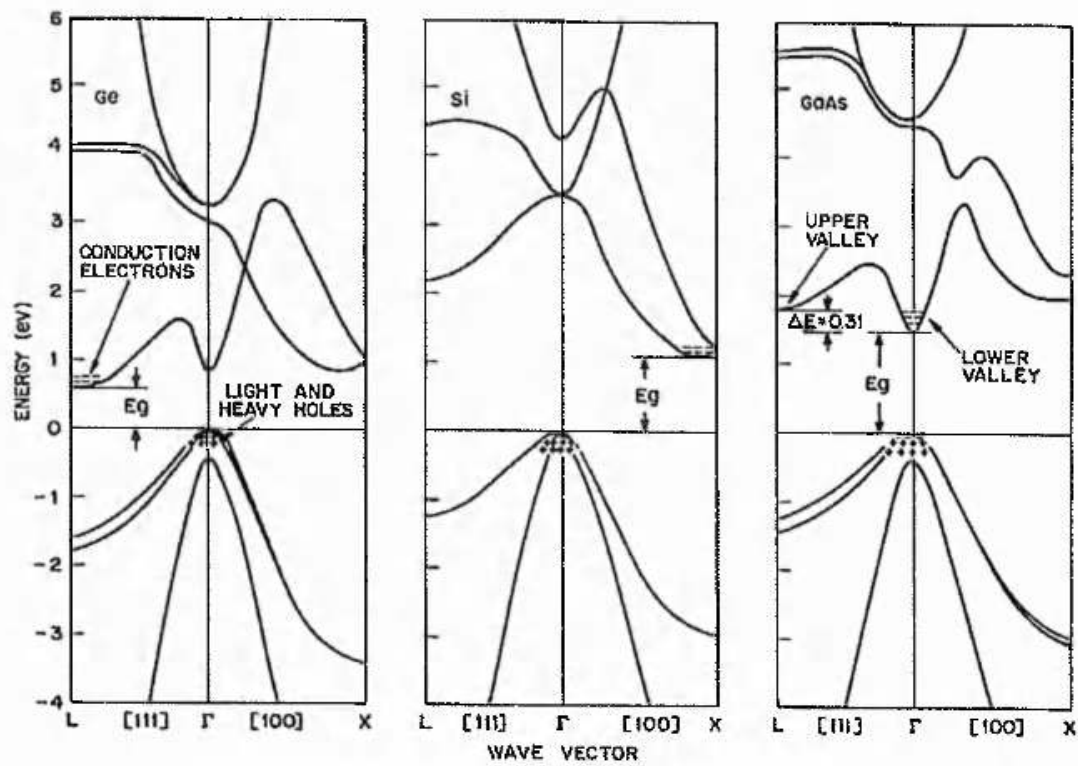

Figure 3.1 Energy band structures of $\mathrm{Ge}, \mathrm{Si}$ and $\mathrm{GaAs}$ along [111] and [100] directions. ( $\mathrm{E}_{\mathrm{g}}$ is the energy band gap). Plus (+) signs indicate holes in the valence bands and minus (-) signs indicate electrons in the conduction bands. (From L.C. Kimerling et al. [4]).

To obtain large luminescence efficiency, the nonradiative recombination rate must be smaller than the radiative recombination rate. The internal quantum luminescence efficiency of a semiconductor is the ratio of the number of photons emitted to the number of electrons-holes excited. In terms of lifetime it is defined as

$$
\eta=\frac{\tau_{\text {nourad }}}{\tau_{\text {nourrad }}+\tau_{\text {rad }}} \text { or } \eta=\left(1+\frac{\tau_{\text {rad }}}{\tau_{\text {rourad }}}\right)^{-1}
$$

where $\tau_{\text {rad }}$ is the radiative lifetime and $\tau_{\text {nowad }}$ is the time constant for nonradiative recombination processes [5]. Typical values of the internal recombination efficiency for direct band gap materials are $10^{-3}$ to $\sim 1$. Indirect band gap materials have much lower efficiencies. At room temperature the internal quantum efficiency of crystalline $\mathrm{Si}(\mathrm{c}-\mathrm{Si})$ is usually of the order of $10^{-4}-10^{-5} \%$. The external quantum 
efficiency is the number of photons emitted from the device divided by the number of electrons supplied and may be much less than the internal value.

\subsection{Intrinsic Luminescence in Silicon}

Silicon has the diamond cubic lattice structure with fourfold coordination of each atom. The band structure is shown in Figure 3.1. The minimum between the conduction and the valence band extrema is $1.17 \mathrm{eV}$ at $0 \mathrm{~K}$ and decreases to 1.125 at $300 \mathrm{~K}$ [6]. The conduction band minimum is located at $\mathbf{k} \sim 0.85 \mathbf{k}(\mathrm{X})$ along the (100) direction. The valence band has a maximum energy at $k=0$. The luminescence properties of bulk crystalline silicon have been studied by J. R. Haynes et al. [7, 8].

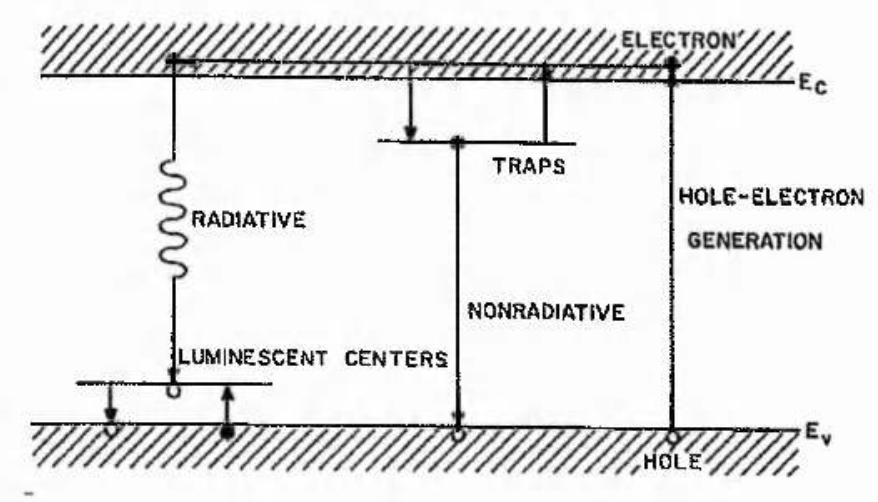

Figure 3.2 Representation of radiative and nonradiative recombinations. (After Ivey [9]).

Radiative transitions in silicon occur with slow rate, so its luminescence efficiency is determined by the competing alternative electron-hole recombination processes. Intrinsic radiative processes are classified as free exciton, electron-hole plasma and electron-hole droplet emission [4]. Intrinsic nonradiative processes include free carrier and excitonic Auger processes. The electron-hole recombination depends on the dissipation of energy difference between the electron and the hole states. For a radiative process this energy is emitted as a photon. For nonradiative processes the energy is absorbed by electrons (Auger) or phonons (heat generation), 
as previously stated. Both nonradiative paths reduce luminescence efficiency (see also Figure 3.2). In order to improve the luminescence efficiency of $\mathrm{Si}$, the basic idea which was used was either to increase the radiative rate or to decrease the nonradiative rate. For instance, the decrease of the nonradiative rate could take place if the electron and hole could be confined in a small volume where the probability of finding a nonradiative center is equal to zero.

\subsection{Ion Implantation}

Ion implantation is the introduction of ionised atoms into the surface layer of a solid substrate by bombardment of the solid with ions. It is a widely-known technique for highly controlled doping into semiconductor materials. In this technique, the beam of ions is being accelerated to kinetic energies in the range of several $\mathrm{keV}$ to $\mathrm{MeV}$ in order to introduce the dopant atoms into the surface of the semiconductor. As the ions move through the target eventually they lose their energy due to a series of collisions with the target atoms, until they come to a rest. There are two major ion stopping mechanisms, the nuclear stopping and the electronic stopping. In the electronic stopping the moving ion collides inelastically with the target atoms causing excitation or ionisation. The ion energy is transferred from the implanted atom to the electrons of the target material and is eventually dissipated as heat. The nuclear stopping is caused by elastic collisions between the incoming ion and the nuclei of the target atom or between whole atoms. The kinetic energy of the implanted ion is transferred to the nuclei of the target atoms which are absorbing the impact.

As the ions travel through the target they undergo a series of nuclear collisions, where a part of their energy is transferred to the target atoms causing displacement from their original positions. Since the binding energy of the lattice atoms is small, they can easily receive enough energy to become free from their position and also displace other lattice atoms. Both the ions and the displaced target 
atoms can cause further displacements so the energy is spread over many moving particles. When the energy per particle becomes very small the cascade of collisions and displacements stops. Therefore the result of the incoming implanted ions is to cause displacement of many target atoms through nuclear scattering. The nuclear stopping predominates for high atomic number $Z$ and low energy $E$, whereas the electronic stopping occurs for high energy $E$ and low atomic number $Z$. This is because if the ions have high energy they are moving too fast and they have not enough time to interact with the target nuclei.

The result of the ion implantation is the lattice disorder created due to the collisions between the ions and the lattice atoms. Those displaced atoms can either diffuse to empty lattice sites to repair the lattice damage or combine with other displaced atoms to form extended defects. The vacancies that remain behind from the displaced atoms can also diffuse and unite to form extended defects. The net result is the creation of a highly disordered region which can be as deep as the ions penetrate. The amount of damage produced depends on the energy and the atomic number of the incoming ions, the atomic number and the temperature of the target atoms and the channelling effect. For instance, heavier atoms displace a greater number of target atoms per ion. In order to repair the lattice damage, post-implantation annealing is always performed also providing enough energy to the dopant atoms to move to the lattice sites, therefore becoming electrically activated. The annealing temperature is around $600{ }^{\circ} \mathrm{C}$ for silicon. However, there are defects which are still present at this annealing temperature. For most dopants a higher temperature (in the region of 800 ${ }^{0} \mathrm{C}$ for boron) is required in order to activate the dopants electrically [10]. Above 600 ${ }^{\circ} \mathrm{C}$ other defects such as dislocations and rodlike defects begin to grow.

As was mentioned above, the implanted ions move through the target randomly losing their energy by nuclear and electron stopping from the collisions between the target atoms. The average penetration length where the implanted atoms finally come to a rest is called projected range $R_{P}$. The distribution of the implanted ions as a function of depth is (range profile) approximately a Gaussian with standard deviation $\sigma_{\mathrm{P}}$ or $\Delta \mathrm{R}_{\mathrm{P}}$, also stated as straggle. In detail, straggle is the value at the half- 
width of the distribution at the $\mathrm{e}^{-1 / 2}$ of the peak value. The value of the projected range depends on the energy of the ion and the atomic number of both the ion and the target atom. The projected range increases approximately linearly with the implantation energy.

Channelling occurs when the ions are moving parallel to certain crystallographic directions (regions between rows of atoms). The result is that the ions going through those directions are facing few nuclear collisions with the target atoms, so they penetrate much deeper into the target. Channelling of ions leads to large tails on the substrate side of the atomic distribution profiles. To avoid channelling the wafers are tilted by $7^{0}$ with respect to the beam direction or by amorphising the lattice of the target.

The idea of doping semiconductors using ion implantation was patented by Schockley [11] in 1954. Early work about implantation has been summarized by Gibbons [12] and L.N. Large and R. W. Bicknell [13] in the 1960s. In the last two decades, many works were performed for ion implantation induced damage in Si. For instance, P. F. Byme et al. [14] used an arsenic beam of $11 \mathrm{MeV}$ in order to achieve a layer of heavily doped silicon centered at $4.4 \mu \mathrm{m}$ below the surface. They observed that by increasing the energy it was possible to achieve a high concentration of electrically active dopants several microns deep into the silicon, with relatively low surface concentration. Before furnace annealing, from cross-sectional transmission electron microscopy experiments, it was shown that buried amorphous regions existed. It was also reported that the secondary defects which were created on subsequent annealing, quantitatively resembled those defects obtained by lower energy implantation and the details depended strongly on the substrate temperature during implantation. 


\subsection{Defects in Silicon}

There are two types of defects that can be classified according to whether they are induced in crystal growth process named as grown-in defects, or whether they are induced during fabrication process, named as process-induced defects. Most of the grown-in defects are attributed to impurity inhomogeneity due to segregation phenomena.

\subsubsection{Dislocations}

Modern as-grown silicon crystals are considered to be dislocation free. Dislocations are line defects created as a consequence of the presence of a missing row or an extra row of atoms along close packed directions in the crystal. Principally, two types of dislocations have been identified in silicon, the edge and screw dislocations. The edge dislocation is created when an extra half plane of atoms is inserted in the crystal. The Burgers vector of the edge dislocation is normal to the line of the dislocation. (Figure 3.3 left).
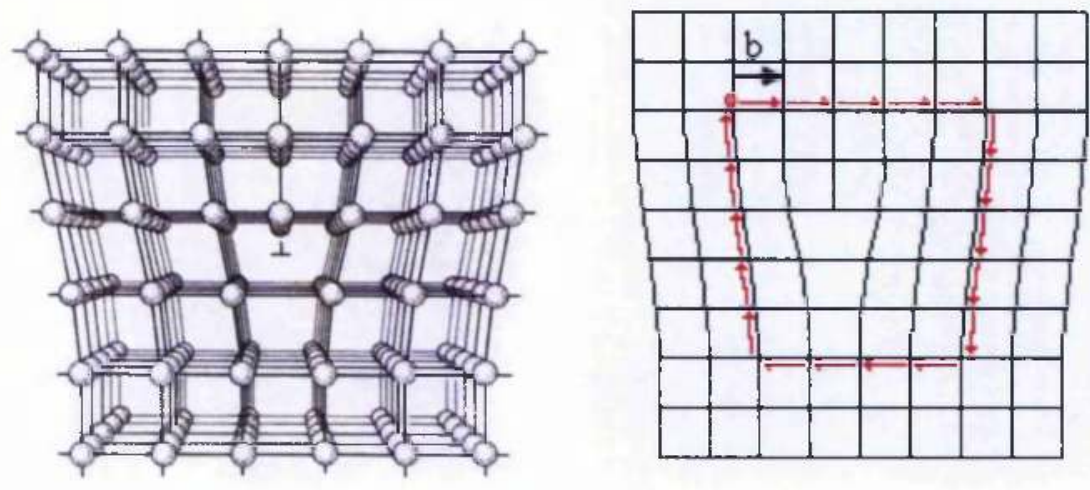

Figure 3.3 Perspective view of an edge dislocation (left) and the Burgers circuit around the edge dislocation (right). (After J.P. Hirth and J. Lothe [15]). 
The other type of dislocation, the screw one can be simulated by displacing the crystal on one side of a face relative to the other side in a specific direction as shown in Figure 3.4. The Burgers vector of a screw dislocation is parallel to the line of the dislocation.
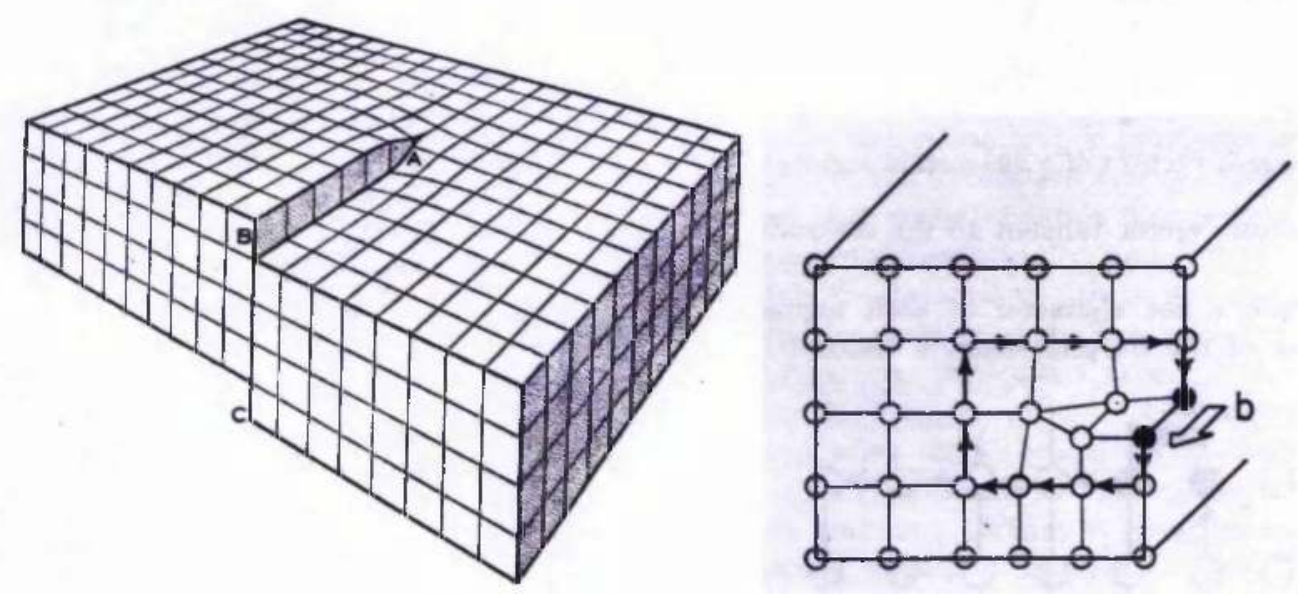

Figure 3.4 Screw dislocation in a simple cubic crystal, (After W.T. Read [16]), and its Burgers circuit around it (After J. and J. R. Weertman [17]).

Dislocation lines can end at the surface of a crystal and at grain boundaries, but never inside the crystal. Thus, either they branch into other dislocations or they form closed loops. The dislocation loops can be formed in the following way. If there is large excess concentration of vacancies which are created either from rapid quenching or from a high temperature or from atomic displacements produced by irradiation with energetic particles, then they may precipitate out in the form of a disc on a close-packed plane. If the disc is large enough, it is energetically favourable for it to collapse to produce a dislocation loop (Figure 3.5). The Burgers vector of the loop is normal to the plane of the loop, so that an edge dislocation has been formed. 


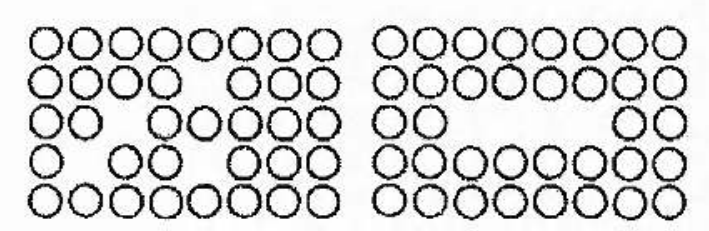

(a) (b)

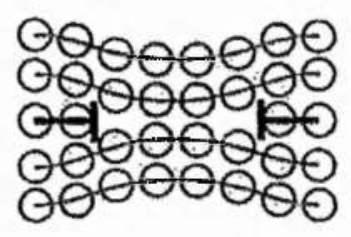

(c)

Figure 3.5 Formation of a prismatic vacancy-type dislocation loop. (a) Represents a crystal with a large non-equilibrium concentration of vacancies. In (b) the vacancies have collected on a close-packed plane and in (c) the disc has collapsed to form an edge dislocation loop. (From D. Hull and D. J. Bacon [18]).

In Figure 3.6 is depicted an interstitial-type dislocation loop. These types of loops are used in our LEDs, as will be described at the following chapters.

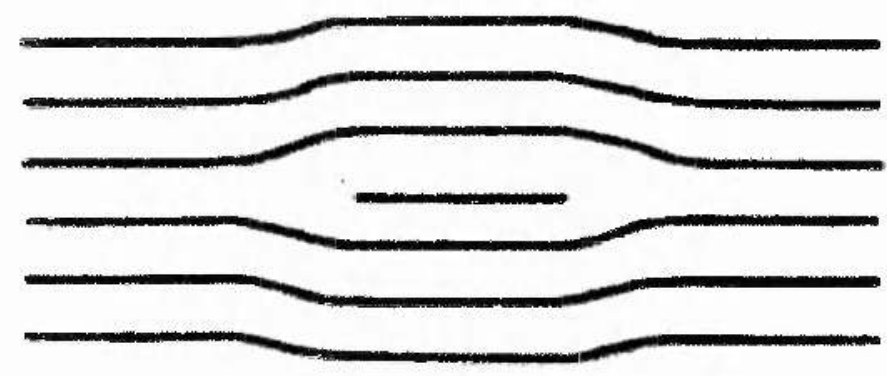

Figure 3.6 Schematic diagram of an interstitial-type dislocation loop. An extra plane is inserted between the rows of atoms. (After G. Carter and W.A. Grant [19]).

Dislocations can be introduced in silicon as a result of a variety of mechanisms. These include: dislocation generation due to thermomechanical stresses, point defect condensation, and chemical impurity effects. Thermomechanical stresses can be introduced into silicon crystals during growth due to non-uniform thermal gradients in the crystal growth process. Because of the thermal expansion which takes place, any perturbation or deviation of the local thermal gradient from the average will result in the generation of internal stresses that will be accommodated by the generation of dislocations. 
If the concentration of point defects in a growing crystal exceeds the equilibrium value at a given temperature, the excess point defects will agglomerate and condense in the form of dislocation loops. These loops can either be faulted or occur as perfect prismatic loops. Once these loops are formed they can grow, shrink and change their shape. This depends on the concentration of point defects in the vicinity, the temperature, the size of the initially nucleated loop, the cooling rate of the crystal and the availability of other sources and sinks for point defects.

Chemical effects are very important in the generation of dislocations especially with the involvement of various dopant and diffusional processes which characterise device processing. In crystal growth the presence of high concentrations of impurities prevents the growth of dislocation-free crystals. The diffusion of impurities and dopants as well as the implantation of energetic ions into silicon wafers can cause dislocation generation. Ion implantation has been used to our samples to create dislocation loops. The generation of defects by the implantation of ions into silicon is a direct process of a cascade of collisions between the ions and the atoms of the host crystal. This form of radiation damage generates a high concentration of point defects which can agglomerate into dislocation loops. Ion implantation is usually followed by thermal annealing in order to activate the dopant atoms and to anneal the radiation damage. Annealing restores the residual damage in the form of dislocations.

\subsection{Light Emitting Diode (LED)}

The basic LED is a p-n junction which is forward biased to inject electrons and holes into the $\mathrm{p}$ - and $\mathrm{n}$-sides respectively. The injected minority carriers from the n- and p-sides recombine with the majority carriers in the depletion region or the neutral region, resulting in the emission of recombination radiation. In direct band semiconductors, this recombination leads to light emission since radiative recombination dominates in high quality materials. In indirect band gap materials, 
the light emission efficiency is quite poor and most of the recombination paths are non-radiative which in most cases generate heat rather than light.

LEDs can emit external spontaneous emission in the ultraviolet, visible and infrared regions of the electromagnetic spectrum. A more detailed description of the LED which is used for the present project will be described in the following chapter, chapter 4 .

\subsubsection{External Efficiency - Calculation of the Extraction Efficiency $\eta_{\mathrm{c}}$ and the Detector Collection Efficiency $\eta_{D}$}

The total external quantum efficiency of our LED devices is determined as the ratio of the number of photons finally emitted to the number of carriers crossing the junction and can be expressed in terms of

$$
\eta_{e x t}=\eta_{i} \eta_{r} \eta_{e}
$$

where $\eta_{i}, \eta_{\mathrm{r}}$ and $\eta_{\mathrm{e}}$ are the injection, radiative recombination and extraction efficiency respectively. Those three efficiencies correspond to the three processes occurring in a junction LED. The first is the injection process, in which the carriers are injected by forward bias. The recombination process is the one in which some of these carriers give up their excess energy as photons and finally, at the extraction process, the generated photons leave from the device. The internal efficiency can be defined as the ratio of the photons generated within the device to the carriers injected across the junction and can be expressed as

$$
\eta_{\text {int }}=\eta_{i} \eta_{r}
$$


The injection efficiency $\eta_{i}$ can be calculated from the ratio of the electron current density to the total device current density. Typical values for $\eta_{i}$ are from $0.3-$ 0.6. The recombination efficiency $\eta_{\mathrm{r}}$ is defined as the ratio of the numbers of photons generated to the number of injected electrons. In indirect bandgap semiconductors such as silicon, this efficiency is smaller than in direct bandgap materials. Typical values for indirect materials are in the region of $10^{-4} \%$ or less. Finally, the extraction efficiency $\eta_{\mathrm{e}}$ gives the amount of light emerging from the device and is the one that determines the overall external efficiency of the device. This efficiency can be low due to several factors and is given by the formula

$$
\eta_{e}=\eta_{a b s} \eta_{r / R} \eta_{F}
$$

where $\eta_{\mathrm{abs}}, \eta_{\mathrm{TIR}}$ and $\eta_{\mathrm{F}}$ are the efficiencies due to absorption, total internal reflection and Fresnel losses, respectively.

The absorption of photons between the point of generation and the emitting surface is one factor for having less extemal efficiency. For a device where the distance from its surface to its pn junction is $\mathrm{x}$, the transmitted fraction after the absorption will be

$$
\eta_{a b s}=e^{-\alpha x}
$$

where $\alpha$ is the absorption coefficient. To minimise this effect the light emitting junction could be placed close to the surface, so that a big fraction of photons will not have to travel long distances to the surface. Unfortunately, the active emission volume cannot be placed too close to the surface because non radiative recombination processes at surface defects will reduce the device efficiency. The value of the transmitted fraction after absorption to the back window can be calculated for our devices as follows:

From the EL results taken place at room temperature, the silicon emission was observed at $\lambda=1.146 \mu \mathrm{m}$. Therefore, substituting to the formula 


$$
E(e V)=\frac{1.2395086}{\lambda(\mu m)}
$$

the corresponding energy to this wavelength is $\mathrm{E}(\mathrm{eV})=1.0815 \mathrm{eV}$. From Properties of Silicon [20], the corresponding absorption coefficient to this energy is $\alpha=0.7 \mathrm{~cm}^{-1}$. The height of our LED device is $x=0.055 \mathrm{~cm}$. Thus, replacing the values of $\alpha$ and $x$ to the equation (3.5) we obtain a value for the transmission efficiency after absorption

$$
\eta_{a b s}=e^{-0.0385} \Rightarrow \eta_{a b s}=0.962
$$

So this loss mechanism is not significant for our devices.

Another loss of photons is due to total internal reflection, (see Figure 3.7). If light impinges at a surface from a region of a high refractive index $\left(\eta_{s}>\eta_{a}\right)$, it is totally reflected back if the angle of incidence is greater than the critical angle $\theta_{\mathrm{c}}$ where

$$
\vartheta_{c}=\sin ^{-1}\left(\frac{\eta_{a}}{\eta_{s}}\right)
$$

and $\eta_{\mathrm{s}}$ and $\eta_{\mathrm{a}}$ are the refractive indexes of silicon and air respectively at $\lambda=1.146 \mu \mathrm{m}$. 


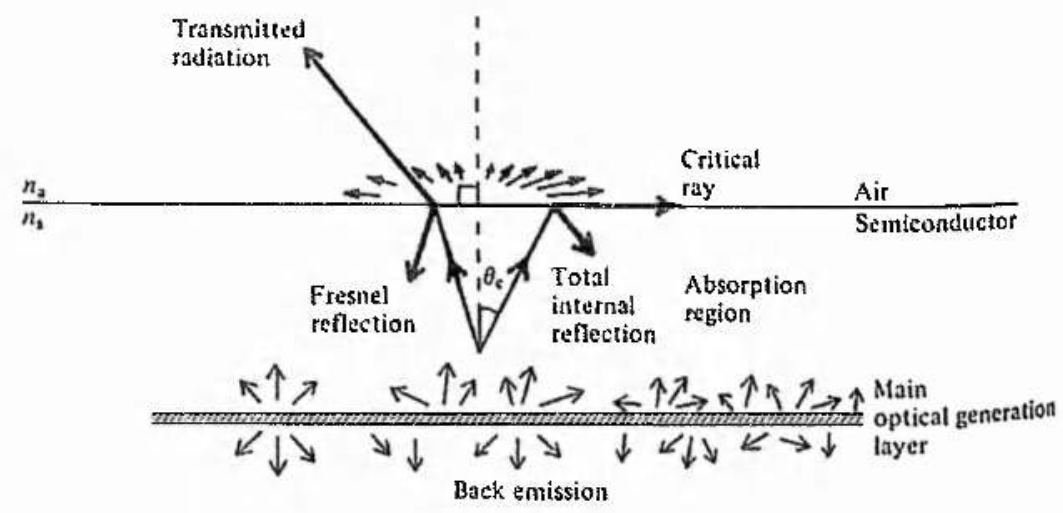

Figure 3.7 Schematic diagram illustrating the main causes of optical loss in an LED. Back emission, limited acceptance cone of the surface, Fresnel reflection and absorption. (After J. Gowar [21]).

The critical angle for our LED device can be calculated by substituting the values of the refractive index of air, $\eta_{\mathrm{a}}=1$ and silicon, $\eta_{\mathrm{s}}=3.519$ at room temperature at $\lambda=1.146 \mu \mathrm{m}$ to the equation (3.8), where we obtain a value of

$$
\vartheta_{c}=\sin ^{-1}\left(\frac{1}{3.519}\right) \Rightarrow \vartheta_{c}=16.5^{\circ}
$$

The efficiency due to total internal refiection $\eta_{\text {TIR }}$ can be calculated as following: We consider that the light which comes out of our device is the same to all directions (isotropic source) and there is also light emitted at the inside of the device, as well, (see Figure 3.8)

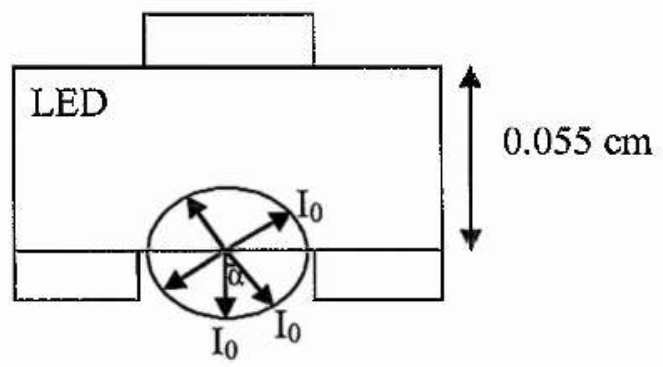

Figure 3.8 Schematic diagram of the light coming out from our LED device. 
The power radiated per solid angle $\theta$ will be:

$$
\mathrm{I}(\theta)=\mathrm{I}_{0}
$$

The total power $\Phi_{0}$ emitted by such a source is obtained by integrating $\mathrm{I}(\theta)$ over all forward directions multiplied by 2 (because there is also inside emission):

$$
\Phi_{0}=2 \int_{0}^{\pi / 2}\left(\mathrm{I}_{0}\right)(2 \pi)(\sin \theta) d \vartheta=-4 \pi \mathrm{I}_{0}[\cos \vartheta]_{0}^{\pi / 2}=4 \pi \mathrm{I}_{0}
$$

The power collected $\Phi$ from such a source is given by integrating $I(\theta)$ from 0 to an angle $\alpha$ :

$$
\Phi=\int_{0}^{\alpha}\left(\mathrm{I}_{0}\right)(2 \pi)(\sin \theta) d \vartheta=-2 \pi \mathrm{I}_{0}[\cos \vartheta]_{0}^{\alpha}=2 \pi \mathrm{I}_{0}(1-\cos \alpha)
$$

Thus, the efficiency $\eta_{T I R}$ will be:

$$
\frac{\Phi}{\Phi_{0}}=\frac{2 \pi \mathrm{I}_{0}(1-\cos \alpha)}{4 \pi \mathrm{I}_{0}}=\frac{1-\cos \alpha}{2}
$$

In equation (3.13) if $\alpha$ is the critical angle $\theta_{c}$, by substituting the value for the critical angle found from (equation 3.9), we obtain:

$$
\eta_{T I R}=\frac{\Phi}{\Phi_{0}}=\frac{1-\cos \left(16.5^{\circ}\right)}{2}=0.0206
$$

Finally, one loss of photons is due to their reflection at the surface because of the change of the refractive index, even though those rays have $\theta<\theta_{\mathrm{c}}$. This is known as Fresnel reflection and the loss Fresnel loss. So from the radiation incident 
perpendicularly on to the surface, a fraction $R$ is reflected and only the remaining fraction is transmitted

$$
T_{F}=1-R=1-\left(\frac{\eta_{s}-\eta_{a}}{\eta_{s}+\eta_{a}}\right)^{2}
$$

The efficiency due to Fresnel loss $\eta_{F}$ for our LED device can be found by substituting the values of refracting index of air $\eta_{\alpha}=1$ and of silicon at room temperature at $\lambda=1.146 \mu \mathrm{m}, \eta_{\mathrm{s}}=3.519$, to equation (3.15). Therefore, the value of $\eta_{\mathrm{F}}$ is as following:

$$
\eta_{F}=1-\left(\frac{3.519-1}{3.519+1}\right)^{2} \Rightarrow \eta_{F}=0.689
$$

The extraction efficiency $\eta_{\mathrm{e}}$ equation (3.4) is given by the product of the values obtained from the efficiencies due to absorption, total internal reflection and Fresnel losses, (equations (3.7), (3.14) and (3.16), respectively). So we have

$$
\eta_{e}=0.962 \times 0.0206 \times 0.689 \Rightarrow \eta_{e}=0.0137 \Rightarrow \eta_{e}=1.37 \%
$$

Finally, an important issue is the fact that not all the light emitted from the LED will be collected, so we must also consider the detector collection efficiency $\eta_{D}$. This one has to do with the light which is actually measured at the detector. The light which comes out from our LED devices is measured at the detector which is placed inside the IR head. Due to geometry factors (i.e. the position of the detector placed inside the IR head or the shape of our LED device), the light which usually is measured from the detector is less than the one emitted from our LED devices. The detector efficiency $\eta_{D}$ can be calculated as follows: 


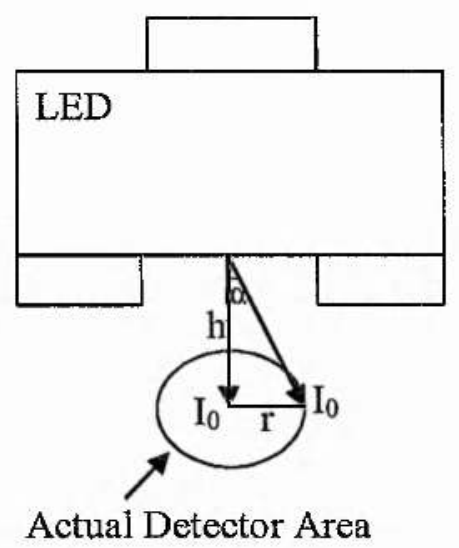

Figure 3.9 Schematic diagram of the light coming out from our LED device along with the actual detector area. (Note that the dimensions of $h$ and $r$ are drawn as a guide for the eye, might not related to the real ones).

We consider that the light which comes out of our device is the same to all directions (isotropic source), (Figure 3.9). The power radiated per solid angle $\theta$ will be:

$$
\mathrm{I}(\theta)=\mathrm{I}_{0}
$$

The total power $\Phi_{0}$ emitted by such a source is obtained by integrating $I(\theta)$ over all forward directions:

$$
\Phi_{0}=\int_{0}^{\pi / 2}\left(\mathrm{I}_{0}\right)(2 \pi)(\sin \theta) d \vartheta=-2 \pi \mathrm{I}_{0}[\cos \vartheta]_{0}^{\pi / 2}=2 \pi \mathrm{I}_{0}
$$

The power collected $\Phi$ from such a source is given by integrating $I(\theta)$ from 0 to an angle $\alpha$ :

$$
\Phi=\int_{0}^{\alpha}\left(\mathrm{I}_{0}\right)(2 \pi)(\sin \theta) d \vartheta=-2 \pi \mathrm{I}_{0}[\cos \vartheta]_{0}^{\alpha}=2 \pi \mathrm{I}_{0}(1-\cos \alpha)
$$

Thus, the detector collection efficiency $\eta_{\mathrm{D}}$ will be: 


$$
\eta_{D}=\frac{\Phi}{\Phi_{0}}=\frac{2 \pi \mathrm{I}_{0}(1-\cos \alpha)}{2 \pi \mathrm{I}_{0}}=1-\cos \alpha
$$

The critical angle $\alpha$ can be found by using basic trigonometry knowing the distances of $h$ and $r$, after measuring them, ( $h=4 \mathrm{~mm}$ and $\mathrm{r}=2 \mathrm{~mm}$ ), (see also Figure 3.9). Thus, we have:

$$
\tan \alpha=\frac{r}{h}=\frac{2}{4} \Rightarrow \alpha=26.5^{\circ}
$$

So substituting the value of $\alpha$ to equation (3.21) we get a value of the detector efficiency $\eta_{\mathbf{D}}$ :

$$
\eta_{D}=1-\cos 26.5^{\circ} \Rightarrow \eta_{D}=0.10557 \Rightarrow \eta_{D}=10.557 \%
$$

This number means that from the actual light emitted from our LED devices, only $10.557 \%$ is measured by the detector. Therefore, the internal efficiency $\eta_{\text {int }}$, i.e. the product of the injection efficiency, $\eta_{\mathrm{i}}$, and the recombination efficiency, $\eta_{\mathrm{r}}$, (formula (3.3)) can then be estimated by dividing, the measured external efficiency $\eta_{\text {ext }}$ (which can be found, since we know the detector efficiency) by the calculated extraction efficiency, $\eta_{\mathrm{e}}$ (see also formula (3.2)).

\subsection{Proposed Model for our Sulphur-based Light Emitting Device}

Our LED device, as described (and in more detail) in the following chapters, consists of a silicon substrate implanted with sulphur. The device is first implanted with sulphur. Boron is further implanted in order to form the pn junction and to introduce the dislocation loops. A suitable heat treatment is performed in order to activate the sulphur atoms and to achieve a controlled distribution of dislocation loops. The dislocation loops, as has been proposed from W. $\mathrm{L}$. $\mathrm{Ng}$ et al. [22], introduce a local strain field, which modifies the band structure and provides spatial 
confinement of the charge carriers. This spatial confinement of carriers favours the radiative recombinations instead of the non-radiative ones. The result of the radiative recombination of carriers is the light emitted from our device.

The effect of sulphur is to expand the above successful and patented method and to create emission at different wavelengths, apart from the one due to silicon. Sulphur's known line from the literature is in the region of $1300 \mathrm{~nm}$, as reported from T. G. Brown [23]. To have a reasonable emission from sulphur, the radiative rate of carriers due to sulphur should be faster than the radiative rate of silicon. Therefore, more radiative recombinations due to sulphur than due to silicon should take place and the emission will be shifted to the longer wavelengths.

In Figure 3.10 is depicted a characteristic interstitial dislocation loop (a) and the hydrostatic pressure created along its sides (b). Well outside the edge of the dislocation loop the hydrostatic pressure is zero. Just inside the dislocation loop, because the distance between the very adjacent row of atoms and the extra one is getting smaller, the silicon lattice is subjected under positive pressure. Just outside the dislocation loop, though, because the above distance is becoming larger, the lattice is placed under negative pressure. The magnitude and the form of the pressure dependence can be calculated by using the elastic theory of dislocations [24], also showing that the pressure decays inversely with distance. The band gap of silicon is pressure dependent, and it decreases with increasing pressure and increases under negative pressure. In Figure 3.10 (c) is depicted a schematic diagram of the modification of the silicon band gap energy due to the presence of a dislocation loop. The exact figure of the modification of the band gap is not clear yet, but the sum $\Delta \mathrm{E}_{\mathrm{c}}$ $+\Delta E_{v}$ is calculated to be in the region of $0.325-0.75 \mathrm{eV}$ [22]. $\Delta \mathrm{E}_{\mathrm{c}}$ and $\Delta \mathrm{E}_{\mathrm{v}}$ is the shift from the conduction and the valence band respectively from the energy gap $E_{\mathrm{g}}$. The effect of the hydrostatic pressure around the dislocation loops is that it modifies the band gap of silicon, causing it to decrease with increasing pressure and to increase under negative pressure [25]. 


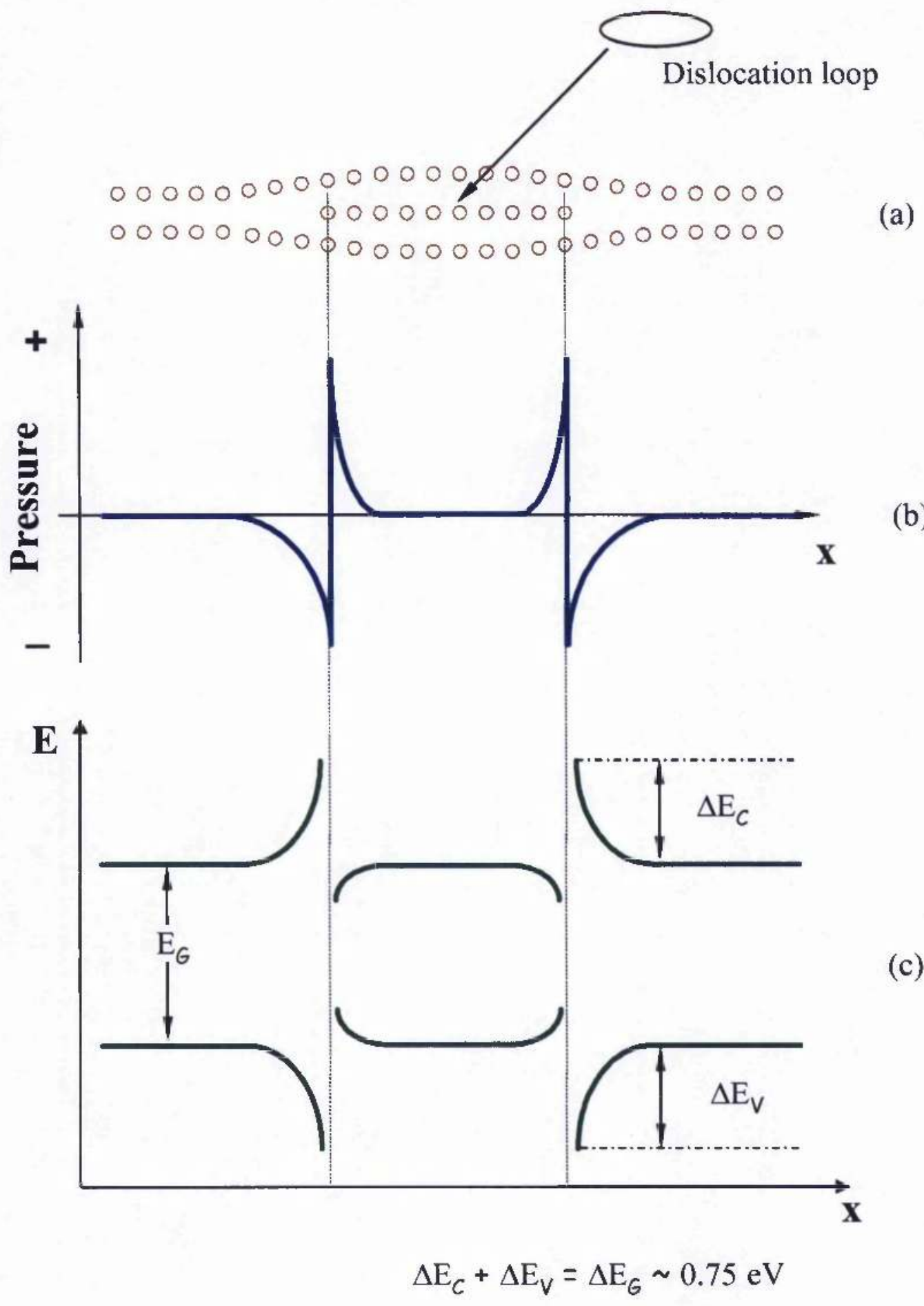

Figure 3.10 (a) Schematic diagram of a typical interstitial dislocation loop used in our LED devices. (b) Hydrostatic pressure along the dislocation loop. (c) Modification of the silicon band gap energy due to the presence of the dislocation loops. 

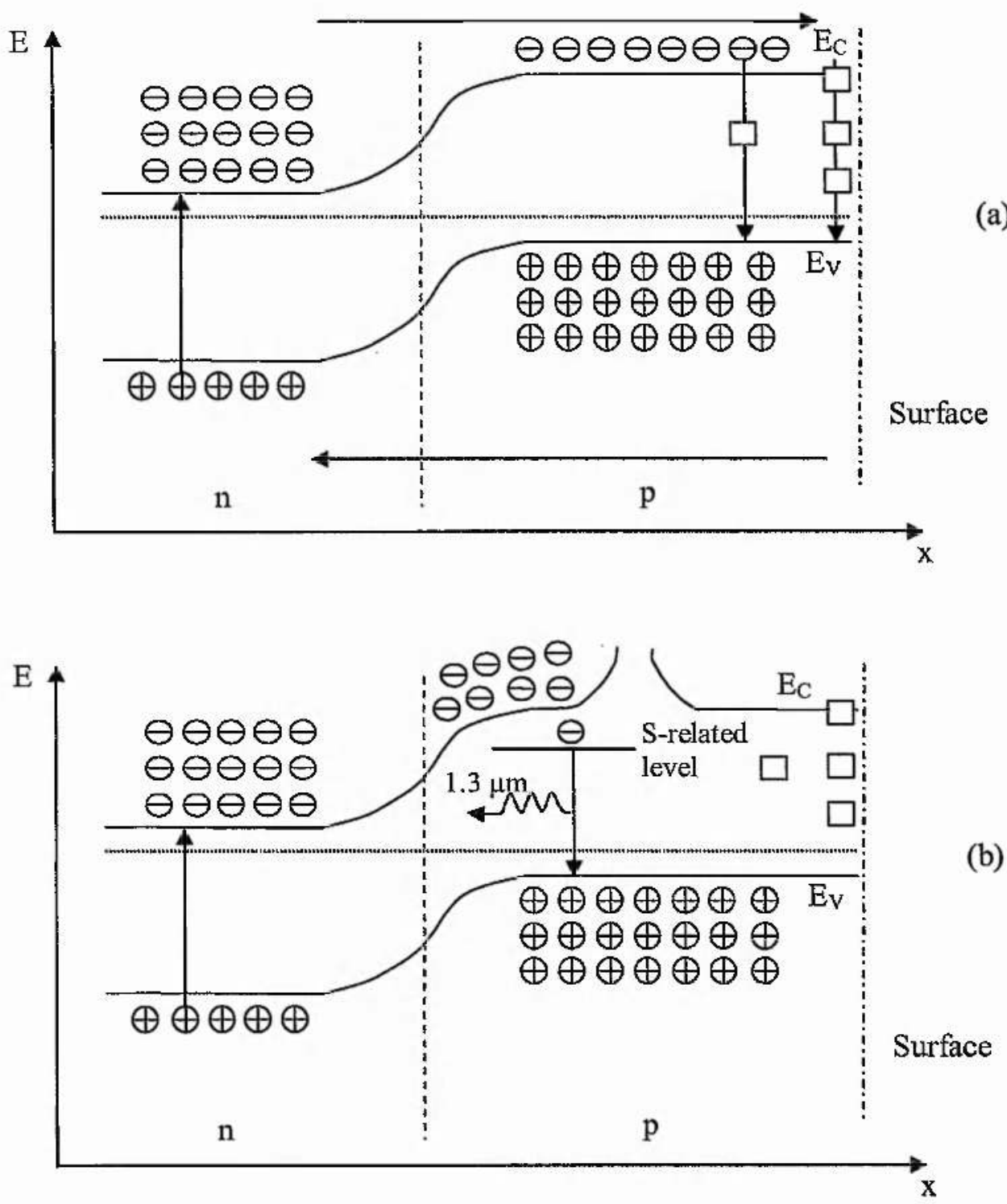

Figure 3.11 (a) Schematic energy diagram of a conventional silicon 'LED' device showing the nonradiative recombination at the bulk and at the surface levels. (b) Energy diagram of our dislocation engineered Si:S LED device after the incorporation of sulphur and boron atoms. The modification of the band gap due to the dislocation loops is also shown. Also depicted is the area where the sulphur level is placed.

Finally, in Figure 3.11 (a) is illustrated a simple energy diagram of a conventional silicon 'LED' device, showing the dominant nonradiative recombination at the bulk and at the surface levels. The introduction of dislocations causes a modification of the band gap. The modification of the band gap due to the 
introduction of dislocations is also shown schematically. The carriers are confined in the region containing the sulphur centres placed between the right edge of the depletion region and the edge of the dislocations, as shown in Figure 3.11 (b). Consequently, by achieving carrier confinement and preventing diffusion to the bulk and surface, the rate of the radiative recombinations at these centres is enhanced in the sulphur doped region, which should lead to light emission at the wavelength of $1.3 \mu \mathrm{m}$. 


\section{References}

[1] B. G. Streetman, S. Banerjee, Solid State Electronic Devices, fifth edition (2000).

[2] T. G. Brown and D. G. Hall, Appl. Phys. Lett. 49, 245 (1986).

[3] N. Peyghambarian, S. W. Koch and A. Mysyrowicz, Introduction to Semiconductor Optics (1993).

[4] L. C. Kimerling, K. D. Kolenmrander, J. Michel and J. Palm, Solid State Phys. 50, 333 (1997).

[5] J. I. Pankove, Optical Processes in Semiconductors (1971).

[6] W. Blundau and A. Onton, W. Heinke, J. Appl. Phys. 451846 (1974).

[7] J. R. Haynes and H. B. Briggs, Phys. Rev. 86, 647 (1952).

[4] J. R. Haynes and W. C. Westphal, Phys. Rev. 101, 1676 (1956).

[9] H. F. Ivey, Electroluminescence and related effects, Suppl. 1 to L. Marton, Ed., Advances in Electronics and Electron Physics, Academic, New York, (1963), p. 205.

[10] G. Z. Pan and K. N. Tu, J. Appl. Phys. 82, 601 (1997).

[11] W. Schockley, "Forming semiconductive devices by ionic bombardment", US patent 2787564.

[12] J. F. Gibbons, Part I, Proc. IEEE, 56, 295 (1968), Part II, Proc. IEEE, 60, 1062 (1960).

[13] L.N. Large and R. W. Bicknell, J. Mater. Sci. 2, 589 (1967).

[14] P. F. Byrne and N. W. Cheung, D. K. Sadana, Appl. Phys. Lett. 41, 537 (1982).

[15] J. Price Hirth and J. Lothe, Theory of dislocations, McGraw-Hill (1968).

[16] W. T. Read, Dislocations in crystals, McGraw-Hill (1953).

[17] J. Weertman and J. R. Weertman, Elementary dislocation theory (1964).

[18] D. Hull and D. J. Bacon, Introduction to dislocations, third edition (1995). 
[19] G. Carter and W.A. Grant, Ion implantation of semiconductors, E. Arnold, (1976).

[20] Properties of Silicon, INSPEC, London (1988).

[21] J. Gowar, 'Optical Communication Systems', Second. edition, Prentice Hall International Series.

[22] W. L. Ng, M. A. Lourenço, R. M. Gwilliam, S. Ledain, G. Shao and K. P. Homewood, Nature 410, 192 (2001).

[23] T. G. Brown and D. G. Hall, Appl. Phys. Lett. 49, 245 (1986).

[24] J. Price Hirth and J. Lothe, Theory of dislocations, McGraw-Hill (1968).

[25] M. A. Lourenço, M. S. Siddiqui, G. Shao, R. M. Gwilliam and K. P. Homewood, L. Pavesi et al. (eds). Towards the first silicon laser, 11-20 (2003), Kluwer Academic Publishers, Printed in Netherlands. 


\section{EXPERIMENTAL METHODS - BACKGROUND}

\subsection{Introduction}

In this chapter, the preparation of the sulphur doped silicon samples formed by ion implantation will be described. The fabrication of light emitting diodes based on $\mathrm{S}: \mathrm{Si}$ will be also discussed. Ion implantation was used to prepare the samples and secondary ion mass spectrometry (SIMS) was used on one of our samples in order to provide a better explanation of our results, so these techniques will be also explained. Finally, photoluminescence and electroluminescence spectroscopy were the two major techniques used in order to investigate the optical emission propertics of the above samples and devices, so they are also described.

\subsection{Sample preparation}

The starting material which was used was n-type (100) crystalline silicon grown by the Czochralski (CZ) method. The resistivity of the substrate is $2-7 \Omega \mathrm{cm}$. The samples were implanted with sulphur by ion implantation at doses ranging from $10^{11}-10^{14} \mathrm{~S} \mathrm{~cm}^{-2}$ and at $30 \mathrm{keV}$ energy. Each sample was divided into two groups (0 and 1). After sulphur implantation, all samples were annealed either at $1000{ }^{\circ} \mathrm{C}$ (group 0) or at $1100{ }^{\circ} \mathrm{C}$ (group 1) for 10 seconds, in order to activate the sulphur atoms in the $\mathrm{Si}$ lattice. The two different anneal temperatures were done in order to examine the different annealing conditions. After annealing at $1000{ }^{\circ} \mathrm{C}$ or $1100{ }^{\circ} \mathrm{C}$, a further implantation with boron took place at a dose of $10^{15} \mathrm{~B} \mathrm{~cm}^{-2}$ at $30 \mathrm{keV}$ for a selection of samples while the rest remained as they were. Those samples which were implanted with boron, were further annealed at $950{ }^{\circ} \mathrm{C}$ for $1 \mathrm{~min}$. Ion implantation of boron was used as a method to introduce dopant atoms into the lattice as well as a means of introducing dislocations. One problem which occurs after the ion implantation of sulphur or boron is the lattice damage because of the 
collisions between the implanted ions and the lattice atoms. This damage can be removed by annealing at temperatures around $600{ }^{\circ} \mathrm{C}$ [1]. The dislocation loops are formed though by annealing at temperatures above $600{ }^{\circ} \mathrm{C}$. For this reason the above samples were annealed at $950{ }^{\circ} \mathrm{C}$ to deliberately create dislocation loops. All the above samples were studied by photoluminescence and electroluminescence spectroscopy in order to investigate their emission properties. (See also sections 4.6 and 4.7).

\subsection{Light Emitting Diode (LED) Fabrication}

For the (LED) device fabrication, we used n-type (100) (CZ) silicon wafers of 2-7 $\Omega \mathrm{cm}$ resistivity. The same conditions as in section 4.2 were performed for this case; the n-type silicon was doped with sulphur at doses in the region of $10^{11}-10^{14}$ $\mathrm{cm}^{-2}$ at $30 \mathrm{keV}$. After sulphur implantation, the samples were annealed at $1000^{\circ} \mathrm{C}$ or $1100{ }^{\circ} \mathrm{C}$ for $10 \mathrm{~s}$. A further implantation with boron took place at $10^{15} \mathrm{~B} \mathrm{~cm}^{-2}$ at 30 $\mathrm{keV}$. Finally, a further anneal at $950^{\circ} \mathrm{C}$ for $1 \mathrm{~min}$ took place in order to activate the boron in the Si host lattice and to form the dislocation loops layer.

The procedure for the device fabrication is the following: Firstly, we apply a 'three-stage cleaning' with trichloroethylene, acetone, IPA and de-ionised water. Then the samples were ready to be etched with $40 \% \mathrm{HF}$ acid for 1 minute, in order to remove the oxide layer which was formed from the air. The metallic contacts were made by evaporation of aluminium (Al) and gold/antimony (AuSb) at the borondoped side and the n-type substrate respectively. The ohmic contacts were sintered at $360{ }^{\circ} \mathrm{C}$ for 2 minutes. During evaporation the samples were in contact from both sides with a specially designed mask consisting of holes. The two parts of the mask were slightly displaced the one from another by $\mathrm{x}$, where $\mathrm{x}$ is half the period of the hole spacing (Figure 4.1(a)). Thus, after evaporation, the samples looked as shown in Figure 4.1(b). In Figures 4.1 (c) and (d) is shown the top and the bottom side of the 
samples after cleaving them into individual devices, as they look like to the eye. A simple diagram of the device is also shown in Figure 4.2.

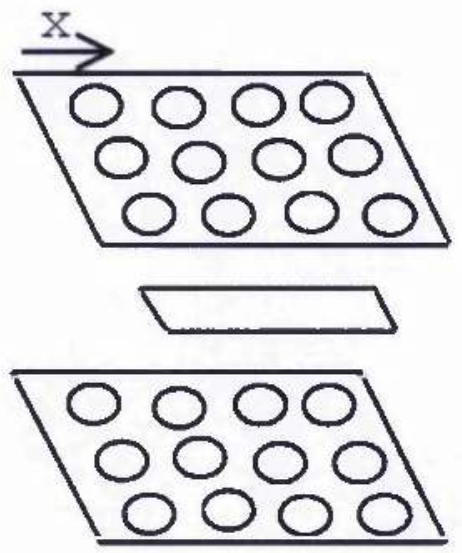

(a)

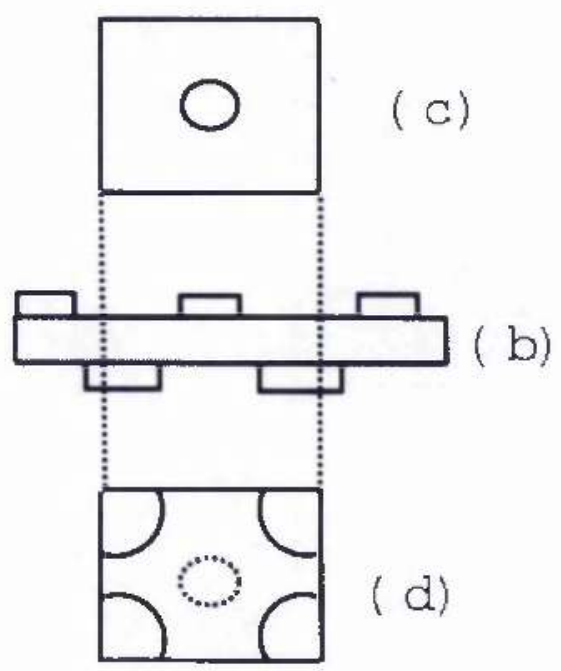

Figure 4.1 Schematic diagram of the mask and the samples after evaporation. (a) The two parts of the mask slightly displaced each other by $\mathrm{x}$ at the horizontal direction, where $\mathrm{x}$ is half the period of the hole spacing. Samples are in contact with the two parts of the mask during evaporation. (b) Side view of samples after evaporation having the contacts $\mathrm{Al}$ and AuSb. (Note that the dimensions of the sample and the contacts drawn might not be very close to the real ones) (c) Top view and (d) bottom view of a sample after cleaving it into an individual device.

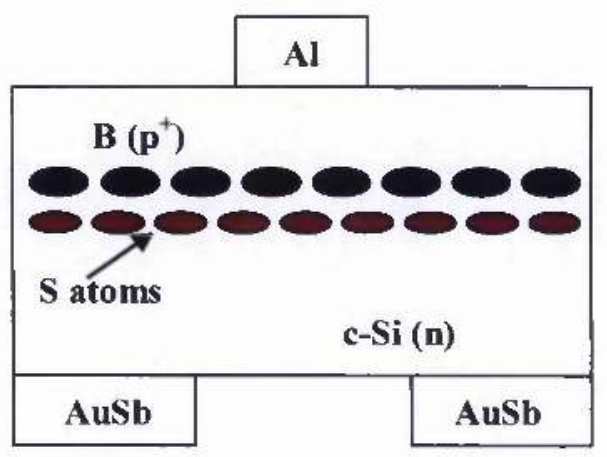

Figure 4.2 A schematic diagram of the sulphur doped silicon light emitting diode (LED) 
In order to allow the electroluminescence out of the device a window was left in the back larger contact. A procedure called 'mesa etching' was then followed. This is done in order to isolate the pn junction. The top $\mathrm{Al}$ contact and the bottom side of the device were painted by black wax in order to be 'protected' from the following etching. The 'silicon etching' which followed consists of a solution of $125 \mathrm{ml}$ of $\mathrm{HNO}_{3}, 5 \mathrm{ml}$ of $\mathrm{HF}$ and $125 \mathrm{ml}$ of de-ionised water. The devices were etched for 15 minutes in the above solution. After etching, the black wax from the device was removed with the help of toluene. Finally, the three-stage cleaning was applied again to the devices.

Current-voltage (I-V) measurements were made between the front and back contacts to check that the devices were behaving like diodes. Electroluminescence spectroscopy was used to study the light which came out from the above devices when current was applied to them, (see also section 4.7).

\subsection{Ion implantation Technique}

As described in sections 4.2 and 4.3, sulphur and boron was introduced to our Si n-type substrates by ion implantation. Ion implantation is the introduction of energetic charged atomic particles into a substrate by ion bombardment in the energy range of $\mathrm{keV}$ to $\mathrm{MeV}$. The aim of this technique is, for example, to change the electrical, mechanical, optical, magnetic and super-conducting properties of the substrate in a very controlled way and a very precise area. The theory of ion implantation has been described in chapter 3 (section 3.5).

The basic parts of an ion implantation system are the ion source, the acceleration tube, the mass separator, the beam integrator and the target chamber. $\mathrm{A}$ schematic diagram of the ion implantation system is illustrated in Figure 4.3. The beam of ions is created at the ion source which contains an ion plasma with the species of interest. The ions in the beam are extracted to the acceleration tube and 
they are accelerated to a higher energy by an applied extraction voltage between the source and the acceleration tube. A high vacuum pump is used to keep the pressure low (below $10^{-6}$ Torr) to avoid ion-gas scattering.

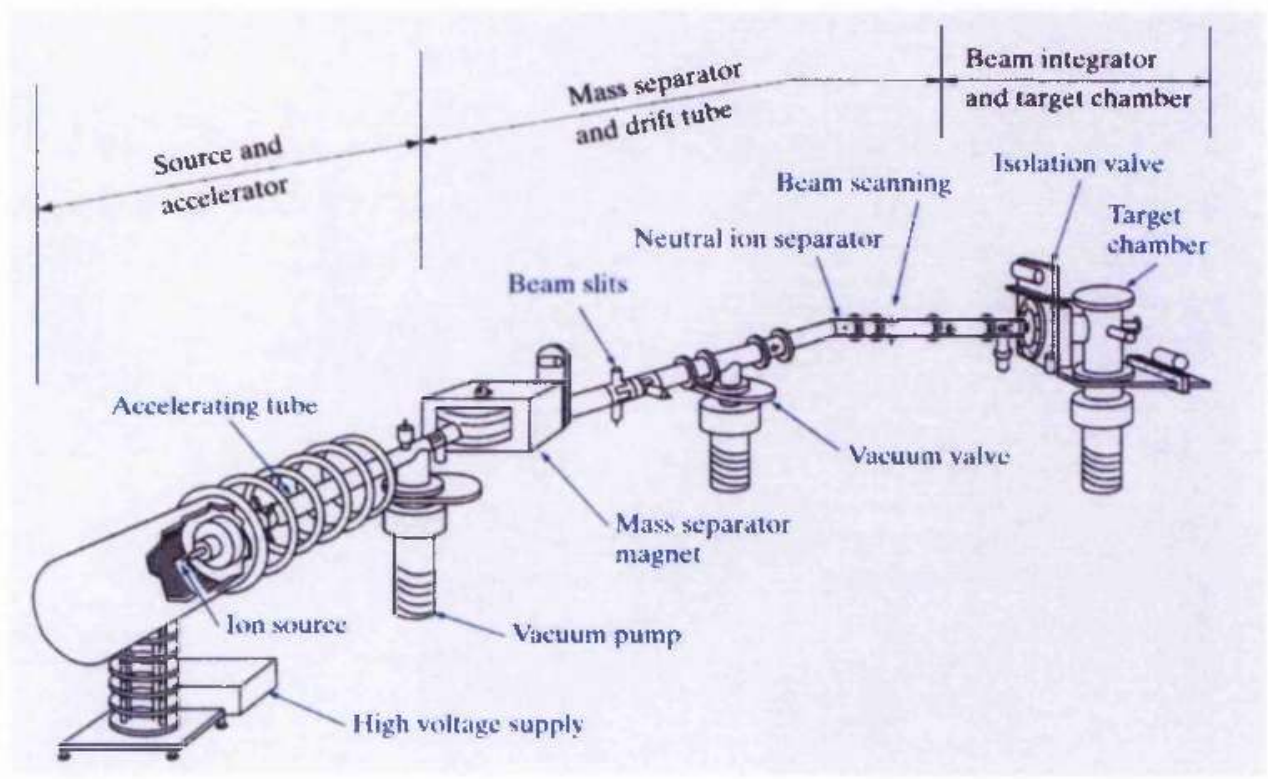

Figure 4.3 Schematic diagram of an ion implantation system [2].

The ion source produces apart from the desired ion species many isotopes and other charge states of the ion species. Therefore, the accelerated ions are separated by a mass separator magnet that selects only the desired ion species and rejects the other ones. The desired ions are passing through from the resolving slits so that the ion beam is well collimated. Electrostatic deflection plates in both directions ( $\mathrm{x}$ and $\mathrm{y}$ ) are used to scan the beam and obtain uniform implantation over the target area. The ion beam is transported to the chamber through a high vacuum system to avoid any charge-exchange effects. Finally, the integrator integrates the beam. The current that goes through the integrator becomes neutralised. The four Faraday cups which are situated at the four ends of the target chamber measure the magnitude of the current. The wafer is tilted by $7^{0}$ with respect to the beam direction and twisted by $22^{\circ}$ with respect to the [110] direction in order to avoid any channelling effects. 
The major parameters which affect the ion implantation technique are the ion mass, energy, dose and its charge state and the mass of the target atom, the accelerating voltage $\mathrm{V}$ and the magnetic applied field $\mathrm{B}$.

\subsection{SIMS - Secondary Ion Mass Spectrometry}

For the interpretation of our results a chosen sample was studied using the Secondary Ion Mass Spectrometry (SIMS).

This method is the mass spectrometry of ionized particles which are emitted from a surface, which is solid in our case, when it is bombarded by energetic primary particles [3]. The primary particles are usually ions. The emitted secondary particles from the surface will be in an ionized state or if they are in neutral state, they will be post-ionized before the analysis. The secondary ions are those which are detected and analysed with a mass spectrometer. This process of the collision of primary ions with the solid surface and the emission of secondary ions is known as sputtering. The two main processes which are involved in the SIMS technique are the emission of the particles or sputtering and their ionization.

SIMS is a powerful technique for the microcharacterisation of solid materials and their surfaces. It provides a mass spectrum of a surface also enabling a detailed chemical analysis of this surface. The most popular application of SIMS is that it can provide quantitative concentration versus depth profiles of dopants or impurities in a material, in a very high sensitivity. That application of SIMS we made use of for our sample. 


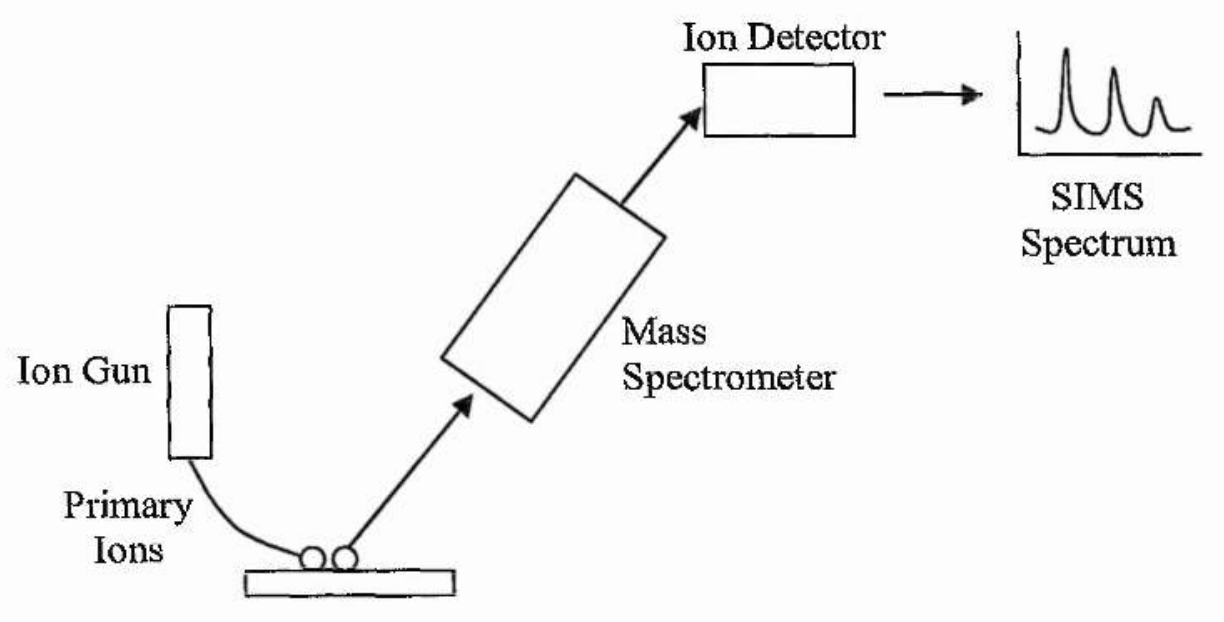

Figure 4.4 Schematic diagram of the main components of the SIMS experiment

The basic components of a SIMS system are the primary ion gun and the mass analyser (see Figure 4.4). According to the SIMS operating mode that will be chosen, the instrumentation is different. For the depth profiling that we are interested in, the dynamic SIMS mode is mostly used. The surface is etched with a high flux of primary ions in order to progressively remove surface layers. The surface is eroded very rapidly and it is possible to monitor the changes of elemental composition with depth and a depth profile can be provided. The primary particle source is able to produce a beam of ions or atoms ranging at energies between $0.5-50 \mathrm{keV}$. The emitted secondary ions are collected and directed by transfer optics into a mass spectrometer where they are analysed and finally detected by the ion detector. The three commonly used mass spectrometers are the quadrupole, the magnetic sector and the time-of-flight one. Their basic differences are in the mass resolution and range and in the secondary ion transmission and sensitivity. For the depth profiling the magnetic sector one is most widely used which mainly consists of large magnets to produce the magnetic field and a pair of cylindrical electrodes to produce the electrostatic field. The whole system is under ultra-high vacuum to eliminate the scattering between the ions. 


\subsection{Photoluminescence Spectroscopy}

As was mentioned in section 4.2 , the samples which were implanted with sulphur and further implanted with boron were studied with photoluminescence spectroscopy measurements. The setup which was used for our PL experiments is as follows: (see also Figures 4.5 and 4.6). The samples were excited by an Argon laser (Spectra Physics Model 2020) set to $514 \mathrm{~nm}$. The laser power was adjusted to the required power, typically around $150 \mathrm{~mW}$. The laser beam was mechanically chopped by an EG\&G Princeton Applied Research 197 chopper. The path of the modulated beam was directed into the cryostat by a mirror. A line-pass filter was used to remove any unwanted plasma lines of the laser. The beam was directed and focused by a lens onto the sample. The sample was mounted onto the sample-holder, which is placed inside an Oxford Instruments dynamic-flow cryostat in a vertical position (z-axis). The cryostat has two windows at the bottom, one to permit the light to hit the sample and the other one to allow the luminescence deriving from the sample to leave the cryostat.

The beam impinges the sample along the optical axis of the spectrometer. The sample was rotated around the vertical axis, so that the reflected laser beam terminated inside the cryostat. This is done in order to ensure that the light coming out of the window is the result of the luminescence from the sample and not light from the laser beam.

$\mathrm{PL}$ was performed from room temperature to low temperatures $(\sim 80 \mathrm{~K})$ having a continuous flow of nitrogen vapour in the cryostat. The cryostat was maintained under vacuum, by the two pumps, the rotary and the diffusion one. The temperature inside the cryostat was regulated by using an Oxford ITC4 temperature controller driving a heater element in a feedback loop arrangement. The luminescence which was emitted from the samples was directed via two lenses into a Spex $1702 / 04$ spectrometer fitted with a $1 \mu \mathrm{m}$ grating. A long-pass filter was used to prevent the $514 \mathrm{~nm}$ line coming through the spectrometer. The slit width of the 
spectrometer was set to $3000 \mu \mathrm{m}$ to obtain the highest signal. The spectrometer was set to scan at wavelengths between $900 \mathrm{~nm}$ to $1750 \mathrm{~nm}$. This wavelength range area was divided into 200 channels and the time spent to 'record' the information from every each channel was set to be $300 \mathrm{~ms}$. The signal is dispersed by the spectrometer and detected with a E1 Edinburgh Instrument liquid nitrogen-cooled germanium p-i$\mathrm{n}$ diode. The detected output is then passed to an EG\&G Princeton Applied Research 5209 lock-in amplifier. The lock-in amplifier extracts the signal from the sample that is at the same frequency and in-phase with the chopper's frequency. This reduces random noise, which has no phase relationship with the modulation frequency and so averages it to zero.

The output from the lock-in amplifier was directed to a $\mathrm{PC}$ which has the software to display the luminescence spectra. This software provides storage of the data, regulates the temperature and drives the spectrometer. For every change of temperature inside the cryostat, a waiting period of about 30 minutes was necessary in order to assure that the change in temperature was completed. This was also checked by setting the spectrometer at a wavelength of a known peak and constantly observing the signal values from the lock-in amplifier until they are constant.

The samples are cooled inside the cryostat and then excited with the laser source with photon energy $h v>E_{g}$, generating electron-hole pairs which then recombine. When this recombination is radiative photons are emitted and this is the actual PL output which is detected and analysed.

Low temperature $(\sim 80 \mathrm{~K})$ measurements of the samples are done in order to obtain the fullest spectroscopic information by minimising thermally activated nonradiative recombination processes and thermal line broadening. The thermal distribution of carriers excited to a band contributes a width of $\sim \mathrm{kT}$ to an emission originating from that band. So cooling the samples reduces the width. The photon energy which is emitted from the samples depends on the recombination process. So we see different emission lines at the PL spectra. In general, with the PL technique it is easy to detect and identify the impurities in semiconductors but not the densities of 
those impurities. This is because it is not easy to draw a quantitative correlation between the intensity of a given impurity spectral line and the density of that impurity. This is due to parallel nonradiative recombination through deep-level bulk or surface recombination centers [4].

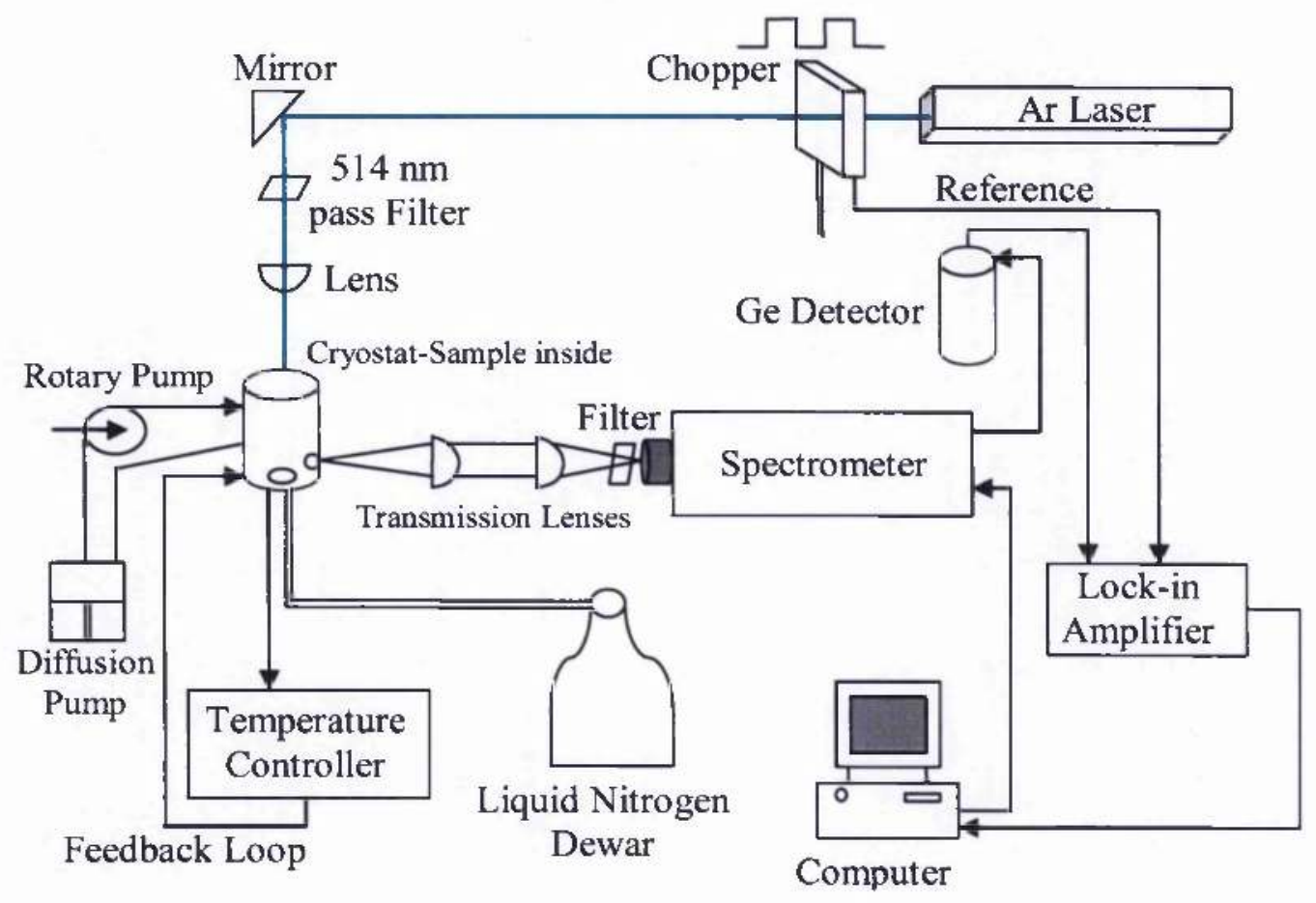

Figure 4.5 Schematic view of the photoluminescence spectroscopy setup 


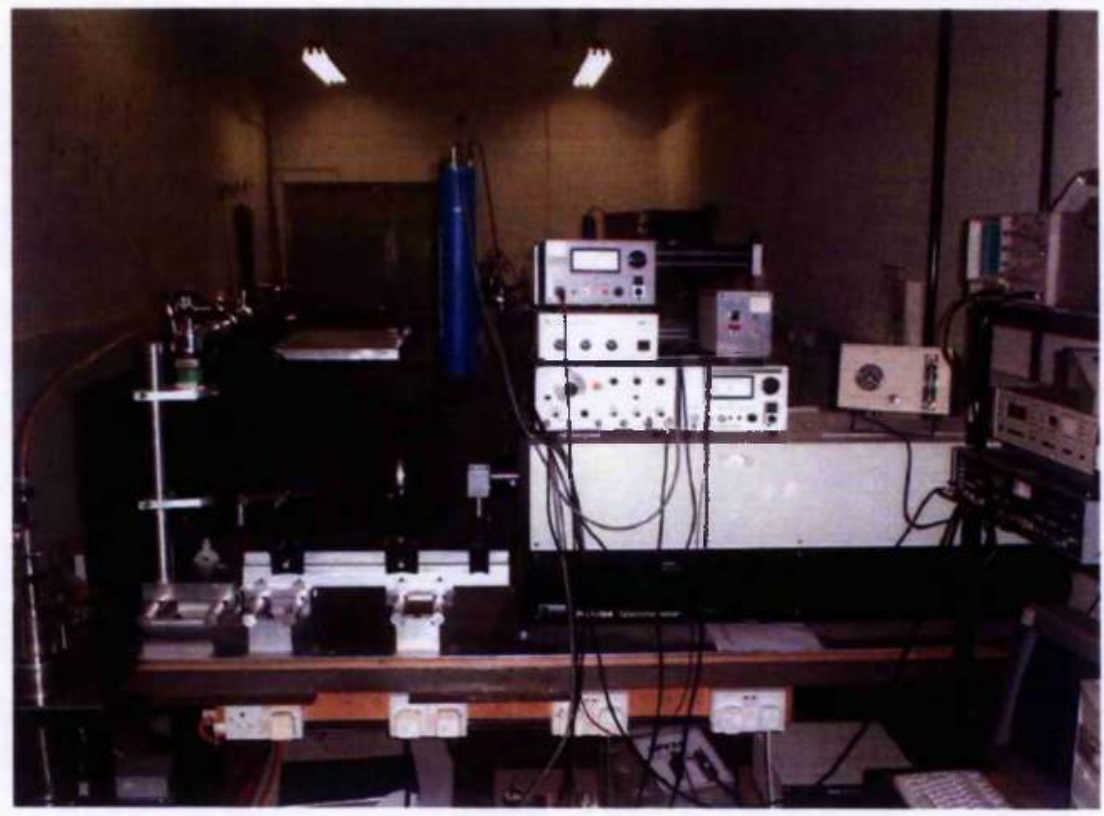

Figure 4.6 General view of the photoluminescence spectroscopy setup. From left to right is illustrated the cryostat where the samples are mounted, the (blue) p-i-n detector, the spectrometer. At the very right end of the picture is illustrated from top to bottom, the oscilloscope, the temperature controller, the lock-in amplifier and the PC. The laser which excites the samples is behind the spectrometer and is not seen in this picture.

\subsection{Electroluminescence Spectroscopy}

The LED devices which were fabricated as described in section 4.3 , were studied by the electroluminescence spectroscopy experiments. EL spectroscopy is quite similar to PL. The major difference is that the samples for the EL are excited by an electric current which is applied through them, instead of a light beam directed to them for the case of PL spectroscopy.

The setup for the EL is quite similar to the PL one. (See Figures 4.7 and 4.8). The samples were mounted onto a specially designed mechanical holder in such a way that on their top and bottom contacts could be applied a voltage. The sample holder was connected to a function generator PFG605 capable of driving current up to $\sim 250 \mathrm{~mA}$. The frequency which was applied from the generator was in our case 
23.1 $\mathrm{Hz}$. This value for the frequency was chosen as the optimum frequency for obtaining the highest signal. The sample holder, as for the case of PL, was inserted inside the liquid-nitrogen-cooled Oxford Instruments cryostat with continuous flow of nitrogen vapour. The vacuum inside the cryostat was produced and maintained by the two pumps, a rotary and a diffusion pump.

The light from the device was emitted from its back window area (n-type Si region). The diode was under forward bias. The luminescence from the device was focused by a two lens system onto the slits of the Spex 500M Spectrometer. The temperature was set by an Oxford ITC 503 temperature controller in a feedback loop arrangement. The values of the applied current and voltage were continuously monitored by the two oscilloscopes connected with the sample throughout the experiment. The signal from the spectrometer was detected by a liquid-nitrogen cooled p-i-n E1 Edinburgh Instrument Germanium diode and then directed to the EG\&G Princeton Applied Research lock-in amplifier. The lock-in amplifier extracts the signal from the sample that is at the same frequency and in-phase with the generator's frequency. This reduces random noise, which has no phase relationship with the modulation frequency and so averages it to zero. The output signal was processed with the help of the same software program as for the PL setup at a PC.

As for the PL, EL measurements were made from room temperature to $80 \mathrm{~K}$. The same procedure was followed for the change of measurement temperature; a waiting period of about 30 minutes and checking the values from the lock-in amplifier to be constant when the spectrometer was set at a certain wavelength. 


\section{Chapter 4 - Experimental Methods-Background}

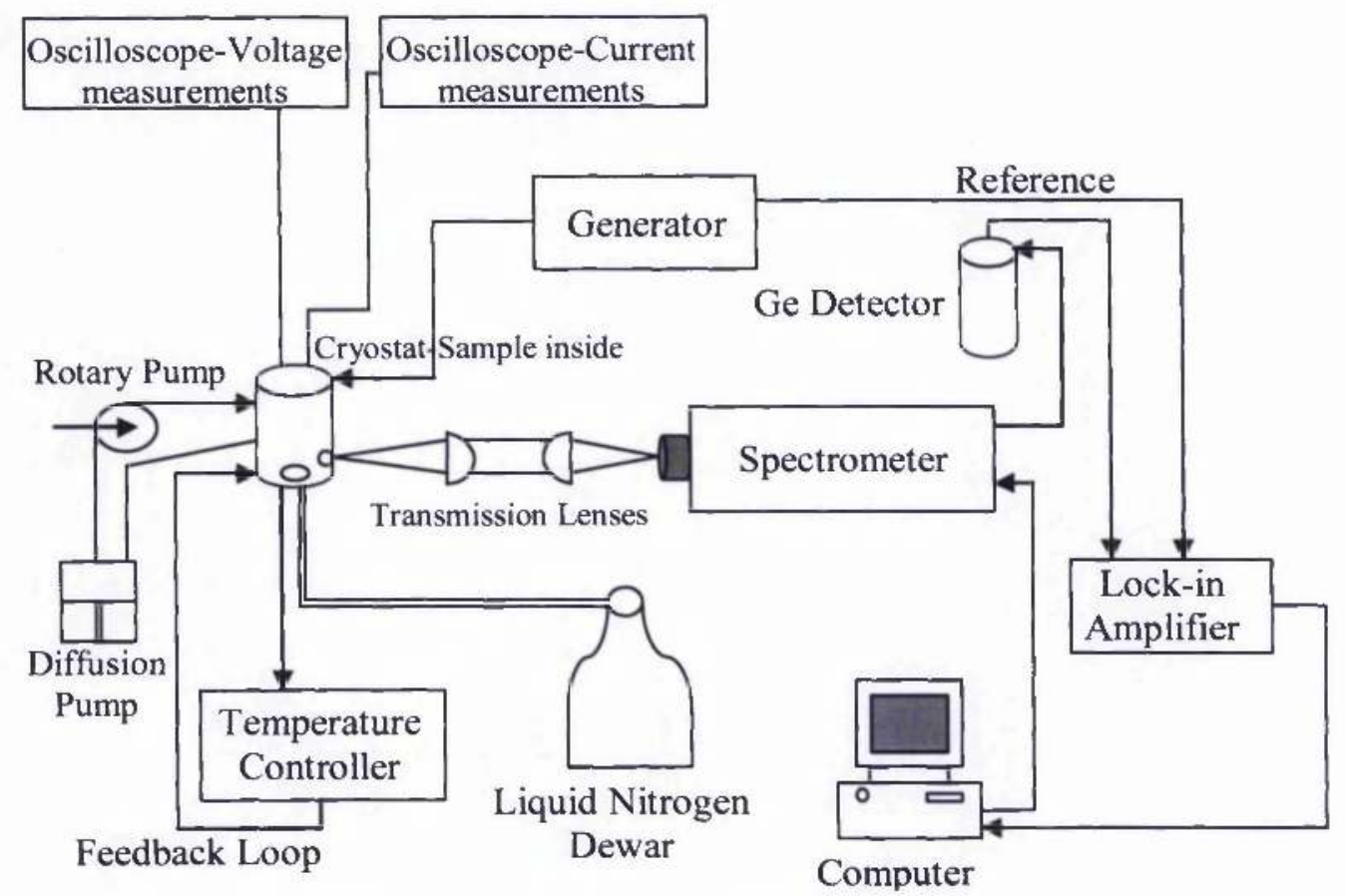

Figure 4.7 Schematic view of the electroluminescence spectroscopy setup

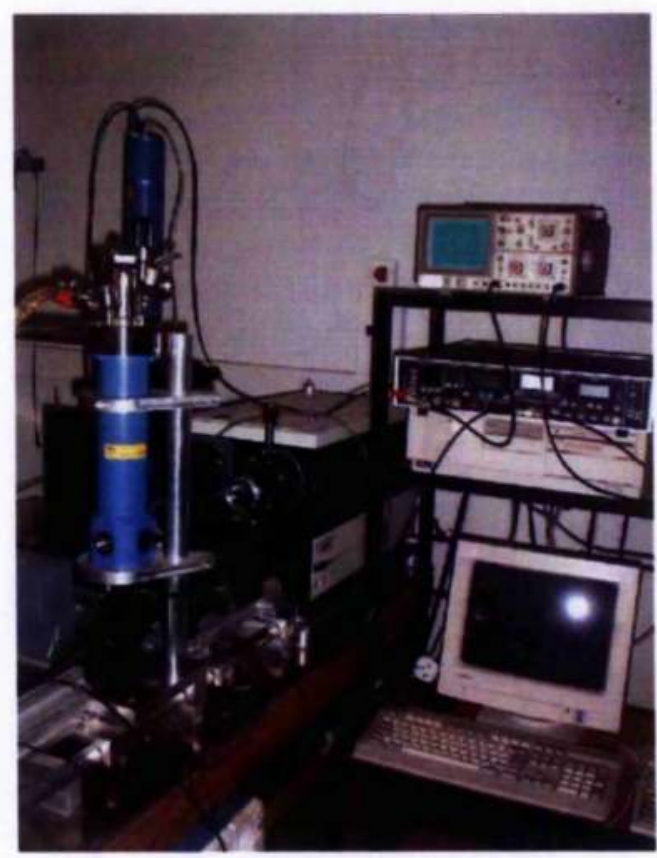

Figure 4.8 General view of the electroluminescence spectroscopy setup. It is depicted the cryostat, the p-i-n detector and the spectrometer plus one of the two oscilloscopes, the lockin amplifier and the PC. The functional generator is not shown. 


\section{References}

[1] J. M. Mayer, L. Eriksson, S. T. Picraux and J. A. Davies, Can. J. of Phys, 46, 663 (1968).

[2] B. G. Streetman, S. Banerjee, Solid State Electronic Devices, fifth edition (2000).

[3] D. Briggs, A. Brown and J. C. Vickerman, Handbook of Static Secondary Ion Mass Spectrometry (SIMS) (1989).

[4] S. B. Felch, R. Brennan, S. F. Corcoran and G. Webster, 'A comparison of three techniques for profiling ultrashallow $\mathrm{p}^{+} \mathrm{n}$ junctions, Solid State Technol. 36, 45-51 (Jan. 1993). 


\section{EXPERIMENTAL RESULTS ON Si:S SAMPLES}

\subsection{Introduction}

In this chapter I will present the results obtained on Si:S samples from photoluminescence and electroluminescence experiments. This chapter is divided into two major sections; the first section includes results from PL variable temperature and PL variable laser power experiments on Si:S samples. The other section provides results from EL variable temperature and EL variable current experiments on $\mathrm{Si}: \mathrm{S}$ devices.

\subsection{PL results on Si:S samples}

\subsubsection{PL variable temperature measurements}

The samples under investigation were Si n-type (100) wafers of 2-7 $\Omega \mathrm{cm}$ resistivity implanted with sulphur at doses of $10^{11}, 10^{12}, 10^{13}$ and $10^{14} \mathrm{~S} \mathrm{~cm} \mathrm{~cm}^{-2}$ and at $30 \mathrm{keV}$ energy. Each sample was divided into two parts (0 and 1). After implantation, all samples were annealed either at $1000^{\circ} \mathrm{C}$ (part 0) or at $1100{ }^{\circ} \mathrm{C}$ (part 1) for 10 seconds, in order to activate the sulphur atoms in the Si lattice. After annealing at $1000{ }^{\circ} \mathrm{C}$ or $1100{ }^{\circ} \mathrm{C}$, a further implantation with boron took place at a dose of $10^{15} \mathrm{~B} \mathrm{~cm}^{-2}$ at $30 \mathrm{keV}$ for a selection of samples while the rest remained as they were. Those samples which were implanted with boron, were further annealed at $950{ }^{\circ} \mathrm{C}$ for $1 \mathrm{~min}$. A table of the samples used is shown on Table 5.1. 


\begin{tabular}{|c|c|c|c|}
\hline Label & Implant Energy & Dopant & $\begin{array}{l}\text { Anneal } \\
\text { Conditions }\end{array}$ \\
\hline $0 / \mathrm{S} 11$ & $10^{11} \mathrm{~S} \mathrm{~cm}^{-2}, 30 \mathrm{keV}$ & $\bar{S}$ & $\mathrm{~S}$ at $1000^{\circ} \mathrm{C}, 10 \mathrm{sec}$ \\
\hline $0 / \mathrm{S} 11 \_\mathrm{B}$ & $\begin{array}{l}10^{11} \mathrm{~S} \mathrm{~cm}^{-2}, 30 \mathrm{keV}, \\
10^{15} \mathrm{~B} \mathrm{~cm}^{-2}, 30 \mathrm{keV}\end{array}$ & S, B & $\begin{array}{l}\mathrm{S} \text { at } 1000^{\circ} \mathrm{C}, 10 \mathrm{sec}, \\
\mathrm{B} \text { at } 950{ }^{\circ} \mathrm{C}, 1 \mathrm{~min}\end{array}$ \\
\hline $0 / \mathrm{S} 12$ & $10^{12} \mathrm{~S} \mathrm{~cm}^{-2}, 30 \mathrm{keV}$ & $\mathrm{S}$ & $\mathrm{S}$ at $1000^{\circ} \mathrm{C}, 10 \mathrm{sec}$, \\
\hline $0 / \mathrm{S} 12 \mathrm{~B}$ & $\begin{array}{l}10^{12} \mathrm{~S} \mathrm{~cm}^{-2}, 30 \mathrm{keV} \\
10^{15} \mathrm{~B} \mathrm{~cm}^{-2}, 30 \mathrm{keV}\end{array}$ & S, B & $\begin{array}{l}\mathrm{S} \text { at } 1000^{\circ} \mathrm{C}, 10 \mathrm{sec}, \\
\mathrm{B} \text { at } 950^{\circ} \mathrm{C}, 1 \mathrm{~min}\end{array}$ \\
\hline $0 / \mathrm{S} 13$ & $10^{13} \mathrm{~S} \mathrm{~cm}^{-2}, 30 \mathrm{keV}$ & $\mathrm{S}$ & $\mathrm{S}$ at $1000^{\circ} \mathrm{C}, 10 \mathrm{sec}$ \\
\hline 0/S13_B & $\begin{array}{l}10^{13} \mathrm{~S} \mathrm{~cm}^{-2}, 30 \mathrm{keV} \\
10^{15} \mathrm{~B} \mathrm{~cm}^{-2}, 30 \mathrm{keV}\end{array}$ & S, B & $\begin{array}{l}\mathrm{S} \text { at } 1000^{\circ} \mathrm{C}, 10 \mathrm{sec}, \\
\mathrm{B} \text { at } 950^{\circ} \mathrm{C}, 1 \mathrm{~min}\end{array}$ \\
\hline $0 / \mathrm{S} 14$ & $10^{14} \mathrm{~S} \mathrm{~cm}^{-2}, 30 \mathrm{keV}$ & $\mathrm{S}$ & $\mathrm{S}$ at $1000^{\circ} \mathrm{C}, 10 \mathrm{sec}$ \\
\hline 0/S14_B & $\begin{array}{l}10^{14} \mathrm{~S} \mathrm{~cm}^{-2}, 30 \mathrm{keV} \\
10^{15} \mathrm{~B} \mathrm{~cm}^{-2}, 30 \mathrm{keV}\end{array}$ & $\mathrm{S}, \mathrm{B}$ & $\begin{array}{l}\mathrm{S} \text { at } 1000^{\circ} \mathrm{C}, 10 \mathrm{sec}, \\
\mathrm{B} \text { at } 950^{\circ} \mathrm{C}, 1 \mathrm{~min}\end{array}$ \\
\hline 1/S11 & $10^{11} \mathrm{~S} \mathrm{~cm}^{-2}, 30 \mathrm{keV}$ & $\mathrm{S}$ & $\mathrm{S}$ at $1100^{\circ} \mathrm{C}, 10 \mathrm{sec}$ \\
\hline 1/S11_B & $\begin{array}{l}10^{11} \mathrm{~S} \mathrm{~cm}^{-2}, 30 \mathrm{keV}, \\
10^{15} \mathrm{~B} \mathrm{~cm}^{-2}, 30 \mathrm{keV}\end{array}$ & $\mathrm{S}, \mathrm{B}$ & $\begin{array}{l}\mathrm{S} \text { at } 1100^{\circ} \mathrm{C}, 10 \mathrm{sec}, \\
\mathrm{B} \text { at } 950^{\circ} \mathrm{C}, 1 \mathrm{~min}\end{array}$ \\
\hline $1 / \mathrm{S} 12$ & $10^{12} \mathrm{~S} \mathrm{~cm}^{-2}, 30 \mathrm{keV}$ & $\mathrm{S}$ & $\mathrm{S}$ at $1100^{\circ} \mathrm{C}, 10 \mathrm{sec}$ \\
\hline 1/S12_B & $\begin{array}{l}10^{12} \mathrm{~S} \mathrm{~cm}^{-2}, 30 \mathrm{keV} \\
10^{15} \mathrm{~B} \mathrm{~cm}^{-2}, 30 \mathrm{keV}\end{array}$ & $\mathrm{S}, \mathrm{B}$ & $\begin{array}{l}\mathrm{S} \text { at } 1100^{\circ} \mathrm{C}, 10 \mathrm{sec}, \\
\mathrm{B} \text { at } 950^{\circ} \mathrm{C}, 1 \mathrm{~min}\end{array}$ \\
\hline $1 / \mathrm{S} 13$ & $10^{13} \mathrm{~S} \mathrm{~cm}^{-2}, 30 \mathrm{keV}$ & $S$ & $\mathrm{~S}$ at $1100^{\circ} \mathrm{C}, 10 \mathrm{sec}$ \\
\hline 1/S13_B & $\begin{array}{l}10^{13} \mathrm{~S} \mathrm{~cm}^{-2}, 30 \mathrm{keV} \\
10^{15} \mathrm{~B} \mathrm{~cm}^{-2}, 30 \mathrm{keV}\end{array}$ & S, B & $\begin{array}{l}\mathrm{S} \text { at } 1100^{\circ} \mathrm{C}, 10 \mathrm{sec}, \\
\mathrm{B} \text { at } 950^{\circ} \mathrm{C}, 1 \mathrm{~min}\end{array}$ \\
\hline $1 / \mathrm{S} 14$ & $10^{14} \mathrm{~S} \mathrm{~cm}^{-2}, 30 \mathrm{keV}$ & $S$ & $\mathrm{~S}$ at $1100^{\circ} \mathrm{C}, 10 \mathrm{sec}$ \\
\hline 1/S14_B & $\begin{array}{l}10^{14} \mathrm{~S} \mathrm{~cm}^{-2}, 30 \mathrm{keV}, \\
10^{15} \mathrm{~B} \mathrm{~cm}^{-2}, 30 \mathrm{keV}\end{array}$ & S, B & $\begin{array}{l}\mathrm{S} \text { at } 1100^{\circ} \mathrm{C}, \overline{10 \mathrm{sec}}, \\
\mathrm{B} \text { at } 950^{\circ} \mathrm{C}, 1 \mathrm{~min}\end{array}$ \\
\hline
\end{tabular}

Table 5.1 List of samples used for PL (and EL) experiments. There are 16 samples in total. Listed is their label, the dopants involved, their implant doses and energies, and the annealing conditions used. Note that the label $0 / \mathrm{S} 13$ stands for a sample in which 0 : comes from the $1000{ }^{\circ} \mathrm{C}$ annealing temperature used after the sulphur implantation and $\mathrm{S} 13$ : is the

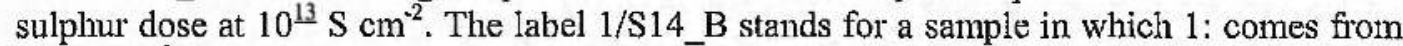
the $1100^{\circ} \mathrm{C}$ annealing temperature used after the sulphur implantation, S14: is the sulphur dose at $10^{14} \mathrm{~S} \mathrm{~cm}^{-2}$ and $\mathrm{B}$; is the dopant boron which has the same dose at $10^{15} \mathrm{~B} \mathrm{~cm}^{-2}$ and 30 $\mathrm{keV}$, for all these samples. 
PL measurements were performed on all samples listed in Table 5.1 over a wide range of laser powers. From the experiments presented in the following pages, we have chosen two laser powers $(150 \mathrm{~mW}$ and $50 \mathrm{~mW})$ in order to perform more detailed temperature dependent PL experiments. Furthermore, from PL experiments of all samples made at $80 \mathrm{~K}$, three of them revealed PL peaks of particular interest. So, for those three samples, more detailed PL experiments were made as a function of temperature. The three samples which were studied in more detail and the description of the PL variable temperature experiments undertaken are depicted on Table 5.2.

\begin{tabular}{|l|l|l|l|}
\hline Sample & Implants & Annealing conditions & PL conditions \\
\hline 0/S12 & $10^{12} \mathrm{~S} \mathrm{~cm}^{-2}, 30 \mathrm{keV}$, & $1000^{0} \mathrm{C}, 10 \mathrm{~s}$ & $\begin{array}{l}80 \mathrm{~K}-150 \mathrm{~K} \text {, at } 150 \\
\mathrm{~mW} \text { and } 50 \mathrm{~mW}\end{array}$ \\
\hline 0/S13_B & $\begin{array}{l}10^{13} \mathrm{~S} \mathrm{~cm} \\
10^{15} \mathrm{~B} \mathrm{~cm}^{-2}, 30 \mathrm{keV},\end{array}$ & $\begin{array}{l}1000^{0} \mathrm{C}, 10 \mathrm{~s}, 950^{0} \mathrm{C}, \\
1 \mathrm{~min}\end{array}$ & $\begin{array}{l}80 \mathrm{~K}-150 \mathrm{~K} \text {, at } 150 \\
\mathrm{~mW} \text { and } 50 \mathrm{~mW}\end{array}$ \\
\hline 0/S14 & $10^{14} \mathrm{~S} \mathrm{~cm}^{-2}, 30 \mathrm{keV}$, & $1000^{0} \mathrm{C}, 10 \mathrm{~s}$ & $\begin{array}{l}80 \mathrm{~K}-140 \mathrm{~K}, \text { at } 150 \\
\mathrm{~mW} \text { and } 50 \mathrm{~mW}\end{array}$ \\
\hline
\end{tabular}

Table 5.2 Details of the three samples used for the variable temperature PL experiments made at the two different laser powers.

The results from the PL measurements at $80 \mathrm{~K}$ for the two different applied laser powers (150 and $50 \mathrm{~mW}$ ) for all the three samples are shown in Figures 6.1 ((a),(b),(c),(d)) and 5.2 ((a),(b),(c)). Also shown for comparison (Figure 5.1 (a)) is the PL spectrum at $80 \mathrm{~K}$ from a sample consisting only of boron at the same dose, energy and annealing temperature $\left(10^{15} \mathrm{~B} \mathrm{~cm} \mathrm{~cm}^{-2}, 30 \mathrm{keV}\right.$, annealed at $950{ }^{\circ} \mathrm{C}$ for 1 min) as the sample which is implanted with sulphur and boron (0/S13_B) at 150 $\mathrm{mW}$. 


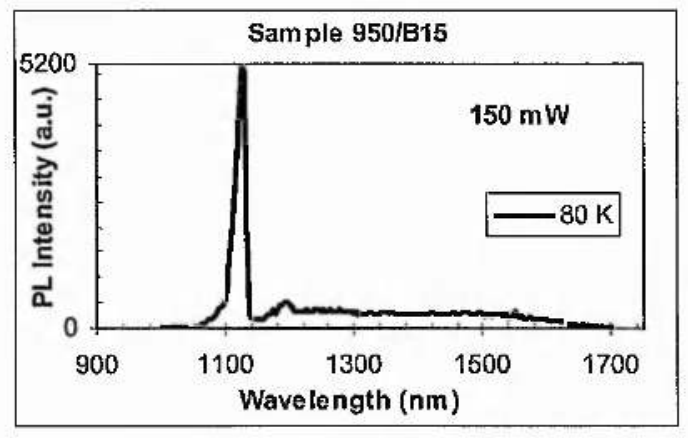

(a)

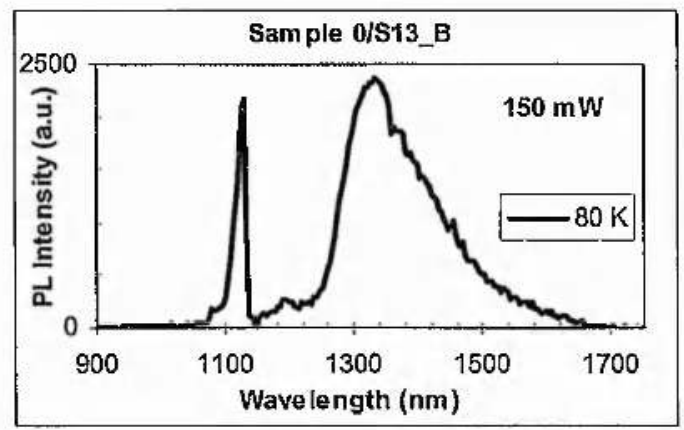

(c)

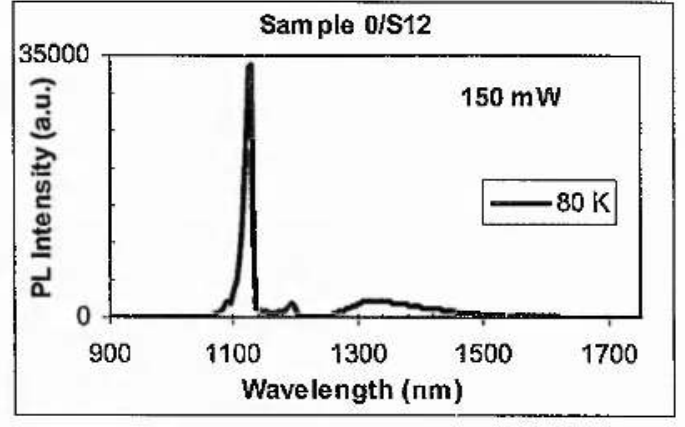

(b)

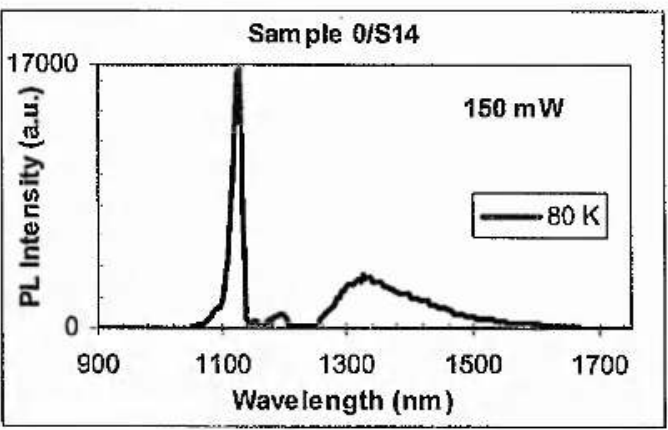

(d)

Figure 5.1 PL spectra taken at $80 \mathrm{~K}$ at $150 \mathrm{~mW}$ applied laser power for samples (a) 950/B15 (implanted with boron at $10^{15} \mathrm{~B} \mathrm{~cm}^{-2}$ at $30 \mathrm{keV}$, annealed at $950{ }^{\circ} \mathrm{C}$ for $1 \mathrm{~min}$ ), (b) $0 / \mathrm{S} 12$ (implanted with sulphur at $10^{12} \mathrm{~S} \mathrm{~cm}^{-2}$ at $30 \mathrm{keV}$, annealed at $1000^{\circ} \mathrm{C}$ for $10 \mathrm{sec}$ ), (c) 0/S13_B (implanted with sulphur at $10^{13} \mathrm{~S} \mathrm{~cm}^{-2}$ at $30 \mathrm{keV}$, annealed at $1000^{\circ} \mathrm{C}$ for $10 \mathrm{sec}$, further implanted with boron at $10^{15} \mathrm{~B} \mathrm{~cm}{ }^{-2}$ at $30 \mathrm{keV}$ and further annealed at $950{ }^{\circ} \mathrm{C}$ for 1 min), and finally (d) sample $0 / \mathrm{S} 14$ (implanted with sulphur at $10^{14} \mathrm{~S} \mathrm{~cm}^{-2}$ at $30 \mathrm{keV}$, annealed at $1000{ }^{\circ} \mathrm{C}$ for $10 \mathrm{sec}$ ). PL at $80 \mathrm{~K}$ for sample $950 / \mathrm{B} 15$ (a) was done for comparison.

From Figure 5.1 ((a)-(d)), it is observed that all samples reveal a peak at $1129.5 \mathrm{~nm}$ (or equivalent photon energy of $1.0977 \mathrm{eV}$ ) which is due to the Si TO phonon assisted band-to-band transition and its phonon replica at $1193.25 \mathrm{~nm}$ (or $1.0391 \mathrm{eV}$ ). The samples which are implanted with sulphur only (Figure 5.1 (b) and (d)) or with sulphur and boron (Figure 5.1 (c)) reveal an extra peak, quite strong for some cases around $1334 \mathrm{~nm}$ (or $0.930 \mathrm{eV}$ ) which is due to sulphur, as has been also stated in literature [1]. The additional sulphur related peak does not exist for the sample which is only implanted with boron (Figure 5.1 (a)). In addition, the sulphur related peak varies in intensity for the different sulphur doses. In Figure 5.2 are 
shown the PL spectra at $80 \mathrm{~K}$ from the same three samples of Table 5.2 at $50 \mathrm{~mW}$ applied laser power.

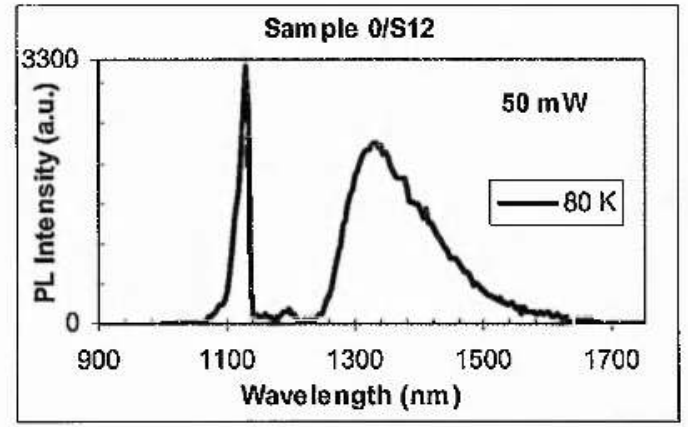

(a)

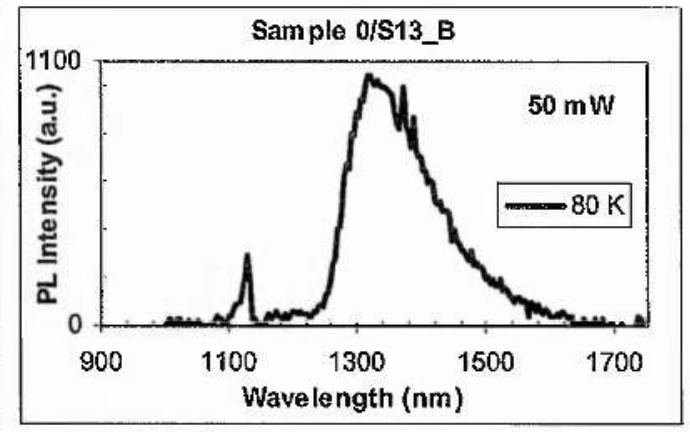

(b)

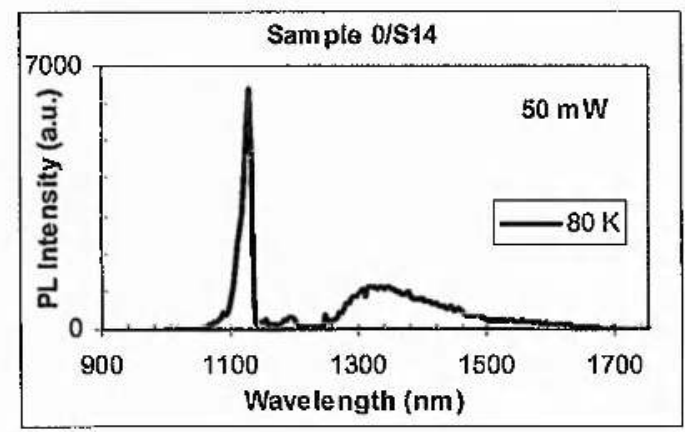

(c)

Figure 5.2 PL spectra at $80 \mathrm{~K}$ at $50 \mathrm{~mW}$ applied laser power for samples (a) $0 / \mathrm{S} 12$ (implanted with sulphur at $10^{12} \mathrm{~S} \mathrm{~cm}^{-2}$ at $30 \mathrm{keV}$, annealed at $1000{ }^{\circ} \mathrm{C}$ for $10 \mathrm{sec}$ ), (b) 0/S13_B (implanted with sulphur at $10^{13} \mathrm{~S} \mathrm{~cm}^{-2}$ at $30 \mathrm{keV}$, annealed at $1000{ }^{0} \mathrm{C}$ for $10 \mathrm{sec}$, further implanted with boron at $10^{15} \mathrm{~B} \mathrm{~cm}^{-2}$ at $30 \mathrm{keV}$ and further annealed at $950{ }^{\circ} \mathrm{C}$ for 1 $\mathrm{min}$ ), and (c) sample $0 / \mathrm{S} 14$ (implanted with sulphur at $10^{14} \mathrm{~S} \mathrm{~cm}^{-2}$ at $30 \mathrm{keV}$, annealed at $1000{ }^{\circ} \mathrm{C}$ for $\left.10 \mathrm{sec}\right)$.

From Figure 5.2 it is observed that at $50 \mathrm{~mW}$ the same two peaks due to $\mathrm{Si}$ and $\mathrm{S}$ are also observed at the same wavelengths. The clear difference from the 150 $\mathrm{mW}$ applied laser power (Figure 5.1) is the shift in PL intensities between the main two peaks, as well as the expected overall reduction in PL intensity. Further PL variable temperature experiments were then undertaken on all of the three samples in order to have a better understanding of this behaviour. In Figure 5.3 is illustrated the PL temperature dependence of sample 0/S12 (S implanted at $30 \mathrm{keV}$, and at a dose $1 \times 10^{12} \mathrm{~S} \mathrm{~cm}^{-2}$, annealed at $1000^{\circ} \mathrm{C}$ for $10 \mathrm{~s}$ ) at both applied laser powers. 


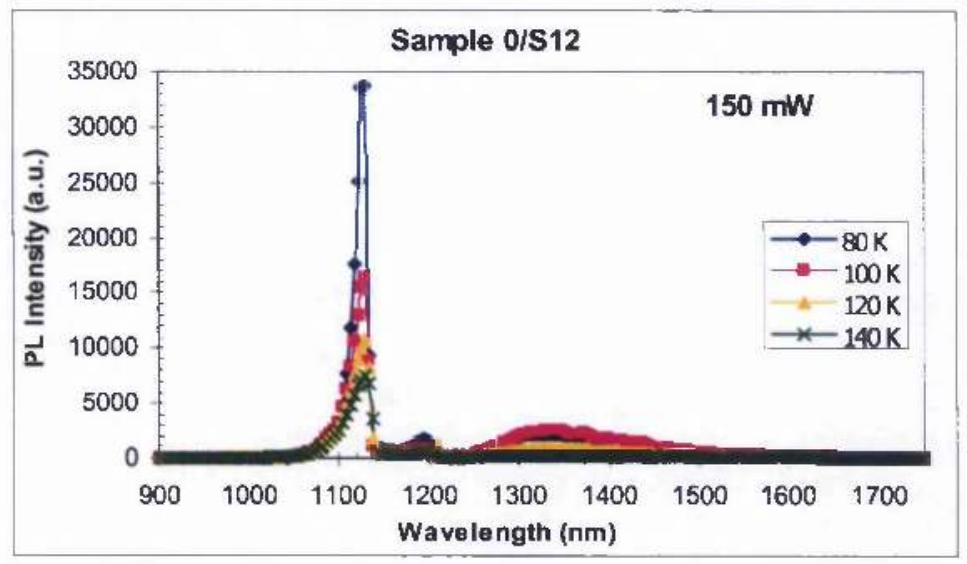

(a)

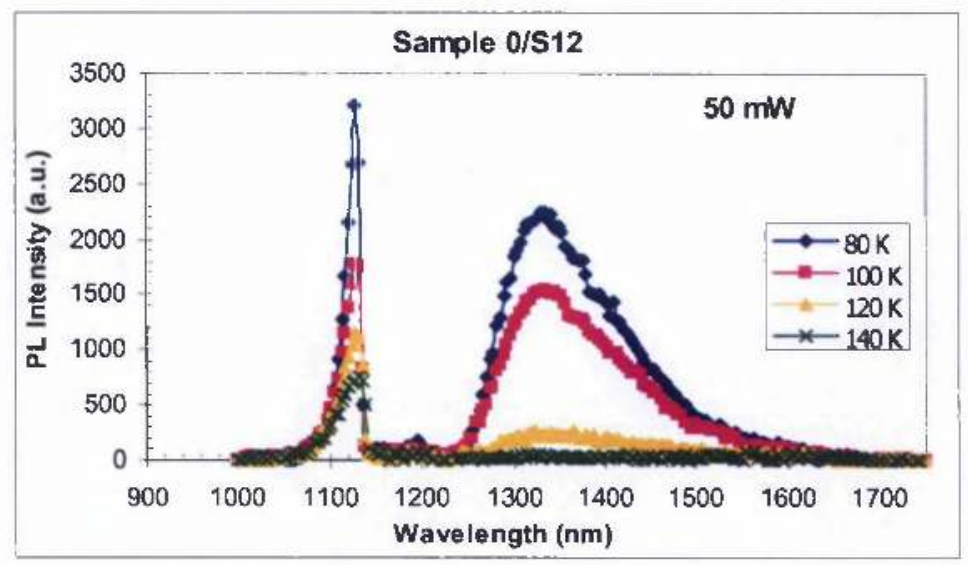

(b)

Figure 5.3 PL variable temperature measurements of sample $0 / \mathrm{S} 12$ at (a) $150 \mathrm{~mW}$ and (b) $50 \mathrm{~mW}$ applied laser power from $80 \mathrm{~K}-140 \mathrm{~K}$. The sample is implanted with sulphur at a dose of $1 \times 10^{12} \mathrm{~S} \mathrm{~cm}^{-2}$ and at an energy of $30 \mathrm{keV}$. It is annealed at $1000{ }^{\circ} \mathrm{C}$ for $10 \mathrm{~s}$. PL measurements took place up to $140 \mathrm{~K}$, where the PL signal disappears for the sulphur related peak.

From the variable temperature measurements of the $0 / \mathrm{S} 12$ sample (S implanted at $30 \mathrm{keV}$, and at a dose $1 \times 10^{12} \mathrm{~S} \mathrm{~cm}^{-2}$, annealed at $1000^{\circ} \mathrm{C}$ for $10 \mathrm{~s}$ ) at $80 \mathrm{~K}-140 \mathrm{~K}$, we observe the Si peak present at all temperatures, and the S related peak at low temperatures $(80 \mathrm{~K}, 90 \mathrm{~K}$ and $100 \mathrm{~K})$ at $1334 \mathrm{~nm}(0.930 \mathrm{eV})$, shifting slightly to longer wavelengths (lower energies) with the increase of temperature. The peak due to the $\mathrm{S}$ implant is relatively stronger compared to the Si peak when the power of the applied laser is $50 \mathrm{~mW}$ rather than $150 \mathrm{~mW}$. The ratio of the peak 
intensities of the two peaks $\left(\mathrm{I}_{\mathrm{Si}} / \mathrm{I}_{\mathrm{S}}\right)$ for the $50 \mathrm{~mW}$ laser power is varying with the temperature, e.g. 1.44 at $80 \mathrm{~K}, 1.16$ at $90 \mathrm{~K}$ and 1.16 at $100 \mathrm{~K}$. The same ratio for the $150 \mathrm{~mW}$ is much bigger ( 15.48 at $80 \mathrm{~K}, 8.2$ at $90 \mathrm{~K}$ and 6.49 at $100 \mathrm{~K})$ meaning that the peak due to $\mathrm{Si}$ is much stronger than the $\mathrm{S}$ one.

In Figure 5.4 is illustrated the PL variable temperature measurements (from $80 \mathrm{~K}-140 \mathrm{~K}$ ) of sample 0/S13_B (implanted with sulphur at $10^{13} \mathrm{~S} \mathrm{~cm}^{-2}$ at $30 \mathrm{keV}$, annealed at $100{ }^{\circ} \mathrm{C}$ for $10 \mathrm{sec}$, further implanted with boron at $10^{15} \mathrm{~B} \mathrm{~cm}^{-2}$ at 30 $\mathrm{keV}$ and further annealed at $950{ }^{\circ} \mathrm{C}$ for $\left.1 \mathrm{~min}\right)$. The results from sample $0 / \mathrm{S} 13 \_\mathrm{B}$ are similar to the previous one. The sulphur peak is also observed at $1334 \mathrm{~nm}(0.930 \mathrm{eV})$ shifting to longer wavelengths with the temperature increase. For $150 \mathrm{~mW}$ applied laser power, the sulphur peak is stronger compared to the $\mathrm{Si}$ one, for temperatures up to $100 \mathrm{~K}$. The ratios of the intensities of the two peaks $\left(\mathrm{I}_{\mathrm{S}} / \mathrm{I}_{\mathrm{S}}\right)$ are 0.92 at $80 \mathrm{~K}, 0.80$ at $90 \mathrm{~K}$ and 0.86 at $100 \mathrm{~K}$. For temperatures above $100 \mathrm{~K}$, the sulphur peak is quenching with temperature increase, whereas the Si peak intensity is approximately stable for all measured temperatures. At $50 \mathrm{~mW}$ applied laser power, the S peak for the same sample is much stronger than the Si one, especially at low temperatures. This is in contrast to the results at $150 \mathrm{~mW}$ excitation power. The ratios of the intensities of the two peaks $\left(\mathrm{I}_{\mathrm{Si}} / \mathrm{I}_{\mathrm{S}}\right)$ are 0.28 at $80 \mathrm{~K}, 0.25$ at $90 \mathrm{~K}$ and 0.22 at $100 \mathrm{~K}$. However, the intensity of the S peak again is decreasing fast for temperatures above $120 \mathrm{~K}$. 


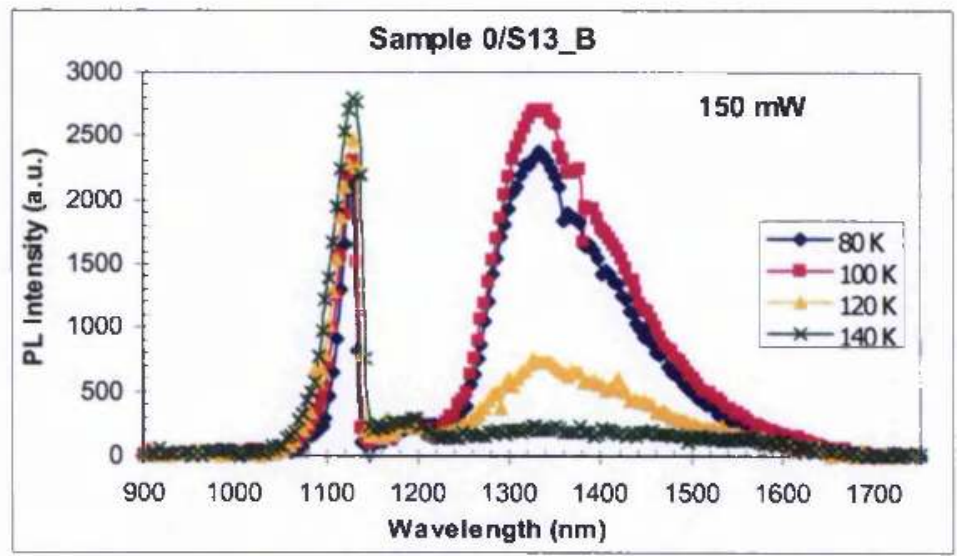

(a)

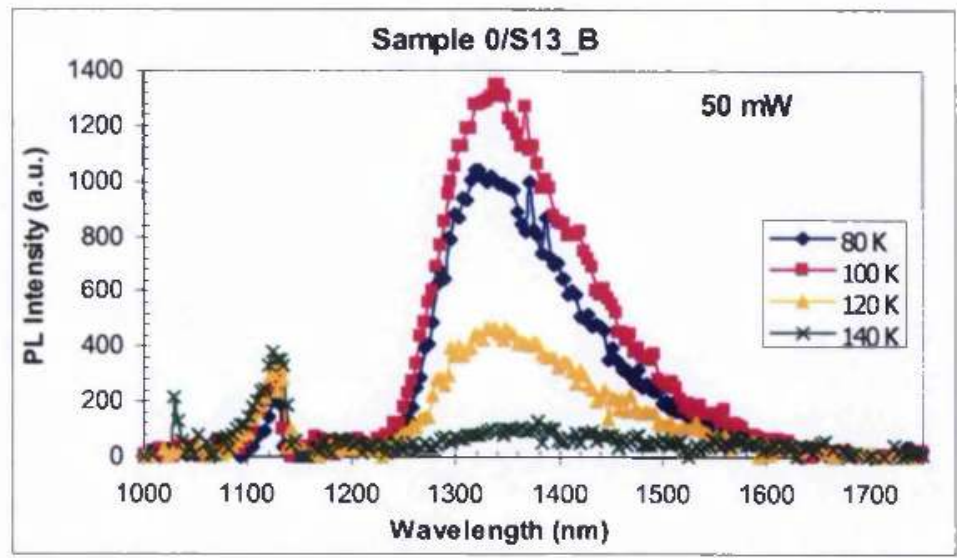

(b)

Figure 5.4 PL variable temperature measurements of sample $0 / \mathrm{S} 13$ B $\mathrm{B}$ at (a) $150 \mathrm{~mW}$ and (b) $50 \mathrm{~mW}$ applied laser power from $80 \mathrm{~K}-140 \mathrm{~K}$. The sample is implanted with sulphur at a dose of $1 \times 10^{13} \mathrm{~S} \mathrm{~cm}^{-2}$ and at an energy of $30 \mathrm{keV}$ and is annealed at $1000^{0} \mathrm{C}$ for $10 \mathrm{~s}$. It is further implanted with boron at $10^{15} \mathrm{~B} \mathrm{~cm}^{-2}$ at $30 \mathrm{keV}$ and further annealed at $950{ }^{\circ} \mathrm{C}$ for 1 min. PL measurements took place up to $140 \mathrm{~K}$, where the PL signal is minimal for the sulphur peak.

In Figure 5.5 is illustrated the PL variable temperature measurements $(80 \mathrm{~K}$ $140 \mathrm{~K}$ ) of sample $0 / \mathrm{S} 14$ (S implanted at $30 \mathrm{keV}$, at a dose $1 \times 10^{14} \mathrm{~S} \mathrm{~cm}^{-2}$, annealed at $1000{ }^{\circ} \mathrm{C}$ for $10 \mathrm{~s}$ ). The two peaks due to $\mathrm{Si}$ and $\mathrm{S}$ have also been observed. At 150 $\mathrm{mW}$ applied laser power, the intensity of the Si peak is lower than the equivalent one at the lower $\mathrm{S}$ dose sample $\left(10^{12} \mathrm{~S} \mathrm{~cm}^{-2}\right)$ and at the same laser power which was studied previously, but the S peak intensity is higher for this higher dose sample $\left(10^{14} \mathrm{~S} \mathrm{~cm}^{-2}\right)$. The ratios of the peak intensities of the two peaks $\left(I_{\mathrm{Si}} / I_{\mathrm{S}}\right)$ are 5.08 at 
$80 \mathrm{~K}, 4.20$ at $90 \mathrm{~K}$ and 3.80 at $100 \mathrm{~K}$. The $\mathrm{S}$ peak is decreasing for temperatures above $100 \mathrm{~K}$. At $50 \mathrm{~mW}$ applied laser power, the Si peak is higher in intensity than the equivalent one at the lower $\mathrm{S}$ dose sample $\left(10^{12} \mathrm{~S} \mathrm{~cm}^{-2}\right)$ and at the same laser power but the $\mathrm{S}$ peak is lower in intensity for the higher dose sample. The ratios of the intensities of the two peaks ( $\left.\mathrm{I}_{\mathrm{S}} / \mathrm{I}_{\mathrm{S}}\right)$ are 5.83 at $80 \mathrm{~K}, 3.96$ at $90 \mathrm{~K}$ and 3.44 at $100 \mathrm{~K}$. Finally, for this dose $\left(10^{14} \mathrm{~S} \mathrm{~cm}^{-2}\right)$ both $\mathrm{Si}$ and $\mathrm{S}$ peaks have higher intensities at $150 \mathrm{~mW}$ applied laser power than the equivalent ones at $50 \mathrm{~mW}$ applied laser power, as expected.

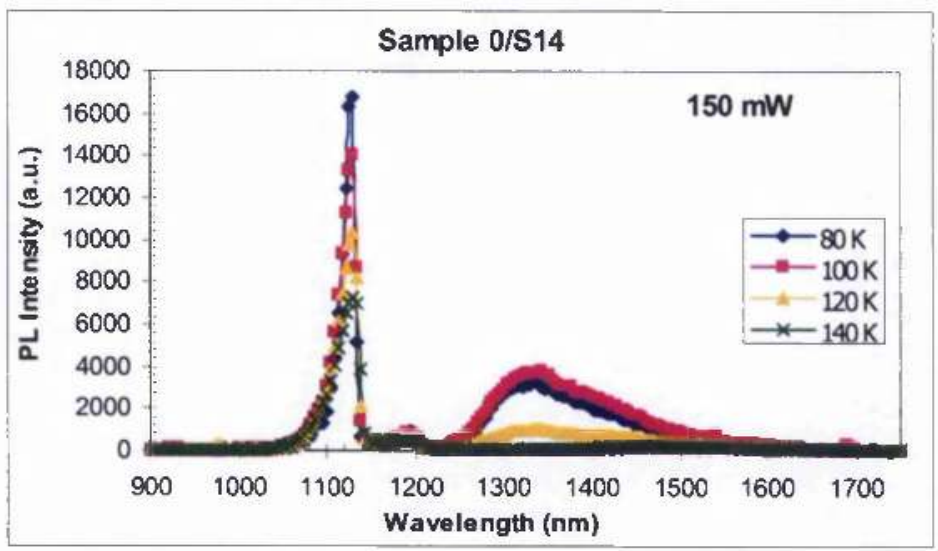

(a)

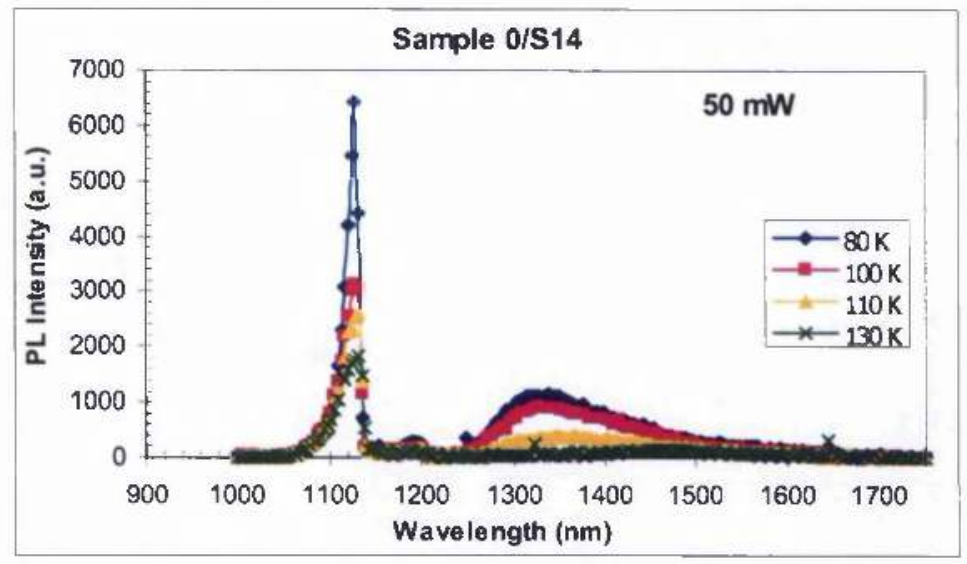

(b)

Figure 5.5 PL variable temperature measurements of sample $0 / \mathrm{S} 14$ at (a) $150 \mathrm{~mW}$ and (b) $50 \mathrm{~mW}$ applied laser power from $80 \mathrm{~K}-140 \mathrm{~K}$ ( $80 \mathrm{~K}-130 \mathrm{~K}$ for the $50 \mathrm{~mW}$ laser power). The sample is implanted with sulphur at a dose of $1 \times 10^{12} \mathrm{~S} \mathrm{~cm}^{-2}$ and at an energy of $30 \mathrm{keV}$. It is annealed at $1000^{\circ} \mathrm{C}$ for $10 \mathrm{~s}$. 
In the following part of this section will be summarised the silicon, sulphur and total integrated intensity and the silicon and sulphur peak position and peak intensity, with the measurement temperature, for the two applied laser powers (50 $\mathrm{mW}$ and $150 \mathrm{~mW}$ ) for all the three samples studied. The graphs from Figures 5.3-5.5 were transformed from PL intensity versus wavelength $(\mathrm{nm})$ to PL intensity versus energy (eV) using the formula $\mathrm{E}(\mathrm{eV})=1240 / \lambda(\mathrm{nm})$ and the integration carried out with respect to energy. From Figure 5.6 ((a) and (b)) it is observed that the $\mathrm{Si}$ integrated intensity trend is decreasing with increase of temperature for both applied laser powers. For $150 \mathrm{~mW}$ applied laser power the sample $0 / \mathrm{S} 12$ which was implanted at $10^{12} \mathrm{~S} \mathrm{~cm}^{-2}$ has the highest $\mathrm{Si}$ integrated intensity trend for all temperatures ( $80 \mathrm{~K}-150 \mathrm{~K}$ ), whereas for $50 \mathrm{~mW}$ applied laser power the sample $0 / \mathrm{S} 14$ which was implanted at higher $\mathrm{S}$ dose $\left(10^{14} \mathrm{~S} \mathrm{~cm} \mathrm{~cm}^{-2}\right)$ has the highest Si integrated intensity values for all temperatures ( $80 \mathrm{~K}-150 \mathrm{~K})$. What is noticeable is that the sample 0/S13_B which was implanted with both $\mathrm{S}$ and $\mathrm{B}\left(10^{13} \mathrm{~S} \mathrm{~cm}^{-2}, 10^{15} \mathrm{~B}\right.$ $\mathrm{cm}^{-2}$ ) appears to have the lowest $\mathrm{Si}$ integrated intensity values for both applied laser powers. Also, their trend is increasing slightly with the increase of temperature (from $80 \mathrm{~K}-150 \mathrm{~K}$ ), whereas the trends of the $\mathrm{Si}$ integrated intensities for the other two samples are decreasing for the temperatures studied. At $150 \mathrm{~mW}$ laser power, the sample $0 / \mathrm{S} 12$ with the lower $\mathrm{S}$ dose $\left(10^{12} \mathrm{~S} \mathrm{~cm}^{-2}\right)$ has higher $\mathrm{Si}$ integrated intensity values than sample $0 / \mathrm{S} 14$ of the higher $\mathrm{S}$ dose $\left(10^{14} \mathrm{~S} \mathrm{~cm}^{-2}\right)$, whereas at $50 \mathrm{~mW}$ laser power we see the converse, meaning that the high $\mathrm{S}$ dose sample $(0 / \mathrm{S} 14)$ appears to have the higher values of Si integrated intensity. Also, the values of the $\mathrm{Si}$ integrated intensity are higher for the $150 \mathrm{~mW}$ laser power than the $50 \mathrm{~mW}$ ones. The quenching has the same shape for the two $\mathrm{S}$ only implanted samples at $50 \mathrm{~mW}$, whereas at $150 \mathrm{~mW}$ the trend of sample $0 / \mathrm{S} 14\left(10^{14} \mathrm{~S} \mathrm{~cm}^{-2}\right)$ is increasing at low temperatures peaking at $90 \mathrm{~K}$ and then is decreasing. The errors of the $\mathrm{Si}$ integrated intensity, as well as for the measurement temperature are within the size of the symbol. 


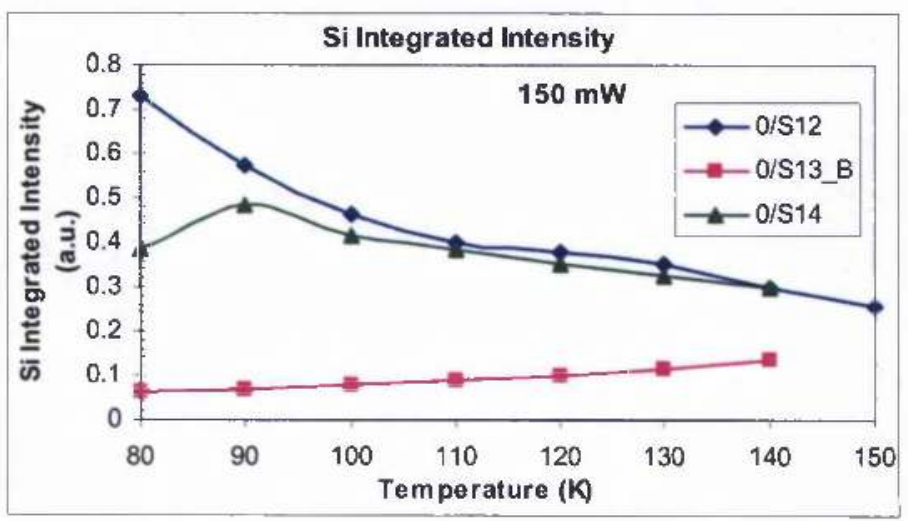

(a)

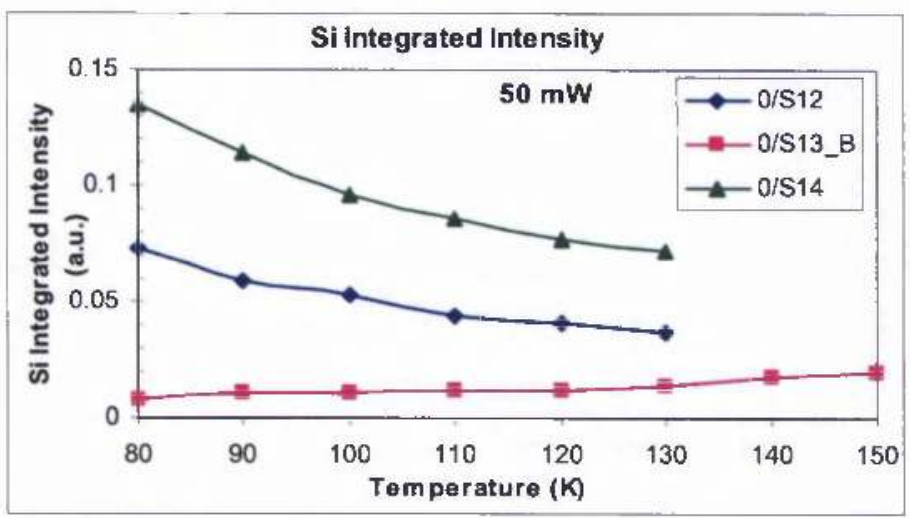

(b)

Figure 5.6 Temperature dependence of the silicon integrated intensity as taken from the PL spectra for the samples $0 / \mathrm{S} 12$ (implanted with sulphur at $10^{12} \mathrm{~S} \mathrm{~cm}^{-2}$ at $30 \mathrm{keV}$, annealed at $1000{ }^{\circ} \mathrm{C}$ for $10 \mathrm{sec}$ ), $0 / \mathrm{S} 13$ _B (implanted with sulphur at $10^{13} \mathrm{~S} \mathrm{~cm}^{-2}$ at $30 \mathrm{keV}$, annealed at $1000{ }^{\circ} \mathrm{C}$ for $10 \mathrm{sec}$, further implanted with boron at $10^{15} \mathrm{~B} \mathrm{~cm}$ at $30 \mathrm{keV}$ and further annealed at $950^{\circ} \mathrm{C}$ for $1 \mathrm{~min}$ ), and sample $0 / \mathrm{S} 14$ (implanted with sulphur at $10^{14} \mathrm{~S} \mathrm{~cm}^{-2}$ at 30 $\mathrm{keV}$, annealed at $1000^{\circ} \mathrm{C}$ for $10 \mathrm{sec}$ ) for (a) $150 \mathrm{~mW}$ and (b) $50 \mathrm{~mW}$ applied laser power. The errors in $\mathrm{Si}$ integrated intensity and measurement temperature are within the symbol size. The solid lines are provided as a guide to the eye.

In Figure $5.7((a)$ and (b)) is illustrated the sulphur integrated intensity for all the three samples studied, for the two applied laser powers $(150 \mathrm{~mW}$ and $50 \mathrm{~mW})$. At $150 \mathrm{~mW}$, the $\mathrm{S}$ integrated intensity of all three samples is increasing having a peak at $90 \mathrm{~K}$ and then is decreasing until $140 \mathrm{~K}$. Sample $0 / \mathrm{S} 14\left(10^{14} \mathrm{~S} \mathrm{~cm}^{-2}\right)$ has the highest $\mathrm{S}$ integrated intensity values for all studied temperatures $(80 \mathrm{~K}-140 \mathrm{~K})$. Sample 0/S13_B $\left(10^{13} \mathrm{~S} \mathrm{~cm}^{-2}, 10^{15} \mathrm{~B} \mathrm{~cm}^{-2}\right)$ has the next highest from $80 \mathrm{~K}-110 \mathrm{~K}$ and at 120 $\mathrm{K}-140 \mathrm{~K}$ sample $0 / \mathrm{S} 12\left(10^{12} \mathrm{~S} \mathrm{~cm}^{-2}\right)$ is having higher $\mathrm{S}$ integrated intensity values. At $50 \mathrm{~mW}$ applied laser power, the $\mathrm{S}$ integrated intensity trends for the three samples 
are rather different from those at $150 \mathrm{~mW}$. Sample $0 / \mathrm{S} 13$ B $\left(10^{13} \mathrm{~S}^{-2}, 10^{15} \mathrm{~B}\right.$ $\mathrm{cm}^{-2}$ ) has a similar $\mathrm{S}$ integrated intensity trend to the equivalent one at $150 \mathrm{~mW}$ peaking at $100 \mathrm{~K}$. Samples $0 / \mathrm{S} 12\left(10^{12} \mathrm{~S} \mathrm{~cm}^{-2}\right)$ and $0 / \mathrm{S} 14\left(10^{14} \mathrm{~S} \mathrm{~cm}^{-2}\right)$ have similar $\mathrm{S}$ integrated intensity trends; the low $\mathrm{S}$ dose $(0 / \mathrm{S} 12)$ sample has higher $\mathrm{S}$ integrated intensity values than the other two samples from $80 \mathrm{~K}-100 \mathrm{~K}$ and from $110 \mathrm{~K}-140 \mathrm{~K}$ sample 0/S13_B $\left(10^{13} \mathrm{~S} \mathrm{~cm}^{-2}, 10^{15} \mathrm{~B} \mathrm{~cm}^{-2}\right)$ has the highest $\mathrm{S}$ integrated intensity values.

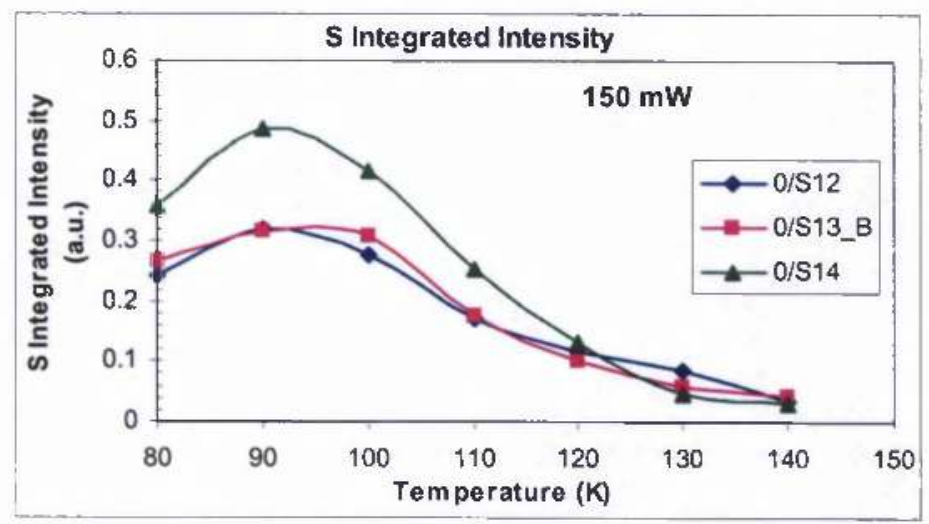

(a)

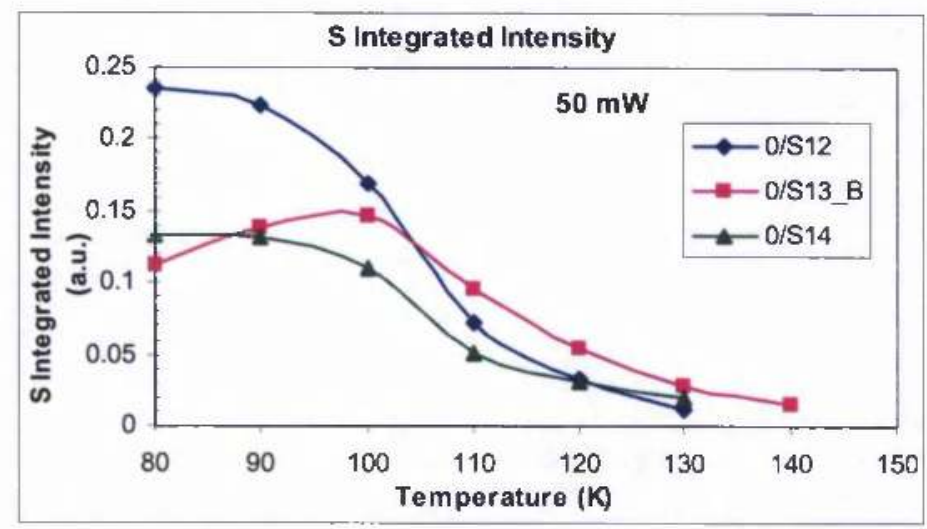

(b)

Figure 5.7 Temperature dependence of the sulphur integrated intensity as taken from the PL spectra for the samples $0 / \mathrm{S} 12$ (implanted with sulphur at $10^{12} \mathrm{~S} \mathrm{~cm}^{-2}$ at $30 \mathrm{keV}$, annealed at $1000^{\circ} \mathrm{C}$ for $10 \mathrm{sec}$ ), $0 / \mathrm{S} 13$ B (implanted with sulphur at $10^{13} \mathrm{~S} \mathrm{~cm}^{-2}$ at $30 \mathrm{keV}$, annealed at $1000{ }^{\circ} \mathrm{C}$ for $10 \mathrm{sec}$, further implanted with boron at $10^{15} \mathrm{~B} \mathrm{~cm}^{-2}$ at $30 \mathrm{keV}$ and further annealed at $950{ }^{\circ} \mathrm{C}$ for $1 \mathrm{~min}$ ), and sample $0 / \mathrm{S} 14$ (implanted with sulphur at $10^{14} \mathrm{~S} \mathrm{~cm}^{-2}$ at 30 $\mathrm{keV}$, annealed at $1000^{\circ} \mathrm{C}$ for $10 \mathrm{sec}$ ) for (a) $150 \mathrm{~mW}$ and (b) $50 \mathrm{~mW}$ applied laser power. The errors in $\mathrm{S}$ integrated intensity and measurement temperature are within the symbol size. The solid lines are provided as a guide to the eye. 
In Figure $5.8((\mathrm{a})$ and (b)) is depicted the total integrated intensity trends for all samples for both applied laser powers. The values of the total integrated intensity are higher at $150 \mathrm{~mW}$ applied laser power, as expected. The trend is decreasing for all three samples and the quenching is different for all of them. At $150 \mathrm{~mW}$ applied laser power, the total integrated intensity trends of the samples $0 / \mathrm{S} 14\left(10^{14} \mathrm{~S} \mathrm{~cm}^{-2}\right)$ and $0 / \mathrm{S} 13 \_\mathrm{B}\left(10^{13} \mathrm{~S} \mathrm{~cm}^{-2}, 10^{15} \mathrm{~B} \mathrm{~cm}^{-2}\right)$ are increasing at $90 \mathrm{~K}$ and $100 \mathrm{~K}$, respectively and then are decreasing. The total integrated intensity trend of sample $0 / \mathrm{S} 12\left(10^{12} \mathrm{~S} \mathrm{~cm}^{-2}\right)$ is decreasing for all studied temperatures $(80 \mathrm{~K}-150 \mathrm{~K})$. From 90 $\mathrm{K}-120 \mathrm{~K}$ the sample $(0 / \mathrm{S} 14)$ with the higher $\mathrm{S}$ dose has the highest total integrated intensity values, whereas from $120 \mathrm{~K}-140 \mathrm{~K}$ the sample $(0 / \mathrm{S} 12)$ with the lowest $\mathrm{S}$ dose appears to have the highest total integrated intensity values. At $50 \mathrm{~mW}$, the total integrated intensity of the sample $0 / \mathrm{S} 13 \_\mathrm{B}\left(10^{13} \mathrm{~S} \mathrm{~cm}^{-2}, 10^{15} \mathrm{~B} \mathrm{~cm}^{-2}\right)$ has a similar shape to the one at $150 \mathrm{~mW}$ for the same sample but with lower intensity. The total integrated intensities trends of the $S$ only implanted samples $0 / \mathrm{S} 14\left(10^{14} \mathrm{~S} \mathrm{~cm}^{-2}\right)$, $0 / \mathrm{S} 12\left(10^{12} \mathrm{~S} \mathrm{~cm}^{-2}\right)$ are decreasing with the increase of temperature. Sample $0 / \mathrm{S} 12$ $\left(10^{12} \mathrm{~S} \mathrm{~cm}^{-2}\right)$ has the highest total integrated intensity values from $80 \mathrm{~K}-100 \mathrm{~K}$ and then from $110 \mathrm{~K}-130 \mathrm{~K}$ sample $0 / \mathrm{S} 14\left(10^{14} \mathrm{~S} \mathrm{~cm}^{-2}\right)$ is the one with the highest integrated intensity values. 


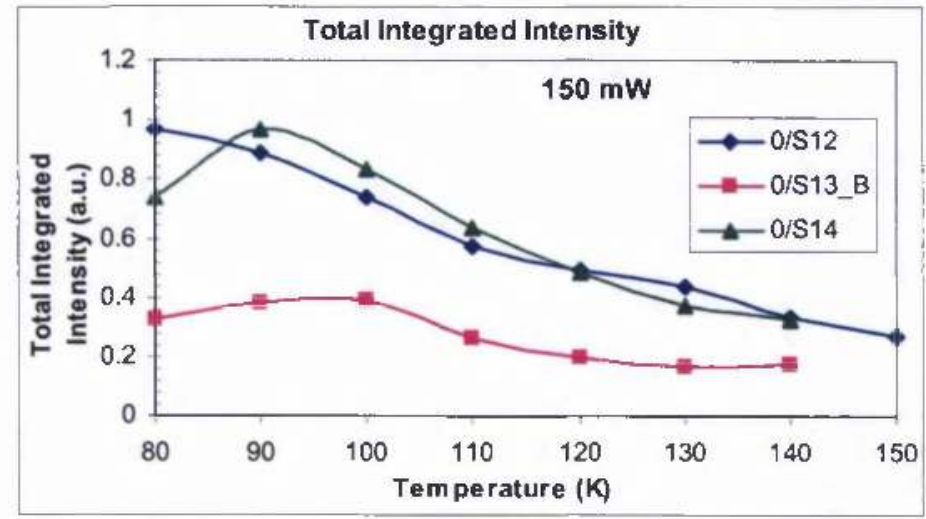

(a)

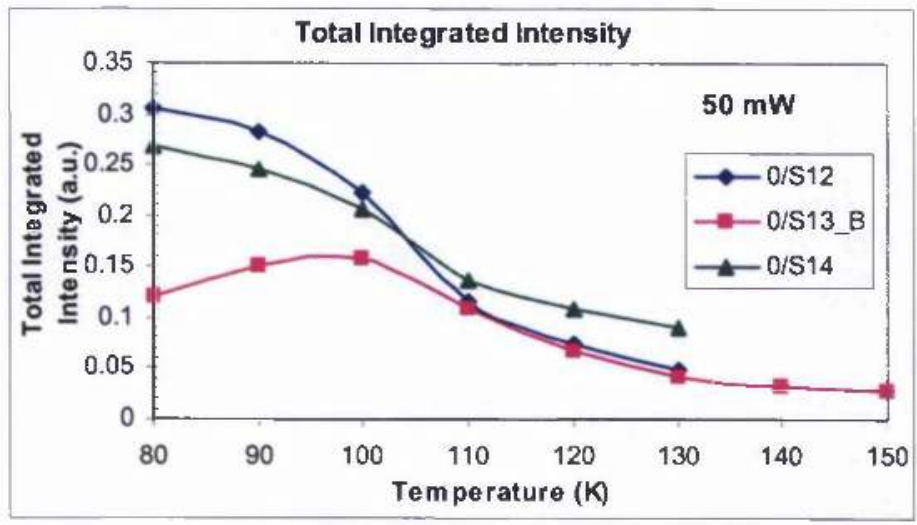

(b)

Figure 5.8 Temperature dependence of the total integrated intensity as taken from the PL spectra for the samples $0 / \mathrm{S} 12$ (implanted with sulphur at $10^{12} \mathrm{~S} \mathrm{~cm}^{-2}$ at $30 \mathrm{keV}$, annealed at $1000{ }^{\circ} \mathrm{C}$ for $10 \mathrm{sec}$ ), $0 / \mathrm{S} 13$ B (implanted with sulphur at $10^{13} \mathrm{~S} \mathrm{~cm}^{-2}$ at $30 \mathrm{keV}$, annealed at $1000{ }^{\circ} \mathrm{C}$ for $10 \mathrm{sec}$, further implanted with boron at $10^{15} \mathrm{~B} \mathrm{~cm}^{-2}$ at $30 \mathrm{keV}$ and further annealed at $950^{\circ} \mathrm{C}$ for $1 \mathrm{~min}$ ), and sample $0 / \mathrm{S} 14$ (implanted with sulphur at $10^{14} \mathrm{~S} \mathrm{~cm}^{-2}$ at 30 $\mathrm{keV}$, annealed at $1000{ }^{\circ} \mathrm{C}$ for $10 \mathrm{sec}$ ) for (a) $150 \mathrm{~mW}$ and (b) $50 \mathrm{~mW}$ applied laser power. The errors in total integrated intensity and measurement temperature are within the symbol size. The solid lines are provided as a guide to the eye.

In Figure $5.9((\mathrm{a})-(\mathrm{d}))$ is presented the silicon and sulphur peak position and silicon and sulphur peak intensity for $150 \mathrm{~mW}$ applied laser power. 


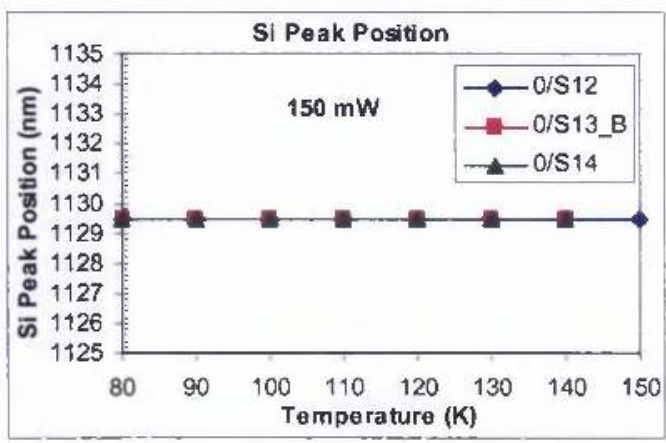

(a)

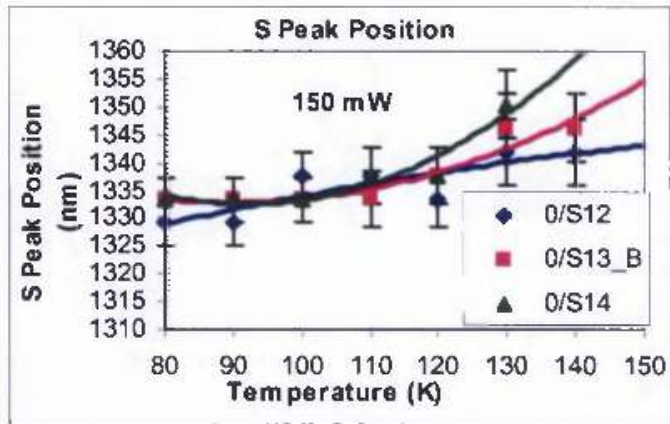

(c)

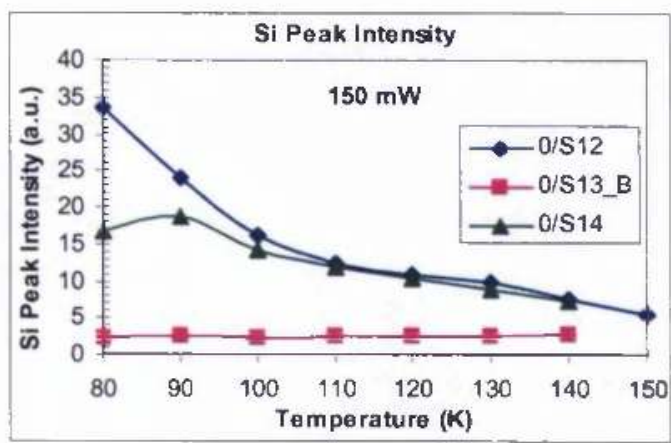

(b)

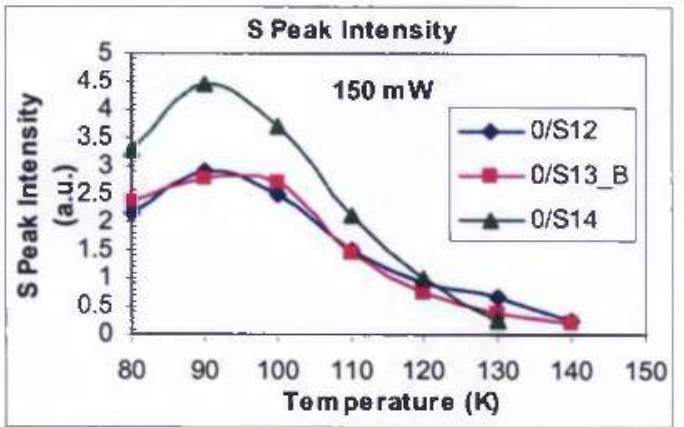

(d)

Figure 5.9 Temperature dependence of the silicon peak position (a), silicon peak intensity (b), sulphur peak position (c) and sulphur peak intensity (d), as taken from the PL spectra for the samples $0 / \mathrm{S} 12$ (implanted with sulphur at $10^{12} \mathrm{~S} \mathrm{~cm}^{-2}$ at $30 \mathrm{keV}$, annealed at $1000^{\circ} \mathrm{C}$ for $10 \mathrm{sec}$ ), 0/S13_B (implanted with sulphur at $10^{13} \mathrm{~S} \mathrm{~cm}^{-2}$ at $30 \mathrm{keV}$, annealed at $1000{ }^{\circ} \mathrm{C}$ for $10 \mathrm{sec}$, further implanted with boron at $10^{15} \mathrm{~B} \mathrm{~cm}^{-2}$ at $30 \mathrm{keV}$ and further annealed at $950{ }^{\circ} \mathrm{C}$ for $1 \mathrm{~min}$ ), and sample $0 / \mathrm{S} 14$ (implanted with sulphur at $10^{14} \mathrm{~S} \mathrm{~cm}^{-2}$ at $30 \mathrm{keV}$, annealed at $1000^{\circ} \mathrm{C}$ for $10 \mathrm{sec}$ ) at $150 \mathrm{~mW}$ applied laser power. The errors in Si peak position and $\mathrm{Si}, \mathrm{S}$ peak intensity and measurement temperature are within the symbol size. For the $\mathrm{S}$ peak position a best fit of the values for each sample has been provided for a better presentation of the data. The errors in the $S$ peak position are included in the plot ranging from $8 \mathrm{~nm}-12 \mathrm{~nm}$ with the increase of measurement temperature. The solid lines are provided as a guide to the eye.

From Figure 5.9 (a) is also observed that the silicon band edge peak is at a wavelength of $1129.5 \mathrm{~nm}$ (or $1.0977 \mathrm{eV}$ ) from low temperatures up to $150 \mathrm{~K}$. The sulphur feature has a peak at $1334 \mathrm{~nm}$ (or $0.930 \mathrm{eV}$ ), which shifts much faster than the silicon, towards longer wavelengths with the increase of temperature. The silicon and sulphur peak intensity trends (Figure 5.9 (b) and (d)) are similar to the silicon and sulphur integrated intensity trends (Figures 5.6 (a) and 5.7 (a)). 
In Figure $5.10((\mathrm{a})-(\mathrm{d}))$ are presented the silicon and sulphur peak position and silicon and sulphur peak intensity for $50 \mathrm{~mW}$ applied laser power.

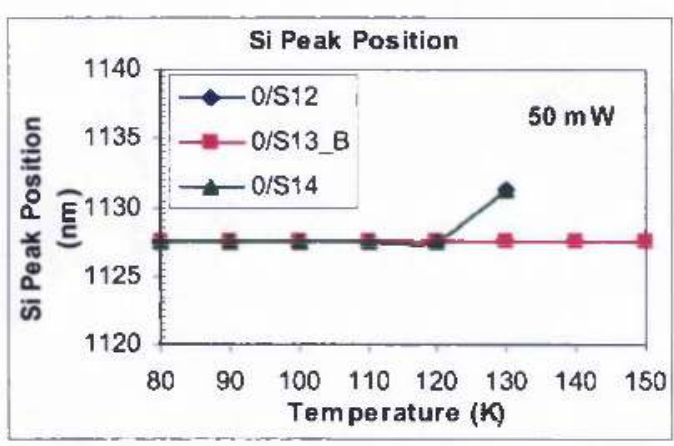

(a)

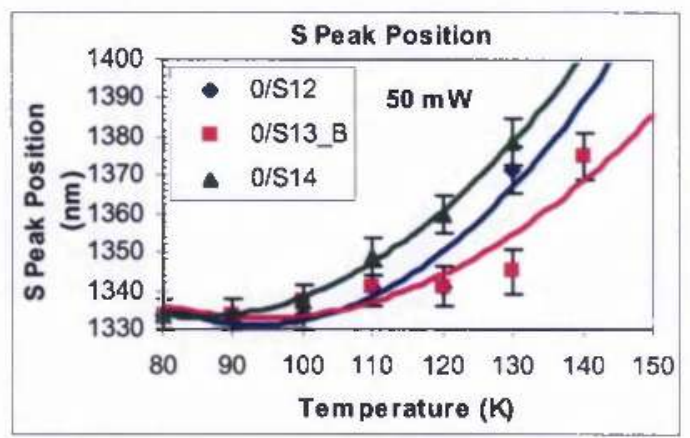

(c)

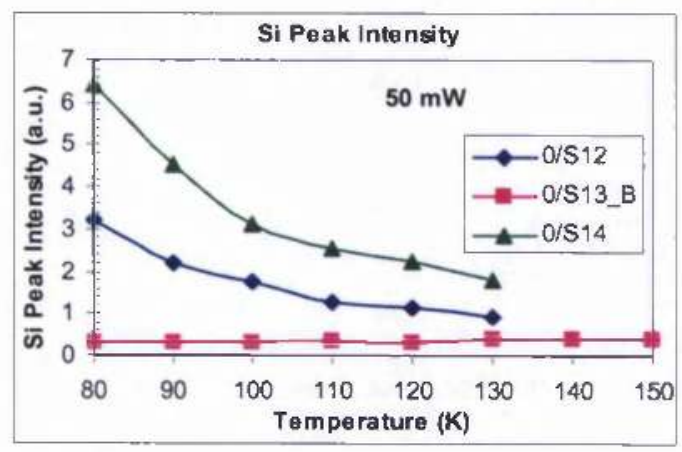

(b)

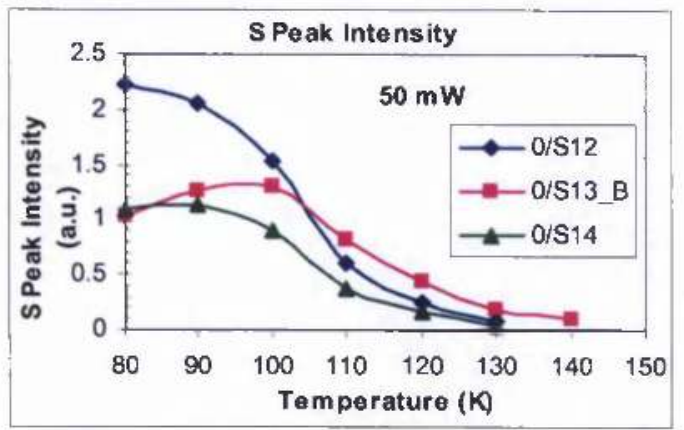

(d)

Figure 5.10 Temperature dependence of the silicon peak position (a), silicon peak intensity (b), sulphur peak position (c) and sulphur peak intensity (d), as taken from the PL spectra for the samples $0 / \mathrm{S} 12$ (implanted with sulphur at $10^{12} \mathrm{~S} \mathrm{~cm}^{-2}$ at $30 \mathrm{keV}$, annealed at $1000^{\circ} \mathrm{C}$ for $10 \mathrm{sec}$ ), $0 / \mathrm{S} 13 \mathrm{~B}$ (implanted with sulphur at $10^{13} \mathrm{~S} \mathrm{~cm}^{-2}$ at $30 \mathrm{keV}$, annealed at $1000{ }^{\circ} \mathrm{C}$ for $10 \mathrm{sec}$, further implanted with boron at $10^{15} \mathrm{~B} \mathrm{~cm}^{-2}$ at $30 \mathrm{keV}$ and further annealed at $950{ }^{\circ} \mathrm{C}$ for $1 \mathrm{~min}$ ), and sample $0 / \mathrm{S} 14$ (implanted with sulphur at $10^{14} \mathrm{~S} \mathrm{~cm}$ at $30 \mathrm{keV}$, annealed at $1000{ }^{\circ} \mathrm{C}$ for $10 \mathrm{sec}$ ) at $50 \mathrm{~mW}$. The errors in Si peak position and $\mathrm{Si}, \mathrm{S}$ peak intensity and measurement temperature are within the symbol size. For the $\mathrm{S}$ peak position a best fit of the values for each sample has been provided for a better presentation of the data. The errors in the $S$ peak position are included in the plot ranging from $8 \mathrm{~nm}-12 \mathrm{~nm}$ with the increase of measurement temperature. The solid lines are provided as a guide to the eye.

Similar observations apply for Figure 5.10 ((a)-(d)) at $50 \mathrm{~mW}$. The silicon peak is observed at $1129.5 \mathrm{~nm}$ for all samples up to $130 \mathrm{~K}$, whereas the sulphur peak position is shifting from $1333.75 \mathrm{~nm}$ at $80 \mathrm{~K}$ to longer wavelengths at higher temperatures for all samples. The silicon and sulphur peak intensity trends (Figure 5.10 (b) and (d)) are very similar to the silicon and sulphur integrated intensity trends 
(Figures $5.6(\mathrm{~b})$ and $5.7(\mathrm{~b})$ ); the values though are different. In addition, the $\mathrm{Si}$ and $\mathrm{S}$ peak intensity trends are different for the two different applied laser powers; the trends have similar shape but they are not identical (Figure 5.9 (b), (d) and Figure $5.10(\mathrm{~b}),(\mathrm{d}))$.

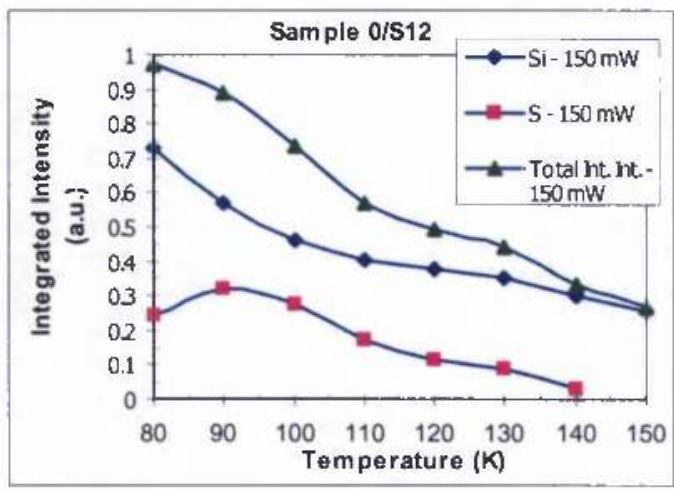

(a)

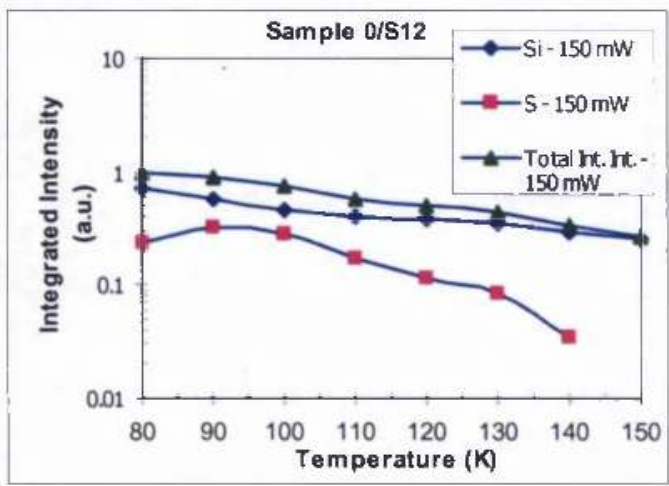

(c)

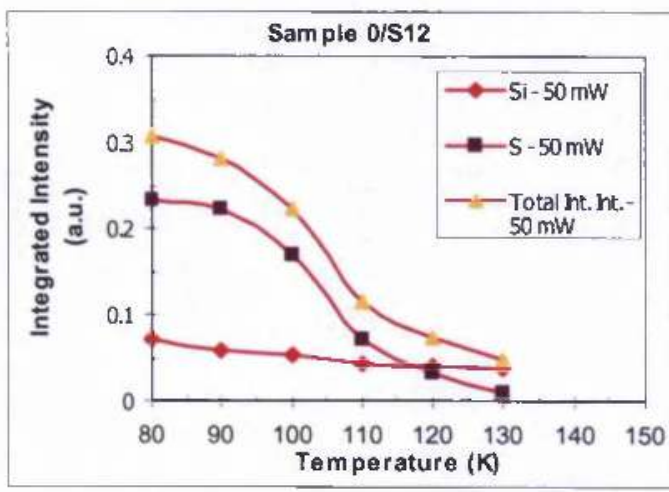

(b)

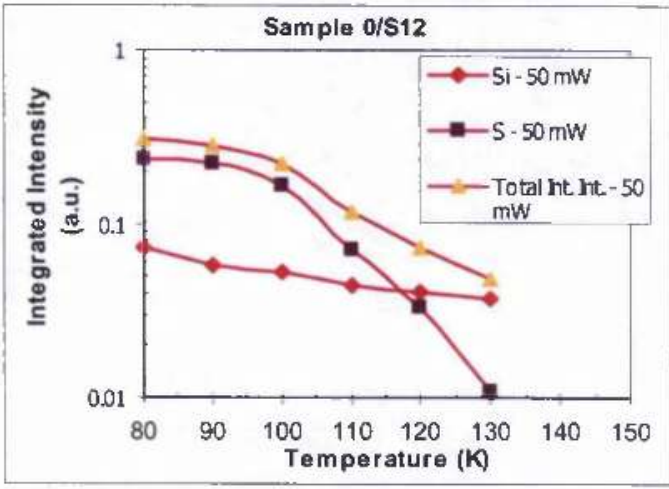

(d)

Figure 5.11 Temperature dependence of the silicon, sulphur and total integrated intensity at (a) $150 \mathrm{~mW}$ and (b) $50 \mathrm{~mW}$ applied laser power for sample 0/S12 (implanted with sulphur at $10^{12} \mathrm{~S} \mathrm{~cm}^{-2}$ at $30 \mathrm{keV}$, annealed at $1000^{\circ} \mathrm{C}$ for $10 \mathrm{sec}$ ). In (c) and (d) are plotted the data of (a) and (b) in logarithmic scale. The errors in $\mathrm{Si}, \mathrm{S}$ and total integrated intensity and measurement temperature are within the symbol size. The solid lines are provided as a guide to the eye.

In Figures 5.11-5.13 are illustrated the $\mathrm{Si}, \mathrm{S}$ and the total integrated intensity trends for each sample studied separately at both laser powers with the measurement temperature. It can be observed from Figure 5.12 (a) and (b) and Figure 5.13 (a) and (b) (samples $0 / \mathrm{S} 13$ B $\mathrm{B}$ and $0 / \mathrm{S} 14$, respectively), that the total integrated intensity trend is influenced mostly by the shape of the $\mathrm{S}$ integrated intensity trend for both 
applied laser powers. In Figure 5.11 (sample 0/S12), the total integrated intensity trend is influenced mostly by the $\mathrm{S}$ integrated intensity trend only at $50 \mathrm{~mW}$, whereas at $150 \mathrm{~mW}$ it is influenced by the Si integrated intensity trend. In Figures 5.11-5.13 (c), (d) are also presented the logarithm of the integrated intensity trends with the measurement temperature.

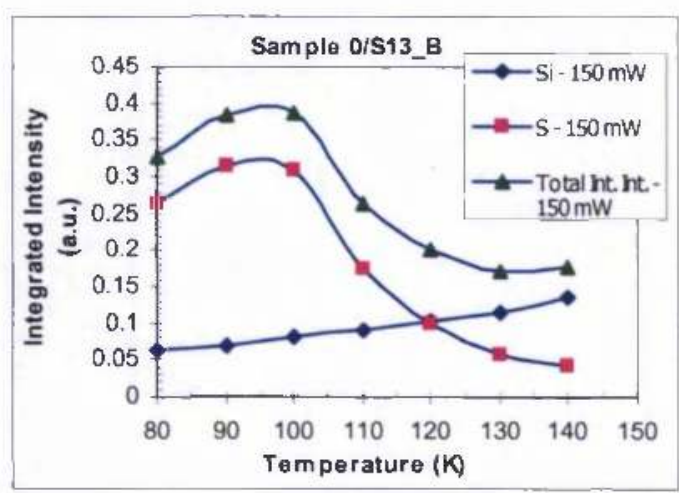

(a)

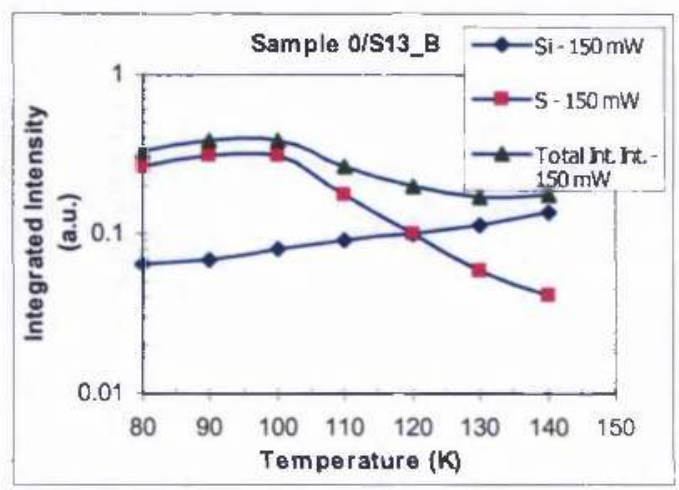

(c)

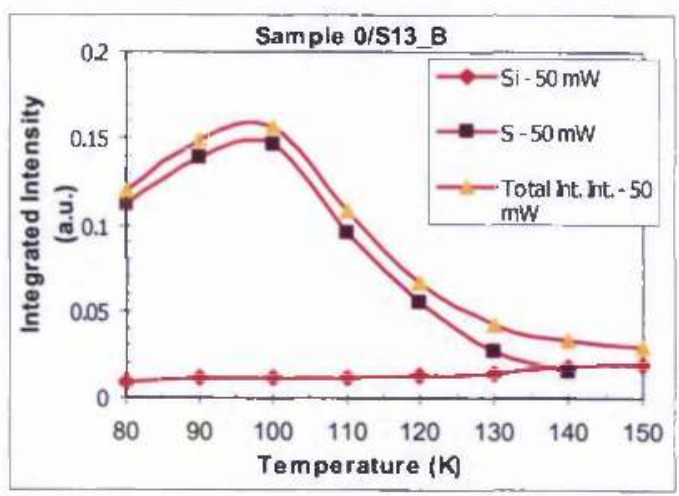

(b)

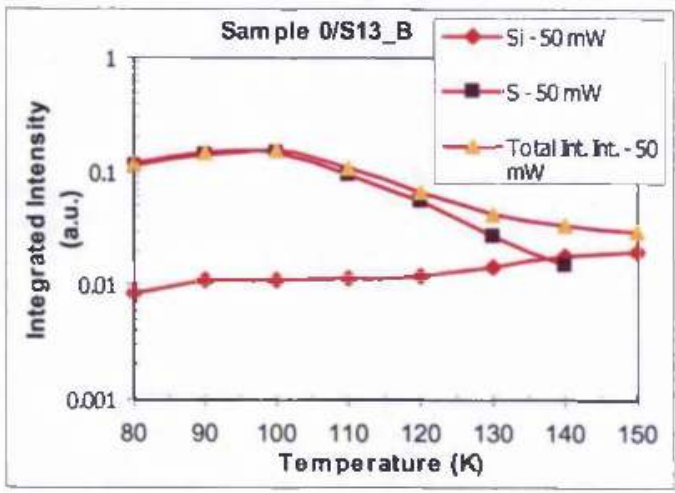

(d)

Figure 5.12 Temperature dependence of the silicon, sulphur and total integrated intensity at (a) $150 \mathrm{~mW}$ and (b) $50 \mathrm{~mW}$ applied laser power for sample $0 / \mathrm{S} 13$ _B (implanted with sulphur at $10^{13} \mathrm{~S} \mathrm{~cm}^{-2}$ at $30 \mathrm{keV}$, annealed at $1000^{\circ} \mathrm{C}$ for $10 \mathrm{sec}$, further implanted with boron at $10^{15}$ $\mathrm{B} \mathrm{cm}{ }^{-2}$ at $30 \mathrm{keV}$ and further annealed at $950{ }^{\circ} \mathrm{C}$ for $1 \mathrm{~min}$ ). In (c) and (d) are plotted the data of (a) and (b) in logarithmic scale. The errors in $\mathrm{Si}, \mathrm{S}$ and total integrated intensity and measurement temperature are within the symbol size. The solid lines are provided as a guide to the eye. 


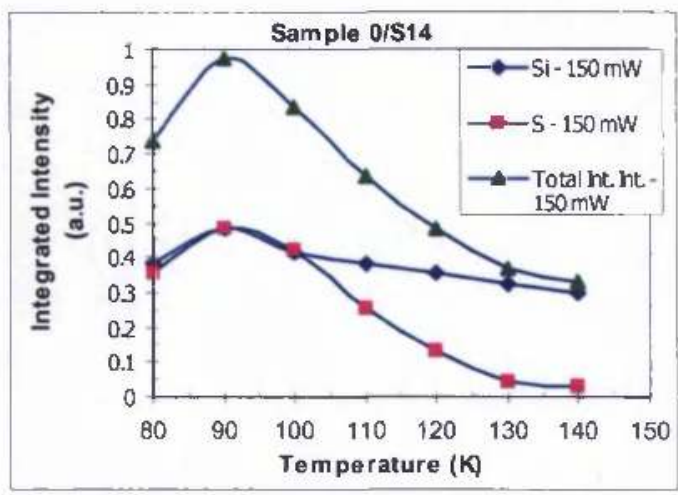

(a)

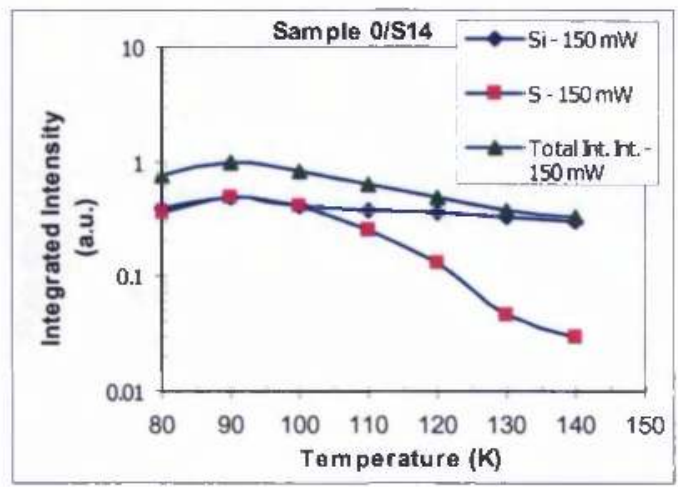

(c)

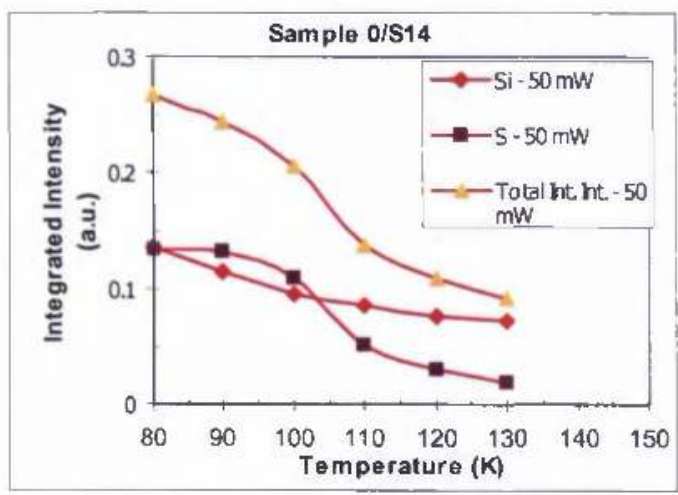

(b)

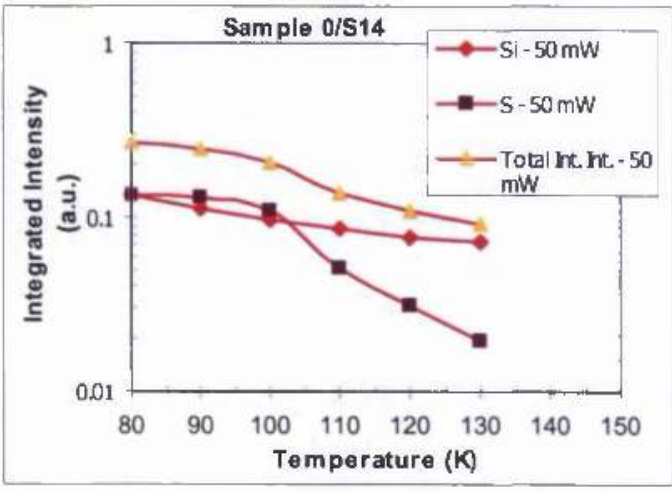

(d)

Figure 5.13 Temperature dependence of the silicon, sulphur and total integrated intensity at (a) $150 \mathrm{~mW}$ and (b) $50 \mathrm{~mW}$ applied laser power for sample 0/S14 (implanted with sulphur at $10^{14} \mathrm{~S} \mathrm{~cm}^{-2}$ at $30 \mathrm{keV}$, annealed at $1000{ }^{\circ} \mathrm{C}$ for $10 \mathrm{sec}$ ). In (c) and (d) are plotted the data of (a) and (b) in logarithmic scale. The errors in Si, S and total integrated intensity and measurement temperature are within the symbol size. The solid lines are provided as a guide to the eye.

In Figure 5.14 is presented the quenching ratio of the three samples for $\mathrm{Si}, \mathrm{S}$ and total integrated intensity for both $150 \mathrm{~mW}$ and $50 \mathrm{~mW}$. The quenching ratio is the ratio of the highest-temperature ( $\mathrm{Si}, \mathrm{S}$ and total) integrated intensity, up to where we can observe a significant PL feature, which in our case is $130 \mathrm{~K}$, divided by the lowest-measured temperature ( $\mathrm{Si}, \mathrm{S}$ and total) integrated intensity, which is at $80 \mathrm{~K}$. Therefore, from the graphs of Figure 5.14 it is concluded that the quenching ratio is below 1 for almost all intensities and all three samples. This means that the integrated intensities at $130 \mathrm{~K}$ are lower than the integrated intensities at $80 \mathrm{~K}$. The only case that the quenching ratio is above 1 is the $\mathrm{Si}$ integrated intensity for sample 0/S13_B $\left(10^{13} \mathrm{~S} \mathrm{~cm}^{-2}, 10^{15} \mathrm{~B} \mathrm{~cm}^{-2}\right)$ for both applied laser powers. In this case the 
value of the Si integrated intensity at $130 \mathrm{~K}$ is higher than the one at $80 \mathrm{~K}$, as was mentioned before and also observed in Figures 5.6 and 5.12 .

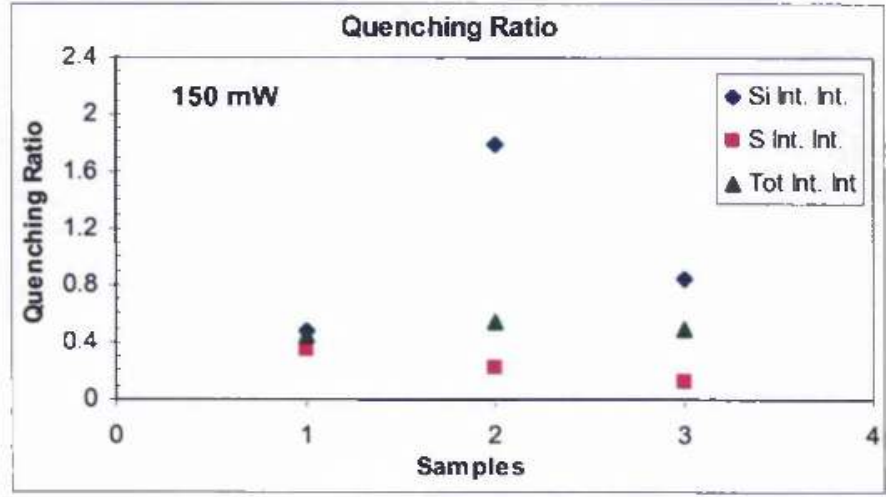

(a)

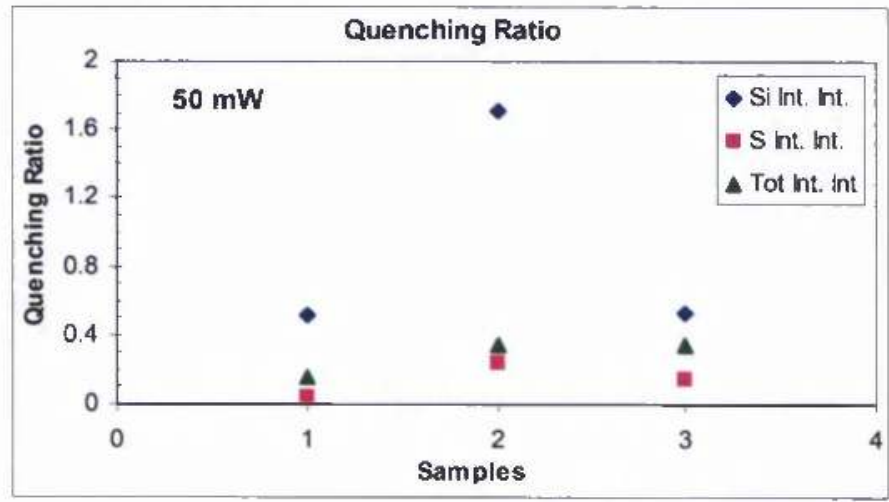

(b)

Figure 5.14 Quenching ratio (value of $\mathrm{S}, \mathrm{Si}$, total integrated intensity at $130 \mathrm{~K}$ divided by the value of $\mathrm{S}, \mathrm{Si}$, total integrated intensity at $80 \mathrm{~K}$ ) of samples $1: 0 / \mathrm{S} 12$ (implanted with sulphur at $10^{12} \mathrm{~S} \mathrm{~cm}^{-2}$ at $30 \mathrm{keV}$, annealed at $1000^{\circ} \mathrm{C}$ for $10 \mathrm{sec}$ ), 2: $0 / \mathrm{S} 13$ B (implanted with sulphur at $10^{13} \mathrm{~S} \mathrm{~cm}^{-2}$ at $30 \mathrm{keV}$, annealed at $1000^{\circ} \mathrm{C}$ for $10 \mathrm{sec}$, further implanted with boron at $10^{15} \mathrm{~B} \mathrm{~cm}^{-2}$ at $30 \mathrm{keV}$ and further annealed at $950{ }^{\circ} \mathrm{C}$ for $1 \mathrm{~min}$ ), 3: $0 / \mathrm{S} 14$ (implanted with sulphur at $10^{14} \mathrm{~S} \mathrm{~cm}^{-2}$ at $30 \mathrm{keV}$, annealed at $1000^{\circ} \mathrm{C}$ for $10 \mathrm{sec}$ ) for silicon, sulphur and total integrated intensity.

In conclusion, in this section, variable temperature experiments were done for the three samples $0 / \mathrm{S} 12,0 / \mathrm{S} 13$ B and $0 / \mathrm{S} 14$ implanted at $10^{12} \mathrm{~S} \mathrm{~cm}^{-2}, 10^{13} \mathrm{~S} \mathrm{~cm}^{-2}$ plus $10^{15} \mathrm{~B} \mathrm{~cm}^{-2}$ and $10^{14} \mathrm{~S} \mathrm{~cm}^{-2}$, respectively, at two laser powers $(150 \mathrm{~mW}$ and 50 $\mathrm{mW}$ ). We observed two main peaks due to $\mathrm{Si}$ and $\mathrm{S}$ at $1129.5 \mathrm{~nm}$ (or $1.0997 \mathrm{eV}$ ) and $1334 \mathrm{~nm}$ (or $0.930 \mathrm{eV}$ ), respectively, shifting towards longer wavelengths (lower energies) with the increase of temperature. The $S$ peak intensity values are 
decreasing much faster than the $\mathrm{Si}$ ones with the increase of temperature, almost disappearing at temperatures above $130 \mathrm{~K}$ for $150 \mathrm{~mW}$ applied laser power. The $\mathrm{Si}$, $\mathrm{S}$ and total integrated intensity trends are decreasing with the increase of temperature for all samples at both applied laser powers. In addition, for the same sample, the $\mathrm{Si}$, $\mathrm{S}$ and total integrated intensity trends are changing differently for the two applied laser powers. Therefore, at $150 \mathrm{~mW}$, sample $0 / \mathrm{S} 12$ (lowest $\mathrm{S}$ dose, $10^{12} \mathrm{~S} \mathrm{~cm}^{-2}$ ) has the highest $\mathrm{Si}$ and the lowest $\mathrm{S}$ integrated intensity trends for all measured temperatures, whereas at $50 \mathrm{~mW}$, sample $0 / \mathrm{S} 14$ (highest $\mathrm{S}$ dose, $10^{14} \mathrm{~S} \mathrm{~cm}^{-2}$ ) has the highest $\mathrm{Si}$ and the lowest $\mathrm{S}$ integrated intensity trends for all measured temperatures. Finally, sample 0/S13_B $\left(10^{13} \mathrm{~S} \mathrm{~cm}^{-2}\right.$ and $\left.10^{15} \mathrm{~B} \mathrm{~cm}^{-2}\right)$ has the lowest Si integrated intensity trend for all measured temperatures for both applied laser powers, slightly increasing with the increase of measurement temperature and the second highest $\mathrm{S}$ integrated intensity trend at $150 \mathrm{~mW}$; at $50 \mathrm{~mW}$ the $\mathrm{S}$ integrated intensity trend of sample 0/S13_B is in between the other two samples up to $100 \mathrm{~K}$, then becoming the highest trend for the rest temperatures.

\subsubsection{PL variable power measurements}

So far we have reported the effect of temperature in $\mathrm{Si}, \mathrm{S}$ and total integrated intensity at two laser powers. Clearly of great particular interest is the non-linear dependence of the spectral distribution on the laser power. This effect is further reported on here. In Figures 5.15-5.23 are illustrated the results of the variable power measurements for each one of the three samples studied at $80 \mathrm{~K}, 100 \mathrm{~K}$ and $130 \mathrm{~K}$, respectively. In particular, in Figure 5.15 (a) are presented the three trends of Si, S and total integrated intensity with the applied laser power for sample $0 / \mathrm{S} 12\left(10^{12} \mathrm{~S}\right.$ $\mathrm{cm}^{-2}$ ) at $80 \mathrm{~K}$. What can be noted is the fact that the $S$ integrated intensity trend is sublinear, increasing fast at the low laser power regime and then increasing slightly with the increase of laser power. The Si integrated intensity trend is superlinear, increasing slower than the $\mathrm{S}$ integrated intensity at the low laser power regime and then increasing faster with the increase of laser power. This behaviour is observed 
more clearly in Figure Figure 5.15 (b). In Figure 5.15 (c) are presented the Si and S and total integrated intensities trends on a $\log$-log scale. The total integrated intensity trend is following the $\mathrm{S}$ one at low applied laser power (up to $100 \mathrm{~mW}$ ) and above $100 \mathrm{~mW}$ is following the $\mathrm{Si}$ integrated intensity.

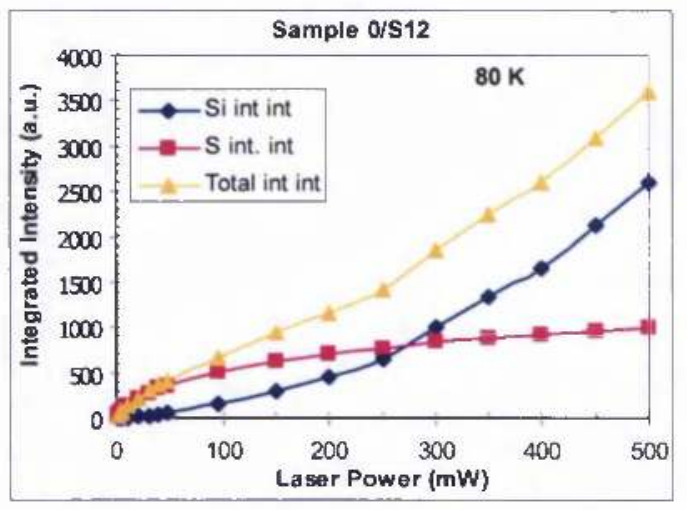

(a)

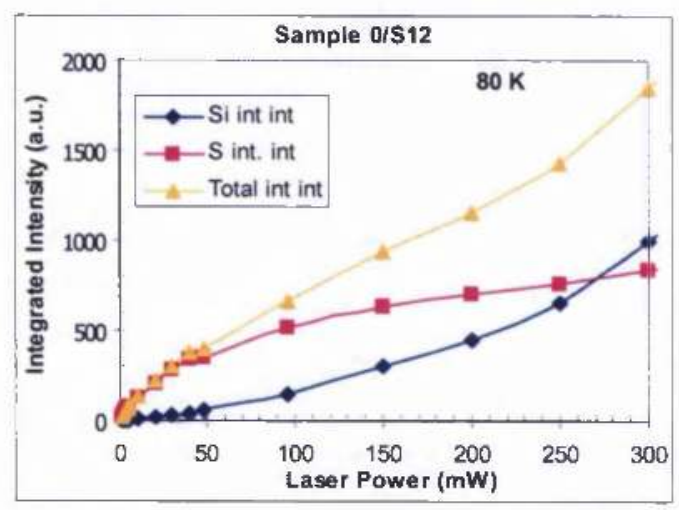

(b)

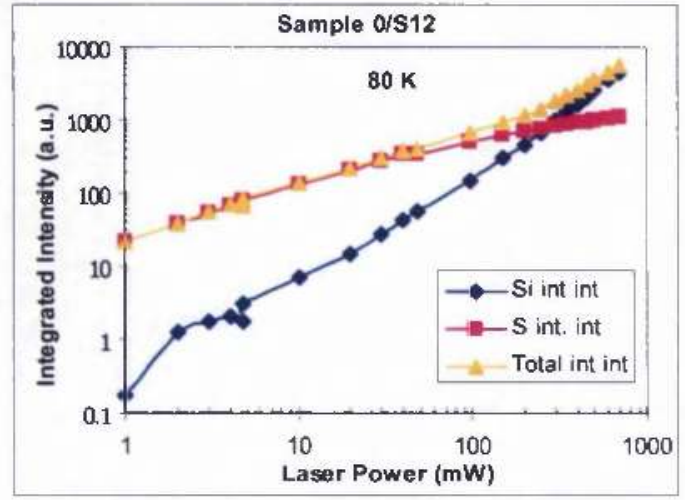

(c)

Figure 5.15 Power dependence of the silicon, sulphur and total integrated intensity as taken from the PL measurements at $80 \mathrm{~K}$ from sample $0 / \mathrm{S} 12$ (implanted with sulphur at $10^{12} \mathrm{~S}$ $\mathrm{cm}^{-2}$ at $30 \mathrm{keV}$, annealed at $1000^{\circ} \mathrm{C}$ for $10 \mathrm{sec}$ ), (a) Linear scale, (b) Linear scale expanded to illustrate better the low power dependence, (c) Log-Log plot of all data. The errors in $\mathrm{Si}, \mathrm{S}$ and total integrated intensity and laser power are within the symbol size. The solid lines are provided as a guide to the eye.

The same behaviour is also observed at $100 \mathrm{~K}$, as depicted in Figure 5.16 (a). In this case the total integrated intensity trend is following the shape of the $S$ integrated intensity trend at lower applied laser power, up to $50 \mathrm{~mW}$, and then above 
$50 \mathrm{~mW}$ is following the Si integrated intensity trend. All the values of the three integrated intensities at $100 \mathrm{~K}$, though, are lower than the ones at $80 \mathrm{~K}$, as expected. In Figure 5.16 (b) is shown an expanded area of Figure 5.16 (a) graphs for the laser power dependence of the integrated intensity trends. In Figure 5.16 (c) are also shown the three integrated intensities on a log-log scale which are quite similar to the equivalent ones at $80 \mathrm{~K}$.

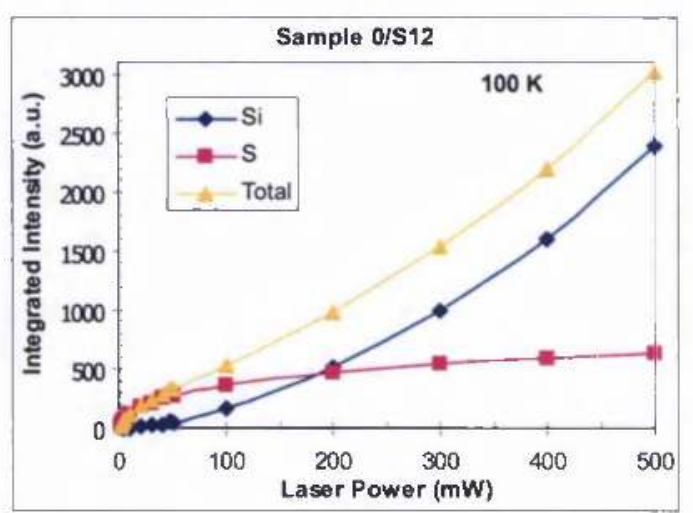

(a)

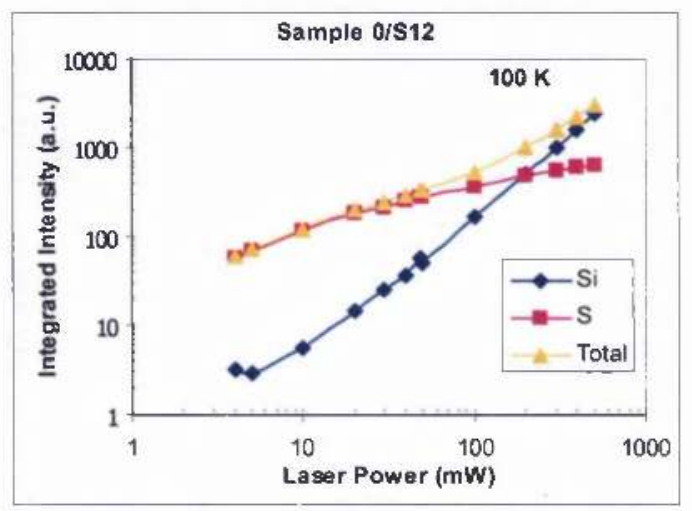

(c)

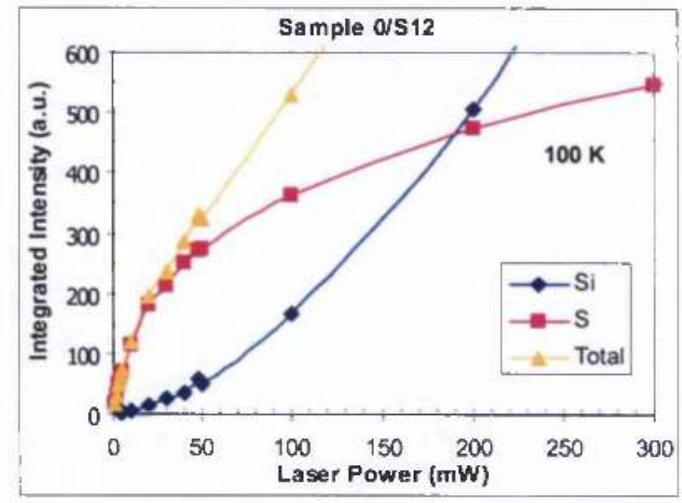

(b)

Figure 5.16 Power dependence of the silicon, sulphur and total integrated intensity as taken from the PL measurements at $100 \mathrm{~K}$ from sample $0 / \mathrm{S} 12$ (implanted with sulphur at $10^{12} \mathrm{~S}$ $\mathrm{cm}^{-2}$ at $30 \mathrm{keV}$, annealed at $1000^{\circ} \mathrm{C}$ for $10 \mathrm{sec}$ ), (a) Linear scale, (b) Linear scale expanded at lower power, (c) Log-Log plot of all data. The errors in Si, S and total integrated intensity and laser power are within the symbol size. The solid lines are provided as a guide to the eye. 


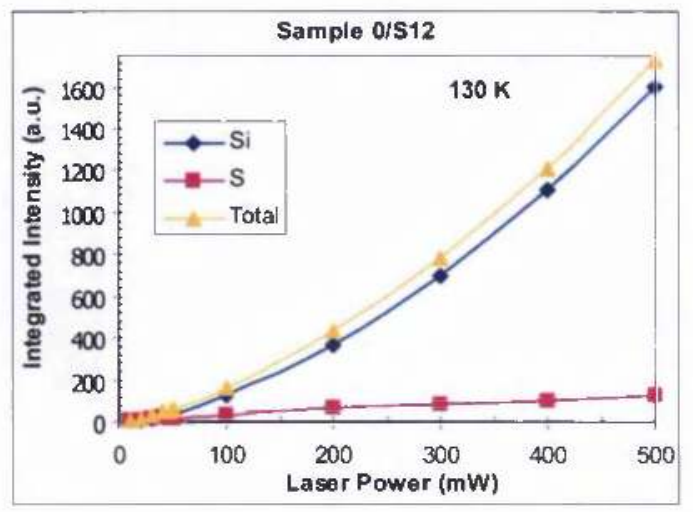

(a)

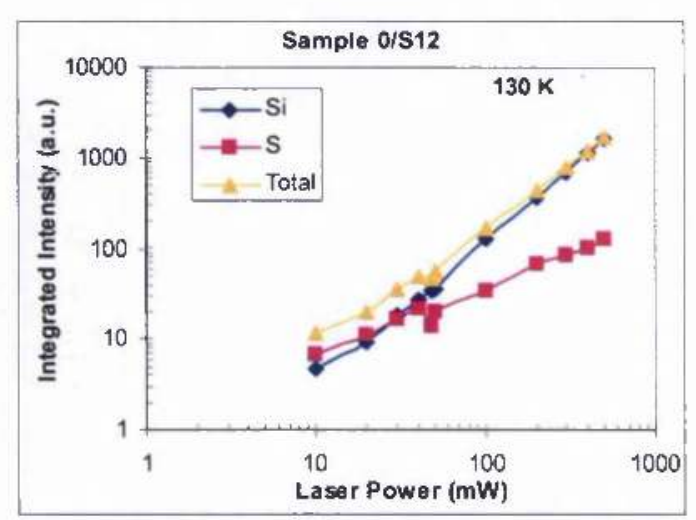

(c)

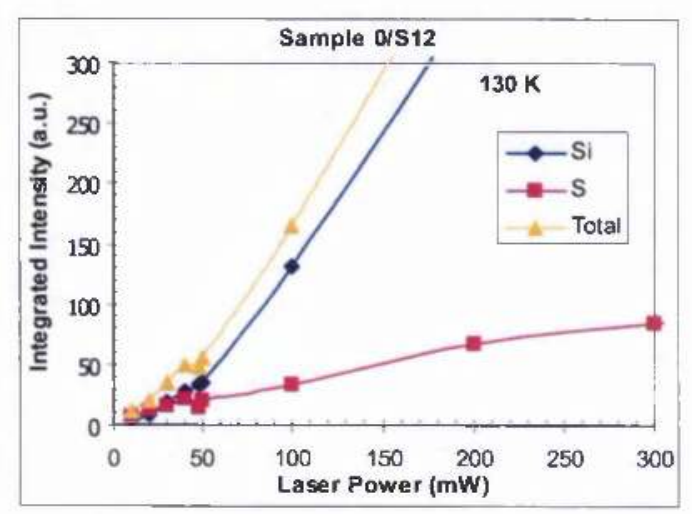

(b)

Figure 5.17 Power dependence of the silicon, sulphur and total integrated intensity as taken from the PL measurements at $130 \mathrm{~K}$ from sample $0 / \mathrm{S} 12$ (implanted with sulphur at $10^{12} \mathrm{~S}$ $\mathrm{cm}^{-2}$ at $30 \mathrm{keV}$, annealed at $100{ }^{\circ} \mathrm{C}$ for $10 \mathrm{sec}$ ), (a) Linear scale, (b) Linear scale expanded at lower power, (c) Log-Log plot of all data. The errors in $\mathrm{Si}, \mathrm{S}$ and total integrated intensity and laser power are within the symbol size. The solid lines are provided as a guide to the eye.

In Figure 5.17 are shown the integrated intensities trends at $130 \mathrm{~K}$. The behaviour is quite similar to those at $80 \mathrm{~K}$ and $100 \mathrm{~K}$. The values of the integrated intensities are however much smaller. The $\mathrm{S}$ integrated intensity trend is sublinear being quite small and approximately stable for most of the applied laser power range, whereas the $\mathrm{Si}$ integrated intensity trend is increasing with the increase of laser power. 


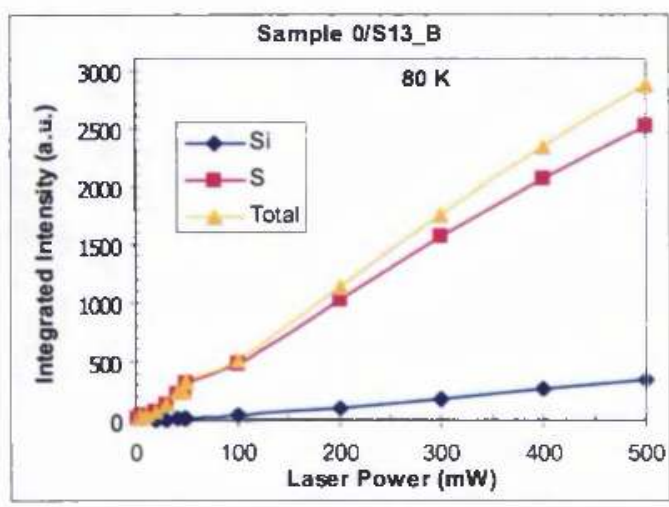

(a)

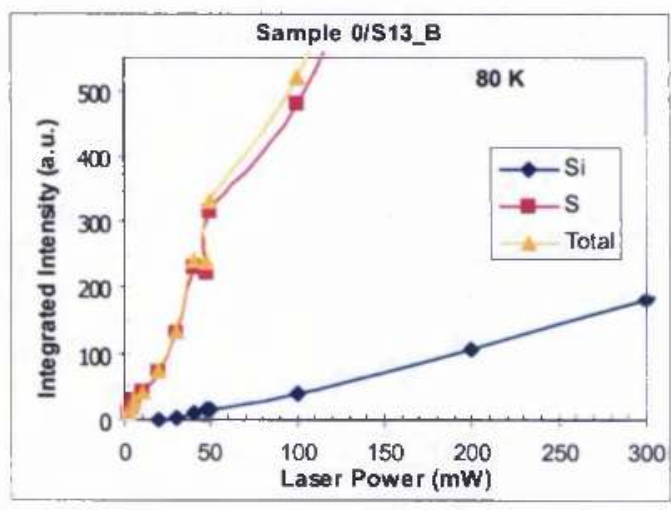

(b)

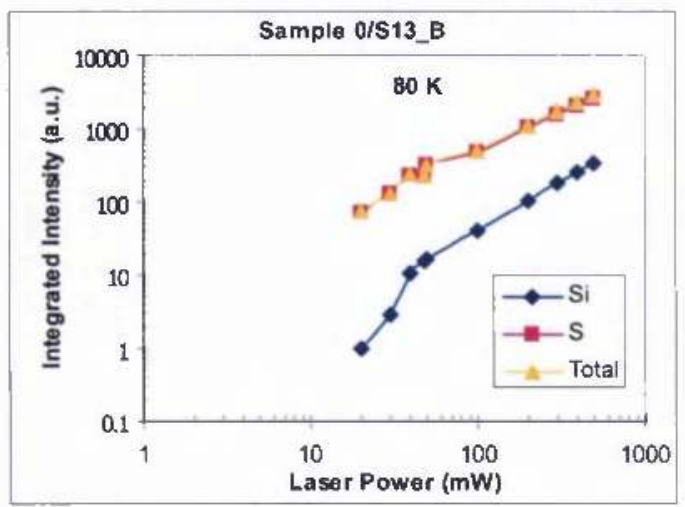

(c)

Figure 5.18 Power dependence of the silicon, sulphur and total integrated intensity as taken from the PL measurements at $80 \mathrm{~K}$ from sample 0/S13_B (implanted with sulphur at $10^{13} \mathrm{~S}$ $\mathrm{cm}^{-2}$ at $30 \mathrm{keV}$, annealed at $1000{ }^{\circ} \mathrm{C}$ for $10 \mathrm{sec}$, further implanted with boron at $10^{15} \mathrm{~B} \mathrm{~cm}^{-2}$ at $30 \mathrm{keV}$ and further annealed at $950{ }^{\circ} \mathrm{C}$ for $1 \mathrm{~min}$ ), (a) Linear scale, (b) Linear scale expanded at lower power, (c) Log-Log plot of all data. The errors in $\mathrm{Si}, \mathrm{S}$ and total integrated intensity and laser power are within the symbol size. The solid lines are provided as a guide to the eye.

In Figures 5.18-5.20 is shown the effect of laser power on the $\mathrm{Si}, \mathrm{S}$ and total integrated intensity for sample $0 / \mathrm{S} 13$ B $\left(10^{13} \mathrm{~S} \mathrm{~cm}^{-2}, 10^{15} \mathrm{~B} \mathrm{~cm}^{-2}\right)$ at $80 \mathrm{~K}, 100 \mathrm{~K}$ and $130 \mathrm{~K}$, respectively. At $80 \mathrm{~K}$ (Figure 5.18), the Si integrated intensity is small compared to the $\mathrm{S}$ one and is increasing slowly with the increase of laser power. The $\mathrm{S}$ integrated intensity is increasing faster with increase of the laser power. The same behaviour is observed at $100 \mathrm{~K}$ (Figure 5.19) where the shape of the $\mathrm{S}$ integrated intensity is slightly different from the $80 \mathrm{~K}$ one. The values of the integrated intensities are higher at $100 \mathrm{~K}$ than at $80 \mathrm{~K}$. At $130 \mathrm{~K}$, (Figure 5.20 ), the Si integrated intensity is increasing approximately as much as the $\mathrm{S}$ one, always having smaller 
values from the $\mathrm{S}$ one up to $400 \mathrm{~mW}$. Above $400 \mathrm{~mW}$ the Si integrated intensity is increasing more than the $\mathrm{S}$ one.

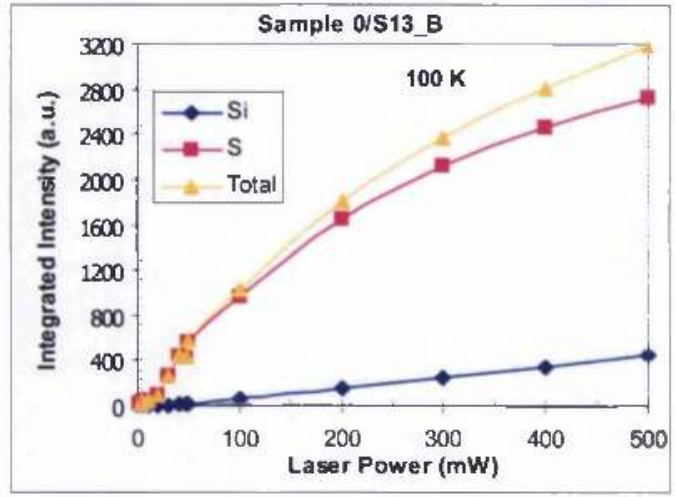

(a)

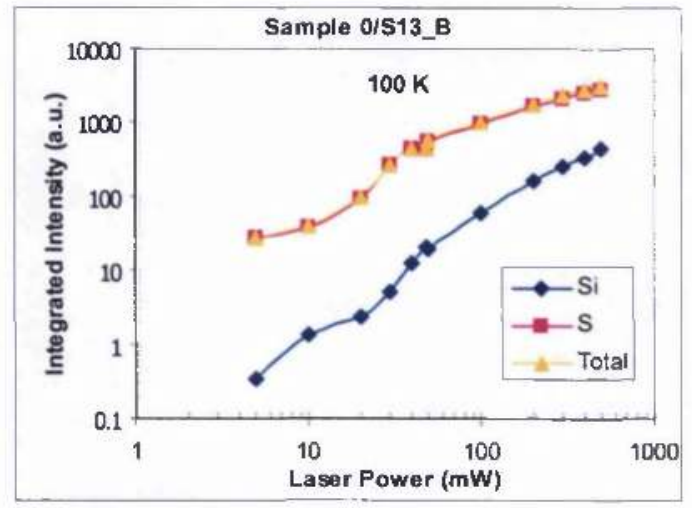

(c)

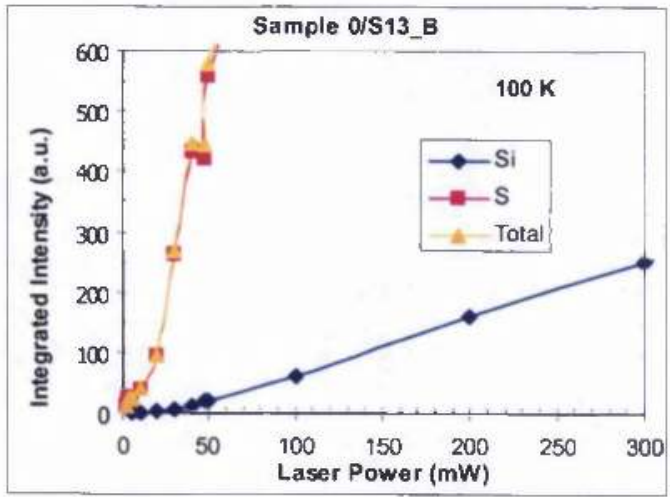

(b)

Figure 5.19 Power dependence of the silicon, sulphur and total integrated intensity as taken from the PL measurements at $100 \mathrm{~K}$ from sample $0 / \mathrm{S} 13 \mathrm{~B}$ (implanted with sulphur at $10^{13} \mathrm{~S}$ $\mathrm{cm}^{-2}$ at $30 \mathrm{keV}$, annealed at $1000{ }^{0} \mathrm{C}$ for $10 \mathrm{sec}$, further implanted with boron at $10^{15} \mathrm{~B} \mathrm{~cm}^{-2}$ at $30 \mathrm{keV}$ and further annealed at $950{ }^{\circ} \mathrm{C}$ for $1 \mathrm{~min}$ ), (a) Linear scale, (b) Linear scale expanded at lower power, (c) Log-Log scale of all data. The errors in Si, S and total integrated intensity and laser power are within the symbol size. The solid lines are provided as a guide to the eye. 


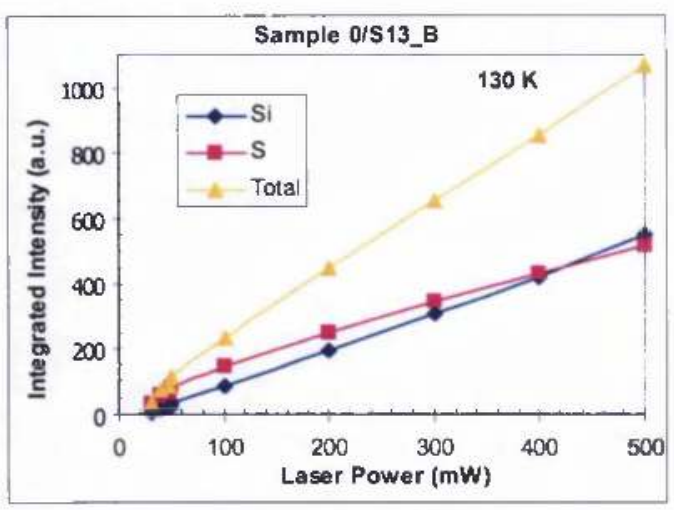

(a)

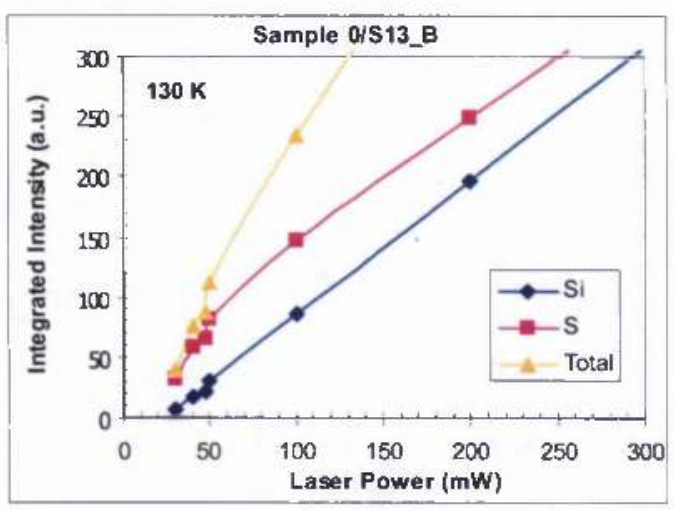

(b)

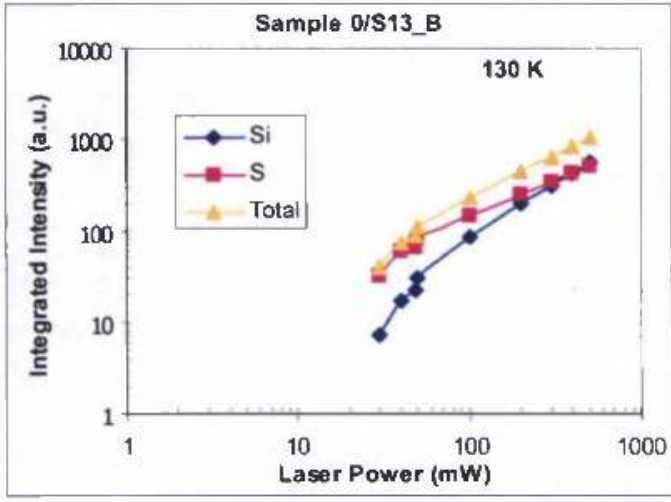

(c)

Figure 5.20 Power dependence of the silicon, sulphur and total integrated intensity as taken from the PL measurements at $130 \mathrm{~K}$ from sample $0 / \mathrm{S} 13 \mathrm{~B}$ (implanted with sulphur at $10^{12} \mathrm{~S}$ $\mathrm{cm}^{-2}$ at $30 \mathrm{keV}$, annealed at $1000^{\circ} \mathrm{C}$ for $10 \mathrm{sec}$, further implanted with boron at $10^{15} \mathrm{~B} \mathrm{~cm}^{-2}$ at $30 \mathrm{keV}$ and further annealed at $950{ }^{\circ} \mathrm{C}$ for $1 \mathrm{~min}$ ), (a) Linear scale, (b) Linear scale expanded at lower power, (c) Log-Log scale of all data. The errors in Si, S and total integrated intensity and laser power are within the symbol size. The solid lines are provided as a guide to the eye.

Finally, in Figures 5.21-5.23 are presented the trends of $\mathrm{Si}, \mathrm{S}$ and total integrated intensity with the applied laser power for sample $0 / \mathrm{S} 14\left(10^{14} \mathrm{~S} \mathrm{~cm}^{-2}\right)$. At $80 \mathrm{~K}$, (Figure 5.21), the Si and S integrated intensities are increasing in the same way as the equivalent ones for the sample $0 / \mathrm{S} 12$ which has the lower $\mathrm{S}$ dose $\left(10^{12} \mathrm{~S} \mathrm{~cm}^{-2}\right)$ for the same temperature. The $S$ integrated intensity is increasing sublinearly with the increase of applied laser power and the Si integrated intensity is increasing superlinearly. The increase, though, for both of the two intensities is higher for the sample with the higher $\mathrm{S}$ dose with the increase of applied laser power. 


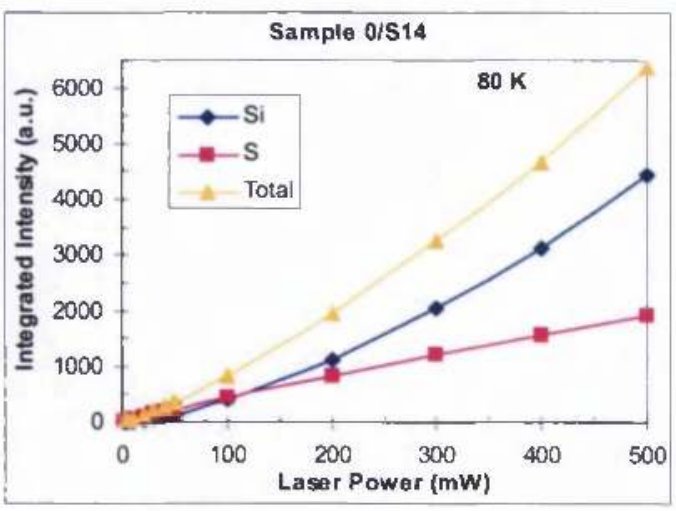

(a)

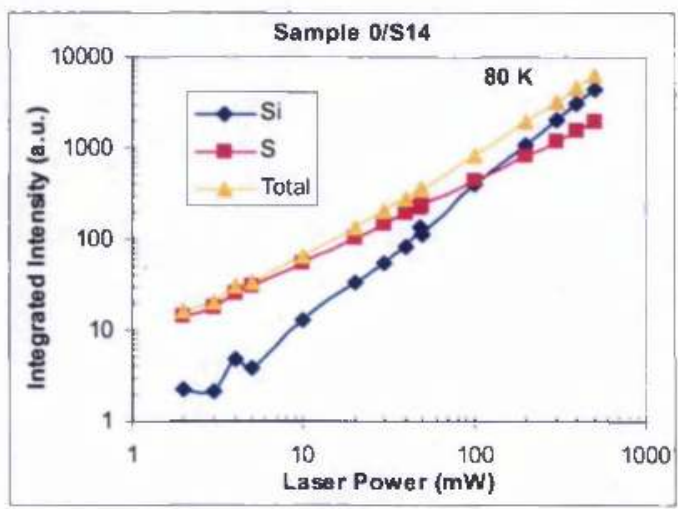

(c)

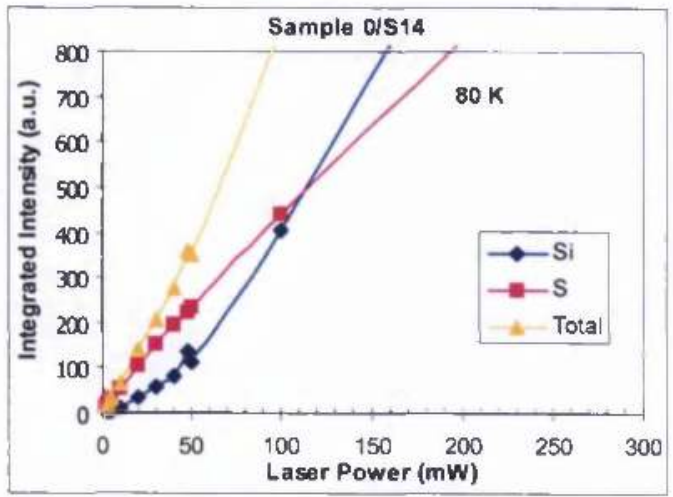

(b)

Figure 5.21 Power dependence of the silicon, sulphur and total integrated intensity as taken from the PL measurements at $80 \mathrm{~K}$ from sample $0 / \mathrm{S} 14$ (implanted with sulphur at $10^{14} \mathrm{~S}$ $\mathrm{cm}^{-2}$ at $30 \mathrm{keV}$, annealed at $1000{ }^{\circ} \mathrm{C}$ for $10 \mathrm{sec}$ ), (a) Linear scale, (b) Linear scale expanded at lower power, (c) Log-Log scale of all data. The errors in Si, S and total integrated intensity and laser power are within the symbol size. The solid lines are provided as a guide to the eye.

At $100 \mathrm{~K}$, (Figure 5.22 ), the trends are very similar to the ones at $80 \mathrm{~K}$ for the same sample; the values of the integrated intensities are lower than the ones at $80 \mathrm{~K}$ for the same sample but they are higher than the ones at $100 \mathrm{~K}$ for the sample with the lower $\mathrm{S}$ dose $(0 / \mathrm{S} 12)$. The $\mathrm{Si}$ and $\mathrm{S}$ integrated intensity trends are superlinear and sublinear, respectively. This behaviour is more prominent at the low laser power regime. Lastly, at $130 \mathrm{~K}$, (Figure 5.23 ) the $\mathrm{S}$ integrated intensity trend is increasing very slightly with the increase of laser power being approximately stable, whereas the Si integrated intensity trend continues to increase. In addition, both values of the 
$\mathrm{Si}$ and $\mathrm{S}$ integrated intensities are higher than the equivalent ones at $130 \mathrm{~K}$ for the sample with the lower $\mathrm{S}$ dose $(0 / \mathrm{S} 12)$.

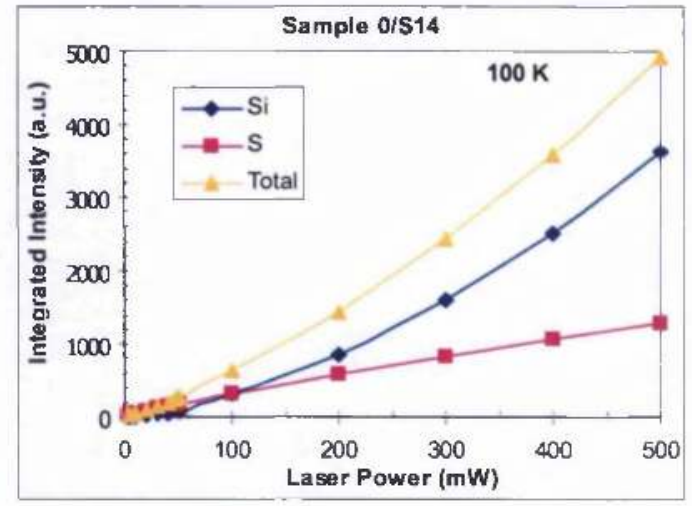

(a)

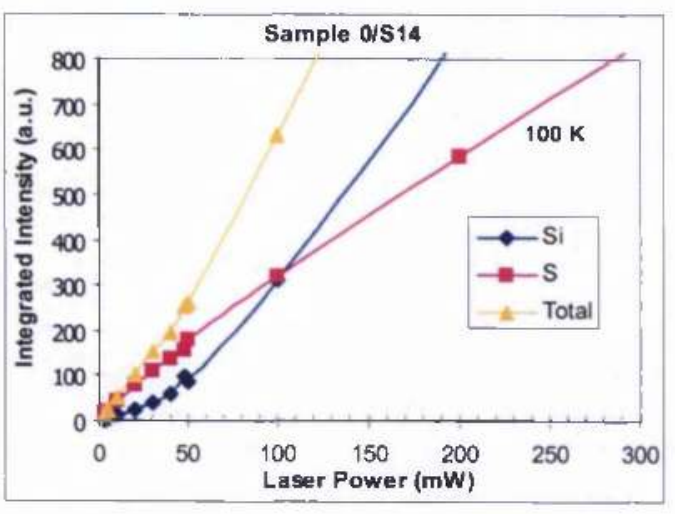

(b)

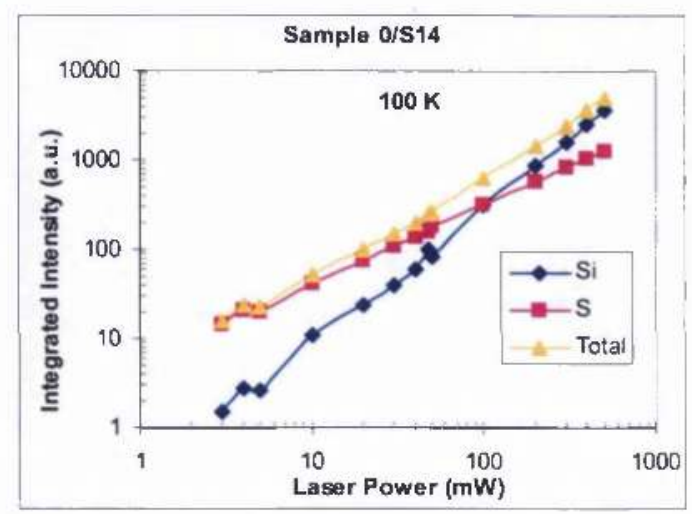

(c)

Figure 5.22 Power dependence of the silicon, sulphur and total integrated intensity as taken from the PL measurements at $100 \mathrm{~K}$ from sample $0 / \mathrm{S} 14$ (implanted with sulphur at $10^{14} \mathrm{~S}$ $\mathrm{cm}^{-2}$ at $30 \mathrm{keV}$, annealed at $1000{ }^{\circ} \mathrm{C}$ for $10 \mathrm{sec}$ ), (a) Linear scale, (b) Linear scale expanded at lower power, (c) Log-Log scale of all data. The errors in Si, S and total integrated intensity and laser power are within the symbol size. The solid lines are provided as a guide to the eye. 


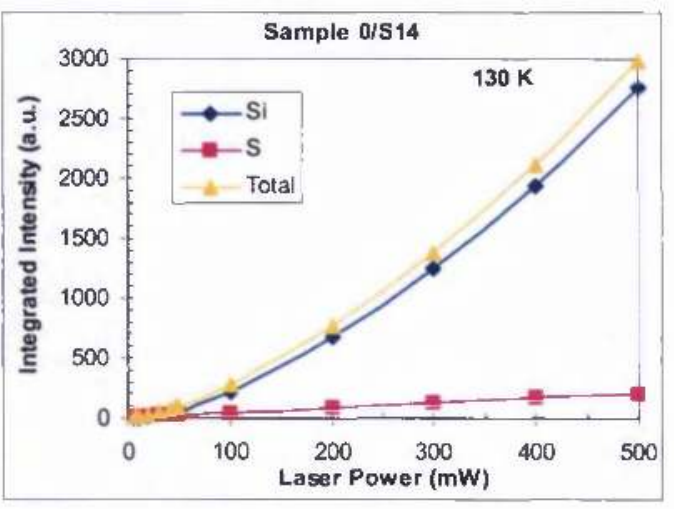

(a)

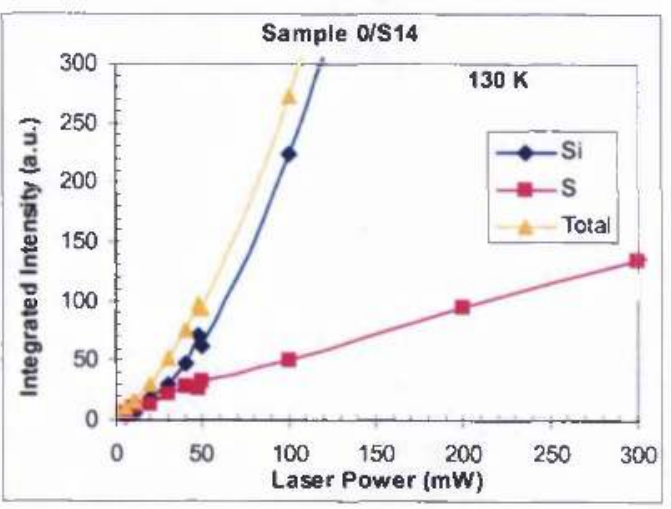

(b)

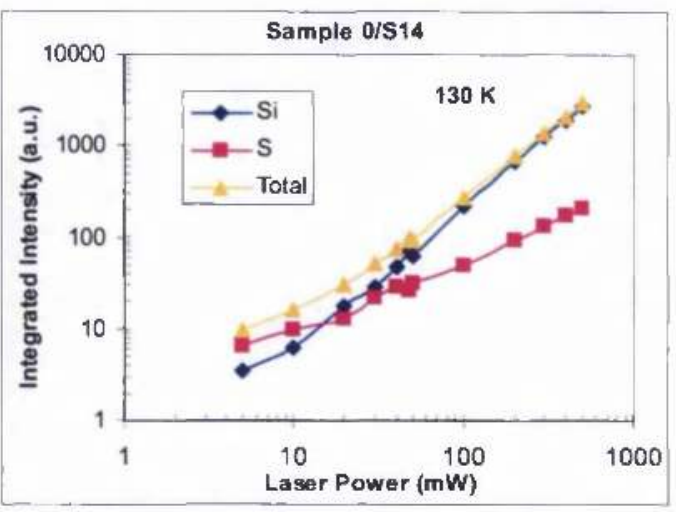

(c)

Figure 5.23 Power dependence of the silicon, sulphur and total integrated intensity as taken from the PL measurements at $130 \mathrm{~K}$ from sample $0 / \mathrm{S} 14$ (implanted with sulphur at $10^{14} \mathrm{~S}$ $\mathrm{cm}^{-2}$ at $30 \mathrm{keV}$, annealed at $1000^{\circ} \mathrm{C}$ for $10 \mathrm{sec}$ ), (a) Linear scale, (b) Linear scale expanded at lower power, (c) Log-Log scale of all data. The errors in Si, S and total integrated intensity and laser power are within the symbol size. The solid lines are provided as a guide to the eye.

In conclusion, in this section variable laser power PL experiments were done at the three samples $0 / \mathrm{S} 12,0 / \mathrm{S} 13 \_\mathrm{B}$ and $0 / \mathrm{S} 14$ implanted at $10^{12} \mathrm{~S} \mathrm{~cm}^{-2}$ at $30 \mathrm{keV}$, $10^{13} \mathrm{~S} \mathrm{~cm}^{-2}$ at $30 \mathrm{keV}$ plus $10^{15} \mathrm{~B} \mathrm{~cm}^{-2}$ at $30 \mathrm{keV}$ and $10^{14} \mathrm{~S} \mathrm{~cm}^{-2}$ at $30 \mathrm{keV}$, respectively, at three temperatures $80 \mathrm{~K}, 100 \mathrm{~K}$ and $130 \mathrm{~K}$. From the shapes of the integrated intensity curves it is observed that the $S$ integrated intensity has a sublinear behaviour whereas the $\mathrm{Si}$ integrated intensity increases superlinearly. This behaviour is more obvious at $80 \mathrm{~K}$ and $100 \mathrm{~K}$ and less at $130 \mathrm{~K}$, mostly for sample $0 / \mathrm{S} 12$ (lower S dose) and less for sample 0/S14 (higher S dose). In addition, this behaviour is more prominent at the low laser power regime. Sample 0/S13_B which 
is implanted both with $\mathrm{S}$ and $\mathrm{B}$ has a different dependence on the laser power than the other two samples; the $\mathrm{S}$ is increasing much faster than the Si integrated intensity trend with the increase of the applied laser power at $80 \mathrm{~K}$ and $100 \mathrm{~K}$. At $130 \mathrm{~K}$, the $\mathrm{Si}$ and $\mathrm{S}$ integrated intensity trends are increasing similarly with the latter having the higher values up to $400 \mathrm{~mW}$. From $400 \mathrm{~mW}$ up to $500 \mathrm{~mW}$ applied laser power the $\mathrm{Si}$ integrated intensity is higher than the $\mathrm{S}$.

\subsection{EL results on Si:S samples}

\subsubsection{EL variable temperature measurements}

The devices which were used for electroluminescence experiments were fabricated from the same boron doped material measured in the photoluminescence experiments (Table 5.1). They were Si wafers implanted with sulphur at different doses, further implanted with boron and then further annealed. All samples were annealed either at $1000{ }^{\circ} \mathrm{C}$ or at $1100{ }^{\circ} \mathrm{C}$ for $10 \mathrm{sec}$ after sulphur implantation, and they were further annealed at $950{ }^{\circ} \mathrm{C}$ for $1 \mathrm{~min}$ after boron implantation. $\mathrm{EL}$ temperature dependence measurements were done from $80 \mathrm{~K}$ to $300 \mathrm{~K}$ at $25 \mathrm{~mA}$ applied drive current on the above samples. A table of the samples along with the EL conditions is shown in Table 5.3. 


\begin{tabular}{|c|c|c|c|}
\hline Sample & Implants & $\begin{array}{l}\text { Annealing } \\
\text { conditions }\end{array}$ & $\begin{array}{l}\text { EL } \\
\text { conditions }\end{array}$ \\
\hline 0/S11_B & $\begin{array}{l}10^{11} \mathrm{~S} \mathrm{~cm}^{-2}, 30 \mathrm{keV}, 10^{15} \mathrm{~B} \mathrm{~cm}^{-2}, 30 \\
\mathrm{keV}\end{array}$ & $\begin{array}{l}\mathrm{S} \text { at } 1000^{\circ} \mathrm{C}, 10 \mathrm{sec}, \mathrm{B} \\
\text { at } 950^{\circ} \mathrm{C}, 1 \mathrm{~min}\end{array}$ & $\begin{array}{l}80 \mathrm{~K}-300 \mathrm{~K} \text {, } \\
\text { at } 25 \mathrm{~mA}\end{array}$ \\
\hline$\overline{0 / S 12 \_B}$ & $\begin{array}{l}10^{12} \mathrm{~S} \mathrm{~cm}^{-2}, 30 \mathrm{keV}, 10^{15} \mathrm{~B} \mathrm{~cm}^{-2}, 30 \\
\mathrm{keV}\end{array}$ & $\begin{array}{l}\mathrm{S} \text { at } 1000^{\circ} \mathrm{C}, 10 \mathrm{sec}, \mathrm{B} \\
\text { at } 950^{\circ} \mathrm{C}, 1 \mathrm{~min}\end{array}$ & $\begin{array}{l}80 \mathrm{~K}-300 \mathrm{~K} \\
\text { at } 25 \mathrm{~mA}\end{array}$ \\
\hline 0/S13_B & $\begin{array}{l}10^{13} \mathrm{~S} \mathrm{~cm}^{-2}, 30 \mathrm{keV}, 10^{15} \mathrm{~B} \mathrm{~cm}^{-2}, 30 \\
\mathrm{keV}\end{array}$ & $\begin{array}{l}\mathrm{S} \text { at } 1000^{\circ} \mathrm{C}, 10 \mathrm{sec}, \mathrm{B} \\
\text { at } 950^{\circ} \mathrm{C}, 1 \mathrm{~min}\end{array}$ & $\begin{array}{l}80 \mathrm{~K}-300 \mathrm{~K} \text {, } \\
\text { at } 25 \mathrm{~mA}\end{array}$ \\
\hline 0/S14_B & $\begin{array}{l}10^{14} \mathrm{~S} \mathrm{~cm}^{-2}, 30 \mathrm{keV}, 10^{15} \mathrm{~B} \mathrm{~cm}^{-2}, 30 \\
\mathrm{keV}\end{array}$ & $\begin{array}{l}\mathrm{S} \text { at } 1000^{\circ} \mathrm{C}, 10 \mathrm{sec}, \mathrm{B} \\
\text { at } 950^{\circ} \mathrm{C}, 1 \mathrm{~min}\end{array}$ & $\begin{array}{l}80 \mathrm{~K}-300 \mathrm{~K} \text {, } \\
\text { at } 25 \mathrm{~mA}\end{array}$ \\
\hline 1/S11_B & $\begin{array}{l}10^{11} \mathrm{~S} \mathrm{~cm}^{-2}, 30 \mathrm{keV}, 10^{15} \mathrm{~B} \mathrm{~cm}^{-2}, 30 \\
\mathrm{keV}\end{array}$ & $\begin{array}{l}\mathrm{S} \text { at } 1100^{\circ} \mathrm{C}, 10 \mathrm{sec}, \mathrm{B} \\
\text { at } 950^{\circ} \mathrm{C}, 1 \mathrm{~min}\end{array}$ & $\begin{array}{l}80-300 \mathrm{~K} \text {, at } \\
25 \mathrm{~mA}\end{array}$ \\
\hline 1/S12_B & $\begin{array}{l}10^{12} \mathrm{~S} \mathrm{~cm}^{-2}, 30 \mathrm{keV}, 10^{15} \mathrm{~B} \mathrm{~cm}^{-2}, 30 \\
\mathrm{keV}\end{array}$ & $\begin{array}{l}\mathrm{S} \text { at } 1100^{\circ} \mathrm{C}, 10 \mathrm{sec}, \mathrm{B} \\
\text { at } 950^{\circ} \mathrm{C}, 1 \mathrm{~min}\end{array}$ & $\begin{array}{l}80 \mathrm{~K}-300 \mathrm{~K} \text {, } \\
\text { at } 25 \mathrm{~mA}\end{array}$ \\
\hline 1/S13_B & $\begin{array}{l}10^{13} \mathrm{~S} \mathrm{~cm}^{-2}, 30 \mathrm{keV}, 10^{15} \mathrm{~B} \mathrm{~cm}^{-2}, 30 \\
\mathrm{keV}\end{array}$ & $\begin{array}{l}\mathrm{S} \text { at } 1100^{\circ} \mathrm{C}, 10 \mathrm{sec}, \mathrm{B} \\
\text { at } 950^{\circ} \mathrm{C}, 1 \mathrm{~min}\end{array}$ & $\begin{array}{l}80 \mathrm{~K}-300 \mathrm{~K} \text {, } \\
\text { at } 25 \mathrm{~mA}\end{array}$ \\
\hline 1/S14_B & $\begin{array}{l}10^{14} \mathrm{~S} \mathrm{~cm}^{-2}, 30 \mathrm{keV}, 10^{15} \mathrm{~B} \mathrm{~cm}^{-2}, 30 \\
\mathrm{keV}\end{array}$ & $\begin{array}{l}\mathrm{S} \text { at } 1100^{\circ} \mathrm{C}, 10 \mathrm{sec}, \mathrm{B} \\
\text { at } 950{ }^{\circ} \mathrm{C}, 1 \mathrm{~min}\end{array}$ & $\begin{array}{l}80 \mathrm{~K}-300 \mathrm{~K} \text {, at } \\
25 \mathrm{~mA}\end{array}$ \\
\hline
\end{tabular}

Table 5.3 Details of the eight samples used for the variable temperature EL experiments that took place at $25 \mathrm{~mA}$ applied drive current. Note that the label sample, e.g. 1/S14_B stands for a sample in which 1: comes from the $1100^{\circ} \mathrm{C}$ annealing temperature used after the sulphur implantation, S14: is the sulphur dose at $10^{14} \mathrm{~S} \mathrm{~cm}^{-2}$ and $\mathrm{B}$ : is the dopant boron which has the same dose of $10^{15} \mathrm{~B} \mathrm{~cm}^{-2}$ and implant energy $30 \mathrm{keV}$, for all samples.

The results from the EL measurements taken at $80 \mathrm{~K}$ for all samples annealed at $1000^{\circ} \mathrm{C}$ for $10 \mathrm{~s}$ at $25 \mathrm{~mA}$ applied current are shown in Figure 5.24 ((a) and (b)). 


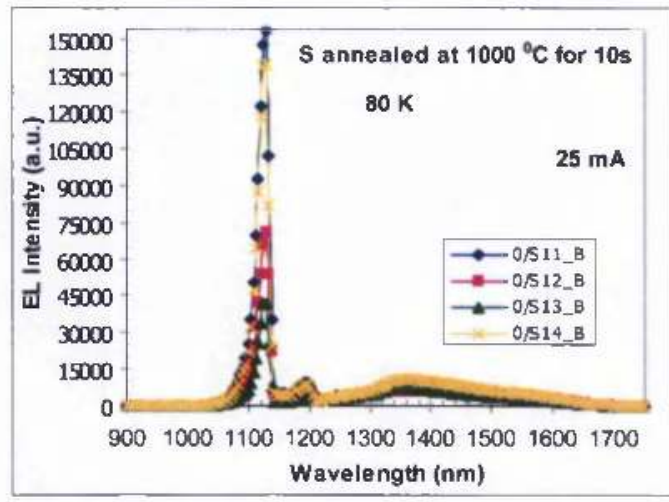

(a)

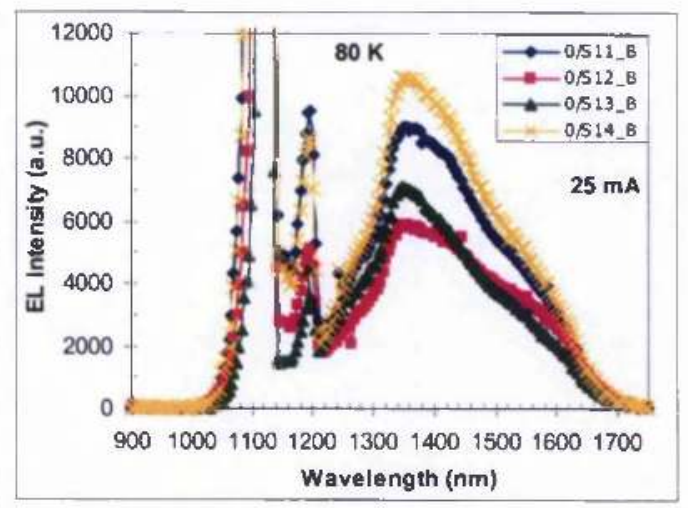

(b)

Figure 5.24 (a) EL spectra at $80 \mathrm{~K}$ of samples $0 / \mathrm{S} 11$ B $, 0 / \mathrm{S} 12 \_\mathrm{B}, 0 / \mathrm{S} 13 \_\mathrm{B}, 0 / \mathrm{S} 14$ B (implanted with sulphur at $10^{11}, 10^{12}, 10^{13}, 10^{14} \mathrm{~S} \mathrm{~cm}^{-2}$ at $30 \mathrm{keV}$, annealed at $1000^{\circ} \mathrm{C}$ for 10 sec, further implanted with boron at $10^{15} \mathrm{~B} \mathrm{~cm}^{-2}$ at $30 \mathrm{keV}$ and further annealed at $950{ }^{\circ} \mathrm{C}$ for $1 \mathrm{~min})$. All samples are annealed at $1000{ }^{\circ} \mathrm{C}$ for $10 \mathrm{~s}$ after sulphur implantation. EL experiments were done at $25 \mathrm{~mA}$ applied drive current to each one of those samples. (b) EL at $80 \mathrm{~K}$ as in (a) expanded at lower intensities to show the sulphur peak.

From Figure 5.24 is observed that apart from the $\mathrm{Si}$ TO phonon assisted peak at $1129.5 \mathrm{~nm}$ (or $1.0977 \mathrm{eV}$ ) and its phonon replica at $1193.25 \mathrm{~nm}(1.0391 \mathrm{eV})$, there is another quite weak and broad peak. This peak which is due to sulphur has a peak position ranging from $1350.5 \mathrm{~nm}-1363.25 \mathrm{~nm}$ (or $0.9181 \mathrm{eV}-0.9095 \mathrm{eV}$ ) for the four samples at $80 \mathrm{~K}$. Therefore, a series of $\mathrm{EL}$ variable temperature experiments was made on all samples in order to have a more detailed description of the behaviour of the samples. In particular, from the variable temperature measurements of sample 0/S11_B (S implanted at $30 \mathrm{keV}$, at a dose of $1 \times 10^{11} \mathrm{~S} \mathrm{~cm}^{-2}$, annealed at $1000{ }^{\circ} \mathrm{C}$ for $10 \mathrm{~s}$, B implanted at $30 \mathrm{keV}$ at a dose of $10^{15} \mathrm{~cm}^{-2}$, annealed at $950^{\circ} \mathrm{C}$ for $1 \mathrm{~min}$ ) at $80 \mathrm{~K}-300 \mathrm{~K}$, the S related peak is seen at $1363.25 \mathrm{~nm}(0.9095 \mathrm{eV}$ ) at $80 \mathrm{~K}$ (see also Figure 5.25). This peak is shifting to longer wavelengths (smaller energies) with the increase of temperature, becoming broader and almost disappearing at $300 \mathrm{~K}$. Furthermore, it is weak and broad compared to the Si peak. The ratio of the intensities of the two peaks $\left(\mathrm{I}_{\mathrm{S}} / \mathrm{I}_{\mathrm{S}}\right)$ at $25 \mathrm{~mA}$ is varying with the temperature, e.g. 17.08 at $80 \mathrm{~K}, 21.93$ at $100 \mathrm{~K}$ and 29.02 at $120 \mathrm{~K}$. 


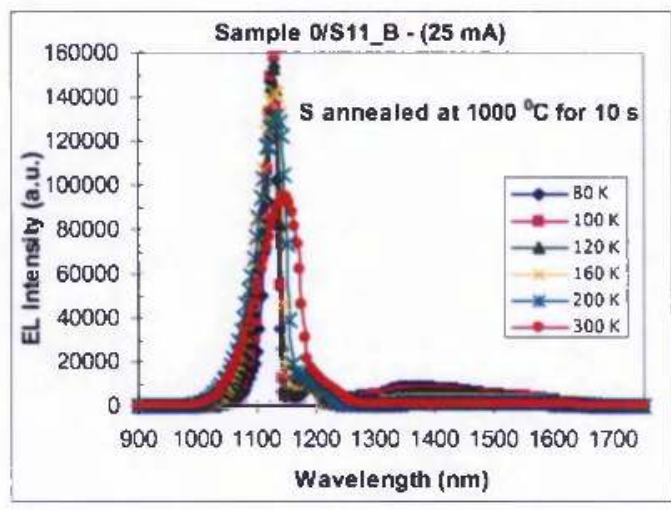

(a)

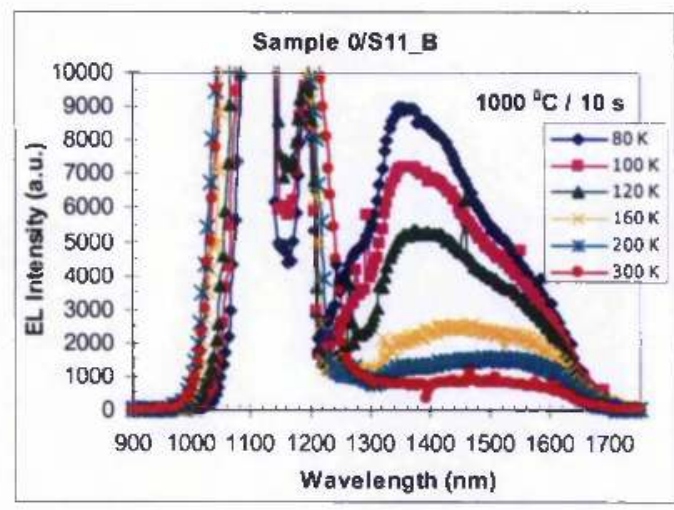

(b)

Figure 5.25 (a) EL variable temperature measurements at $25 \mathrm{~mA}$ applied drive current of sample 0/S11_B (implanted with sulphur at $10^{11} \mathrm{~S} \mathrm{~cm}^{-2}$ at $30 \mathrm{keV}$, annealed at $1000^{\circ} \mathrm{C}$ for $10 \mathrm{sec}$, further implanted with boron at $10^{15} \mathrm{~B} \mathrm{~cm}^{-2}$ at $30 \mathrm{keV}$ and further annealed at $950{ }^{\circ} \mathrm{C}$ for $1 \mathrm{~min}$ ). (b) EL temperature dependence as in (a) expanded to lower intensities to show the sulphur peak.

Similar results are taken from the variable temperature measurements of sample 0/S12_B (S implanted at a dose of $10^{12} \mathrm{~S} \mathrm{~cm}^{-2}$ at $30 \mathrm{keV}$, annealed at $1000^{\circ} \mathrm{C}$ for $10 \mathrm{~s}, \mathrm{~B}$ implanted at a dose of $10^{15} \mathrm{~B} \mathrm{~cm}^{-2}$ and further annealed at $950{ }^{\circ} \mathrm{C}$ for 1 minute). The sulphur peak is observed at $1354.75 \mathrm{~nm}(0.9152 \mathrm{eV})$ at $80 \mathrm{~K}$ shifting at longer wavelengths with the temperature increase. At $25 \mathrm{~mA}$ applied current the silicon peak is stronger compared to the $S$ one for all temperatures. The ratios of the intensities of the two peaks $\left(\mathrm{I}_{\mathrm{S}} / \mathrm{I}_{\mathrm{S}}\right)$ are 12.07 at $80 \mathrm{~K}, 15.27$ at $100 \mathrm{~K}$ and 18.88 at 120 $\mathrm{K}$. The values of the EL peak intensities from both the Si and S peak are lower for this sample (higher $\mathrm{S}$ dose, $\left.10^{12} \mathrm{~S} \mathrm{~cm}^{-2}\right)$ than the previous one $\left(10^{11} \mathrm{~S} \mathrm{~cm}^{-2}\right)$. The $\mathrm{S}$ peak is decreasing with the increase of temperature, becoming almost insignificant compared to the Si one at $300 \mathrm{~K}$.

The variable temperature measurements of sample 0/S13_B (S implanted at a dose of $10^{13} \mathrm{~S} \mathrm{~cm}^{-2}$ at $30 \mathrm{keV}$, annealed at $1000^{\circ} \mathrm{C}$ for $10 \mathrm{~s}, \mathrm{~B}$ implanted at a dose of $10^{15} \mathrm{~B} \mathrm{~cm}^{-2}$ and further annealed at $950{ }^{\circ} \mathrm{C}$ for 1 minute) are similar to the two other samples studied above. In this case also the Si peak intensity is higher than the S one. At $80 \mathrm{~K}$ and at $25 \mathrm{~mA}$ applied drive current, the $\mathrm{S}$ peak is revealed at $1350.5 \mathrm{~nm}$ $(0.9181 \mathrm{eV})$. The sulphur peak is quenching with temperature increase and it is shifting towards longer wavelengths (smaller energies). The ratios of the intensities 
of the two peaks $\left(\mathrm{I}_{\mathrm{S}} / \mathrm{I}_{\mathrm{S}}\right)$ are 5.89 at $80 \mathrm{~K}, 8.37$ at $100 \mathrm{~K}$ and 11.45 at $120 \mathrm{~K}$. The $\mathrm{EL}$ peak intensity values of $S$ are in between the values of the $S$ peak intensities of the two previous samples studied above. The Si peak intensity values are the lowest of all samples of this set.

The variable temperature measurements of sample 0/S14_B (S implanted at a dose of $10^{14} \mathrm{~S} \mathrm{~cm}^{-2}$ at $30 \mathrm{keV}$, annealed at $1000^{\circ} \mathrm{C}$ for $10 \mathrm{~s}, \mathrm{~B}$ implanted at a dose of $10^{15} \mathrm{~B} \mathrm{~cm}^{-2}$ and further annealed at $950{ }^{\circ} \mathrm{C}$ for 1 minute) are also similar to all studied samples with $\mathrm{S}$ doses: $10^{11}, 10^{12}$ and $10^{13} \mathrm{~S} \mathrm{~cm}^{-2}$. The sulphur peak is seen at $1363.25 \mathrm{~nm}(0.9095 \mathrm{eV})$ at $80 \mathrm{~K}$. The ratios of the intensities of the two peaks $\left(\mathrm{I}_{\mathrm{S}} / \mathrm{I}_{\mathrm{S}}\right)$ are 13.31 at $80 \mathrm{~K}, 16.14$ at $100 \mathrm{~K}$ and 21.52 at $120 \mathrm{~K}$. The S peak is quenching and is shifting towards bigger wavelengths with the increase of temperature as the other samples. The EL peak intensity values of the $\mathrm{S}$ peak are the highest of all the equivalent ones from the other samples of this set and the Si peak intensity values are the second highest of the others for the same applied drive current $(25 \mathrm{~mA})$. The trends of the $\mathrm{S}$ and $\mathrm{Si}$ peak intensity for this set of samples are also depicted in Figure 5.32 ((a) and (c)), page 124.

The EL results at $80 \mathrm{~K}$ from the other set of samples are illustrated in Figure 5.26. These samples have the same $\mathrm{S}$ and $\mathrm{B}$ doses as the samples studied above, the annealing temperature after the $\mathrm{S}$ implantation is now $1100{ }^{\circ} \mathrm{C}$ for $10 \mathrm{~s}$, instead of $1000^{\circ} \mathrm{C}$ for $10 \mathrm{~s}$ for the previous samples. 


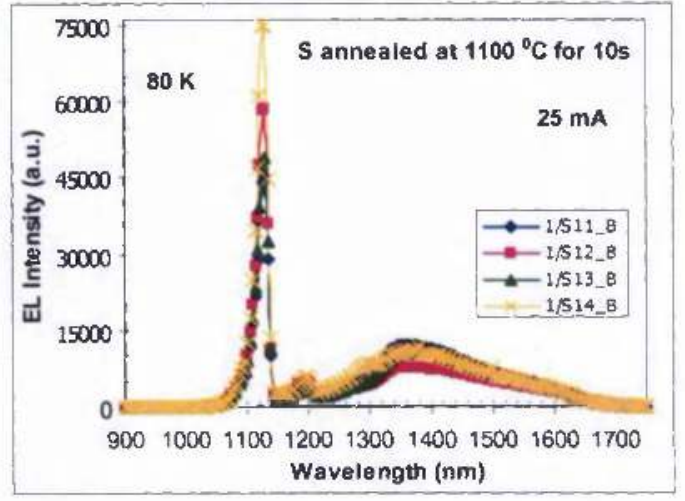

(a)

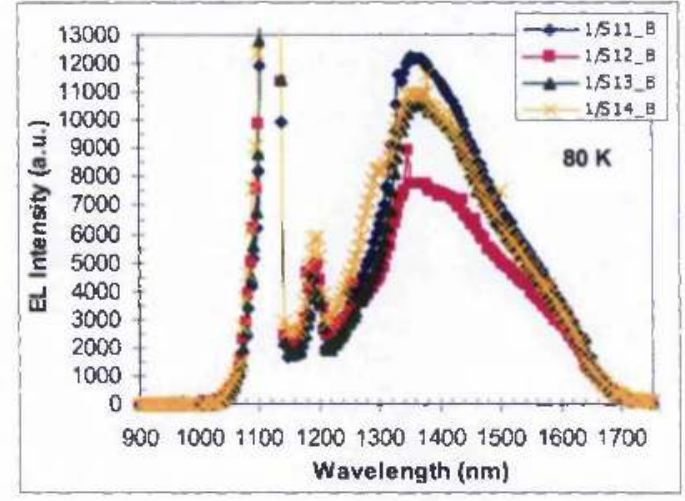

(b)

Figure 5.26 (a) EL spectra at $80 \mathrm{~K}$ of samples $1 / \mathrm{S} 11$ B, 1/S12_B, 1/S13_B, 1/S14_B (implanted with sulphur at $10^{11}, 10^{12}, 10^{13}, 10^{14} \mathrm{~S} \mathrm{~cm}^{-2}$ at $30 \mathrm{keV}$, annealed at $1100^{\circ} \mathrm{C}$ for 10 sec, further implanted with boron at $10^{15} \mathrm{~B} \mathrm{~cm}^{-2}$ at $30 \mathrm{keV}$ and further annealed at $950{ }^{\circ} \mathrm{C}$ for $1 \mathrm{~min}$ ). All samples are annealed at $1100{ }^{\circ} \mathrm{C}$ for $10 \mathrm{~s}$ after sulphur implantation. EL experiments were done at $25 \mathrm{~mA}$ applied drive current to each one of those samples. (b) EL at $80 \mathrm{~K}$ as in (a) expanded at lower intensities to show the sulphur peak.

The same features (the two main peaks due to $\mathrm{Si}$ and $\mathrm{S}$ ) are illustrated in Figure 5.26. The intensities and the $\mathrm{S}$ peak position are varying slightly for each sample. EL variable temperature measurements were also made on all samples of this set. Thus, from the EL variable temperature measurements of sample 1/S11_B (S implanted at $30 \mathrm{keV}$, at a dose $1 \times 10^{11} \mathrm{~S} \mathrm{~cm}^{-2}$, annealed at $1100^{\circ} \mathrm{C}$ for $10 \mathrm{~s}$ ) at $25 \mathrm{~mA}$ applied current, the $\mathrm{S}$ peak occurred at $1363.25 \mathrm{~nm}(0.9095 \mathrm{eV})$ (see also Figure 5.27). The ratios of the intensities of the two peaks $\left(\mathrm{I}_{\mathrm{Si}} / \mathrm{I}_{\mathrm{S}}\right)$ are 3.69 at $80 \mathrm{~K}, 4.74$ at $100 \mathrm{~K}$ and 6.64 at $120 \mathrm{~K}$. The $\mathrm{S}$ peak is quenching and is shifting towards longer wavelengths with the temperature increase. The $S$ peak intensity values are the highest of all the samples of this set in contrast to the Si peak intensity values which are the lowest. In addition, the S EL peak intensity values are higher whereas the Si EL peak intensity values are lower for this sample compared to the sample with the same $\mathrm{S}$ and $\mathrm{B}$ dose and lower anneal $\left(1000^{\circ} \mathrm{C}\right.$, sample $0 / \mathrm{S} 11$ B $)$. 


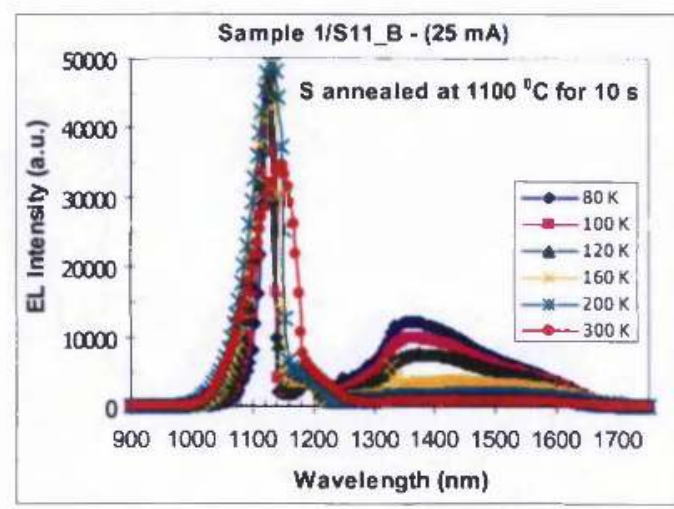

(a)

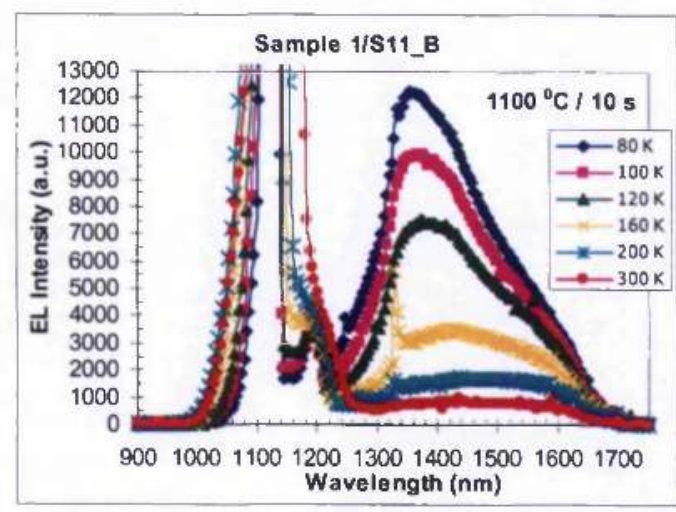

(b)

Figure 5.27 (a) EL variable temperature measurements at $25 \mathrm{~mA}$ applied drive current of sample 1/S11_B (implanted with sulphur at $10^{11} \mathrm{~S} \mathrm{~cm}^{-2}$ at $30 \mathrm{keV}$, annealed at $1100{ }^{\circ} \mathrm{C}$ for $10 \mathrm{sec}$, further implanted with boron at $10^{15} \mathrm{~B} \mathrm{~cm}^{-2}$ at $30 \mathrm{keV}$ and further annealed at $950{ }^{\circ} \mathrm{C}$ for $1 \mathrm{~min}$ ). (b) EL temperature dependence as in (a) expanded to lower intensities to show the sulphur peak.

From the EL variable temperature measurements of sample 1/S12_B (S implanted at $30 \mathrm{keV}$, at a dose $1 \times 10^{12} \mathrm{~S} \mathrm{~cm}^{-2}$, annealed at $1100^{\circ} \mathrm{C}$ for $10 \mathrm{~s}$ ) at $25 \mathrm{~mA}$ applied current, the $\mathrm{S}$ peak is seen at $1363.25 \mathrm{~nm}(0.9095 \mathrm{eV})$. The ratios of the intensities of the two peaks $\left(\mathrm{I}_{\mathrm{Si}} / \mathrm{I}_{\mathrm{S}}\right)$ are 7.58 at $80 \mathrm{~K}, 10.40$ at $100 \mathrm{~K}$ and 13.95 at 120 $\mathrm{K}$. The $\mathrm{S}$ peak intensity values are the lowest all the samples of this set and the $\mathrm{Si}$ peak intensity values are the second highest. Comparing the two samples 1/S12_B and $0 / \mathrm{S}_{2}{ }_{2} \mathrm{~B}$ it is apparent that the higher temperature anneal enhances the $\mathrm{S}$ emission. However, the Si EL peak intensity values are lower for the higher temperature anneal sample (1/S12_B) and at the low temperature regime (until 160 K).

The EL variable temperature measurement results from sample 1/S13_B (S implanted at $30 \mathrm{keV}$, at a dose $1 \times 10^{13} \mathrm{~S} \mathrm{~cm}^{-2}$, annealed at $1100^{\circ} \mathrm{C}$ for $10 \mathrm{~s}$ ) at $25 \mathrm{~mA}$ applied current are similar to the previous samples. The S peak is observed at 1367.5 $\mathrm{nm}(0.9067 \mathrm{eV})$ at $80 \mathrm{~K}$. The ratios of the intensities of the two peaks $\left(\mathrm{I}_{\mathrm{S}_{\mathrm{i}}} / \mathrm{I}_{\mathrm{S}}\right)$ are 4.56 at $80 \mathrm{~K}, 5.23$ at $100 \mathrm{~K}$ and 7.69 at $120 \mathrm{~K}$. Both S and Si peak intensity values are the third highest of this set of four samples. Also, the $\mathrm{S}$ and $\mathrm{Si}$ peak intensity values are higher for sample 1/S13_B than the ones of sample 0/S13_B $\left(1000{ }^{0} \mathrm{C}\right.$ temperature anneal). 
Finally, the variable temperature measurements from sample 1/S14_B (S implanted at $30 \mathrm{keV}$, at a dose $1 \times 10^{14} \mathrm{~S} \mathrm{~cm}^{-2}$, annealed at $1100{ }^{\circ} \mathrm{C}$ for $10 \mathrm{~s}$ ) at $25 \mathrm{~mA}$ applied current showed the $\mathrm{S}$ peak at $1363.25 \mathrm{~nm}(0.9095 \mathrm{eV})$ at $80 \mathrm{~K}$. The ratios of the intensities of the two peaks $\left(\mathrm{I}_{\mathrm{Si}} / \mathrm{I}_{\mathrm{S}}\right)$ are 4.14 at $80 \mathrm{~K}, 8.90$ at $100 \mathrm{~K}$ and 11.32 at $120 \mathrm{~K}$. The S peak intensity values are the second highest of this set of samples for temperatures up to $160 \mathrm{~K}$ and the Si peak intensity values are the highest of all of them up to $240 \mathrm{~K}$. Comparing with sample $0 / \mathrm{S} 14 \_\mathrm{B}$ (annealed at $1000{ }^{\circ} \mathrm{C}$ for $10 \mathrm{~s}$ ) it is concluded that the $S$ peak intensity values are higher for sample $1 / \mathrm{S} 14 \_B$ in contrast to the $\mathrm{Si}$ peak intensity values which are lower. The trends of the $\mathrm{S}$ and $\mathrm{Si}$ peak intensity for this set of samples are also depicted in Figure 5.32 ((b) and (d)), page 124.

In order to have a better understanding of the samples behaviour we have plotted the integrated intensity with the measurement temperature. For more precision, the graphs from Figures 5.24-5.27 were first transformed from EL intensity versus wavelength $(\mathrm{nm})$ to EL intensity versus energy (eV) graphs, using the formula $E(e V)=1240 / \lambda(n m)$ before integration, as it was also done in section 5.2.1 for the PL variable temperature measurements. 


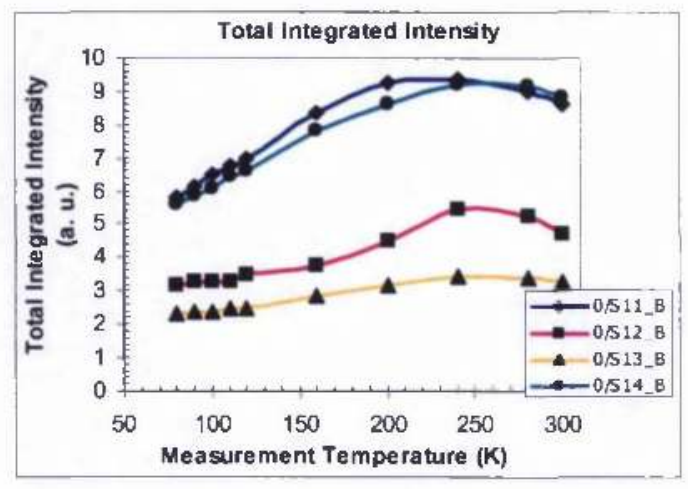

(a)

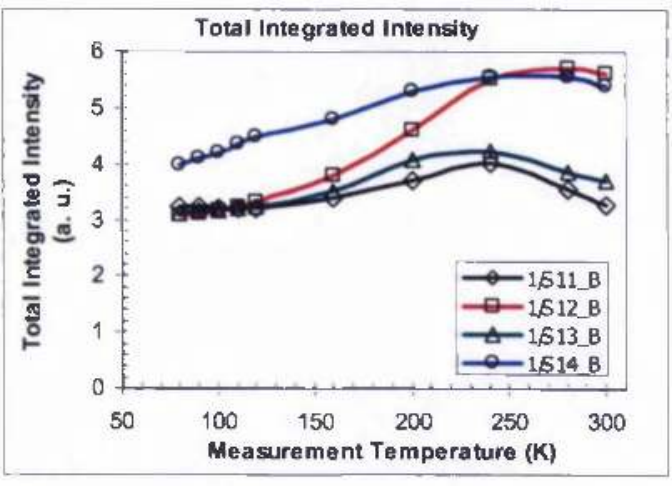

(b)

Figure 5.28 Temperature dependence of the total integrated intensity as taken from the EL spectra of samples (a) 0/S11_B, 0/S12_B, 0/S13 B, 0/S14 B, (implanted with sulphur at $10^{11}, 10^{12}, 10^{13}, 10^{14} \mathrm{~S} \mathrm{~cm}^{-2}$ at $30 \mathrm{keV}$, annealed at $1000^{\circ} \mathrm{C}$ for $10 \mathrm{sec}$, further implanted with boron at $10^{15} \mathrm{~B} \mathrm{~cm}^{-2}$ at $30 \mathrm{keV}$ and further annealed at $950{ }^{\circ} \mathrm{C}$ for $1 \mathrm{~min}$ ), and (b) $1 / \mathrm{S} 11 \mathrm{~B}$, 1/S12_B, 1/S13_B, 1/S14_B (implanted with sulphur at $10^{11}, 10^{12}, 10^{13}, 10^{14} \mathrm{~S} \mathrm{~cm}^{-2}$ at 30 $\mathrm{keV}$, annealed at $1100{ }^{\circ} \mathrm{C}$ for $10 \mathrm{sec}$, further implanted with boron at $10^{15} \mathrm{~B} \mathrm{~cm}^{-2}$ at $30 \mathrm{keV}$ and further annealed at $950{ }^{\circ} \mathrm{C}$ for $1 \mathrm{~min}$ ). EL experiments were done at $25 \mathrm{~mA}$ applied drive current. The errors in total integrated intensity and measurement temperature are within the symbol size.The solid lines are provided as a guide to the eye.

In Figure 5.28 ((a) and (b)) are shown the total integrated intensity with measurement temperature for all studied samples at $25 \mathrm{~mA}$ applied drive current. The total integrated intensity trend of the set of samples annealed at $1000{ }^{0} \mathrm{C}$ for $10 \mathrm{~s}$ (Figure $5.28(\mathrm{a})$ ), is increasing with the increase of temperature until $240 \mathrm{~K}$ and then is slightly decreasing up to $300 \mathrm{~K}$. In particular, sample 0/S11_B (S implanted at 30 $\mathrm{keV}$, at a dose of $1 \times 10^{11} \mathrm{~S} \mathrm{~cm}^{-2}$, annealed at $1000^{\circ} \mathrm{C}$ for $10 \mathrm{~s}, \mathrm{~B}$ implanted at $30 \mathrm{keV}$ at a dose of $10^{15} \mathrm{~cm}^{-2}$, annealed at $950^{\circ} \mathrm{C}$ for $1 \mathrm{~min}$ ) has the highest total integrated intensity from all samples and its trend, as mentioned, is increasing with the increase of measurement temperature up to $240 \mathrm{~K}$, further slightly decreasing up to $300 \mathrm{~K}$. The same trend applies to sample 0/S14_B (S implanted at a dose of $10^{14} \mathrm{~S} \mathrm{~cm}^{-2}$ at $30 \mathrm{keV}$, annealed at $1000{ }^{\circ} \mathrm{C}$ for $10 \mathrm{~s}, \mathrm{~B}$ implanted at a dose of $10^{15} \mathrm{~B} \mathrm{~cm}^{-2}$ and further annealed at $950{ }^{\circ} \mathrm{C}$ for 1 minute) which has slight lower total integrated intensity values than the previous sample up to $240 \mathrm{~K}$, but from then and up to $300 \mathrm{~K}$ reaches higher values than sample $0 / \mathrm{S} 11$ _B.

Sample 0/S12_B (S implanted at $30 \mathrm{keV}$, at a dose $1 \times 10^{12} \mathrm{~S} \mathrm{~cm}^{-2}$, annealed at $1000{ }^{\circ} \mathrm{C}$ for $10 \mathrm{~s}$ and $\mathrm{B}$ implanted as above) has lower total integrated intensity 
values than the two previous studied samples for all measurement temperatures. Its trend is approximately stable for low temperatures up to $120 \mathrm{~K}$, further increasing gently with the increase of temperature up to $240 \mathrm{~K}$. From $240 \mathrm{~K}-300 \mathrm{~K}$ the trend of the total integrated intensity is decreasing. A similar trend to the previous one is observed for sample 0/S13_B (S implanted at $30 \mathrm{keV}$, at a dose $1 \times 10^{13} \mathrm{~S} \mathrm{~cm}^{-2}$, annealed at $1000{ }^{\circ} \mathrm{C}$ for $10 \mathrm{~s}$ and $\mathrm{B}$ implanted as above). In this case the total integrated intensity trend is the lowest of all samples and is approximately stable for all temperatures. It is increasing slightly with temperature having a maximum at 240 K.

Sample 1/S14_B (S implanted at $30 \mathrm{keV}$, at a dose $1 \times 10^{14} \mathrm{~S} \mathrm{~cm}^{-2}$, annealed at $1100{ }^{\circ} \mathrm{C}$ for $10 \mathrm{~s}$ and $\mathrm{B}$ implanted as above) has the highest total integrated intensity trend of the samples of its set (Figure 5.28 (b)). The total integrated intensity increases with temperature up to $240 \mathrm{~K}$ and then decreases up to $300 \mathrm{~K}$. Sample 1/S11_B (S implanted at $30 \mathrm{keV}$, at a dose $1 \times 10^{11} \mathrm{~S} \mathrm{~cm}^{-2}$, annealed at $1100{ }^{\circ} \mathrm{C}$ for 10 $\mathrm{s}$ and $\mathrm{B}$ implanted as above) has a similar trend to sample 1/S14_B, has the second highest total integrated intensity values until $110 \mathrm{~K}$, then has the lowest values of all the samples of this set. Its trend is also increasing with the increase of the temperature up to $240 \mathrm{~K}$ then decreasing until $300 \mathrm{~K}$.

Sample 1/S13_B (S implanted at $30 \mathrm{keV}$, at a dose $1 \times 10^{13} \mathrm{~S} \mathrm{~cm}^{-2}$, annealed at $1100{ }^{\circ} \mathrm{C}$ for $10 \mathrm{~s}$ and $\mathrm{B}$ implanted as above) has a very similar total integrated intensity trend to the sample 1/S11_B. Its values are smaller than sample 1/S11_B up to $110 \mathrm{~K}$, then becoming higher than the latter up to $300 \mathrm{~K}$. Also, it has a maximum at $240 \mathrm{~K}$. Finally, sample $1 / \mathrm{S} 12 \_\mathrm{B}$ (S implanted at $30 \mathrm{keV}$, at a dose $1 \times 10^{12} \mathrm{~S} \mathrm{~cm}^{-2}$, annealed at $1100{ }^{\circ} \mathrm{C}$ for $10 \mathrm{~s}$ and $\mathrm{B}$ implanted as above) has the lowest total integrated intensity values from all the samples of this set up to $110 \mathrm{~K}$. Above $110 \mathrm{~K}$ its trend is increasing abruptly having the second highest values up to $240 \mathrm{~K}$, ending from $240 \mathrm{~K}$ up to $300 \mathrm{~K}$ with the highest total integrated intensity values of all samples of this set. The maximum of its trend is at $280 \mathrm{~K}$. 


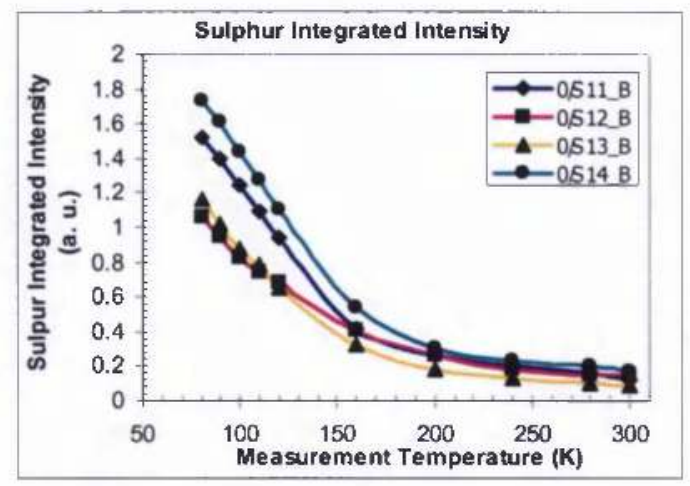

(a)

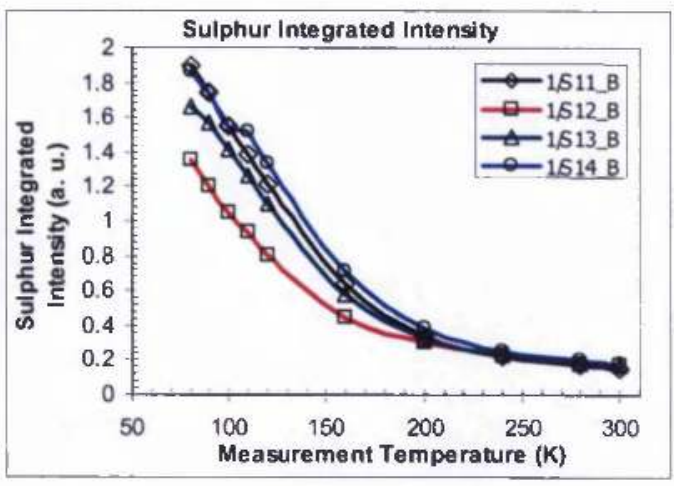

(b)

Figure 5.29 Temperature dependence of the sulphur integrated intensity as taken from the EL spectra of samples (a) 0/S11_B, 0/S12_B, 0/S13_B, 0/S14_B, (implanted with sulphur at $10^{11}, 10^{12}, 10^{13}, 10^{14} \mathrm{~S} \mathrm{~cm}^{-2}$ at $30 \mathrm{keV}$, annealed at $1000^{\circ} \mathrm{C}$ for $10 \mathrm{sec}$, further implanted with boron at $10^{15} \mathrm{~B} \mathrm{~cm}^{-2}$ at $30 \mathrm{keV}$ and further annealed at $950^{\circ} \mathrm{C}$ for $1 \mathrm{~min}$ ), and (b) $1 / \mathrm{S} 11$ B, 1/S12_B, 1/S13_B, 1/S14_B (implanted with sulphur at $10^{11}, 10^{12}, 10^{13}, 10^{14} \mathrm{~S} \mathrm{~cm}^{-2}$ at 30 $\mathrm{keV}$, annealed at $1100{ }^{\circ} \mathrm{C}$ for $10 \mathrm{sec}$, further implanted with boron at $10^{15} \mathrm{~B} \mathrm{~cm}^{-2}$ at $30 \mathrm{keV}$ and further annealed at $950^{\circ} \mathrm{C}$ for $1 \mathrm{~min}$ ). EL experiments were done at $25 \mathrm{~mA}$ applied drive current. The errors in sulphur integrated intensity and measurement temperature are within the symbol size. The solid lines are provided as a guide to the eye.

In Figure 5.29 are depicted the sulphur integrated intensity trends with the measurement temperature for all measured samples. A general comment is that for all of them the $S$ integrated intensity trend is decreasing with the increase of temperature. In detail, sample 0/S14_B (S implanted at a dose of $10^{14} \mathrm{~S} \mathrm{~cm}^{-2}$ at 30 $\mathrm{keV}$, annealed at $1000^{0} \mathrm{C}$ for $10 \mathrm{~s}, \mathrm{~B}$ implanted at a dose of $10^{15} \mathrm{~B} \mathrm{~cm}^{-2}$ and further annealed at $950{ }^{\circ} \mathrm{C}$ for 1 minute) has the highest $\mathrm{S}$ integrated intensity values of all samples of this set (see Figure 5.29 (a)). Its trend is decreasing fast with the increase of the temperature until $200 \mathrm{~K}$ and then up to $300 \mathrm{~K}$ it is decreasing slightly with the increase of the temperature. The $S$ integrated intensity of sample $0 / \mathrm{S} 11$ _B is very similar to the 0/S14_B having lower values than the latter one, for all the measured temperatures. Sample 0/S13_B also has a very similar trend with smaller S integrated intensity values than the two previous mentioned samples. Finally, sample 0/S12_B has the lowest $\mathrm{S}$ integrated intensity values up to $110 \mathrm{~K}$ from all the four samples. Its trend is decreasing with the increase of the measurement temperature but it is not so abrupt as for the other three samples. From $120 \mathrm{~K}-300 \mathrm{~K}$ sample $0 / \mathrm{S} 13$ _ B has the lowest $\mathrm{S}$ integrated intensity values. 
From the set of samples annealed at higher temperature $\left(1100{ }^{\circ} \mathrm{C}\right.$ for $\left.10 \mathrm{~s}\right)$, sample 1/S14_B (S implanted at $30 \mathrm{keV}$, at a dose $1 \times 10^{14} \mathrm{~S} \mathrm{~cm}^{-2}$, annealed at 1100 ${ }^{0} \mathrm{C}$ for $10 \mathrm{~s}$ and $\mathrm{B}$ implanted as above) has the highest sulphur integrated intensity trend of the samples from its set from $100 \mathrm{~K}-300 \mathrm{~K}$ (Figure 5.29 (b)). From $80 \mathrm{~K}-90$ $\mathrm{K}$ sample 1/S11_B has the highest $\mathrm{S}$ integrated intensity values from all samples and from $100 \mathrm{~K}-300 \mathrm{~K}$ its values are the second highest. The trend of sample 1/S11_B is similar to the sample 1/S14_B. Sample 1/S13_B has a very similar S integrated intensity trend to the two previous mentioned samples but with smaller values than them. Finally, sample 1/S12_B has the lowest total integrated intensity values from all the samples of this set. Its trend is very similar to the rest of the samples as its values of the $\mathrm{S}$ integrated intensity are decreasing with the increase of measurement temperature.

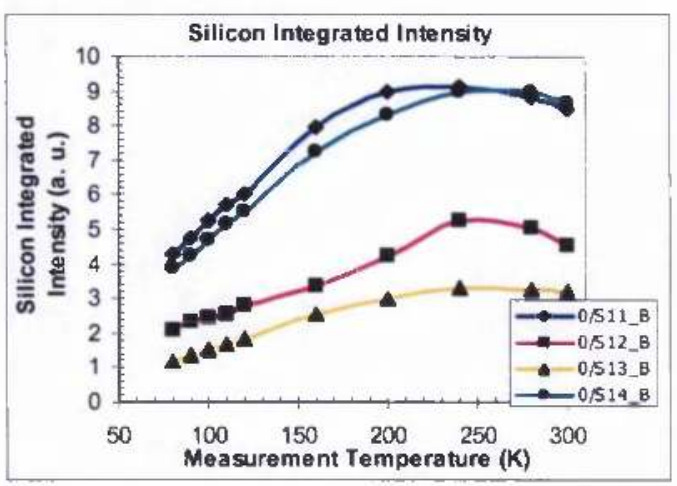

(a)

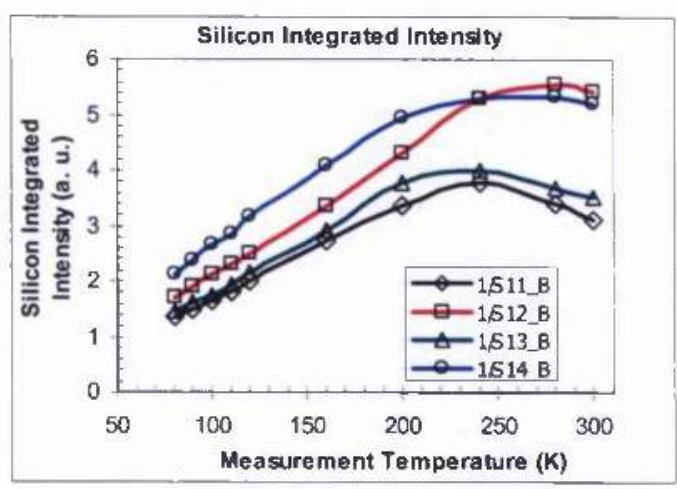

(b)

Figure 5.30 Temperature dependence of the silicon integrated intensity as taken from the EL spectra of samples (a) 0/S11_B, 0/S12_B, 0/S13_B, 0/S14_B, (implanted with sulphur at $10^{11}, 10^{12}, 10^{13}, 10^{14} \mathrm{~S} \mathrm{~cm}^{-2}$ at $30 \mathrm{keV}$, annealed at $1000^{\circ} \mathrm{C}$ for $10 \mathrm{sec}$, further implanted with boron at $10^{15} \mathrm{~B} \mathrm{~cm}^{-2}$ at $30 \mathrm{keV}$ and further annealed at $950{ }^{\circ} \mathrm{C}$ for $1 \mathrm{~min}$ ), and (b) $1 / \mathrm{S} 11 \mathrm{~B}$, 1/S12_B, 1/S13_B, 1/S14_B (implanted with sulphur at $10^{11}, 10^{12}, 10^{13}, 10^{14} \mathrm{~S} \mathrm{~cm}^{-2}$ at 30 $\mathrm{keV}$, annealed at $1100^{\circ} \mathrm{C}$ for $10 \mathrm{sec}$, further implanted with boron at $10^{15} \mathrm{~B} \mathrm{~cm}^{-2}$ at $30 \mathrm{keV}$ and further annealed at $950^{\circ} \mathrm{C}$ for $1 \mathrm{~min}$ ). EL experiments were done at $25 \mathrm{~mA}$ applied drive current. The errors in silicon integrated intensity and measurement temperature are within the symbol size. The solid lines are provided as a guide to the eye.

In Figure 5.30 is illustrated the silicon integrated intensity with the measurement temperature for all the measured samples. The trends are very similar to the total integrated intensity trends. Therefore, sample 0/S11_B (S implanted at 30 $\mathrm{keV}$, at a dose $1 \times 10^{11} \mathrm{~S} \mathrm{~cm}^{-2}$, annealed at $1000^{\circ} \mathrm{C}$ for $10 \mathrm{~s}$ and $\mathrm{B}$ implanted at a dose 
of $10^{15} \mathrm{~B} \mathrm{~cm}^{-2}$ and further annealed at $950{ }^{\circ} \mathrm{C}$ for 1 minute) has the highest $\mathrm{Si}$ integrated intensity values from all samples. Its trend is increasing with the increase of the measurement temperature up to $240 \mathrm{~K}$ and then is decreasing up to $300 \mathrm{~K}$ (Figure 5.30 (a)). The same trend applies to sample 0/S14_B which has slightly lower $\mathrm{Si}$ integrated intensity values than the previous sample up to $240 \mathrm{~K}$, then and up to $300 \mathrm{~K}$ is reaching higher values than sample $0 / \mathrm{S} 11$ B. Sample $0 / \mathrm{S} 12$ _B has lower $\mathrm{Si}$ integrated intensity than the two previous studied samples for all measurement temperatures. Its trend is changing less abruptly than the other two samples for low temperatures up to $120 \mathrm{~K}$, further increasing gently with the increase of temperature up to $240 \mathrm{~K}$. From $240 \mathrm{~K}-300 \mathrm{~K}$ the trend of the Si integrated intensity decreases. A similar trend to the previous one is observed for sample 0/S13_B. In this case the Si integrated intensity trend is the lowest of all samples and is not changing very much with the increase of the measurement temperature. It is increasing slightly with temperature having a maximum at $240 \mathrm{~K}$.

From the other set of samples, sample 1/S14_B (S implanted at $30 \mathrm{keV}$, at a dose $1 \times 10^{14} \mathrm{~S} \mathrm{~cm}^{-2}$, annealed at $1100{ }^{\circ} \mathrm{C}$ for $10 \mathrm{~s}$ and $\mathrm{B}$ implanted as above) has the highest total integrated intensity trend of the samples of its set (Figure 5.30 (b)). It is increasing with temperature until $240 \mathrm{~K}$ then decreasing up to $300 \mathrm{~K}$. Sample 1/S12_B has a similar trend to the sample 1/S14_B, having the second highest total integrated intensity values up to $240 \mathrm{~K}$ then having the highest values of all the samples of this set. Its trend is also increasing with the increase of the temperature up to $240 \mathrm{~K}$ then decreasing up to $300 \mathrm{~K}$. Sample $1 / \mathrm{S} 13$ _B has a very similar total integrated intensity trend to sample $1 / \mathrm{S} 14 \_\mathrm{B}$, but its values are smaller than sample 1/S14_B. Also, its trend has a maximum at $240 \mathrm{~K}$. Finally, sample 1/S11_B has the lowest total integrated intensity values from all the samples of this set. It has a very similar trend to sample 1/S13_B, increasing with the increase of temperature up to $240 \mathrm{~K}$ and then slowly decreasing up to $300 \mathrm{~K}$. 


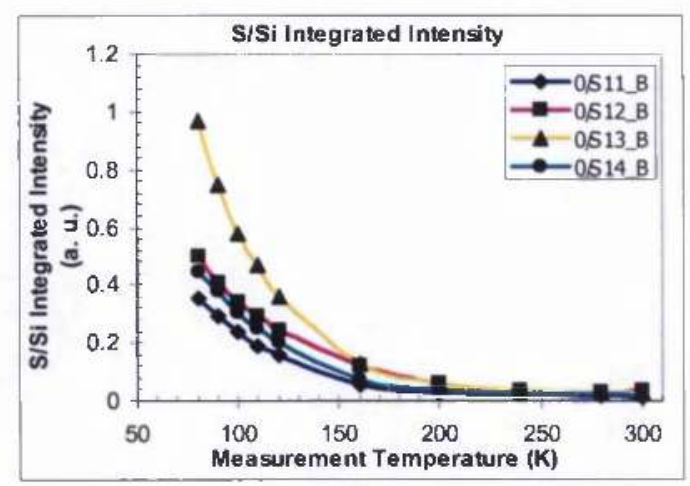

(a)

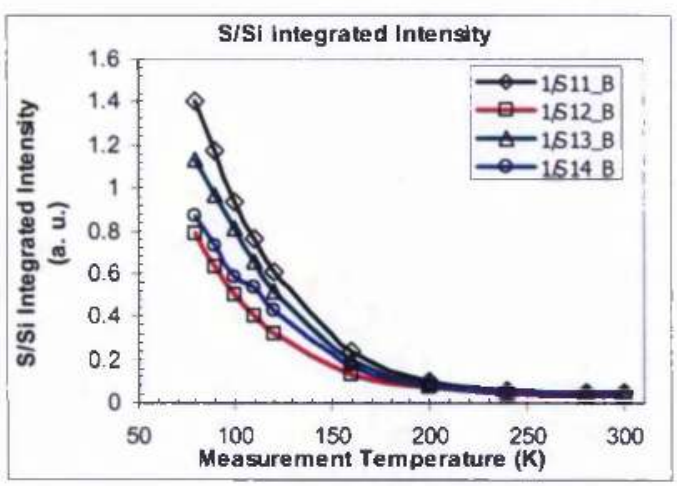

(b)

Figure 5.31 Temperature dependence of the sulphur divided by the silicon $(\mathrm{S} / \mathrm{Si})$ integrated intensity as taken from the EL spectra of samples (a) $0 / \mathrm{S} 11$ B, $0 / \mathrm{S} 12$ B, $0 / \mathrm{S} 13$ B, $0 / \mathrm{S} 14$ B, (implanted with sulphur at $10^{11}, 10^{12}, 10^{13}, 10^{14} \mathrm{~S} \mathrm{~cm}^{-2}$ at $30 \mathrm{keV}$, annealed at $1000^{\circ} \mathrm{C}$ for 10 sec, further implanted with boron at $10^{15} \mathrm{~B} \mathrm{~cm}^{-2}$ at $30 \mathrm{keV}$ and further annealed at $950{ }^{\circ} \mathrm{C}$ for $1 \mathrm{~min}$ ), and (b) $1 / \mathrm{S} 11$ B, $1 / \mathrm{S} 12 \_\mathrm{B}, 1 / \mathrm{S} 13$ B, 1/S14_B (implanted with sulphur at $10^{11}, 10^{12}$, $10^{13}, 10^{14} \mathrm{~S} \mathrm{~cm}^{-2}$ at $30 \mathrm{keV}$, annealed at $1100{ }^{\circ} \mathrm{C}$ for $10 \mathrm{sec}$, further implanted with boron at $10^{15} \mathrm{~B} \mathrm{~cm}^{-2}$ at $30 \mathrm{keV}$ and further annealed at $950{ }^{\circ} \mathrm{C}$ for $1 \mathrm{~min}$ ). EL experiments were done at $25 \mathrm{~mA}$ applied drive current. The errors in $\mathrm{Si}, \mathrm{S}$ integrated intensity and measurement temperature are within the symbol size. The solid lines are provided as a guide to the eye.

In Figure 5.31 is shown the sulphur divided by the silicon ( $\mathrm{S} / \mathrm{Si}$ ) integrated intensity trends with the measurement temperature for all the samples. A general comment about the $\mathrm{S} / \mathrm{Si}$ integrated intensity trends is that they are decreasing with the increase of the temperature. In addition, from Figure 5.31 (a) it is observed that for all samples of this set, the $\mathrm{S} / \mathrm{Si}$ integrated intensity values are less than 1 for all measured temperatures. This is because the $\mathrm{S}$ values are smaller than the $\mathrm{Si}$ integrated intensity ones. Sample 0/S13_B (S implanted at $30 \mathrm{keV}$, at a dose $1 \times 10^{13}$ $\mathrm{S} \mathrm{cm}^{-2}$, annealed at $1000{ }^{\circ} \mathrm{C}$ for $10 \mathrm{~s}$ and $\mathrm{B}$ implanted at a dose of $10^{15} \mathrm{~B} \mathrm{~cm}^{-2}$ and further annealed at $950^{\circ} \mathrm{C}$ for 1 minute) has the highest $\mathrm{S} / \mathrm{Si}$ integrated intensity values for all the measurement temperatures for all the samples of this set. From Figure 5.31 (b) is concluded that the $\mathrm{S} / \mathrm{Si}$ integrated intensity values are in general higher for this set of samples. Also these values are above 1 for samples $1 / \mathrm{S} 11$ B and 1/S13_B in the low temperature regime $(80 \mathrm{~K}$ and $90 \mathrm{~K})$. The trends of this set of samples are similar to the previous set with the lower annealed samples (Figure 5.31 (a)), starting with higher values than the previous set, also decreasing with the increase of measurement temperature. 


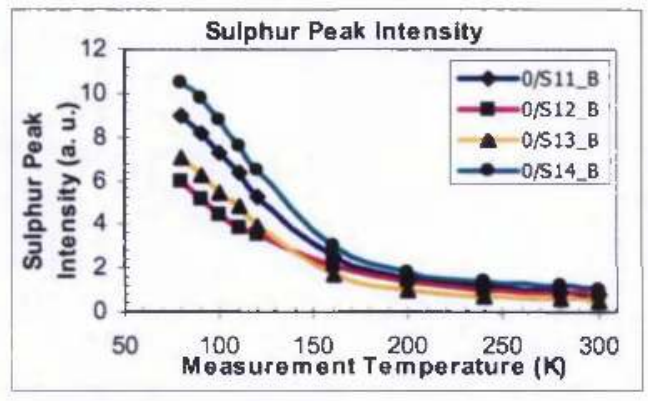

(a)

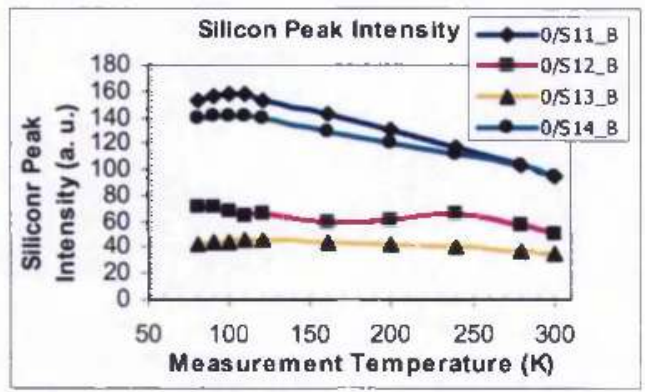

(c)

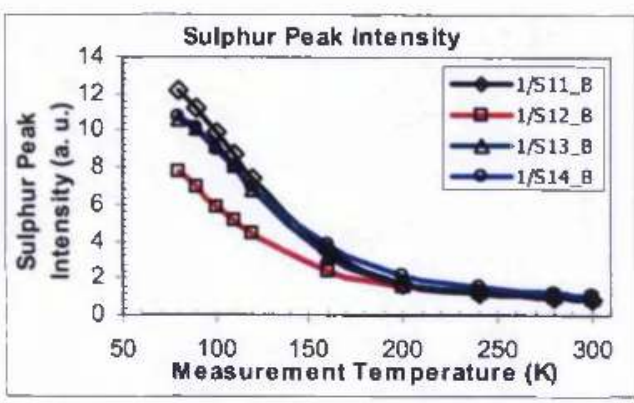

(b)

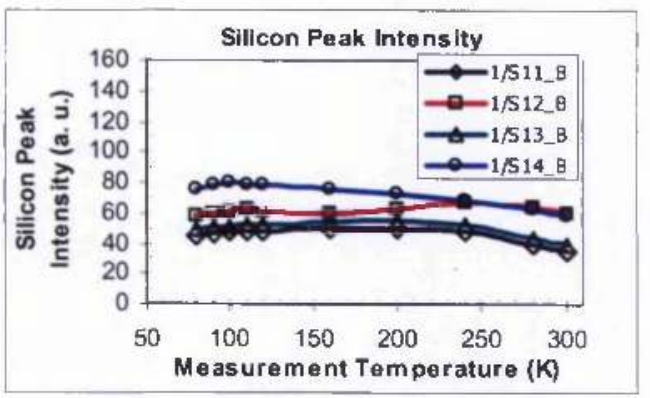

(d)

Figure 5.32 Temperature dependence of the sulphur and silicon peak intensity as taken from the EL spectra of samples (a), (c) $0 / \mathrm{S} 11$ B, 0/S12 B, 0/S13 B, 0/S14 B, (implanted with sulphur at $10^{11}, 10^{12}, 10^{13}, 10^{14} \mathrm{~S} \mathrm{~cm}^{-2}$ at $30 \mathrm{keV}$, annealed at $1000^{0} \mathrm{C}$ for $10 \mathrm{sec}$, further implanted with boron at $10^{15} \mathrm{~B} \mathrm{~cm}^{-2}$ at $30 \mathrm{keV}$ and further annealed at $950{ }^{\circ} \mathrm{C}$ for $1 \mathrm{~min}$ ) and (b), (d) 1/S11_B, 1/S12_B, 1/S13_B, 1/S14_B (implanted with sulphur at $10^{11}, 10^{12}, 10^{13}$, $10^{14} \mathrm{~S} \mathrm{~cm}^{-2}$ at $30 \mathrm{keV}$, annealed at $1100{ }^{\circ} \mathrm{C}$ for $10 \mathrm{sec}$, further implanted with boron at $10^{15} \mathrm{~B}$ $\mathrm{cm}^{-2}$ at $30 \mathrm{keV}$ and further annealed at $950{ }^{\circ} \mathrm{C}$ for $1 \mathrm{~min}$ ). EL experiments were done at 25 $\mathrm{mA}$ applied drive current. The errors in sulphur and silicon peak intensity and measurement temperature are within the symbol size. The solid lines are provided as a guide to the eye.

In Figure $5.32((\mathrm{a})-(\mathrm{d}))$ is illustrated the sulphur and silicon peak intensity with the measurement temperature for all measured samples. A general comment about the sulphur peak intensity trends is that they are decreasing with the increase of temperature, as was also observed from Figures 5.25-5.27. Sample 0/S14_B has the highest S peak intensity values for all measurement temperatures (Figure 5.32 (a)) which are decreasing with the increase of the measurement temperature. Sample 0/S11_B has the same trend but with smaller peak intensity values than the previous sample. Sample 0/S13_B has lower peak intensity values than the two previous samples up to $120 \mathrm{~K}$ then having the lowest values of all samples of this set up to $300 \mathrm{~K}$. Sample $0 / \mathrm{S} 12$ B has the lowest peak intensity values up to $120 \mathrm{~K}$, then having the third highest values for this set. Sample 1/S11_B (Figure 5.32 (b)) has the 
highest S peak intensity values of all samples of its set up to $120 \mathrm{~K}$, then having the lowest values up to $300 \mathrm{~K}$. Its trend is decreasing with the increase of measurement temperature. Samples 1/S13_B and 1/S14_B have very similar peak intensity values and trends and finally, sample $1 / \mathrm{S} 12$ _B has the lowest values up to $200 \mathrm{~K}$. From $240 \mathrm{~K}-300 \mathrm{~K}$ the decrease in its peak intensity values is smaller than the samples 1/S11_B and 1/S13_B therefore it has the second highest values for this temperature regime.

In Figure 5.32 ((c) and (d)) are depicted the silicon peak intensity trends. Samples 0/S11_B and 0/S14_B have very similar Si peak intensity trends which are increasing with the increase of temperature up to $100 \mathrm{~K}$ and $110 \mathrm{~K}$, respectively, then further decreasing up to $300 \mathrm{~K}$. Sample 0/S11_B has the highest values. The Si peak intensity trends of samples $0 / \mathrm{S} 12 \_\mathrm{B}$ and $0 / \mathrm{S} 13$ _B are not changing very much with temperature, especially for sample 0/S13_B which has the lowest values. Sample 1/S14_B has the highest Si peak intensity values of all samples of this set (Figure 5.32 (d)). Its trend is increasing up to $120 \mathrm{~K}$, then slightly decreasing up to $300 \mathrm{~K}$. Sample's 1/S12_B trend is slightly increasing up to $110 \mathrm{~K}$, further slowly decreasing and then again slightly increasing at $240 \mathrm{~K}$ and finally decreasing up to $300 \mathrm{~K}$. Samples 1/S13_B and 1/S11_B have very similar silicon peak intensity trends to sample 1/S14_B. Their silicon peak intensity values are changing very slowly with the increase of measurement temperature both having a maximum at $200 \mathrm{~K}$. Sample 1/S14_B has the lowest values than all the samples of this set. 


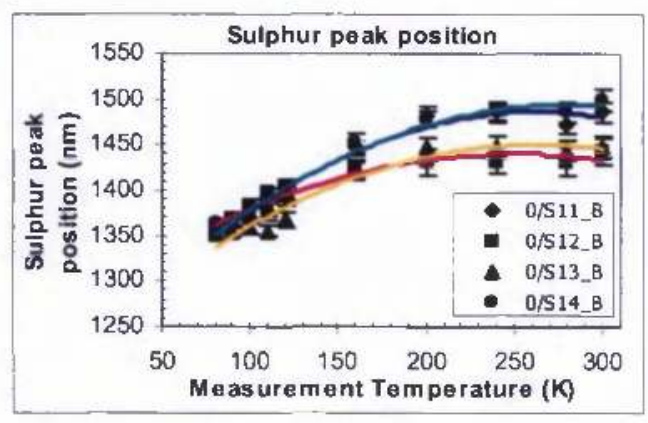

(a)

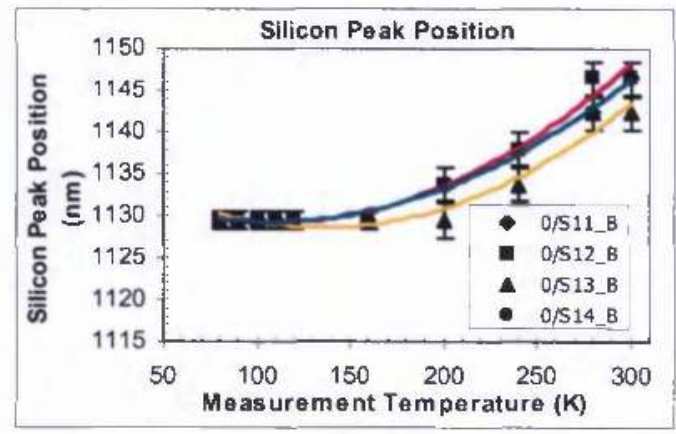

(c)

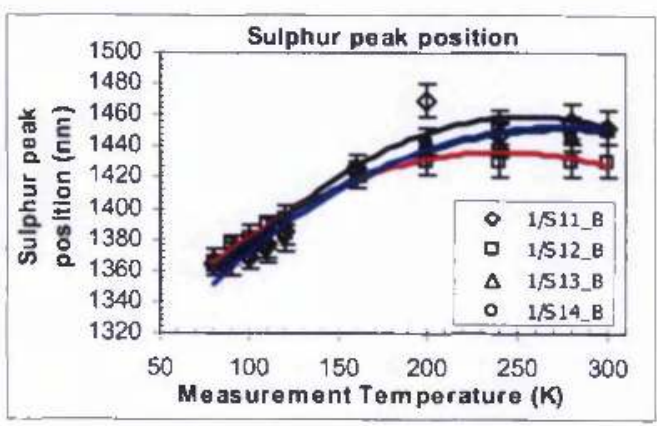

(b)

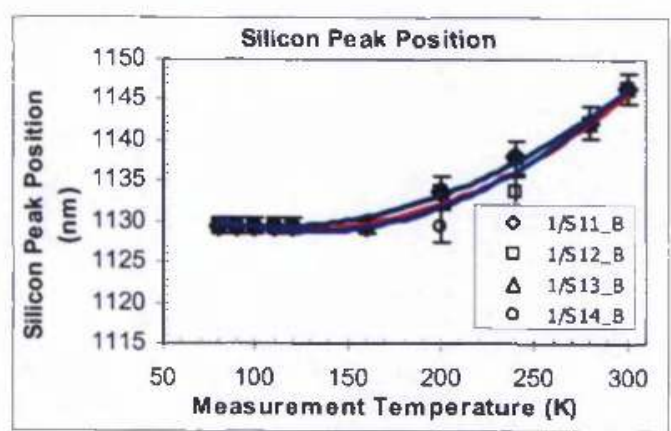

(d)

Figure 5.33 Temperature dependence of the sulphur and silicon peak intensity as taken from the EL spectra of samples (a), (c) 0/S11_B, 0/S12_B, 0/S13 B, 0/S14_B, (implanted with sulphur at $10^{11}, 10^{12}, 10^{13}, 10^{14} \mathrm{~S} \mathrm{~cm}^{-2}$ at $30 \mathrm{keV}$, annealed at $1000{ }^{0} \mathrm{C}$ for $10 \mathrm{sec}$, further implanted with boron at $10^{15} \mathrm{~B} \mathrm{~cm}^{-2}$ at $30 \mathrm{keV}$ and further annealed at $950{ }^{\circ} \mathrm{C}$ for $1 \mathrm{~min}$ ), and (b), (d) 1/S11_B, 1/S12_B, 1/S13_B, 1/S14_B (implanted with sulphur at $10^{11}, 10^{12}, 10^{13}$, $10^{14} \mathrm{~S} \mathrm{~cm}^{-2}$ at $30 \mathrm{keV}$, annealed at $1100^{\circ} \mathrm{C}$ for $10 \mathrm{sec}$, further implanted with boron at $10^{15} \mathrm{~B}$ $\mathrm{cm}^{-2}$ at $30 \mathrm{keV}$ and further annealed at $950^{\circ} \mathrm{C}$ for $1 \mathrm{~min}$ ). EL experiments were done at 25 $\mathrm{mA}$ applied drive current. A best fit of values for each sample has been provided for a better presentation of data. The errors in sulphur and silicon peak position are indicated in the plots ranging from $2 \mathrm{~nm}$ to $4 \mathrm{~nm}$ for the Si peak position and from $8 \mathrm{~nm}$ to $20 \mathrm{~nm}$ for the S peak position with the increase of temperature. The solid lines are provided as a guide to the eye.

Figure 5.33 ((a)-(d)) depicts the change of sulphur and silicon peak position with the measurement temperature for all measured samples. A general comment coming from Figure 5.33 ((a) and (b)) is that the S peak position is shifting towards longer wavelengths with the increase of temperature. This shift is quite fast towards the longer wavelengths with the increase of temperature, especially at the low regime temperature. The $S$ peak position is observed at $1363.25 \mathrm{~nm}(0.9095 \mathrm{eV})$ for most of the samples at $80 \mathrm{~K}$ shifting towards to $1452.5 \mathrm{~nm}(0.8536 \mathrm{eV})$ at $300 \mathrm{~K}$. In Figure $5.33((\mathrm{c})$ and $(\mathrm{d}))$ the Si peak intensity is observed at $1129.5 \mathrm{~nm}(1.0977 \mathrm{eV})$ shifting 
towards $1146.5 \mathrm{~nm}(1.0814 \mathrm{eV})$ at $300 \mathrm{~K}$. The shift towards longer wavelengths in this case is much slower and moves fastest at higher temperatures.

In the following part of this section will be presented the dose dependence of the total, sulphur and silicon integrated intensity values at $80 \mathrm{~K}$ for the two annealing temperatures (Figures 5.34 and 5.35). In Figure 5.34 (a) it is observed that for the $1000{ }^{\circ} \mathrm{C} / 10 \mathrm{sec}$ annealing treatment, the total integrated intensity trend is decreasing with the increase of $\mathrm{S}$ dose, having a minimum at the $10^{13} \mathrm{~S} \mathrm{~cm}^{-2}$ dose (sample $0 / \mathrm{S} 13 \_\mathrm{B}$ ) and then is further increasing at the highest dose, $10^{14} \mathrm{~S} \mathrm{~cm}^{-2}$ (sample 0/S14_B). Similar behaviour but not so pronounced is observed for the $1100{ }^{\circ} \mathrm{C} / 10$ sec annealing treatment; the total integrated intensity trend has its lowest value at the $10^{12} \mathrm{~S} \mathrm{~cm}^{-2}$ dose (sample 1/S12_B), slightly increasing towards the highest dose. The shapes of the sulphur integrated intensity trends for both annealing treatments are very similar (Figure 5.34 (b)). They have a minimum value at the $10^{12} \mathrm{~S} \mathrm{~cm}^{-2}$ dose (samples 0/S12_B and 1/S12_B) further increasing towards the higher dose. In addition, the higher temperature annealed samples $\left(1100^{\circ} \mathrm{C} / 10 \mathrm{sec}\right)$ have higher sulphur integrated intensity values. Finally in Figure 5.34 (c) is shown the change of the silicon integrated intensity trends with the $\mathrm{S}$ dose. For the $1000{ }^{0} \mathrm{C} / 10 \mathrm{sec}$ annealing treatment, the trend is very similar to the total integrated intensity one. Therefore, the Si integrated intensity trend is decreasing with the increase of the $\mathrm{S}$ dose having a minimum at the $10^{13} \mathrm{~S} \mathrm{~cm}^{-2}$ dose (sample $0 / \mathrm{S} 13 \ldots \mathrm{B}$ ), further increasing at the highest dose $10^{14} \mathrm{~S} \mathrm{~cm}^{-2}$ (sample 0/S14_B). At the $1100^{\circ} \mathrm{C} / 10 \mathrm{sec}$ annealing treatment, the silicon integrated intensity trend is also similar to the total one; it is approximately independent of the $\mathrm{S}$ dose. The trend has a shallow minimum and a maximum at the $10^{12}$ and $10^{13} \mathrm{~S} \mathrm{~cm}^{-2}$ doses, respectively (samples $1 / \mathrm{S} 12 \_\mathrm{B}$ and 1/S13_B). 


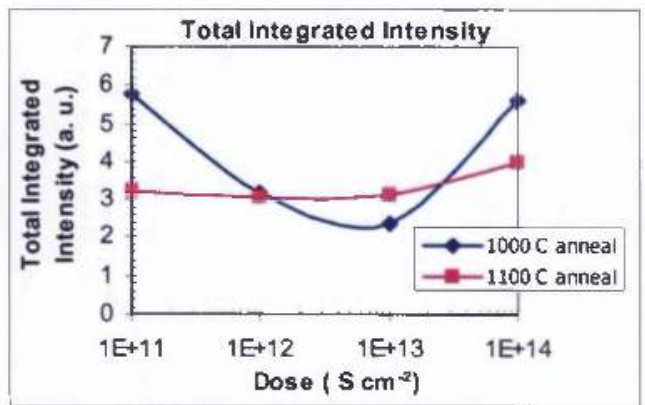

(a)

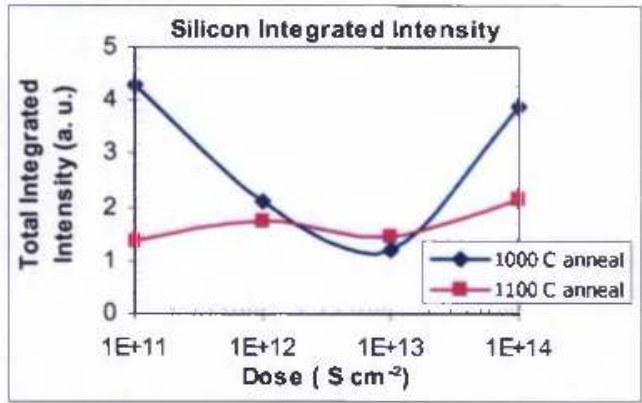

(c)

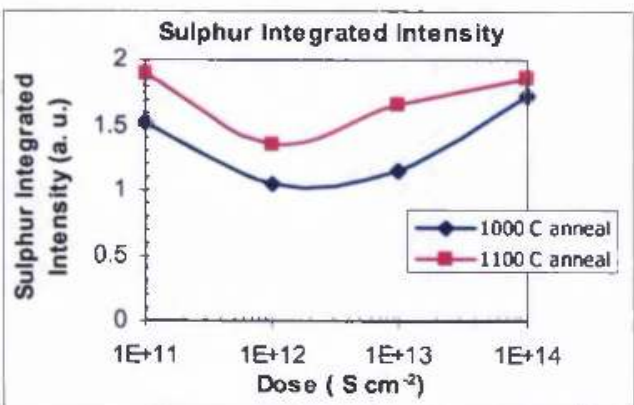

(b)

Figure 5.34 Sulphur dose dependence of the total, sulphur and silicon integrated intensity ((a), (b) and (c), respectively), as taken from the EL spectra of samples $0 / \mathrm{S} 11$ B, 0/S12_B, 0/S13_B, 0/S14_B, (implanted with sulphur at $10^{11}, 10^{12}, 10^{13}, 10^{14} \mathrm{~S}^{-5}$ at $30 \mathrm{keV}$, annealed at $1000^{\circ} \mathrm{C}$ for $10 \mathrm{sec}$, further implanted with boron at $10^{15} \mathrm{~B} \mathrm{~cm}^{-2}$ at $30 \mathrm{keV}$ and further annealed at $950{ }^{\circ} \mathrm{C}$ for $1 \mathrm{~min}$ ), and $1 / \mathrm{S} 11 \_\mathrm{B}, 1 / \mathrm{S} 12$ B $, 1 / \mathrm{S} 13 \_\mathrm{B}, 1 / \mathrm{S} 14$ B (implanted with sulphur at $10^{11}, 10^{12}, 10^{13}, 10^{14} \mathrm{~S} \mathrm{~cm}^{-2}$ at $30 \mathrm{keV}$, annealed at $1100^{0} \mathrm{C}$ for $10 \mathrm{sec}$, further implanted with boron at $10^{15} \mathrm{~B} \mathrm{~cm}^{-2}$ at $30 \mathrm{keV}$ and further annealed at $950{ }^{\circ} \mathrm{C}$ for $1 \mathrm{~min}$ ), at $80 \mathrm{~K}$. EL experiments were done at $25 \mathrm{~mA}$ applied drive current. The errors in total, $\mathrm{S}$ and $\mathrm{Si}$ integrated intensities are within the symbol size. The solid lines are provided as a guide to the eye.

Finally, in Figure 5.35 ((a) and (b)) are depicted the dose dependence of the total, sulphur and silicon integrated intensity at the two annealing conditions, at 80 K. Therefore, in Figure 5.35 (a) the three trends are plotted as a function of the sulphur dose at $80 \mathrm{~K}$, for the $1000^{\circ} \mathrm{C} / 10 \mathrm{sec}$ anneal. The $\mathrm{S}$ integrated intensity trend is not changing much with the increase of the $\mathrm{S}$ dose. It has a minimum value at the $10^{12} \mathrm{~S} \mathrm{~cm}^{-2}$ dose (sample $0 / \mathrm{S} 12$ B). The Si integrated intensity trend is changing more with the $\mathrm{S}$ dose having a deeper minimum at the $10^{13} \mathrm{~S} \mathrm{~cm}^{-2}$ (sample $0 / \mathrm{S} 13$ B). Also it has higher values than the $\mathrm{S}$ integrated intensity trend. The total integrated intensity trend is mainly influenced by the $\mathrm{Si}$ one, so it has a similar trend as the $\mathrm{Si}$ one. Also, a minimum value at the $10^{13} \mathrm{~S} \mathrm{~cm}^{-2}$ is also present. In Figure 5.35 (b) are 
plotted the same three trends for the $1100^{\circ} \mathrm{C} / 10 \mathrm{sec}$ anneal. Both sulphur and silicon integrated intensity trends are changing slightly with the $\mathrm{S}$ dose. The $\mathrm{S}$ integrated intensity trend has a minimum and a maximum at the $10^{i 2}$ and $10^{13} \mathrm{~S} \mathrm{~cm}^{-2}$, respectively, whereas the $\mathrm{Si}$ integrated intensity trend has a maximum and a minimum at these doses. The total integrated intensity trend, which is the sum of the two trends ( $\mathrm{S}$ and $\mathrm{Si}$ ), is also changing slowly with the increase of the $\mathrm{S}$ dose, having a small minimum at the $10^{13} \mathrm{~S} \mathrm{~cm}^{-2}$.

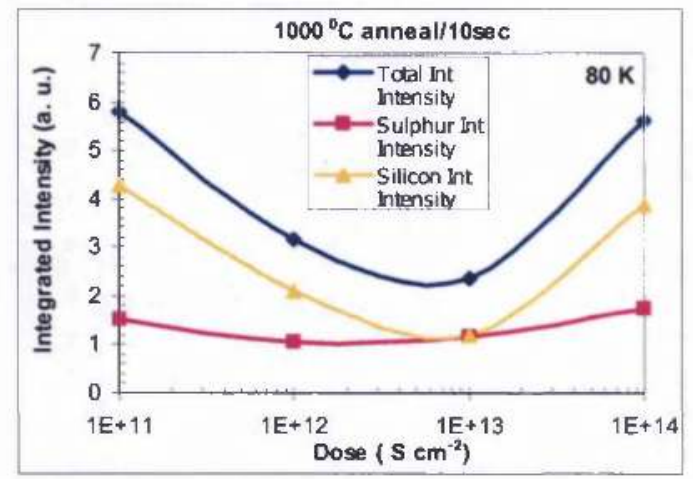

(a)

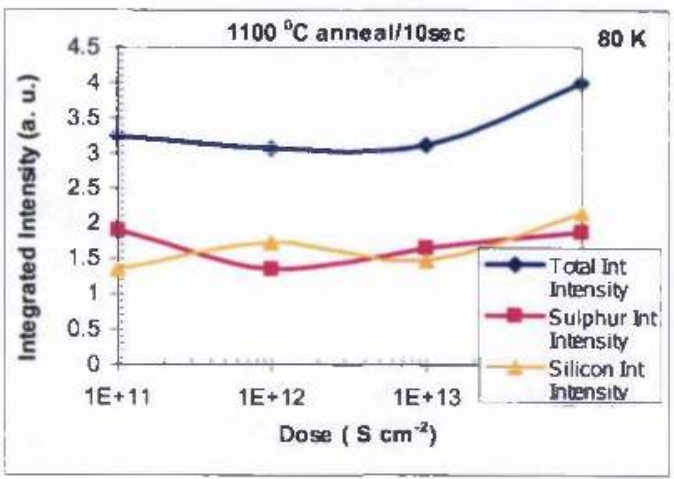

(b)

Figure 5.35 Sulphur dose dependence of the total, sulphur and silicon integrated intensity for the two different annealing conditions $1000{ }^{\circ} \mathrm{C} / 10 \sec (\mathrm{a})$ and $1100{ }^{\circ} \mathrm{C} / 10 \mathrm{sec}$ (b) at $80 \mathrm{~K}$, as taken from the EL spectra of samples 0/S11_B, 0/S12_B, 0/S13_B, 0/S14_B, (implanted with sulphur at $10^{11}, 10^{12}, 10^{13}, 10^{14} \mathrm{~S} \mathrm{~cm}^{-2}$ at $30 \mathrm{keV}$, annealed at $1000^{\circ} \mathrm{C}$ for $10 \mathrm{sec}$, further implanted with boron at $10^{15} \mathrm{~B} \mathrm{~cm}^{-2}$ at $30 \mathrm{keV}$ and further annealed at $950{ }^{\circ} \mathrm{C}$ for $1 \mathrm{~min}$ ), and 1/S11_B, 1/S12_B, 1/S13_B, 1/S14_B (implanted with sulphur at $10^{11}, 10^{12}, 10^{13}, 10^{14} \mathrm{~S} \mathrm{~cm}^{-2}$ at $30 \overline{\mathrm{keV}}$, annealed at $11 \overline{00}{ }^{11} \mathrm{C}$ for $\overline{10} \mathrm{sec}$, further implanted with boron at $10^{15} \mathrm{~B} \mathrm{~cm}^{-2}$ at 30 $\mathrm{keV}$ and further annealed at $950^{\circ} \mathrm{C}$ for $1 \mathrm{~min}$ ). EL experiments were done at $25 \mathrm{~mA}$ applied drive current. The errors in total, $\mathrm{S}$ and $\mathrm{Si}$ integrated intensities are within the symbol size. The solid lines are provided as a guide to the eye.

In conclusion, in this section variable temperature experiments were done for the eight samples 0/S11_B-0/S14_B (implanted with S at $10^{11}-10^{14} \mathrm{~S} \mathrm{~cm}^{-2}$ at $30 \mathrm{keV}$, annealed at $1000{ }^{0} \mathrm{C}$ for $10 \mathrm{sec}$, further implanted with $\mathrm{B}$ at $10^{15} \mathrm{~B} \mathrm{~cm}$ at $30 \mathrm{keV}$, further annealed at $950{ }^{\circ} \mathrm{C}$ for $1 \mathrm{~min}$ ) and $1 / \mathrm{S} 11$ B-1/S14_B (implanted with $\mathrm{S}$ at $10^{11}-10^{14} \mathrm{~S} \mathrm{~cm}^{-2}$ at $30 \mathrm{keV}$, annealed at $1100^{\circ} \mathrm{C}$ for $10 \mathrm{sec}$, further implanted with B at $10^{15} \mathrm{~B} \mathrm{~cm}^{-2}$ at $30 \mathrm{keV}$, further annealed at $950{ }^{\circ} \mathrm{C}$ for $1 \mathrm{~min}$ ) at $25 \mathrm{~mA}$ applied drive current. We observed two main peaks due to $\mathrm{Si}$ and $\mathrm{S}$ at $1129.5 \mathrm{~nm}(1.0997$ $\mathrm{eV})$ and $1363.25 \mathrm{~nm}(0.9095 \mathrm{eV})$, respectively, shifting towards longer wavelengths 
(lower energies) with the increase of temperature. The $\mathrm{S}$ integrated intensity trend is decreasing with the increase of the measurement temperature for all samples and the decrease is fastest at low temperatures. In contrast, the $\mathrm{Si}$ integrated intensity trend is increasing with the increase of measurement temperature up to $240 \mathrm{~K}$ for most of the samples, further slowly decreasing up to $300 \mathrm{~K}$. The total integrated intensity trend, which is the sum of the $\mathrm{S}$ and $\mathrm{Si}$ integrated intensities is increasing but at a slower rate than the $\mathrm{Si}$ trend with the increase of measurement temperature up to $240 \mathrm{~K}$, then slowly decreasing up to $300 \mathrm{~K}$. The total integrated intensity trend is influenced mainly by the Si one because it has the higher values.

In addition, the sulphur integrated intensity trend is changing slowly with the increase of the $\mathrm{S}$ dose for both annealing conditions $\left(1000{ }^{\circ} \mathrm{C} / 10 \mathrm{sec}\right.$ or $1100{ }^{\circ} \mathrm{C} / 10$ $\mathrm{sec}$ ). In detail, the trends are slowly decreasing with the increase of the $\mathrm{S}$ dose having a minimum at the $10^{12} \mathrm{~S} \mathrm{~cm}^{-2}$. The values of the $1100^{\circ} \mathrm{C} / 10 \mathrm{sec}$ are higher than the $1000{ }^{\circ} \mathrm{C} / 10 \mathrm{sec}$ ones. The silicon integrated intensity trend is having a similar trend to the sulphur one for the $1000{ }^{\circ} \mathrm{C} / 10 \mathrm{sec}$ anneal, decreasing with the increase of the $\mathrm{S}$ dose having a minimum at the $10^{13} \mathrm{~S} \mathrm{~cm}^{-2}$ dose, further increasing towards the higher dose $\left(10^{14} \mathrm{~S} \mathrm{~cm}^{-2}\right)$. The Si integrated intensity trend at the $1100{ }^{\circ} \mathrm{C} / 10 \mathrm{sec}$ annealed samples appears to be dose independent since the trend is not changing very much with the dose increase. It has a shallow minimum and a maximum at the $10^{12} \mathrm{~S}$ $\mathrm{cm}^{-2}$ and $10^{13} \mathrm{~S} \mathrm{~cm}^{-2}$ doses, respectively. Finally, the total integrated intensity trend, which is the sum of the two trends ( $\mathrm{S}$ and $\mathrm{Si}$ ), is similar to the $\mathrm{Si}$ one because it has higher values than the $\mathrm{S}$ one. Therefore, for the $1000{ }^{\circ} \mathrm{C} / 10 \mathrm{~s}$ anneal the total integrated intensity trend is decreasing with the $\mathrm{S}$ dose increase having a minimum at the $10^{13} \mathrm{~S} \mathrm{~cm}^{-2}$ dose further increasing to the higher dose. At the $1100{ }^{\circ} \mathrm{C} / 10 \mathrm{sec}$ anneal the total integrated intensity trend is approximately independent of the $\mathrm{S}$ dose having a small minimum at the $10^{12} \mathrm{~S} \mathrm{~cm}^{-2}$ dose, very slightly increasing towards the higher dose. 


\subsubsection{EL variable current measurements}

In the previous section we have studied the effect of temperature in $\mathrm{S}, \mathrm{Si}$ and total integrated intensity at the two annealing conditions $\left(1000{ }^{\circ} \mathrm{C} / 10 \mathrm{sec}\right.$ and 1100 ${ }^{0} \mathrm{C} / 10 \mathrm{sec}$ ). Given the nonlinear laser power dependence previously observed and reported (section 5.2.2) on the PL we here investigate the EL dependence on electrical injection. The effect of the current is reported on this section. In Figures 5.36-5.43 are illustrated the results of the variable applied current measurements for each one of the eight samples studied, at $80 \mathrm{~K}$. In detail, in Figure 5.36 (a) is illustrated the current dependence of the $\mathrm{Si}, \mathrm{S}$ and total integrated intensity trends for sample 0/S11_B (implanted with $\mathrm{S}$ at $10^{11} \mathrm{~S} \mathrm{~cm}^{-2}$ at $30 \mathrm{keV}$, annealed at $1000{ }^{\circ} \mathrm{C}$ for $10 \mathrm{sec}$, further implanted with $\mathrm{B}$ at $10^{15} \mathrm{~B} \mathrm{~cm}^{-2}$ at $30 \mathrm{keV}$, further annealed at $950{ }^{\circ} \mathrm{C}$ for $1 \mathrm{~min}$ ) at $80 \mathrm{~K}$. It is observed that the $\mathrm{S}$ integrated intensity trend is sublinear, increasing fast at the low current regime, further increasing very slowly with the increase of the applied current. The $\mathrm{Si}$ integrated intensity trend though is superlinear, increasing slower at the low current regime than the $S$ one, further increasing much faster with the increase of the applied current. This behaviour can be seen more clearly at the low current regime in Figure 5.36 (b). The total integrated intensity trend is following mainly the $\mathrm{Si}$ integrated intensity trend because the latter one has higher values than the $\mathrm{S}$ trend. In Figure 5.36 (c) are illustrated the $\mathrm{Si}, \mathrm{S}$ and total integrated intensities trends on a log-log scale. 


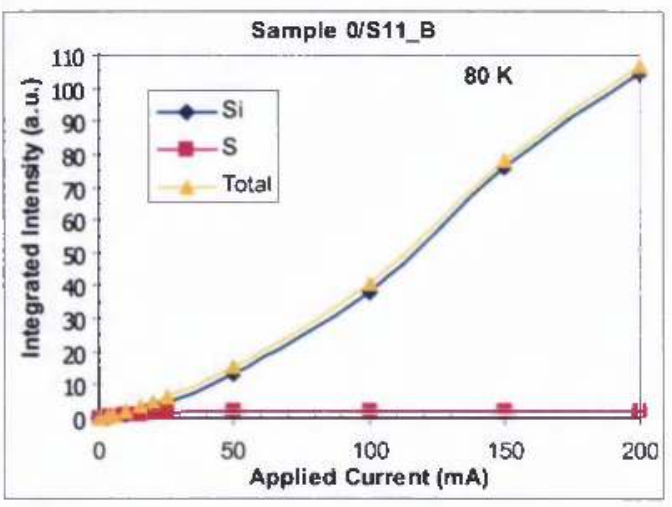

(a)

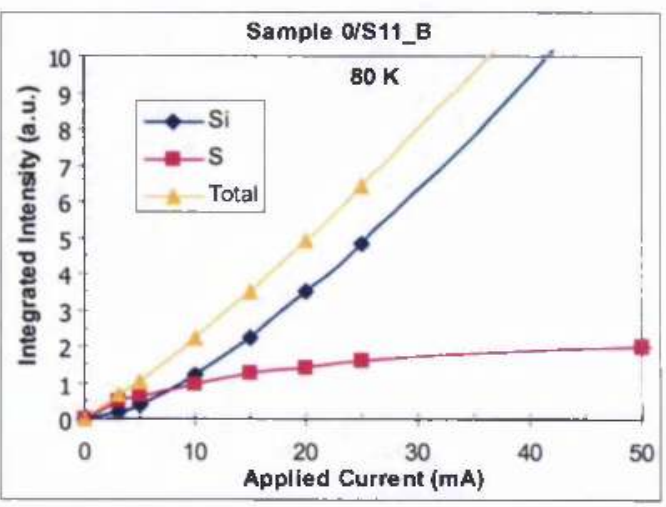

(b)

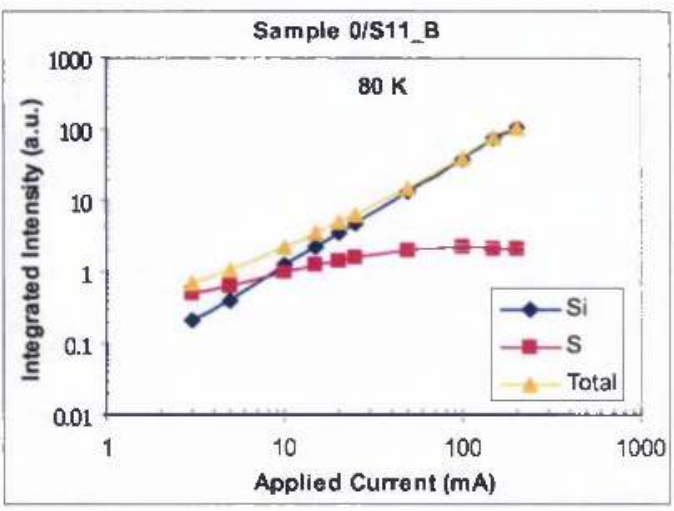

(c)

Figure 5.36 Current dependence of the silicon, sulphur and total integrated intensity as taken from the EL measurements at $80 \mathrm{~K}$ of sample $0 / \mathrm{S} 11$ B (implanted with sulphur at $10^{11} \mathrm{~S}$ $\mathrm{cm}^{-2}$ at $30 \mathrm{keV}$, annealed at $1000^{\circ} \mathrm{C}$ for $10 \mathrm{sec}$, further implanted with $\mathrm{B}$ at $10^{15} \mathrm{~B} \mathrm{~cm}^{-2}$ at 30 $\mathrm{keV}$, further annealed at $950^{\circ} \mathrm{C}$ for $1 \mathrm{~min}$ ), (a) Linear scale, (b) Linear scale expanded at lower current, (c) Log-Log scale of all data. The errors in total, S and Si integrated intensities are within the symbol size. The solid lines are provided as a guide to the eye.

The same behaviour is also observed for sample $0 / \mathrm{S} 12$ B (implanted with $\mathrm{S}$ at $10^{12} \mathrm{~S} \mathrm{~cm}^{-2}$ at $30 \mathrm{keV}$, annealed at $1000^{\circ} \mathrm{C}$ for $10 \mathrm{sec}$, further implanted with $\mathrm{B}$ at $10^{15} \mathrm{~B} \mathrm{~cm}^{-2}$ at $30 \mathrm{keV}$, further annealed at $950{ }^{\circ} \mathrm{C}$ for $1 \mathrm{~min}$ ) at $80 \mathrm{~K}$ (Figure 5.37 (a)). The sublinear and superlinear behaviour of the S and Si integrated intensity trends are not so prominent and they are restricted to the very small current regime (Figure 5.37 (b)). The total integrated intensity trend is nearly linear at low currents and follows the $\mathrm{Si}$ trend at higher currents. The values of the three trends are lower for this sample than the previous one $\left(0 / \mathrm{S} 11 \_\mathrm{B}\right)$. In Figure 5.37 (c) are illustrated the three trends ( $\mathrm{Si}, \mathrm{S}$ and total) on a $\log -\log$ scale. 


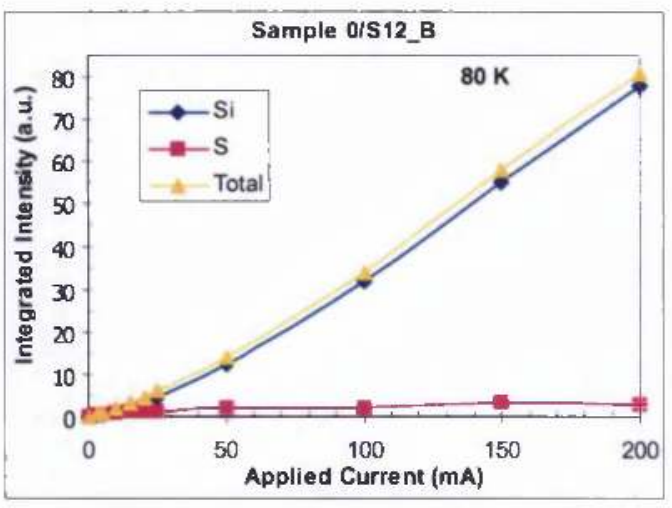

(a)

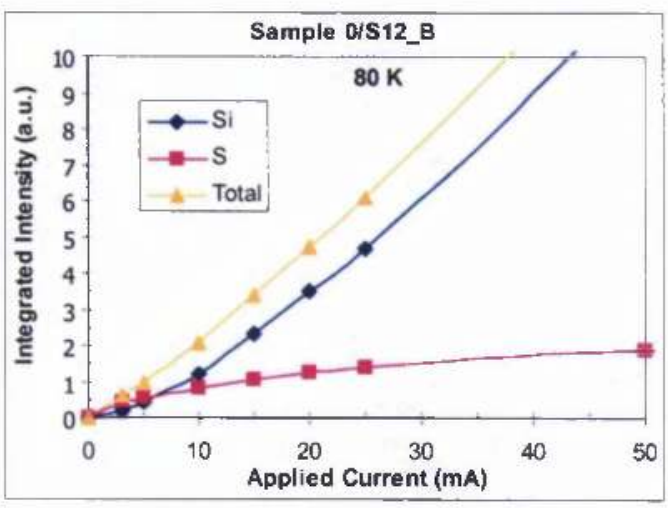

(b)

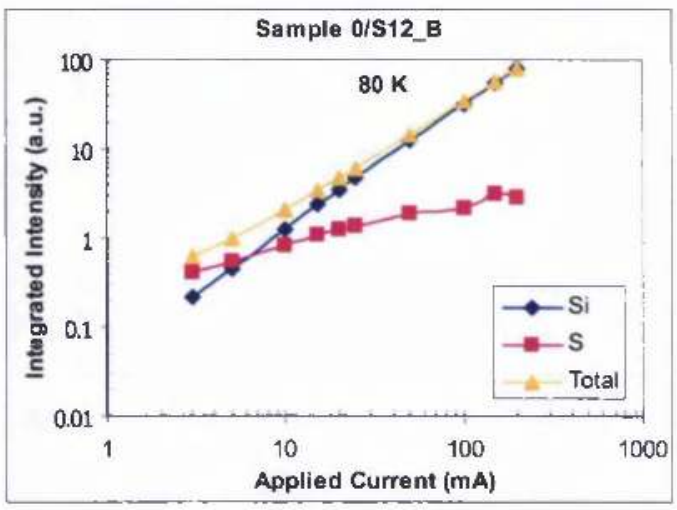

(c)

Figure 5.37 Current dependence of the silicon, sulphur and total integrated intensity as taken from the EL measurements at $80 \mathrm{~K}$ of sample $0 / \mathrm{S} 12 \mathrm{~B}$ (implanted with sulphur at $10^{12} \mathrm{~S}$ $\mathrm{cm}^{-2}$ at $30 \mathrm{keV}$, annealed at $1000^{\circ} \mathrm{C}$ for $10 \mathrm{sec}$, further implanted with $\mathrm{B}$ at $10^{15} \mathrm{~B} \mathrm{~cm}^{-2}$ at 30 $\mathrm{keV}$, further annealed at $950{ }^{\circ} \mathrm{C}$ for $1 \mathrm{~min}$ ), (a) Linear scale, (b) Linear scale expanded at lower current, (c) Log-Log scale of all data. The errors in total, S and Si integrated intensities are within the symbol size. The solid lines are provided as a guide to the eye.

In Figure 5.38 is depicted the $\mathrm{Si}, \mathrm{S}$ and total integrated intensity trends for sample 0/S13_B (implanted with S at $10^{13} \mathrm{~S} \mathrm{~cm}^{-2}$ at $30 \mathrm{keV}$, annealed at $1000^{\circ} \mathrm{C}$ for $10 \mathrm{sec}$, further implanted with $\mathrm{B}$ at $10^{15} \mathrm{~B} \mathrm{~cm}^{-2}$ at $30 \mathrm{keV}$, further annealed at $950{ }^{\circ} \mathrm{C}$ for $1 \mathrm{~min}$ ) at $80 \mathrm{~K}$. The $\mathrm{S}$ and $\mathrm{Si}$ integrated intensity trends are also sublinear and superlinear, respectively. The total integrated intensity trend is nearly linear at low currents but for the higher currents is following the Si trend. In Figure 5.38 (c) are illustrated the $\mathrm{Si}, \mathrm{S}$ and total integrated intensity trends on a $\log -\log$ scale. The values of the three trends ( $\mathrm{Si}, \mathrm{S}$ and total) are much lower than both of the two previous studied samples (0/S11_B and 0/S12_B). 


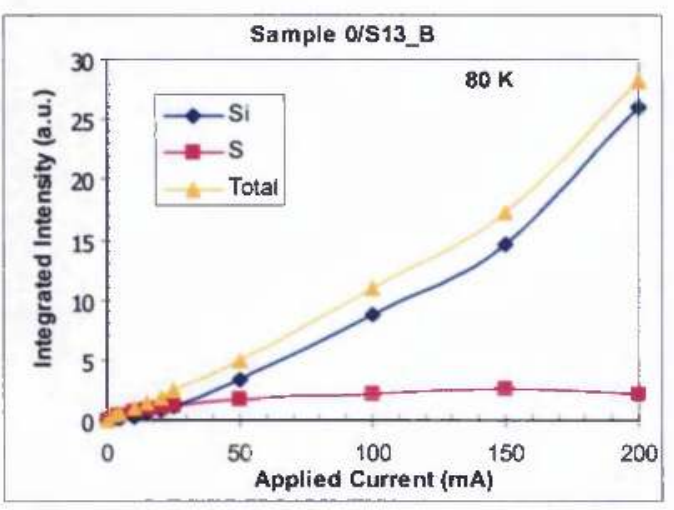

(a)

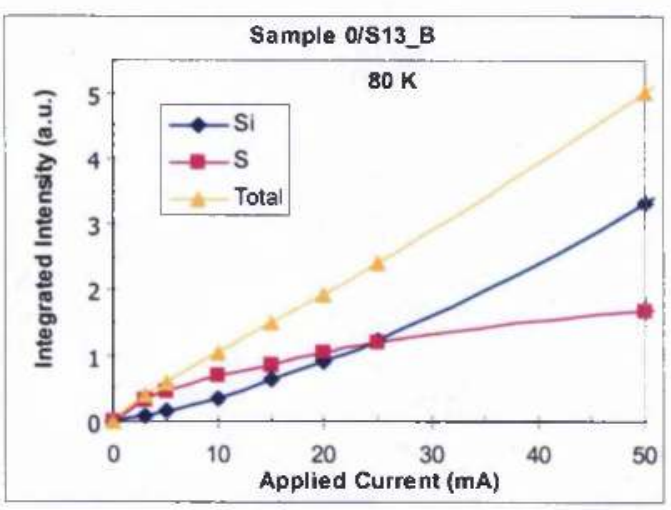

(b)

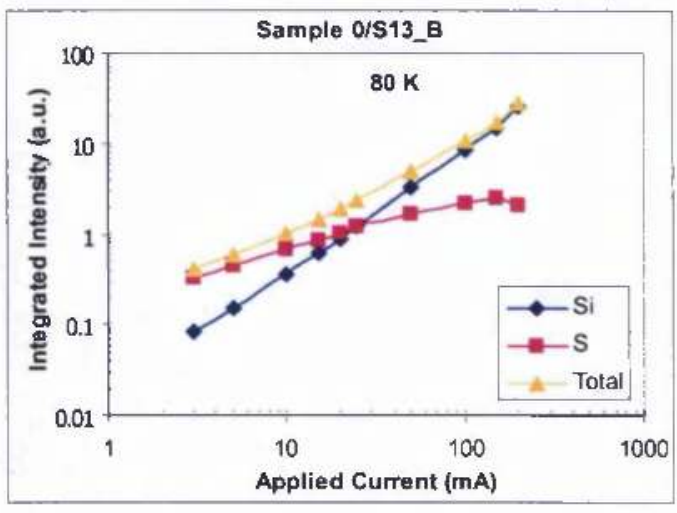

(c)

Figure 5.38 Current dependence of the silicon, sulphur and total integrated intensity as taken from the EL measurements at $80 \mathrm{~K}$ of sample 0/S13_B (implanted with sulphur at $10^{13} \mathrm{~S}$ $\mathrm{cm}^{-2}$ at $30 \mathrm{keV}$, annealed at $1000^{\circ} \mathrm{C}$ for $10 \mathrm{sec}$, further implanted with $\mathrm{B}$ at $10^{15} \mathrm{~B} \mathrm{~cm}^{-2}$ at 30 $\mathrm{keV}$, further annealed at $950{ }^{\circ} \mathrm{C}$ for $1 \mathrm{~min}$ ), (a) Linear scale, (b) Linear scale expanded at lower current, (c) Log-Log scale of all data. The errors in total, S and Si integrated intensities are within the symbol size. The solid lines are provided as a guide to the eye.

Finally, in Figure 5.39 is depicted the current dependence of the $\mathrm{Si}, \mathrm{S}$ and total integrated intensity of the last sample of this set, the 0/S14_B (implanted with S at $10^{14} \mathrm{~S} \mathrm{~cm}^{-2}$ at $30 \mathrm{keV}$, annealed at $1000{ }^{\circ} \mathrm{C}$ for $10 \mathrm{sec}$, further implanted with B at $10^{15} \mathrm{~B} \mathrm{~cm}^{-2}$ at $30 \mathrm{keV}$, further annealed at $950{ }^{\circ} \mathrm{C}$ for $1 \mathrm{~min}$ ) at $80 \mathrm{~K}$. The $\mathrm{S}$ and $\mathrm{Si}$ trends are also showing a sublinear and superlinear behaviour, respectively, with the increase of the applied current, especially obvious at the low current regime (Figure 5.39 (b)). The total integrated intensity trend is closely linear at low currents and follows the Si trend at high currents. The intensities are the third highest of all the 
four samples of this set. In Figure 5.39 (c) are illustrated the Si, S and total integrated intensity on a log-log scale.

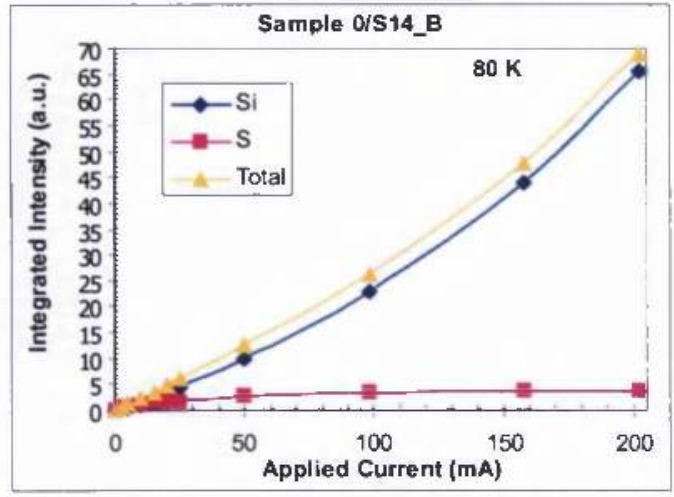

(a)

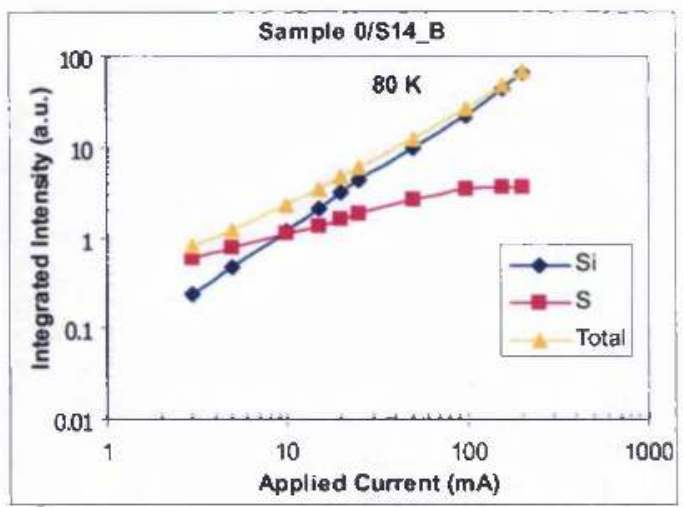

(c)

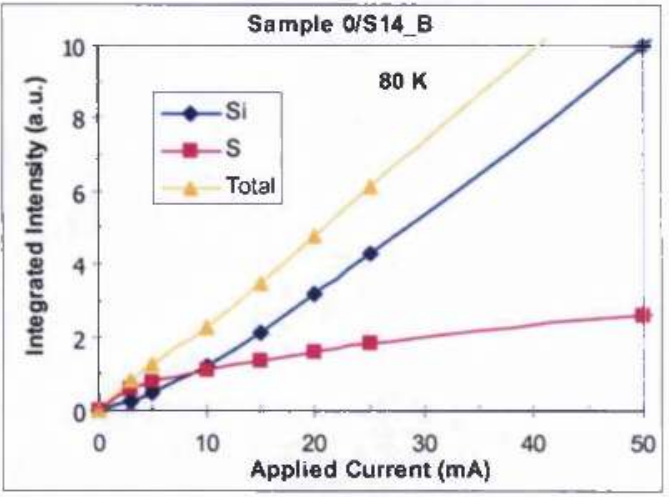

(b)

Figure 5.39 Current dependence of the silicon, sulphur and total integrated intensity as taken from the EL measurements at $80 \mathrm{~K}$ of sample 0/S14_B (implanted with sulphur at $10^{14} \mathrm{~S}$ $\mathrm{cm}^{-2}$ at $30 \mathrm{keV}$, annealed at $1000^{\circ} \mathrm{C}$ for $10 \mathrm{sec}$, further implanted with $\mathrm{B}$ at $10^{15} \mathrm{~B} \mathrm{~cm}^{-2}$ at 30 $\mathrm{keV}$, further annealed at $950{ }^{\circ} \mathrm{C}$ for $1 \mathrm{~min}$ ), (a) Linear scale, (b) Linear scale expanded at lower current, (c) Log-Log scale of all data. The errors in total, S and Si integrated intensities are within the symbol size. The solid lines are provided as a guide to the eye.

In Figure 5.40 are presented the three trends of the $\mathrm{Si}, \mathrm{S}$ and total integrated intensities of sample 1/S11_B (implanted with $\mathrm{S}$ at $10^{11} \mathrm{~S} \mathrm{~cm}^{-2}$ at $30 \mathrm{keV}$, annealed at $1100{ }^{\circ} \mathrm{C}$ for $10 \mathrm{sec}$, further implanted with $\mathrm{B}$ at $10^{15} \mathrm{~B} \mathrm{~cm} \mathrm{c}^{-2}$ at $30 \mathrm{keV}$, further annealed at $950{ }^{\circ} \mathrm{C}$ for $1 \mathrm{~min}$ ) at $80 \mathrm{~K}$. The $\mathrm{S}$ and $\mathrm{Si}$ integrated intensity trends are also sublinear and superlinear, respectively. The total integrated intensity trend is 
again linear at low currents and similar to the Si trend at higher currents. The three trends on a log-log scale are presented in Figure 5.40 (c).

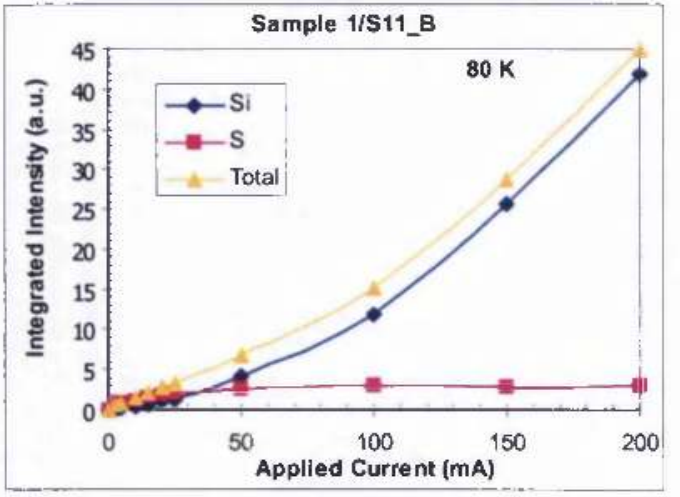

(a)

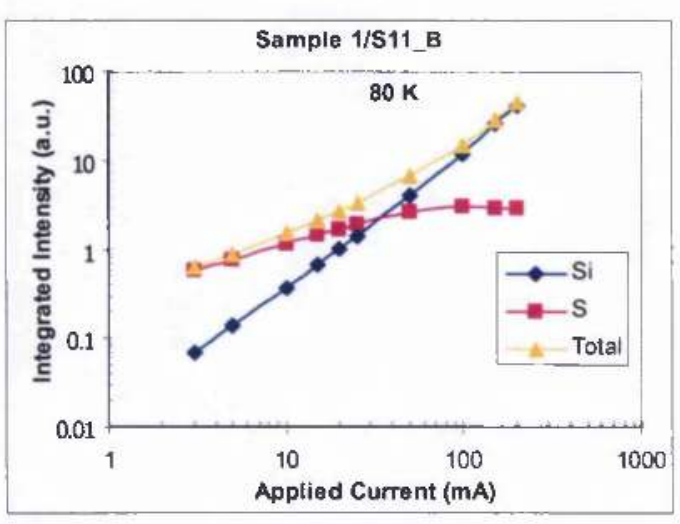

(c)

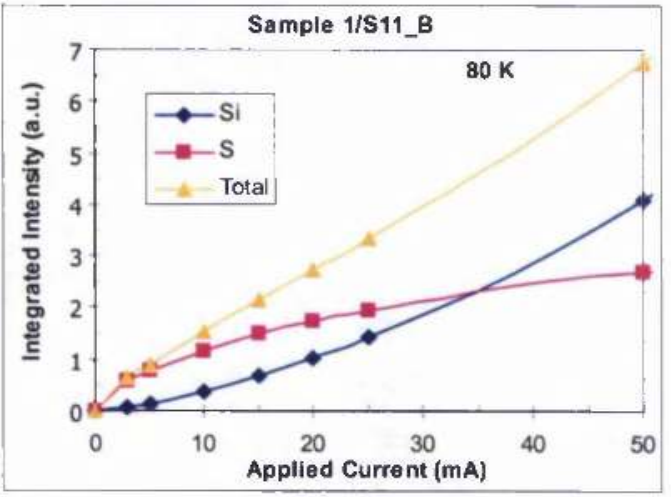

(b)

\section{b)}


addition, the trends are similar to the ones of sample 1/S11_B having also similar values. The three trends on a log-log scale are shown in Figure 5.41 (c).

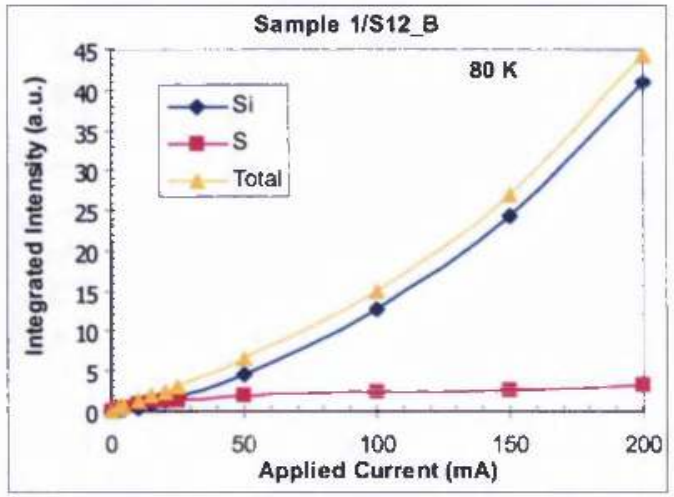

(a)

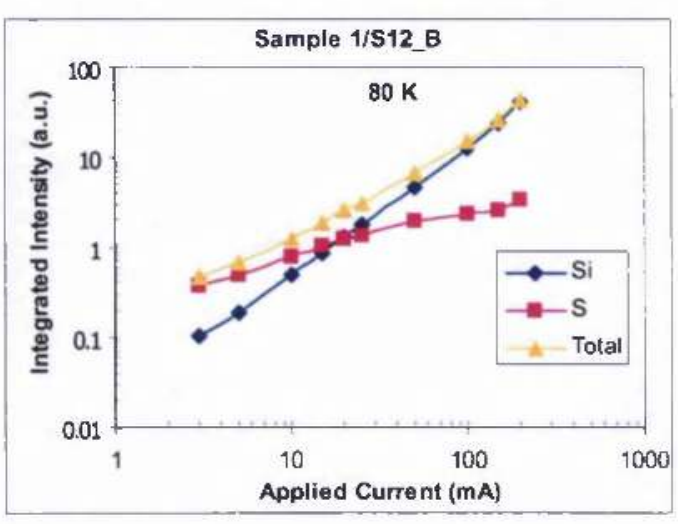

(c)

\section{)}

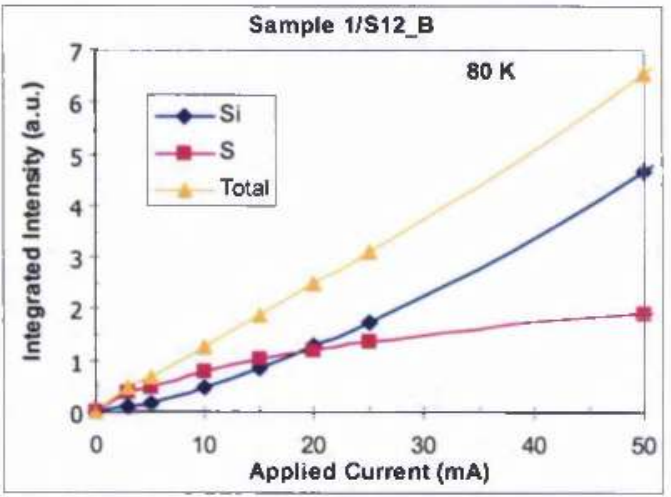

(b)

\section{b)}

Figure 5.41 Current dependence of the silicon, sulphur and total integrated intensity as taken from the EL measurements at $80 \mathrm{~K}$ of sample $1 / \mathrm{S} 12$ B (implanted with sulphur at $10^{12} \mathrm{~S}$ $\mathrm{cm}^{-2}$ at $30 \mathrm{keV}$, annealed at $1100^{\circ} \mathrm{C}$ for $10 \mathrm{sec}$, further implanted with $\mathrm{B}$ at $10^{15} \mathrm{~B} \mathrm{~cm}^{-2}$ at 30 $\mathrm{keV}$, further annealed at $950{ }^{\circ} \mathrm{C}$ for $1 \mathrm{~min}$ ), (a) Linear scale, (b) Linear scale expanded at lower current, (c) Log-Log scale of all data. The errors in total, S and Si integrated intensities are within the symbol size. The solid lines are provided as a guide to the eye.

The trends of $\mathrm{S}, \mathrm{Si}$ and total integrated intensity for sample $1 / \mathrm{S} 13$ _ B (implanted with $\mathrm{S}$ at $10^{13} \mathrm{~S} \mathrm{~cm}^{-2}$ at $30 \mathrm{keV}$, annealed at $1100{ }^{\circ} \mathrm{C}$ for $10 \mathrm{sec}$, further implanted with $\mathrm{B}$ at $10^{15} \mathrm{~B} \mathrm{~cm}^{-2}$ at $30 \mathrm{keV}$, further annealed at $950^{\circ} \mathrm{C}$ for $1 \mathrm{~min}$ ) at $80 \mathrm{~K}$, are depicted in Figure 5.42. The $\mathrm{S}$ and $\mathrm{Si}$ trends are again sublinear and superlinear, respectively. The total integrated intensity is closely linear at the low current regime, whereas for the rest and most of the current values has similar trend 
to the $\mathrm{Si}$ one (Figure 5.42 (b)). Furthermore, the values of the $\mathrm{Si}, \mathrm{S}$ and total integrated intensities are lower for this sample than the previous two mentioned $\left(0 / \mathrm{S} 11\right.$ B B and $\left.0 / \mathrm{S} 12 \_\mathrm{B}\right)$ ones. The $\mathrm{Si}, \mathrm{S}$ and total integrated intensity trends are depicted in Figure 5.42 (c) on a $\log -\log$ scale.

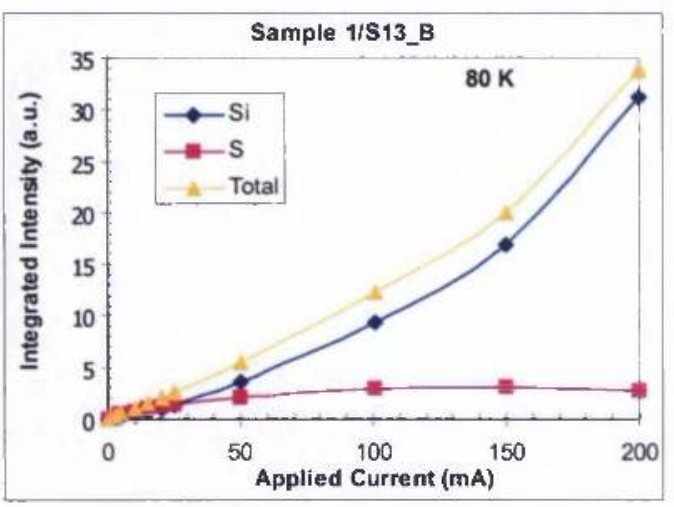

(a)

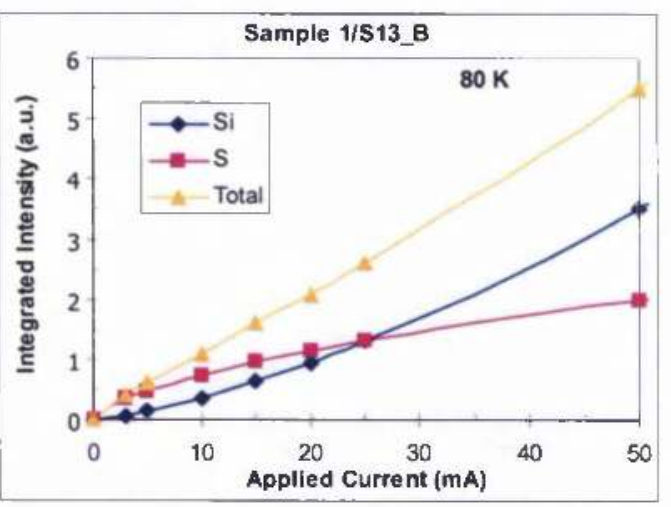

(b)

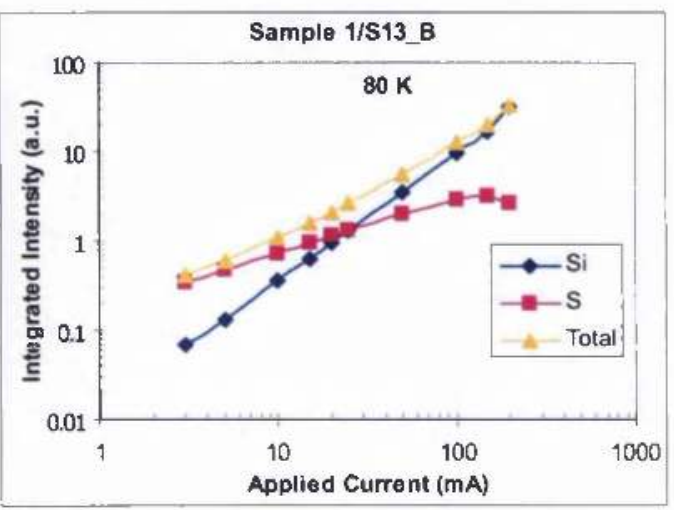

(c)

Figure 5.42 Current dependence of the silicon, sulphur and total integrated intensity as taken from the EL measurements at $80 \mathrm{~K}$ of sample $1 / \mathrm{S} 13$ B (implanted with sulphur at $10^{1.3} \mathrm{~S}$ $\mathrm{cm}^{-2}$ at $30 \mathrm{keV}$, annealed at $1100^{\circ} \mathrm{C}$ for $10 \mathrm{sec}$, further implanted with $\mathrm{B}$ at $10^{15} \mathrm{~B} \mathrm{~cm}^{2}$ at 30 $\mathrm{keV}$, further annealed at $950^{\circ} \mathrm{C}$ for $1 \mathrm{~min}$ ), (a) Linear scale, (b) Linear scale expanded at lower current, (c) Log-Log scale of all data. The errors in total, S and Si integrated intensities are within the symbol size. The solid lines are provided as a guide to the eye.

Finally, in Figure 5.43 are illustrated the $\mathrm{Si}, \mathrm{S}$ and total integrated intensities trends for the last sample of this set $1 / \mathrm{S} 14$ _B (implanted with $\mathrm{S}$ at $10^{14} \mathrm{~S} \mathrm{~cm}^{-2}$ at 30 $\mathrm{keV}$, annealed at $1100^{\circ} \mathrm{C}$ for $10 \mathrm{sec}$, further implanted with $\mathrm{B}$ at $10^{15} \mathrm{~B} \mathrm{~cm}^{-2}$ at 30 $\mathrm{keV}$, further annealed at $950{ }^{\circ} \mathrm{C}$ for $1 \mathrm{~min}$ ) at $80 \mathrm{~K}$. The trends are very similar to all 
the samples of this set; the $\mathrm{S}$ and $\mathrm{Si}$ integrated intensities trends are sublinear and superlinear, more evident at the low current regime. The total integrated intensity trend which is the sum of the two others ( $\mathrm{Si}$ and $\mathrm{S}$ ) is closely sublinear for the low current regime and mostly superlinear for the rest and most of the current values (Figure 5.43 (b)). The Si, S and total integrated intensity trends are displayed on log$\log$ scale in Figure 5.43 (c). Their values for this sample are the highest of all the other samples of this set.

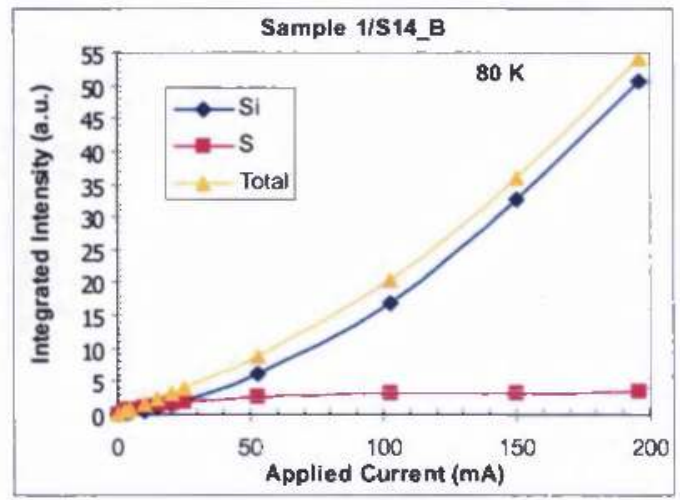

(a)

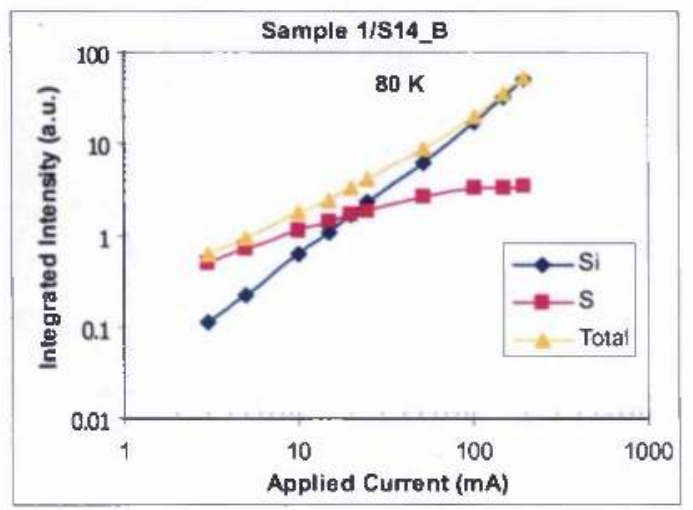

(c)

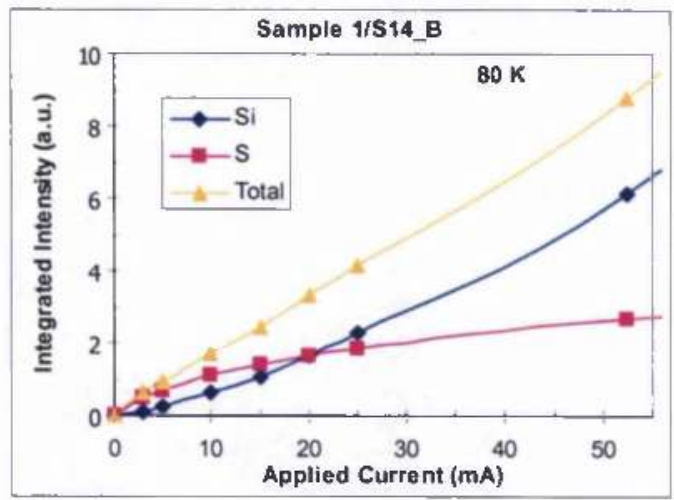

(b)

Figure 5.43 Current dependence of the silicon, sulphur and total integrated intensity as taken from the EL measurements at $80 \mathrm{~K}$ of sample $1 / \mathrm{S} 14$ B (implanted with sulphur at $10^{14} \mathrm{~S}$ $\mathrm{cm}^{-2}$ at $30 \mathrm{keV}$, annealed at $1100^{\circ} \mathrm{C}$ for $10 \mathrm{sec}$, further implanted with $\mathrm{B}$ at $10^{15} \mathrm{~B} \mathrm{~cm}^{-2}$ at 30 $\mathrm{keV}$, further annealed at $950{ }^{\circ} \mathrm{C}$ for $1 \mathrm{~min}$ ), (a) Linear scale, (b) Linear scale expanded at lower current, (c) Log-Log scale of all data. The errors in total, S and Si integrated intensities are within the symbol size. The solid lines are provided as a guide to the eye. 
In conclusion, in this section variable current EL experiments were done at the eight samples 0/S11_B-0/S14_B (implanted with $\mathrm{S}$ at $10^{11}-10^{14} \mathrm{~S} \mathrm{~cm}^{-2}$ at $30 \mathrm{keV}$, annealed at $1000^{\circ} \mathrm{C}$ for $10 \mathrm{sec}$, further implanted with $\mathrm{B}$ at $10^{15} \mathrm{~B} \mathrm{~cm}^{-2}$ at $30 \mathrm{keV}$, further annealed at $950{ }^{\circ} \mathrm{C}$ for $1 \mathrm{~min}$ ) and 1/S11_B-1/S14_B (implanted with $\mathrm{S}$ at $10^{11}-10^{14} \mathrm{~S} \mathrm{~cm}^{-2}$ at $30 \mathrm{keV}$, annealed at $1100^{\circ} \mathrm{C}$ for $10 \mathrm{sec}$, further implanted with $\mathrm{B}$ at $10^{15} \mathrm{~B} \mathrm{~cm}^{-2}$ at $30 \mathrm{keV}$, further annealed at $950{ }^{\circ} \mathrm{C}$ for $1 \mathrm{~min}$ ) at $80 \mathrm{~K}$. From the shape of the integrated intensity trends is observed mainly that the $\mathrm{S}$ has a sublinear trend whereas the Si has a superlinear one. This behaviour is more evident at the very low current regime up to $30 \mathrm{~mA}$ for samples $0 / \mathrm{S} 11$ B-0/S14_B and up to $40 \mathrm{~mA}$ for the samples 1/S11_B-1/S14_B. The total integrated intensity trend is mainly superlinear because it is influenced from the $\mathrm{Si}$ trend after the $\mathrm{S}$ signal saturates. Of particular interest is the closely linear behaviour of the total integrated intensity at low injection. This will be considered and discussed in chapter 6 .

\section{References}

[1] T. G. Brown and D. G. Hall, Appl. Phys. Lett. 49, 245 (1986). 


\section{DISCUSSION ON SI:S SAMPLES}

\subsection{Introduction}

In this chapter I will discuss the results obtained from the Si:S samples. The characteristic of these samples is that they are implanted making use of dislocation engineering as first demonstrated by W. L. Ng et al. [1]. The need though of having emission apart from the $1129.5 \mathrm{~nm}$ which is due to silicon, made us study other centres, such as sulphur, in order to shift the wavelength emission to longer wavelengths such as $1334 \mathrm{~nm}$. The samples under investigation were implanted at the ion beam centre at the University of Surrey. They have different annealing and implant conditions and the aim of this chapter is to evaluate the effect of those conditions using the photoluminescence and electroluminescence spectroscopy.

A discussion on the PL and EL results from the Si:S samples will be provided. A model of the sulphur diffusion will be presented. Finally a model which explains the PL power dependence and EL current dependence results will be demonstrated.

\subsection{Discussion on PL results from Si:S samples}

The samples which were studied were n-type $(100)(\mathrm{CZ})$ silicon wafers of 2-7 $\Omega \mathrm{cm}$ resistivity which were implanted with sulphur at doses $10^{11}, 10^{12}, 10^{13}$ and $10^{14}$ $\mathrm{S} \mathrm{cm}^{-2}$ and at $30 \mathrm{keV}$ energy. Each sample was divided into two parts ( 0 and 1$)$. After implantation, all samples were annealed at $1000{ }^{\circ} \mathrm{C}$ (part 0 ) and at $1100{ }^{\circ} \mathrm{C}$ (part 1 ) for 10 seconds in order to activate the sulphur atoms in the Si lattice. After annealing at $1000{ }^{\circ} \mathrm{C}$ or $1100{ }^{\circ} \mathrm{C}$, a further implantation with boron took place at a dose of $10^{15}$ $\mathrm{B} \mathrm{cm}{ }^{-2}$ at $30 \mathrm{keV}$ for a selection of samples. Those samples which were implanted 
with boron were further annealed at $950{ }^{\circ} \mathrm{C}$ for $1 \mathrm{~min}$. The whole list of samples which were used for our experiments is depicted in Table 5.1 of chapter 5 .

\subsubsection{Peak positions and thermal quenching}

PL measurements took place on all sixteen samples for two different laser powers $(150 \mathrm{~mW}$ and $50 \mathrm{~mW})$ but only three of them revealed sulphur related PL lines of particular interest. All samples revealed a line at $1129.5 \mathrm{~nm}$ (or equivalent photon energy of $1.0977 \mathrm{eV}$ ) at $80 \mathrm{~K}$ which is due to the TO phonon assisted Si transition. Its phonon replica is seen at $1193.25 \mathrm{~nm}$ (or $1.0391 \mathrm{eV}$ ) at $80 \mathrm{~K}$. The line observed at $1334 \mathrm{~nm}$ (or equivalent photon energy of $0.930 \mathrm{eV}$ ) at $80 \mathrm{~K}$ is due to sulphur, in accordance with previous reported work $[2,3]$.

The sulphur line at $1334 \mathrm{~nm}$ is shifting towards higher wavelengths (lower energies) with the increase of measurement temperature. This behaviour is also observed for the $\mathrm{Si}$ and the phonon replica peaks. The shifting of the Si line towards the lower energy range is due to the variation of the band gap with the temperature. The shift of the sulphur peak towards lower wavelengths is much faster than the silicon peak. Comparing Figure 5.1 ((a)-(d)) which shows the PL spectra from a sample implanted only with boron and the samples implanted either with only sulphur or with sulphur and boron, to the sample which was implanted only with boron there is in the latter, a wide background emission probably due to defect damage which ranges from 1200-1500 nm. This wide background emission may not quench as fast as the sulphur peak with the increase of temperature and may be still present at room temperature. Therefore, at higher temperatures what we see as a sulphur peak may be dominated by this background emission leading to the assumption that the primary sulphur peak shifts faster at higher wavelengths with the increase of measurement temperature. The samples which revealed a sulphur PL emission were the three following: $0 / \mathrm{S} 12\left(10^{12} \mathrm{~S} \mathrm{~cm}^{-2}, 30 \mathrm{keV}\right.$, annealed at $1000{ }^{0} \mathrm{C}$ for $10 \mathrm{sec}), 0 / \mathrm{S} 13 \_\mathrm{B}\left(10^{13} \mathrm{~S} \mathrm{~cm}^{-2}, 30 \mathrm{keV}\right.$, annealed at $1000{ }^{0} \mathrm{C}$ for $10 \mathrm{sec}, 10^{15} \mathrm{~B}$ 
$\mathrm{cm}^{-2}, 30 \mathrm{keV}$, annealed at $950{ }^{0} \mathrm{C}$ for $\left.1 \mathrm{~min}\right)$ and sample $0 / \mathrm{S} 14\left(10^{14} \mathrm{~S} \mathrm{~cm}^{-2}, 30 \mathrm{keV}\right.$, annealed at $1000^{\circ} \mathrm{C}$ for $10 \mathrm{sec}$ ).

The fact that the sulphur PL was observed in only some of the samples and not all of them may be due to the annealing conditions which were used. According to the work reported from T. G. Brown et al. [2], the samples were annealed at temperatures from $1000{ }^{\circ} \mathrm{C}-1200{ }^{\circ} \mathrm{C}$ for $10 \mathrm{sec}$. In detail, the samples were subjected to a heating treatment consisting of an up to $10 \mathrm{sec}$ exposure to the flame from a propane torch followed by a rapid quench to room temperature in an ethylene glycol bath. Those conditions are not at all compatible with the VLSI technology for mass production, though. In our case, the heating of the samples took place in an RTA annealer. The anneal consists of the four following stages: i) 1 minute to reach $600{ }^{\circ} \mathrm{C}$ from room temperature, ii) 1 minute at $600{ }^{\circ} \mathrm{C}$, iii) 1 minute from $600{ }^{\circ} \mathrm{C}$ to $1000{ }^{\circ} \mathrm{C} / 1100{ }^{\circ} \mathrm{C}$, iv) 10 seconds at $1000{ }^{\circ} \mathrm{C} / 1100{ }^{\circ} \mathrm{C}$ and finally v) 15 minutes approximate from $1000{ }^{\circ} \mathrm{C} / 1100{ }^{\circ} \mathrm{C}$ to $50{ }^{\circ} \mathrm{C}$ when the annealer can be opened. (See Figure 6.1). Thus, there is a big difference between the two annealing procedures especially the temperature quenching which is much slower in our case. Also, the energy which was used in our case was much lower $(30 \mathrm{keV})$ than the one which was used by T.G. Brown et al. [2], which was $200 \mathrm{keV}$.

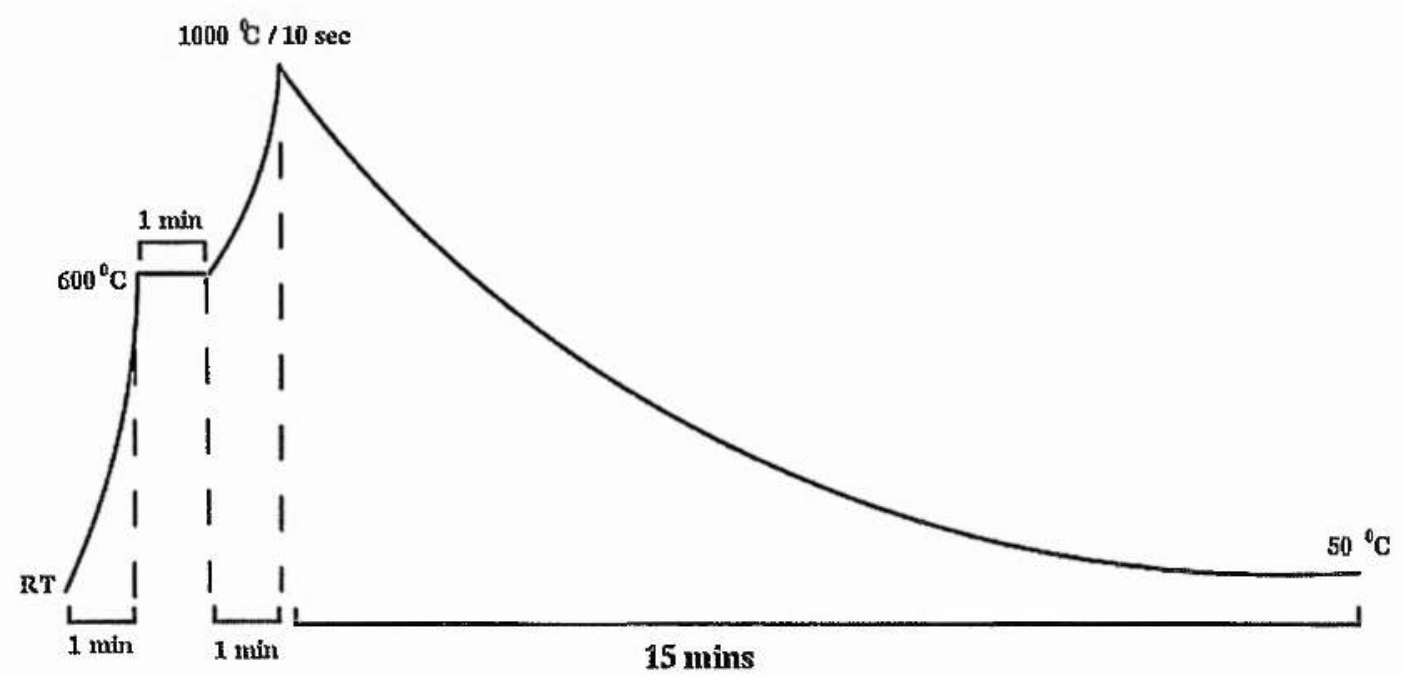

Figure 6.1 Five stages of the heating treatment that took place for our samples. 
In addition, another reason for the fact that the sulphur emission was observed in some of our samples may be due to the fact that photoluminescence spectroscopy measures the light emission close to the surface of the sample, whereas electroluminescence spectroscopy measures the light of the sample which comes from the active region near the pn junction where the carriers are injected and where there are more sulphur atoms making this emission more likely.

As was mentioned, the energy of sulphur implantation was chosen to be 30 $\mathrm{keV}$. This energy was chosen in order to make sure that the sulphur would be in the active region of the samples. This is the reason also why the annealing temperature at $1000{ }^{\circ} \mathrm{C}$ or $1100{ }^{\circ} \mathrm{C}$ was kept only for $10 \mathrm{~s}$. For boron implantation the same energy at $30 \mathrm{keV}$ was also applied, and the annealing temperature was at $950{ }^{\circ} \mathrm{C}$ for $1 \mathrm{~min}$, in order to have high Si emission [4].

Observing the trends of the three integrated intensities ( $\mathrm{Si}, \mathrm{S}$ and total) with the increase of temperature (Figures 5.6-5.8), it is concluded that for the samples implanted only with sulphur $\left(0 / \mathrm{S} 12\right.$, implanted with $10^{12} \mathrm{~S} \mathrm{~cm}^{-2}$ at $30 \mathrm{keV}$, annealed at $1000{ }^{\circ} \mathrm{C}$ for $10 \mathrm{sec}$, and $0 / \mathrm{S} 14$, implanted with $10^{14} \mathrm{~S} \mathrm{~cm}^{-2}, 30 \mathrm{keV}$, annealed at $1000{ }^{\circ} \mathrm{C}$ for $10 \mathrm{sec}$ ), those trends are decreasing with the increase of temperature. Therefore, there is a strong thermal quenching at temperatures above $130 \mathrm{~K}$. The quenching ratio of $\mathrm{S}$ integrated intensity which is the value of the sulphur integrated intensity at $130 \mathrm{~K}$ divided by the value of the sulphur integrated intensity at $80 \mathrm{~K}$ is less than 0.5 at $150 \mathrm{~mW}$ and $50 \mathrm{~mW}$ applied laser power for all samples (Figure 5.14). This low quenching ratio is due to the fact that the non-radiative emission is more dominant.

The sample which is implanted with sulphur and boron, $0 / \mathrm{S} 13$ _B $\left(10^{13} \mathrm{~S}\right.$ $\mathrm{cm}^{-2}, 30 \mathrm{keV}$, annealed at $1000{ }^{\circ} \mathrm{C}$ for $10 \mathrm{sec}, 10^{15} \mathrm{~B} \mathrm{~cm}^{-2}, 30 \mathrm{keV}$, annealed at 950 ${ }^{0} \mathrm{C}$ for $1 \mathrm{~min}$ ) reveals an increase of its $\mathrm{Si}$ integrated intensity trend with the increase of the temperature. This is due to the introduction of the dislocation loops which are produced by the boron ion implantation. This is in agreement with previous results [1]. The quenching ratio of the Si integrated intensity of this sample which is the 
value of the $\mathrm{Si}$ integrated intensity at $130 \mathrm{~K}$ divided by the $\mathrm{Si}$ integrated intensity value at $80 \mathrm{~K}$ is about 1.8 and 1.7 at $150 \mathrm{~mW}$ and at $50 \mathrm{~mW}$ applied laser power, respectively. In addition, from Figure 5.12 it is observed that at low temperatures the sulphur emission is more dominant, while at higher temperatures the silicon band edge dominates. This response was detected at both laser powers for this sample (0/S13_B), whereas for the other two samples it was more prominent at the low laser power $(50 \mathrm{~mW}$ ) (Figures $5.11,513$ ). This behaviour can be ascribed to the saturation of the sulphur related levels responsible for the $1.33 \mu \mathrm{m}$ emission at high excitation powers and at high temperatures [5].

In conclusion, from the observation of our PL results we can deduce that for the sample which was implanted with sulphur and also introduced with the dislocation loops (sample 0/S13_B), the sulphur emission is stronger compared to the silicon one (Figures 5.1-5.5). Also the $\mathrm{S}$ emission remains up to higher temperatures compared to the other samples implanted only with sulphur (samples $0 / \mathrm{S} 12,0 / \mathrm{S} 14$ ). In addition, the sulphur integrated intensity is more dominant than the silicon one in the low temperature regime (Figure 5.12) for the sample implanted with sulphur and also introduced with the dislocation loops. The sulphur integrated intensities are higher though for the samples implanted only with sulphur but are lower in relation to the silicon ones, especially at the high laser power (150 mW) (Figures 5.11, 5.13). Therefore, the effect of laser power is clearly important. This is discussed in the following section.

\subsubsection{Laser power effect}

The effect of laser power on both the sulphur and silicon PL emission is very interesting. From Figures 5.15-5.23 it is observed that the trend of sulphur integrated intensity is sublinear, increasing fast at low applied laser power, then increasing much more slowly, almost being stable, with the increase of applied laser power. On the other hand, the silicon integrated intensity trend is superlinear, increasing slower 
at low applied laser power and then increasing very much with the increase of the applied laser power. The total integrated intensity trend which is the sum of the sulphur and silicon integrated intensity trends is increasing with the increase of laser power. It follows the $\mathrm{S}$ trend at the very low laser powers and the Si trend at the higher laser powers. This behaviour for the sulphur and silicon integrated intensity trends, as was mentioned above, can be attributed to the saturation of the sulphur related levels responsible for the $1.33 \mu \mathrm{m}$ emission at high excitation powers [5].

This behaviour of the sulphur and silicon integrated intensity trends is more prominent at the lower sulphur dose sample $\left(10^{12} \mathrm{~S} \mathrm{~cm}^{-2}\right)$ than the higher one $\left(10^{14} \mathrm{~S}\right.$ $\left.\mathrm{cm}^{-2}\right)$. The sample which was implanted with sulphur and boron $(0 / \mathrm{S} 13$ _B $)$ has a different response on the effect to the applied laser power at $80 \mathrm{~K}$. In this case, the silicon integrated intensity trend is increasing very slowly with the increase of the applied laser power, in contrast to the sulphur, which is much higher than the silicon and is increasing very much faster with the increase of the applied laser power. Therefore, the effect of dislocations on sulphur is enhancing the sulphur emission at higher laser powers. At $100 \mathrm{~K}$ and mainly at $130 \mathrm{~K}$ though, the behaviour of the two integrated intensities ( $\mathrm{S}$ and $\mathrm{Si}$ ) for the sample which was implanted with boron and sulphur (0/S13_B) are similar to the trends of the samples implanted with sulphur only (samples 0/S12 and 0/S14). From Figures 5.15 (c)-5.23 (c) which illustrate the $\log \log$ plot of the power dependence data, the slopes of the lines for the silicon, sulphur and total integrated intensity have been calculated. The values of the slopes of all lines for all measured samples at the three measured temperatures $(80 \mathrm{~K}, 100 \mathrm{~K}$ and $130 \mathrm{~K}$ ) are listed in Table 6.1. The values of the slopes of the silicon integrated intensity are above one for all samples and temperatures showing that it is increasing superlinearly with the increase of laser power, whereas the values of the slopes of the sulphur integrated intensity are below one showing that it is changing sublinearly with the increase of laser power. The values of the slopes of the total integrated intensity trends are close to one at the low power regime and higher than one (but always smaller than the silicon integrated intensity slopes) at the high laser power regime, indicating that the behaviour of the total integrated intensity is closely linear at the low power regime and superlinear at the higher power regime. 
Chapter 6-Discussion on Si:S Samples

\begin{tabular}{|c|c|c|c|c|c|c|c|}
\hline \multicolumn{8}{|c|}{ Slopes } \\
\hline & \multicolumn{4}{|c|}{ Low Power } & \multicolumn{3}{|c|}{ High power } \\
\hline Samples & Temp & $\mathbf{S i}$ & $\mathrm{S}$ & Total & $\mathbf{S i}$ & S & Total \\
\hline \multirow[t]{3}{*}{$0 / \mathrm{S} 12$} & $80 \mathrm{~K}$ & 1.37 & 0.62 & 0.72 & 1.85 & 0.37 & 1.27 \\
\hline & $100 \mathrm{~K}$ & 1.24 & 0.6 & 0.65 & 1.65 & 0.35 & 1.08 \\
\hline & $130 \mathrm{~K}$ & 1.44 & 0.69 & 1.16 & 1.62 & 0.69 & 1.51 \\
\hline \multirow[t]{3}{*}{ 0/S13_B } & $80 \mathrm{~K}$ & & & & 1.37 & 0.95 & 0.98 \\
\hline & $100 \mathrm{~K}$ & & & & 1.40 & 0.73 & 0.77 \\
\hline & $130 \mathrm{~K}$ & & & & 1.38 & 0.86 & 1.05 \\
\hline \multirow[t]{3}{*}{$0 / \mathrm{S} 14$} & $80 \mathrm{~K}$ & 1.48 & 0.89 & 1.009 & 1.49 & 0.91 & 1.25 \\
\hline & $100 \mathrm{~K}$ & 1.51 & 0.95 & 1.06 & 1.53 & 0.86 & 1.28 \\
\hline & $130 \mathrm{~K}$ & 1.25 & 0.69 & 0.97 & 1.56 & 0.89 & 1.48 \\
\hline
\end{tabular}

Table 6.1 List of slopes of the silicon, sulphur and total integrated intensity trends for the three temperatures $80 \mathrm{~K}, 100 \mathrm{~K}$ and $130 \mathrm{~K}$, for the two laser power regimes as they have derived from the power dependence data. Note that for sample 0/S13B (implanted with boron and sulphur) the slope of the trends occurs for the higher laser power regime.

\subsection{Discussion on EL results from $\mathrm{Si}: \mathrm{S}$ samples}

For EL experiments the same samples were used as for the PL experiments. In this case all the samples were implanted with sulphur at doses $10^{11}, 10^{12}, 10^{13}$ and $10^{14} \mathrm{~S} \mathrm{~cm}^{-2}$ and at $30 \mathrm{keV}$ energy, annealed at $1000^{\circ} \mathrm{C}$ or $1100^{\circ} \mathrm{C}$ for $10 \mathrm{~s}$, further implanted with boron at $10^{15} \mathrm{~B} \mathrm{~cm}^{-2}$ at $30 \mathrm{keV}$ and further annealed at $950{ }^{\circ} \mathrm{C}$ for 1 min, and they were made into devices, as described in more detail in chapter 4 (section 4.3). EL experiments took place at $25 \mathrm{~mA}$ drive current for a temperature range from $80 \mathrm{~K}$ up to $300 \mathrm{~K}$. The list of samples which were used for our EL experiments are also listed in Table 5.3 of chapter 5 . 


\subsubsection{Peak positions and thermal quenching}

From the EL experiments three lines were observed, as can be seen in Figures $5.24,5.26$ and 5.33. These lines were observed at $1129.5 \mathrm{~nm}$ (or equivalent photon energy of $1.0977 \mathrm{eV}$ ), at $1193.25 \mathrm{~nm}$ (or $1.0391 \mathrm{eV}$ ) and at $1363.25 \mathrm{~nm}$ (or 0.9095 $\mathrm{eV}$ ) at $80 \mathrm{~K}$. The lines at $1129.5 \mathrm{~nm}$ (or $1.0977 \mathrm{eV}$ ) and at $1193.25 \mathrm{~nm}$ (or 1.0391 $\mathrm{eV}$ ) are due to the TO phonon assisted $\mathrm{Si}$ emission and its replica, respectively, in agreement with our PL experiments. As mentioned, the introduction of dislocation loops to the Si:S engineered LED was done by boron ion implantation followed by controlled thermal annealing. The presence of dislocation loops creates a spatial confinement of the charge carriers within the device which favours the radiative recombination, giving strong emission at $1129.5 \mathrm{~nm}$ at $80 \mathrm{~K}$. The line at $1363.25 \mathrm{~nm}$ (or $0.9095 \mathrm{eV}$ ) is due to sulphur, as observed in our PL experiments and in previously reported work $[6,2,3]$. This emission was attributed to bound exciton luminescence from sulphur related isoelectronic complexes in $\mathrm{Si}$ [2].

As for the PL, all the lines are shifting towards longer wavelengths (smaller energies) with increase of the measurement temperature. The shifting of the Si line towards the longer wavelength regime is due to the variation of the band gap with temperature. The quenching ratio which is the value of $\mathrm{S}$ or $\mathrm{Si}$ or total integrated intensity at $300 \mathrm{~K}$ divided by the value of $\mathrm{S}$ or Si or total integrated intensity at $80 \mathrm{~K}$, of all samples is less than 0.2 and 3.15 for the $\mathrm{S}$ and Si integrated intensity, respectively, as illustrated in Figure 6.2. 


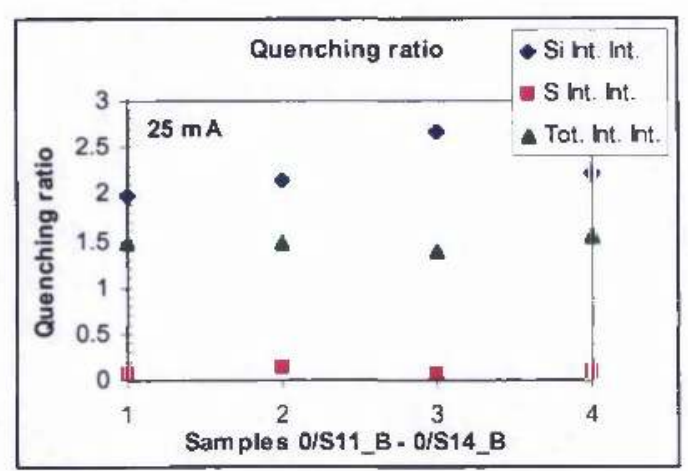

(a)

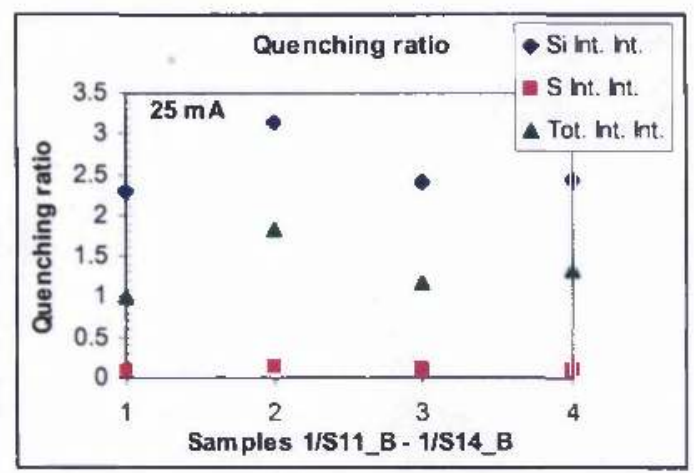

(b)

Figure 6.2 Quenching ratio (value of $\mathrm{S}$, $\mathrm{Si}$, total integrated intensity at $300 \mathrm{~K}$ divided by the value of $\mathrm{S}, \mathrm{Si}$, total integrated intensity at $80 \mathrm{~K}$ ) of samples (a) $1: 0 / \mathrm{S} 11 \mathrm{~B}, 2: 0 / \mathrm{S} 12 \mathrm{~B}, 3$ : 0/S13_B, 4: 0/S14_B (implanted with sulphur at $10^{11}, 10^{12}, 10^{13}, 10^{14} \overline{\mathrm{S}} \mathrm{cm}^{-2}$ at $30 \mathrm{keV}$ respectively, annealed at $1000^{\circ} \mathrm{C}$ for $10 \mathrm{sec}$ further implanted with boron at $10^{15} \mathrm{~B} \mathrm{~cm}^{-2}$ at 30 $\mathrm{keV}$ and further annealed at $950^{\circ} \mathrm{C}$ for $1 \mathrm{~min}$ ), and (b) 1: 1/S11_B, 2: 1/S12_B, 3: 1/S13_B, 4: 1/S14_B (implanted with sulphur at $10^{11}, 10^{12}, 10^{13}, 10^{14} \mathrm{~S} \mathrm{~cm}^{-2}$ at $30 \mathrm{keV}$ respectively, annealed at $1100^{\circ} \mathrm{C}$ for $10 \mathrm{sec}$ further implanted with boron at $10^{15} \mathrm{~B} \mathrm{~cm}^{-2}$ at $30 \mathrm{keV}$ and further annealed at $950^{\circ} \mathrm{C}$ for $1 \mathrm{~min}$ ), for silicon, sulphur and total integrated intensity, respectively.

Possible reasons for this thermal quenching with increasing temperature are due to competing radiative processes between sulphur and silicon and also non radiative processes in sulphur that take place at higher temperatures.

In addition, from Figures 5.28-5.30, it can be seen that the sulphur integrated intensity trend is decreasing with the increase of measurement temperature, whereas the silicon integrated intensity trend is increasing with the increase of measurement temperature. The total integrated intensity results from the competing mechanisms of the sulphur and silicon centres, and therefore its trend remains approximately constant with the increase of temperature.

\subsubsection{Current dependence}

In accordance with the PL experiments, the effect of electrical injection dependence was also studied. As seen from Figures 5.36-5.43 and in correspondence 
with our PL results, the trend of sulphur integrated intensity is sublinear, increasing fast at low applied current, then increasing much more slowly, being almost stable, with the increase of the applied current. To the contrary, the silicon integrated intensity trend is superlinear, increasing slow at low applied drive current, then increasing much faster with the increase of the applied current. Consequently, the sulphur emission dominates at low injection conditions whereas at higher currents the silicon band edge emission prevails. This behaviour, as for the PL results, can be attributed to the saturation of the sulphur related levels responsible for the $1.33 \mu \mathrm{m}$ emission at high injection conditions [5]. The total integrated intensity trend which is the sum of the sulphur and silicon integrated intensity trends is increasing with the increase of injection conditions. It is closely linear at low currents and follows the Si trend at higher currents. Similarly, as for the PL results, the slopes of the lines for the silicon, sulphur and total integrated intensity have been calculated from Figures 5.36 (c) -5.43 (c) which illustrate the log-log plot of the current dependence data. The values of the slopes of all lines for all measured samples at $80 \mathrm{~K}$ are listed in Table 6.2 .

\begin{tabular}{||c|c|c|c||}
\hline \multicolumn{5}{|c||}{ Slopes - EL at 80 K } \\
\hline Samples & Si & S & Total \\
\hline 0/S11_B & 1.48 & 0.35 & 1.19 \\
\hline 0/S12_B & 1.4 & 0.45 & 1.15 \\
\hline 0/S13_B & 1.36 & 0.44 & 1.004 \\
\hline 0/S14_B & 1.34 & 0.43 & 1.05 \\
\hline 1/S11_B & 1.53 & 0.39 & 1.01 \\
\hline 0/S12_B & 1.43 & 0.52 & 1.08 \\
\hline 0/S13_B & 1.46 & 0.48 & 1.05 \\
\hline 0/S14_B & 1.46 & 0.46 & 1.07 \\
\hline \hline
\end{tabular}

Table 6.2 List of slopes of the silicon, sulphur and total integrated intensity trends for all the samples as they have derived from the EL injection current dependence data at $80 \mathrm{~K}$. 
As for the PL data, from the values of the slopes listed in Table 6.2, we can conclude also that the silicon integrated intensity trends of all samples have slopes higher than 1 showing that they are increasing superlinearly with the increase of current injection. The slopes of the sulphur integrated intensity trends are below 1 so they are increasing sublinearly with the increase of the currents injection. Finally, the values of the slopes of the total integrated intensity trends of all samples are close to 1 (slightly above 1) indicating that they are increasing closely to linear with the increase of the injection conditions.

In general, the samples which were annealed at $1100{ }^{\circ} \mathrm{C}$ for $10 \mathrm{sec}$ seem to retain this behaviour, the sulphur integrated intensity trend to be higher than the sulphur integrated intensity trend up to higher currents, than the samples annealed at $1000^{\circ} \mathrm{C}$ for $10 \mathrm{sec}$.

\subsubsection{Effect of implantation dose and annealing conditions}

In Figures 5.34 and 5.35 of chapter 5 are illustrated the effect of implanted sulphur dose on the sulphur, silicon and total integrated intensity for the two different annealing conditions at $1000^{\circ} \mathrm{C}$ and $1100{ }^{\circ} \mathrm{C}$ for $10 \mathrm{sec}$. From these figures it is seen that the sulphur integrated intensity trend is first decreasing with the increase of sulphur dose having a minimum at the $10^{12} \mathrm{~S} \mathrm{~cm}^{-2}$ dose, further increasing up to the $10^{14} \mathrm{~S} \mathrm{~cm}^{-2}$ dose. In addition, the values of the sulphur integrated intensity trend are greater for the samples annealed at $1100{ }^{\circ} \mathrm{C} / 10 \mathrm{~s}$ than to the ones corresponding to the lower temperature anneal (at $1000^{\circ} \mathrm{C} / 10 \mathrm{~s}$ ). Similar behaviour has been observed for the silicon integrated intensity trend (at the $1000{ }^{\circ} \mathrm{C} / 10 \mathrm{~s}$ anneal) which is decreasing with the increase of sulphur dose having a minimum at the $10^{13} \mathrm{~S} \mathrm{~cm}^{-2}$ dose, further increasing up to the $10^{14} \mathrm{~S} \mathrm{~cm}^{-2}$ sulphur dose. The equivalent trend for the $1100^{\circ} \mathrm{C} / 10 \mathrm{~s}$ anneal is having in general smaller values than the trend of the 1000 ${ }^{0} \mathrm{C} / 10 \mathrm{~s}$ and also is not changing very much with the increase of sulphur dose. The total integrated intensity trend is similar to the silicon one. So a general first 
comment is that the sulphur dose does not affect very much the integrated intensity trends.

In order to investigate the sulphur behaviour after implantation and after annealing, two samples were chosen to be measured with the SIMS (Secondary Ion Mass Spectrometry) technique. The two samples which were chosen were (a) sample 0/S14-as implanted (implanted with sulphur at $10^{14} \mathrm{~S} \mathrm{~cm}^{-2}$ at $30 \mathrm{keV}$ ) and (b) sample 0/S14-after anneal (implanted with sulphur at $10^{14} \mathrm{~S} \mathrm{~cm}^{-2}$ at $30 \mathrm{keV}$ and further annealed at $1000{ }^{\circ} \mathrm{C}$ for $10 \mathrm{sec}$ ). The results obtained from SIMS are illustrated in Figure 6.3 ((a) and (b)). 


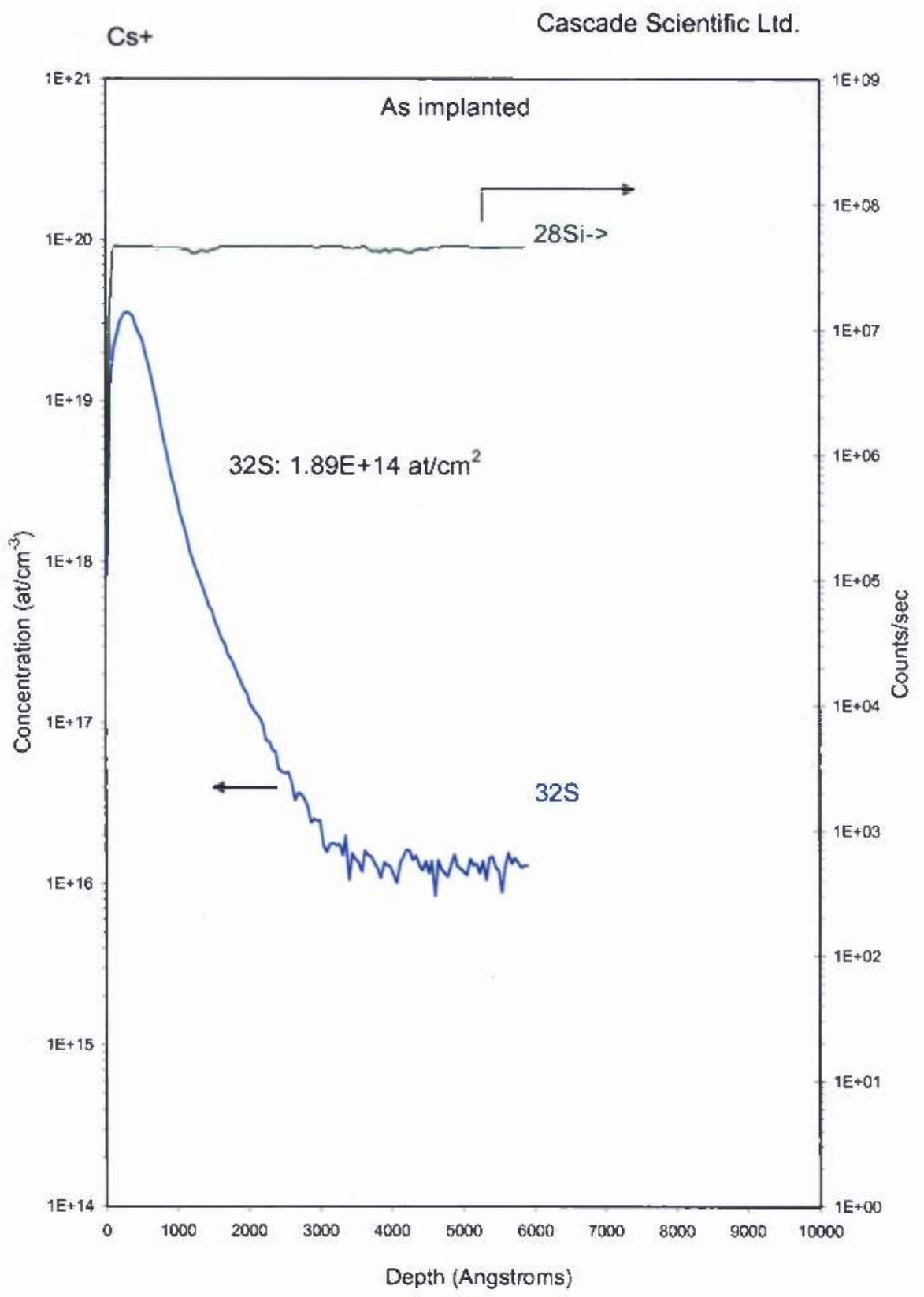

(a) 


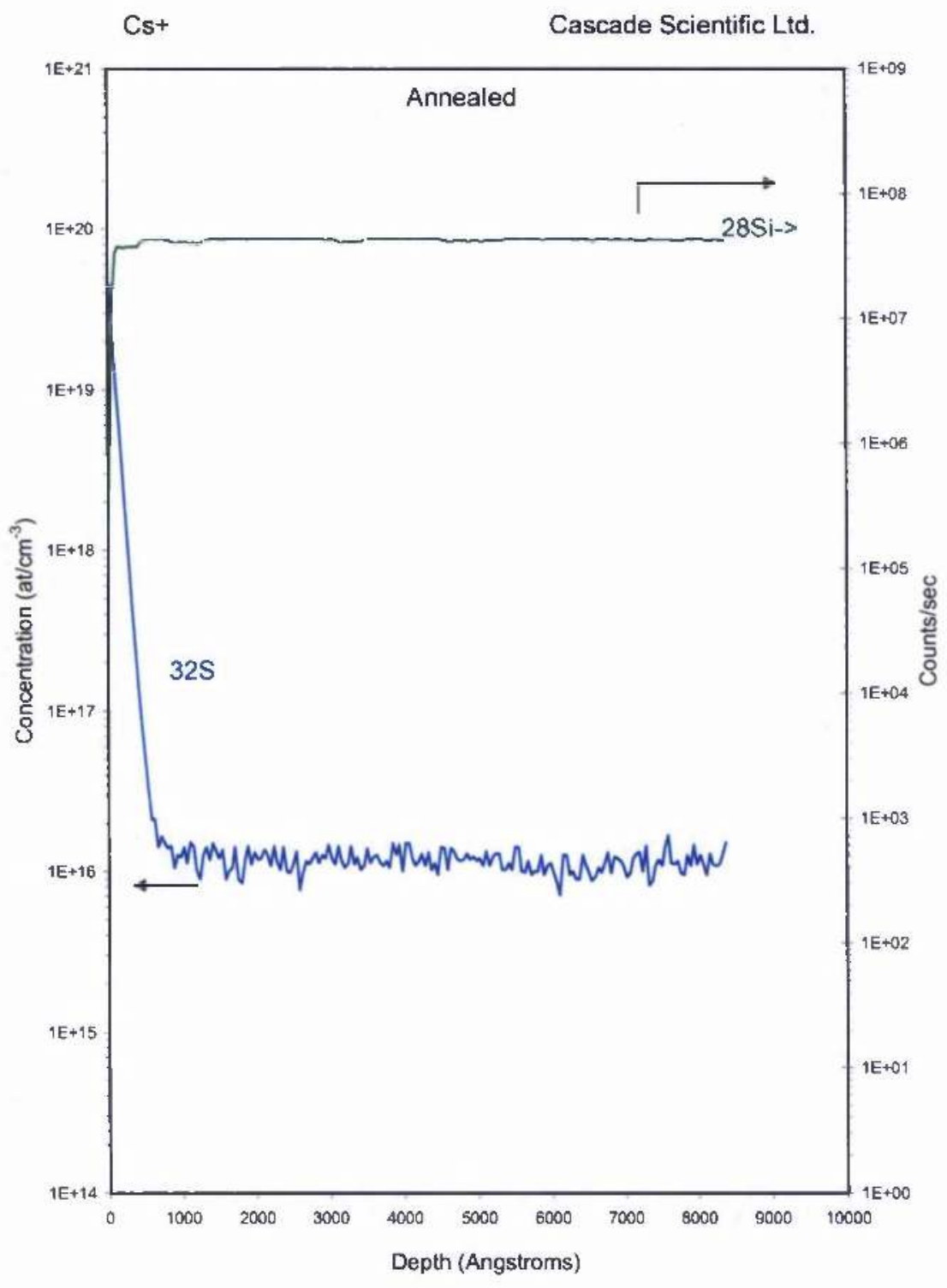

(b)

Figure 6.3 SIMS (Secondary Ion Mass Spectrometry) profiles of samples (a) 0/S14-as implanted (implanted with sulphur at $10^{14} \mathrm{~S} \mathrm{~cm}^{-2}$ at $30 \mathrm{keV}$ ) and (b) 0/S14-after anneal (implanted with sulphur at $10^{14} \mathrm{~S} \mathrm{~cm}^{-2}$ at $30 \mathrm{keV}$ and further annealed at $100{ }^{\circ} \mathrm{C}$ for $10 \mathrm{sec}$ ). Illustrated in blue line is the sulphur profile and in green line is the Si matrix signal indicating that the sputtering rate is constant. The arrows indicate the two axes where the $\mathrm{S}$ profile and the Si matrix signal correspond to.

From Figure 6.3 ((a) and (b)), we can deduce that the amount of sulphur left in the sample after the annealing treatment is much less than originally expected. In Figure 6.3 (a) is indicated the dose of sulphur as $1.89 \times 10^{14} \mathrm{at} / \mathrm{cm}^{2}$, instead of $1 \times 10^{14}$ 
at $/ \mathrm{cm}^{2}$ which was originally implanted. This difference is attributed to the fact that the SIMS measurement was quantified using a $34 \mathrm{~S}$ standard rather than a $32 \mathrm{~S}$ standard due to lack of an available $32 \mathrm{~S}$ standard. In addition, the concentration of sulphur left in the sample after the annealing treatment $\left(1000^{\circ} \mathrm{C} / 10 \mathrm{~s}\right)$ is below the detection limits of SIMS, which is $10^{16} \mathrm{~S} \mathrm{~cm}^{-3}$, therefore it cannot be measured accurately. Also in Figure 6.3 ((a), (b)) is depicted the Si matrix signal, which is stable, indicating that the sputtering rate of $\mathrm{Si}$ is stable. In addition the $\mathrm{S}$ peak in Figure 6.3 (b) indicates that there is some sulphur in the samples which is probably trapped at the surface or at the oxide interface in the sample.

\subsubsection{Explanation of results and modelling of sulphur diffusion}

In order to explain our results, a model will be proposed. Sulphur is a known fast diffuser [7]. To find the sulphur diffusion coefficient which applies to our experimental conditions we used the following formula which is valid for our temperature range and under low concentration conditions [8]:

$$
D(T)=D_{0} \exp \left(\frac{-\Delta \mathrm{E}}{k T}\right)
$$

where $D_{0}$ is the diffusion coefficient extrapolated to finite temperature and $\Delta \mathrm{E}$ is the activation energy of the diffusion and $k$ the Boltzman constant. The units of $D(T)$ are in $\mathrm{cm}^{2} / \mathrm{s}$. Therefore, using the values of $\mathrm{k}=8.6171 \times 10^{-5} \mathrm{eV} / \mathrm{K}$, and $\mathrm{D}_{0}=0.92 \mathrm{~cm}^{2} / \mathrm{s}$ and $\Delta \mathrm{E}=2.2 \mathrm{eV}$ which are valid for the temperature range between $1000^{\circ} \mathrm{C}$ and $1300{ }^{\circ} \mathrm{C}$ [9], we calculated that the diffusion coefficient of sulphur in silicon is

$$
\begin{array}{rlrl}
D_{1} & =1.794 \times 10^{-9} \mathrm{~cm}^{2} / \mathrm{s} & & \text { for } 1000^{\circ} \mathrm{C}(1273 \mathrm{~K}) \\
\text { and } & D_{1}=7.729 \times 10^{-9} \mathrm{~cm}^{2} / \mathrm{s} & \text { for } 1100^{\circ} \mathrm{C}(1373 \mathrm{~K})
\end{array}
$$


We assume that after sulphur implantation, the initial implanted distribution is a Gaussian one. In addition, we assume that the diffusion coefficient is constant and therefore independent of the position, time and defect concentration. So after our annealing treatments the diffused profile would be also a Gaussian one, considering a limited source diffusion. This diffused profile can be found as a solution to the Fick's law equation:

$$
\frac{\partial C(x, t)}{\partial t}=D \frac{\partial^{2} C(x, t)}{\partial^{2} x}
$$

where $\mathrm{C}$ is the sulphur concentration and $\mathrm{x}$ the distance from the surface. Considering the initial condition

$$
\mathrm{C}(\mathrm{x}, 0)=0
$$

and the boundary conditions

$$
\int_{0}^{\infty} C(x, t) d x=Q_{T}
$$

and

$$
C(x, \infty)=0
$$

The solution of equation (6.4) is:

$$
C(x, t)=\frac{Q_{T}}{\sqrt{\pi D t}} \exp \left(\frac{-x^{2}}{4 D t}\right)
$$

If we consider the projected range $R_{p}$, the straggle $\sigma_{p}$ and the dose $Q$, our Gaussian defused profiles can be described in terms of :

$$
C(x)=\frac{Q}{\sqrt{2 \pi} \sigma_{P}} \exp \left(-\frac{\left(x-R_{P}\right)^{2}}{2 \sigma_{P}^{2}}\right)
$$

The broadening of the diffused profiles can be calculated by replacing $\sigma_{\mathrm{P}}$ with an effective sigma, $\sigma_{\text {eff }}[10,11]$ in terms of

$$
\sigma_{e f f}=\sqrt{\sigma_{P}^{2}+2 D_{1} t}
$$

where $\mathrm{D}_{1}$ is the diffusion coefficient of sulphur for $1000{ }^{\circ} \mathrm{C}$ or $1100{ }^{\circ} \mathrm{C}$ (equations (6.2) and (6.3) respectively) and $t_{1}=10 \mathrm{~s}$.

Since for our devices we applied also a further anneal at $950{ }^{\circ} \mathrm{C}$ for $1 \mathrm{~min}$, we need to consider that this anneal also affects the diffused profile (equation (6.9)), and the effective sigma, $\sigma_{\text {eff, }}$ would be written in terms of 


$$
\sigma_{e f f}=\sqrt{\sigma_{p}^{2}+2 D_{1} t_{1}+2 D_{2} t_{2}}
$$

where $D_{1}$ and $t_{1}$ are as for the equation $(6.10)$, the diffusion coefficient of sulphur at $1000{ }^{\circ} \mathrm{C}$ or $1100{ }^{\circ} \mathrm{C}$ at the annealing time of $t_{1}=10 \mathrm{~s}$ and $\mathrm{D}_{2}$ and $t_{2}$ denote the diffusion coefficient of sulphur at $950{ }^{\circ} \mathrm{C}$ at $t_{2}=60 \mathrm{~s}$ ( $1 \mathrm{~min}$ ), which is using equation (6.1) for $950{ }^{\circ} \mathrm{C}(1223 \mathrm{~K})$

$$
\mathrm{D}_{2}=7.901 \times 10^{-10} \mathrm{~cm}^{2} / \mathrm{s} \quad \text { for } 950^{0} \mathrm{C}(1223 \mathrm{~K})
$$

Therefore the Gaussian fit which describes the diffusion of sulphur is:

$$
C(x)=\frac{Q}{\sqrt{2 \pi} \sqrt{\sigma_{P}^{2}+2 D_{1} t_{1}+2 D_{2} t_{2}}} \exp \left(-\frac{\left(x-R_{P}\right)^{2}}{2\left(\sqrt{\sigma_{P}^{2}+2 D_{1} t_{1}+2 D_{2} t_{2}}\right)^{2}}\right)
$$

We have assumed two cases that might take place inside our devices; (a) either perfect reflection from the sample's surface takes place, so the equation that explains the concentration of sulphur is given by:

$$
C(x)=\frac{Q}{\sqrt{2 \pi} \sqrt{\sigma_{P}^{2}+2 D_{1} t_{1}+2 D_{2} t_{2}}}\left(L_{1}+L_{2}\right)
$$

where

$$
L_{1}=\exp \left(-\frac{\left(x-R_{P}\right)^{2}}{2\left(\sqrt{\sigma_{P}^{2}+2 D_{1} t_{1}+2 D_{2} t_{2}}\right)^{2}}\right)
$$

and

$$
L_{2}=\exp \left(-\frac{\left(x+R_{P}\right)^{2}}{2\left(\sqrt{\sigma^{2}{ }_{P}+2 D_{1} t_{2}+2 D_{2} t_{2}}\right)^{2}}\right)
$$

or (b) total loss from the sample's surface take place and the equation that describes the concentration of sulphur for this case is:

$$
C(x)=\frac{Q}{\sqrt{2 \pi} \sqrt{\sigma_{P}^{2}+2 D_{1} t_{1}+2 D_{2} t_{2}}}\left(L_{1}-L_{2}\right)
$$


Using the TRIM program, which gives us the sulphur ion range distribution after the sulphur implantation, can also provide some extra features of the profile such as, values of the projected range, $R_{P}$, the straggle, $\sigma$, and the sputtering of $\mathrm{Si}$ atoms per sulphur ion. The value for the sputtering of $\mathrm{Si}$ atoms per sulphur atom was found to be 1.038. Therefore, multiplying this number by the sulphur dose (which is in our case $10^{11}, 10^{12}, 10^{13}, 10^{14} \mathrm{~S} \mathrm{~cm}^{-2}$ depending on the sample) and dividing by the silicon volume concentration which is around $5 \times 10^{22} \mathrm{~cm}^{-3}$, it was found that even for the highest $\mathrm{S}$ dose $\left(10^{14} \mathrm{~S} \mathrm{~cm}^{-2}\right)$ sample, $0.207 \AA$ is lost from the surface, which is a very small amount and can be neglected.

The active concentration of sulphur is related to the solid solubility of sulphur in silicon, which is the maximum concentration of sulphur that can be accommodated in silicon at any given temperature before being precipitated. The values for the solid solubility in sulphur found in the literature derive mainly from R. O. Carlson et al. $[9,12]$. From the fitting of the solid solubility trend, we found that it follows the trend:

$$
\log Y=23.923-11.426 X
$$

The values of $\mathrm{X}$ are in $10^{3} / \mathrm{K}$ and the values of $\log \mathrm{Y}$ are in $\mathrm{cm}^{-3}$ (the sulphur concentration). Therefore from equation (6.18) it was found that the solid solubility limits of sulphur at $1000^{\circ} \mathrm{C}$ and $1100^{\circ} \mathrm{C}$ are

$$
\begin{array}{lll} 
& 8.859 \times 10^{14} \mathrm{~S} \mathrm{~cm}^{-3} & \text { for } 1000^{\circ} \mathrm{C}(1273 \mathrm{~K}) \\
\text { and } & 3.991 \times 10^{15} \mathrm{~S} \mathrm{~cm}^{-3} & \text { for } 1100^{\circ} \mathrm{C}(1373 \mathrm{~K})
\end{array}
$$

Taking into account all the analysis which was performed above, we have plotted the Gaussian profile after sulphur implantation for samples implanted with $10^{11} \mathrm{~S} \mathrm{~cm}^{-2}$ at $30 \mathrm{keV}$, annealed at $1000{ }^{\circ} \mathrm{C}$ for $10 \mathrm{~s}$ or at $1100{ }^{\circ} \mathrm{C}$ for $10 \mathrm{~s}$, further implanted with boron at $10^{15} \mathrm{~B} \mathrm{~cm}^{-2}$ at $30 \mathrm{keV}$ and further annealed at $950{ }^{\circ} \mathrm{C}$ for 1 min, considering the two hypotheses of perfect reflection from the surface and total loss from the surface (Figures $6.5,6.6$ ). 


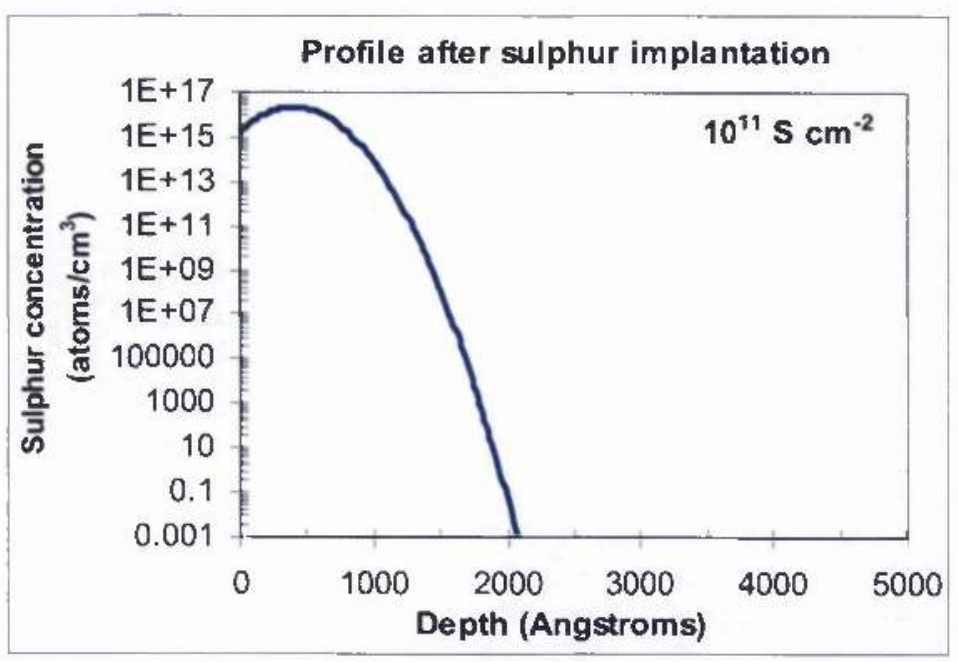

Figure 6.4 Gaussian profile of sulphur concentration for sample implanted with $10^{11} \mathrm{~S} \mathrm{~cm}^{-2}$ at $30 \mathrm{keV}$.

The Gaussian profile of Figure 6.4 has been derived from the raw data of TRIM, which gives us with high precision the concentration of sulphur atoms inside the sample after sulphur implantation. The raw data of TRIM have been imported to ORIGIN and using the equations (6.9), (6.14) and (6.17) the graphs of Figures 6.46.6 have been produced, respectively. The values which have been used are: 402.55 $\AA$ for the projected range, $R_{p}, 177.22 \AA$ for the straggle, $\sigma$, and $1.025 \times 10^{19}$ atoms $/ \AA$ for $\mathrm{Q}$, as derived from fitting a Gaussian to the data in ORIGIN and they are very close to the same values derived from TRIM. 


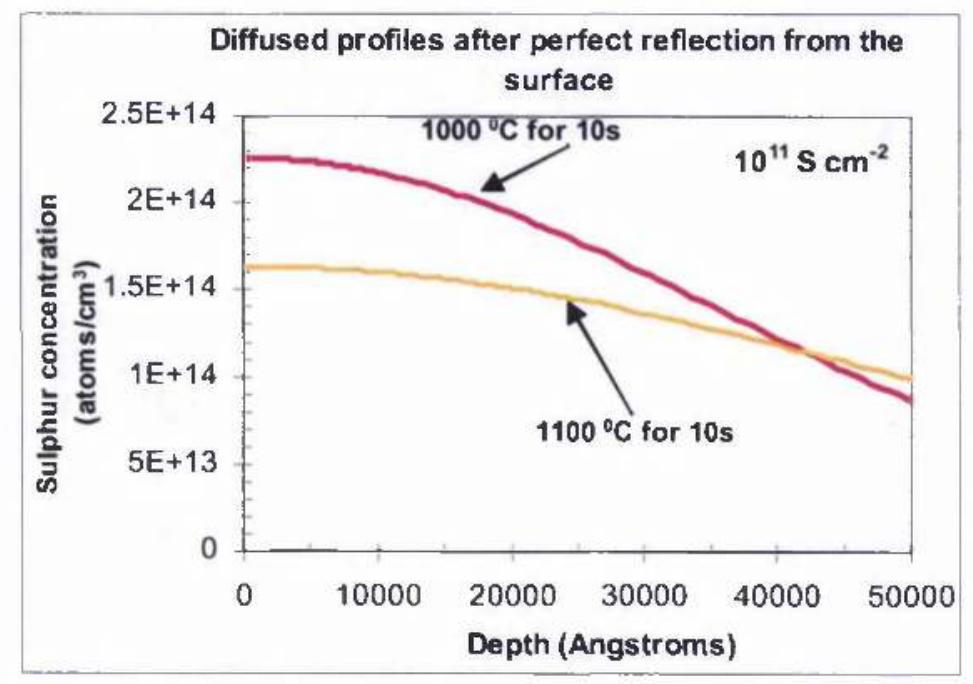

Figure 6.5 Gaussian diffused profiles of sulphur concentration considering the case of perfect reflection from the sample's surface. The samples were implanted with $\mathrm{S}$ at $10^{11} \mathrm{~S}$ $\mathrm{cm}^{-2}$ at $30 \mathrm{keV}$ and were annealed at $1000^{\circ} \mathrm{C}$ for $10 \mathrm{~s}$ or $1100{ }^{\circ} \mathrm{C}$ for $10 \mathrm{~s}$, were implanted with $\mathrm{B}$ at $10^{15} \mathrm{~B} \mathrm{~cm}^{-2}$ at $30 \mathrm{keV}$ and further implanted at $950^{\circ} \mathrm{C}$ for $1 \mathrm{~min}$.

The profile of Figure 6.5 has derived from equation (6.14) using the values of the diffusion coefficients (equations (6.1), (6.2) (or (6.3)) and (6.12)). As can be seen from Figure 6.5, the sulphur concentration after the annealing treatments is considerably decreased. We considered here perfect reflection from the sample's surface.

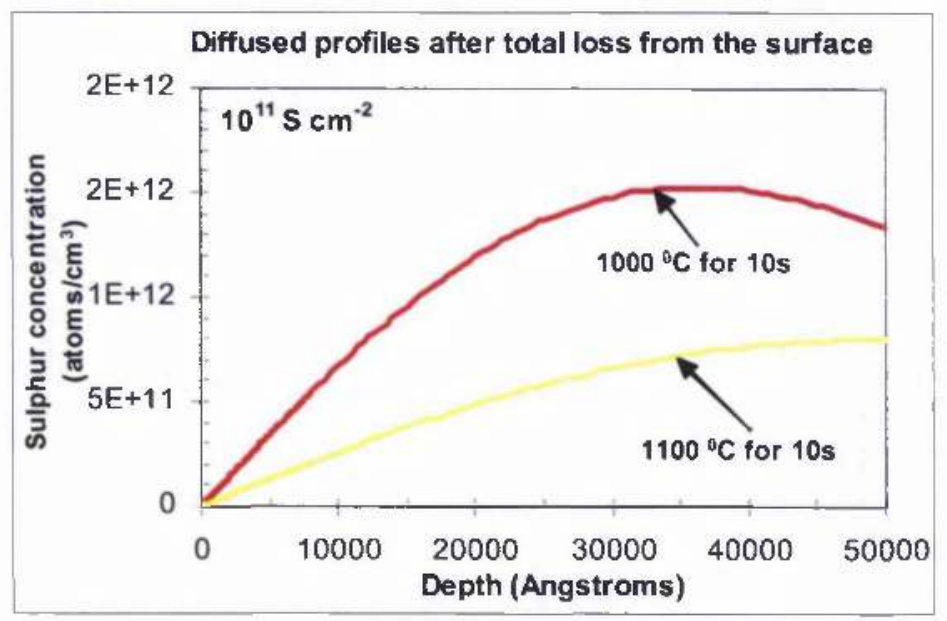

Figure 6.6 Gaussian diffused profiles of sulphur concentration considering the case of total loss from the sample's surface. The samples were implanted with $\mathrm{S}$ at $10^{11} \mathrm{~S} \mathrm{~cm}^{-2}$ at $30 \mathrm{keV}$ and were annealed at $1000^{\circ} \mathrm{C}$ for $10 \mathrm{~s}$ or $1100^{\circ} \mathrm{C}$ for $10 \mathrm{~s}$, were implanted with $\mathrm{B}$ at $10^{15} \mathrm{~B}$ $\mathrm{cm}^{-2}$ at $30 \mathrm{keV}$ and further implanted at $950^{\circ} \mathrm{C}$ for $1 \mathrm{~min}$. 
As for Figure 6.5, Figure 6.6 shows the profile of sulphur concentration after the annealing treatments considering the case of total loss from the sample's surface, using equations $(6.17),(6.1),(6.2)$ (or (6.3)) and (6.12). The sulphur concentration is even smaller in this case when we're having total loss from the sample's surface. The diffused profiles of the rest of the samples implanted with sulphur doses at $10^{12}, 10^{13}$ and $10^{14} \mathrm{~S} \mathrm{~cm}^{-2}$ are very similar to the ones illustrated in Figures 6.5 and 6.6. The only difference is that the sulphur concentration is bigger in numbers of 10,100 , $1000 \mathrm{~S}_{\text {atoms }} \mathrm{cm}^{-3}$ in respect to the values of the profiles for the $10^{11} \mathrm{~S} \mathrm{~cm}^{-2}$ dose.

In order to have a more complete view of the diffused profiles, which stem from equations (6.14) and (6.17) using the values of diffusion coefficients from equations (6.1), (6.2) (or (6.3)) and (6.12), the solid solubility trends (equations (6.19) and (6.20)) will also be displayed on the same graphs. Again we consider the two cases of perfect reflection and total loss from the sample's surface.

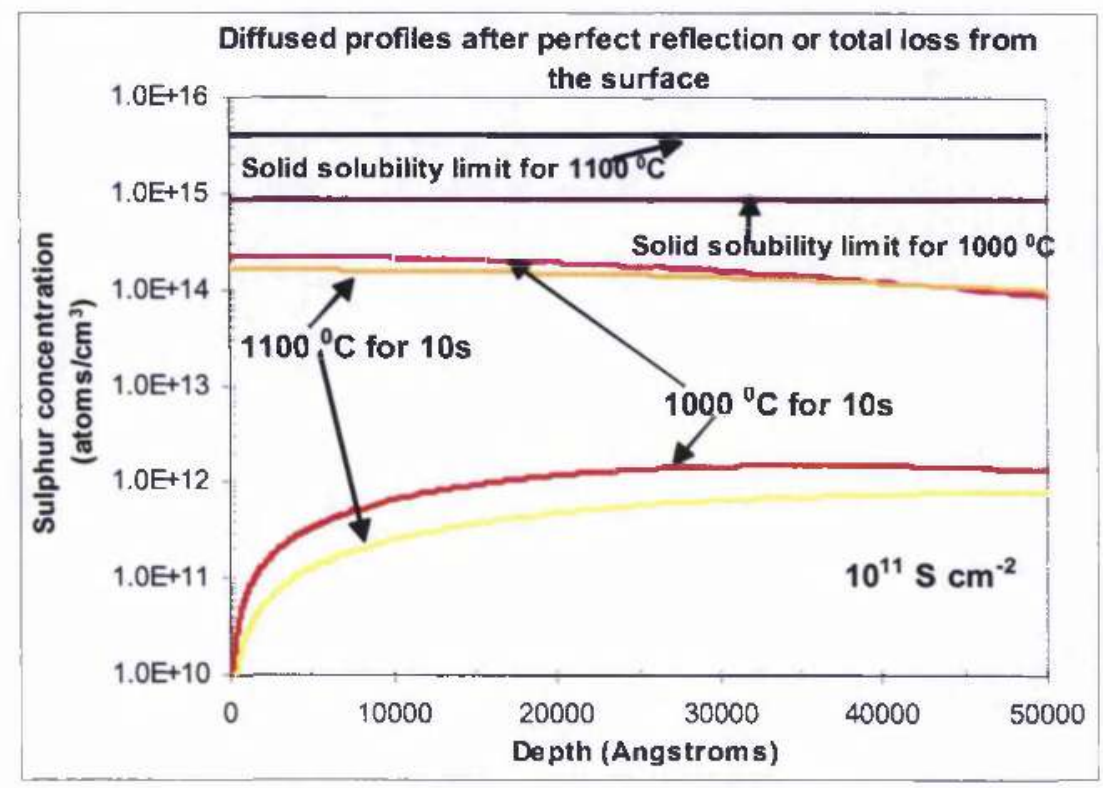

Figure 6.7 Gaussian diffused profiles of sulphur concentration considering the two cases of perfect reflection (upper profiles) and total loss (lower profiles) from the sample's surface. The samples were implanted with $\mathrm{S}$ at $10^{11} \mathrm{~S} \mathrm{~cm}^{-2}$ at $30 \mathrm{keV}$ and were annealed at $1000^{\circ} \mathrm{C}$ for $10 \mathrm{~s}$ or $1100^{\circ} \mathrm{C}$ for $10 \mathrm{~s}$, were further implanted with $\mathrm{B}$ at $10^{15} \mathrm{~B} \mathrm{~cm}^{-2}$ at $30 \mathrm{keV}$ and further annealed at $950{ }^{\circ} \mathrm{C}$ for $1 \mathrm{~min}$. The trends of the solid solubility limits for the two annealing conditions $\left(1000^{\circ} \mathrm{C}\right.$ and $1100^{\circ} \mathrm{C}$ for $10 \mathrm{~s}$ respectively) are also illustrated. 
Therefore in Figure 6.7 it can more clearly be observed that the sulphur concentration for the samples implanted with sulphur at $10^{11} \mathrm{~S} \mathrm{~cm}^{-2}$ for $10 \mathrm{~s}$ is lower than the solid solubility limits, for both cases of perfect reflection and total loss from the sample's surface. In addition the sulphur concentration is higher for the samples that have been annealed for $1000^{\circ} \mathrm{C}$ for $10 \mathrm{~s}$ than those annealed at $1100{ }^{\circ} \mathrm{C}$ for $10 \mathrm{~s}$.

In Figures 6.8-6.10, will be illustrated the Gaussian diffused profiles of the rest of samples, implanted with sulphur doses at $10^{12}, 10^{13}$ and $10^{14} \mathrm{~S} \mathrm{~cm}^{-2}$ at $30 \mathrm{keV}$, annealed at $1000{ }^{\circ} \mathrm{C}$ for $10 \mathrm{~s}$ or at $1100{ }^{\circ} \mathrm{C}$ for $10 \mathrm{~s}$, further annealed with boron at $10^{15} \mathrm{~B} \mathrm{~cm}^{-2}$ at $30 \mathrm{keV}$ and finally annealed at $950{ }^{\circ} \mathrm{C}$ for $1 \mathrm{~min}$, for the two cases of perfect reflection and total loss from the sample's surface, along with the solid solubility trends.

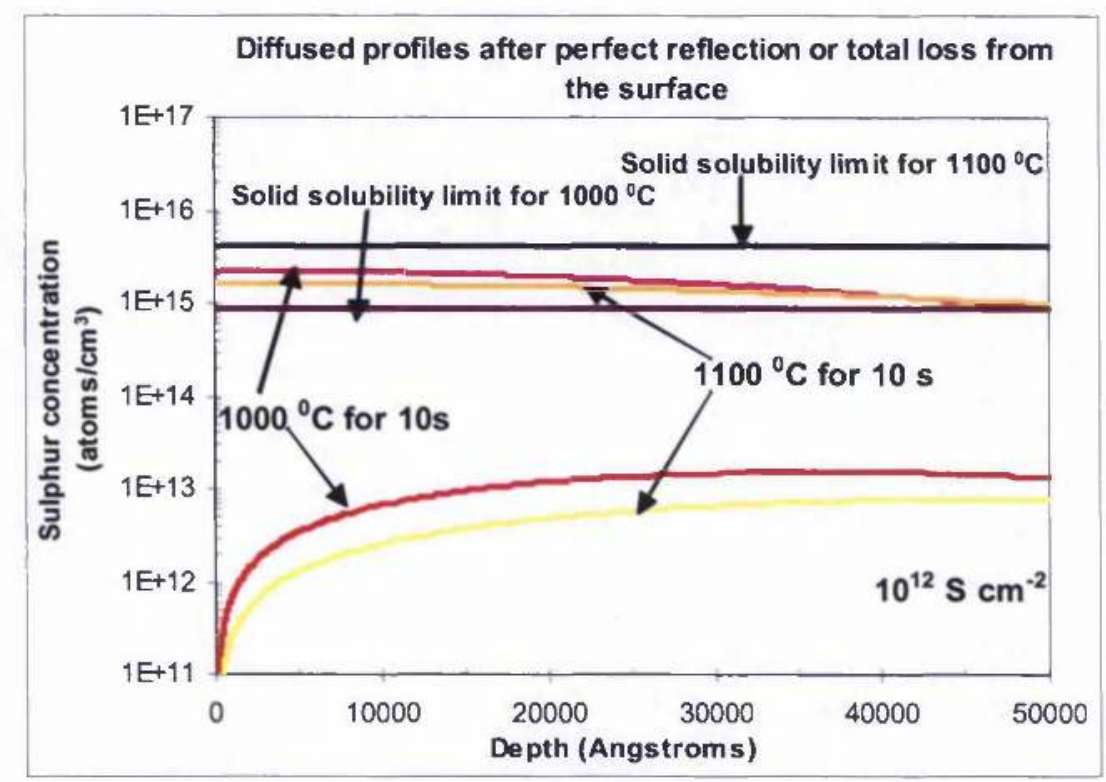

Figure 6.8 Gaussian diffused profiles of sulphur concentration considering the two cases of perfect reflection (upper profiles) and total loss (lower profiles) from the sample's surface. The samples were implanted with $\mathrm{S}$ at $10^{12} \mathrm{~S} \mathrm{~cm}^{-2}$ at $30 \mathrm{keV}$ and were annealed at $1000^{\circ} \mathrm{C}$ for $10 \mathrm{~s}$ or $1100^{\circ} \mathrm{C}$ for $10 \mathrm{~s}$, were further implanted with $\mathrm{B}$ at $10^{15} \mathrm{~B} \mathrm{~cm}^{-2}$ at $30 \mathrm{keV}$ and further annealed at $950{ }^{\circ} \mathrm{C}$ for $1 \mathrm{~min}$. The trends of the solid solubility limits for the two annealing conditions $\left(1000^{\circ} \mathrm{C}\right.$ and $1100^{\circ} \mathrm{C}$ for $10 \mathrm{~s}$ respectively) are also illustrated.

The profile corresponding to the sample implanted at $10^{12} \mathrm{~S} \mathrm{~cm}^{-2}$, annealed at $1000{ }^{\circ} \mathrm{C}$ for $10 \mathrm{~s}$ considering perfect reflection from its surface is exceeding the solid 
solubility limit for $1000{ }^{\circ} \mathrm{C}$, whereas for the $1100{ }^{\circ} \mathrm{C} / 10 \mathrm{~s}$ anneal, the sulphur concentration is still below the solid solubility limit for $1100{ }^{0} \mathrm{C}$ (Figure 6.8). However, the values of the $\mathrm{S}$ concentration considering total loss from the surface are below the solid solubility limits for both annealing temperatures.

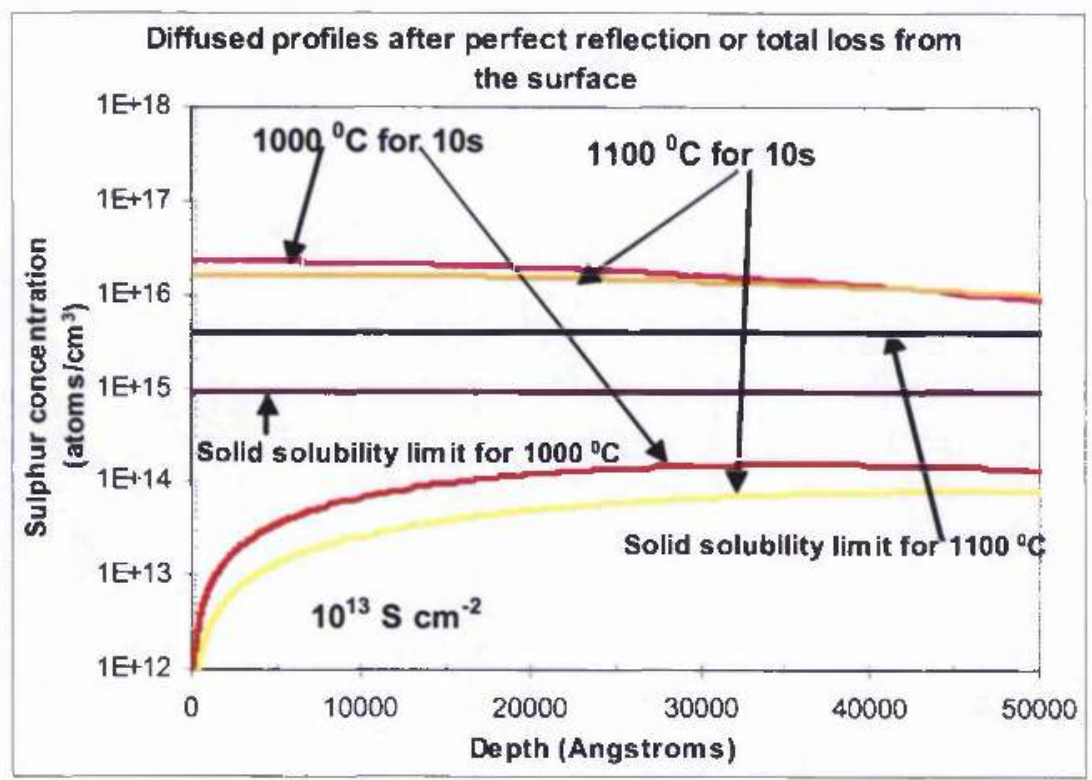

Figure 6.9 Gaussian diffused profiles of sulphur concentration considering the two cases of perfect reflection (upper profiles) and total loss (lower profiles) from the sample's surface. The samples were implanted with $\mathrm{S}$ at $10^{13} \mathrm{~S} \mathrm{~cm}^{-2}$ at $30 \mathrm{keV}$ and were annealed at $1000^{0} \mathrm{C}$ for $10 \mathrm{~s}$ or $1100^{\circ} \mathrm{C}$ for $10 \mathrm{~s}$, were further implanted with $\mathrm{B}$ at $10^{15} \mathrm{~B} \mathrm{~cm}^{-2}$ at $30 \mathrm{keV}$ and further annealed at $950{ }^{\circ} \mathrm{C}$ for $1 \mathrm{~min}$. The trends of the solid solubility limits for the two annealing conditions $\left(1000{ }^{\circ} \mathrm{C}\right.$ and $1100^{\circ} \mathrm{C}$ for $10 \mathrm{~s}$ respectively) are also illustrated.

At the $10^{13} \mathrm{~S} \mathrm{~cm}^{-2}$ dose, the diffused profiles of the sulphur concentration for perfect reflection from the sample's surface are exceeding the solid solubility limits for both of the temperature anneals $\left(1000{ }^{\circ} \mathrm{C}\right.$ and $1100{ }^{\circ} \mathrm{C}$ for $\left.10 \mathrm{~s}\right)$. However, as for the $10^{12} \mathrm{~S} \mathrm{~cm}^{-2}$ dose, the sulphur concentration values for the case of the total loss from the sample's surface are still below the solid solubility limits for both temperatures (Figure 6.9). 


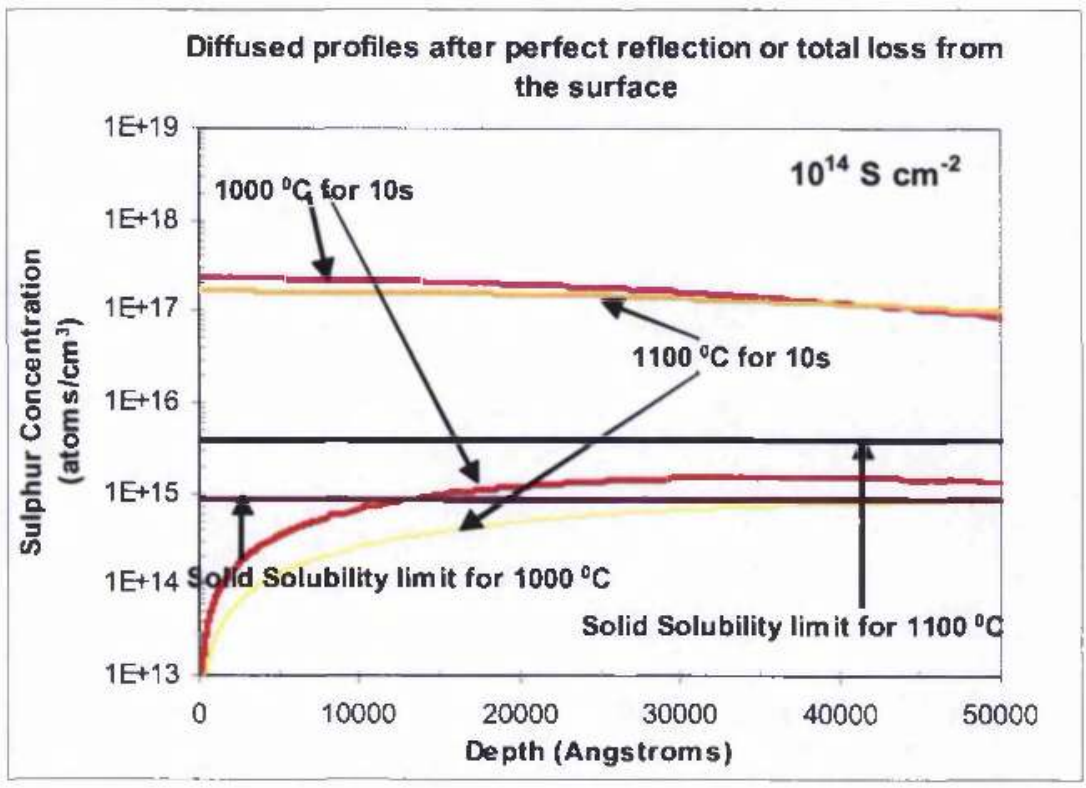

Figure 6.10 Gaussian diffused profiles of sulphur concentration considering the two cases of perfect reflection (upper profiles) and total loss from (lower profiles) the sample's surface. The samples were implanted with $\mathrm{S}$ at $10^{14} \mathrm{~S} \mathrm{~cm}^{-2}$ at $30 \mathrm{keV}$ and were annealed at $1000{ }^{\circ} \mathrm{C}$ for $10 \mathrm{~s}$ or $1100^{\circ} \mathrm{C}$ for $10 \mathrm{~s}$, were further implanted with $\mathrm{B}$ at $10^{15} \mathrm{~B} \mathrm{~cm}$ at $30 \mathrm{keV}$ and further annealed at $950{ }^{\circ} \mathrm{C}$ for $1 \mathrm{~min}$. The trends of the solid solubility limits for the two annealing conditions $\left(1000^{\circ} \mathrm{C}\right.$ and $1100^{\circ} \mathrm{C}$ for $10 \mathrm{~s}$ respectively) are also illustrated.

Finally, at the $10^{14} \mathrm{~S} \mathrm{~cm}^{-2}$ dose, for the case of perfect reflection from the sample's surface, the profiles are much higher than the solid solubility limits for both temperature anneals $\left(1000{ }^{\circ} \mathrm{C}\right.$ and $1100{ }^{\circ} \mathrm{C}$ for $10 \mathrm{~s}$, respectively). For the case of total loss from the surface and at the $1000{ }^{\circ} \mathrm{C}$ annealing temperature, the sulphur concentration is less than the solid solubility limit of $1000{ }^{\circ} \mathrm{C}$ up to the $13500 \AA$. Above that depth the sulphur concentration values exceed the solid solubility limit. At the $1100{ }^{\circ} \mathrm{C}$ annealing temperature the values of the sulphur concentration are still below the solid solubility limits throughout the profile (Figure 6.10).

The key parameter for the devices is the dissolved dose in the active region of the LED which is $1200 \AA$ from the surface. The dissolved sulphur dose is responsible for the creation of the sulphur luminescence centres. Therefore, the values of the dissolved dose come from our profiles (Figures 6.7-6.10) at $1200 \AA$. 
In Figures 6.11-6.14 are illustrated the Figures 6.7-6.10 expanded at the area up to a depth of $1500 \AA$ to show better the values of the diffused sulphur profiles, for all the four sulphur doses.

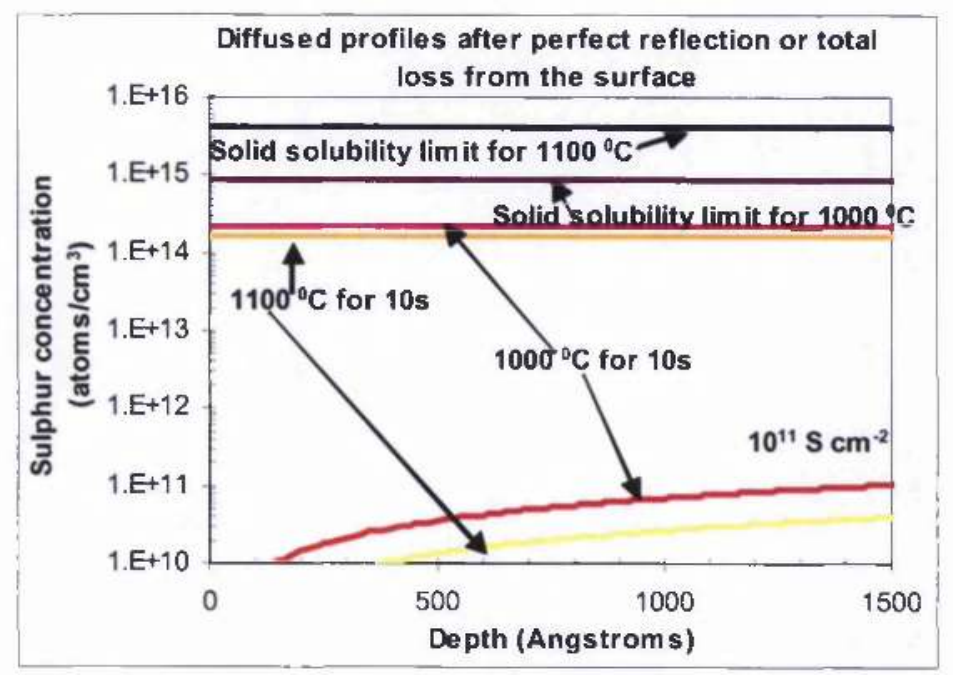

Figure 6.11 Gaussian diffused profiles of sulphur concentration considering the two cases of perfect reflection (upper profiles) and total loss (lower profiles) from the sample's surface. The samples were implanted with $\mathrm{S}$ at $10^{11} \mathrm{~S} \mathrm{~cm}^{-2}$ at $30 \mathrm{keV}$ and were annealed at $1000^{\circ} \mathrm{C}$ for $10 \mathrm{~s}$ or $1100{ }^{\circ} \mathrm{C}$ for $10 \mathrm{~s}$, were further implanted with $\mathrm{B}$ at $10^{15} \mathrm{~B} \mathrm{~cm} \mathrm{~cm}^{-2}$ at $30 \mathrm{keV}$ and further annealed at $950{ }^{\circ} \mathrm{C}$ for $1 \mathrm{~min}$. The trends of the solid solubility limits for the two annealing conditions $\left(1000^{\circ} \mathrm{C}\right.$ and $1100{ }^{\circ} \mathrm{C}$ for $10 \mathrm{~s}$ respectively) are also illustrated. The profiles are expanded up to $1500 \AA$ to illustrate better the depth close to the sample's surface. 


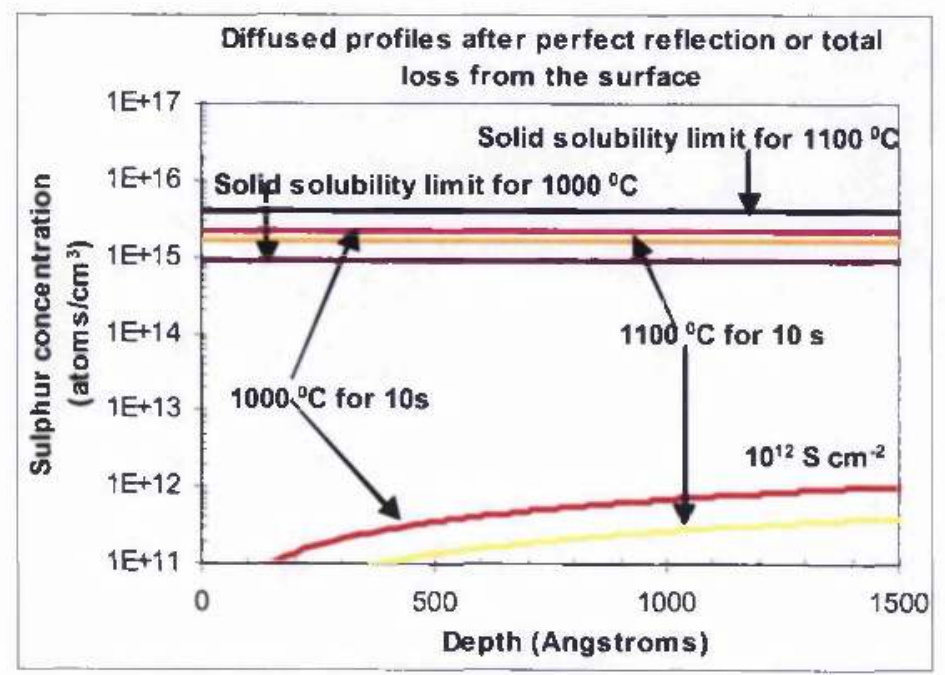

Figure 6.12 Gaussian diffused profiles of sulphur concentration considering the two cases of perfect reflection (upper profiles) and total loss (lower profiles) from the sample's surface. The samples were implanted with $\mathrm{S}$ at $10^{12} \mathrm{~S} \mathrm{~cm}^{-2}$ at $30 \mathrm{keV}$ and were annealed at $1000{ }^{\circ} \mathrm{C}$ for $10 \mathrm{~s}$ or $1100^{\circ} \mathrm{C}$ for $10 \mathrm{~s}$, were further implanted with $\mathrm{B}$ at $10^{15} \mathrm{~B} \mathrm{~cm}$ at $30 \mathrm{keV}$ and further annealed at $950{ }^{\circ} \mathrm{C}$ for $1 \mathrm{~min}$. The trends of the solid solubility limits for the two annealing conditions $\left(1000{ }^{\circ} \mathrm{C}\right.$ and $1100{ }^{\circ} \mathrm{C}$ for $10 \mathrm{~s}$ respectively) are also illustrated. The profiles are expanded up to $1500 \AA$ to depict better the depth close to the sample's surface.

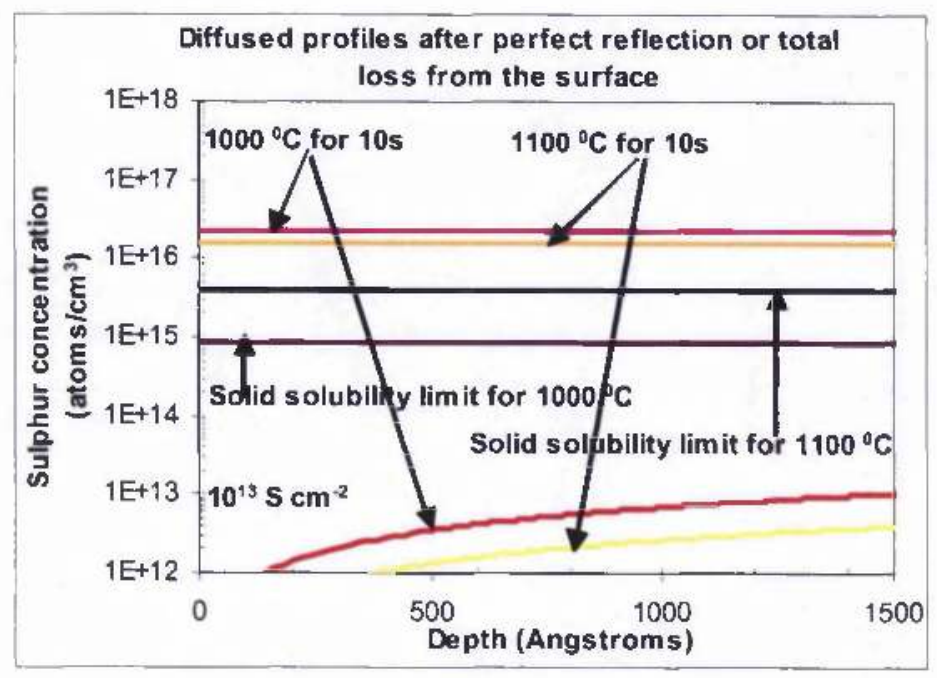

Figure 6.13 Gaussian diffused profiles of sulphur concentration considering the two cases of perfect reflection (upper profiles) and total loss (lower profiles) from the sample's surface. The samples were implanted with $\mathrm{S}$ at $10^{13} \mathrm{~S} \mathrm{~cm}^{-2}$ at $30 \mathrm{keV}$ and were annealed at $1000{ }^{\circ} \mathrm{C}$ for $10 \mathrm{~s}$ or $1100^{\circ} \mathrm{C}$ for $10 \mathrm{~s}$, were further implanted with $\mathrm{B}$ at $10^{15} \mathrm{~B} \mathrm{~cm}$ at $30 \mathrm{keV}$ and further annealed at $950{ }^{\circ} \mathrm{C}$ for $1 \mathrm{~min}$. The trends of the solid solubility limits for the two annealing conditions $\left(1000{ }^{\circ} \mathrm{C}\right.$ and $1100{ }^{\circ} \mathrm{C}$ for $10 \mathrm{~s}$ respectively) are also illustrated. The profiles are expanded up to $1500 \AA$ to depict better the depth close to the sample's surface. 


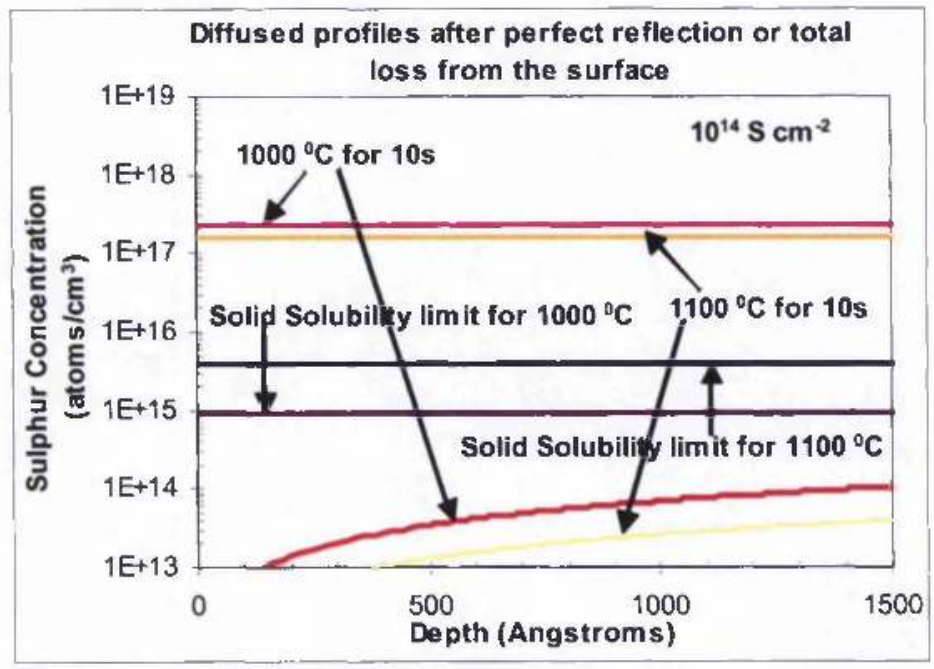

Figure 6.14 Gaussian diffused profiles of sulphur concentration considering the two cases of perfect reflection (upper profiles) and total loss (lower profiles) from the sample's surface. The samples were implanted with S at $10^{13} \mathrm{~S} \mathrm{~cm}^{-2}$ at $30 \mathrm{keV}$ and were annealed at $1000{ }^{\circ} \mathrm{C}$ for $10 \mathrm{~s}$ or $1100{ }^{\circ} \mathrm{C}$ for $10 \mathrm{~s}$, were further implanted with $\mathrm{B}$ at $10^{15} \mathrm{~B} \mathrm{~cm}$ at $30 \mathrm{keV}$ and further annealed at $950{ }^{\circ} \mathrm{C}$ for $1 \mathrm{~min}$. The trends of the solid solubility limits for the two annealing conditions $\left(1000^{\circ} \mathrm{C}\right.$ and $1100{ }^{\circ} \mathrm{C}$ for $10 \mathrm{~s}$ respectively) are also illustrated. The profiles are expanded up to $1500 \AA$ to depict better the depth close to the sample's surface.

From the data of Figures $6.11-6.14$ the dissolved sulphur dose versus the implanted sulphur dose can be plotted, for the two cases of the perfect reflection and total loss from the sample's surface and for both annealing temperatures $\left(1000{ }^{\circ} \mathrm{C}\right.$ and $1100^{\circ} \mathrm{C}$ for $10 \mathrm{~s}$ ), (Figures 6.15 and 6.16 respectively). 


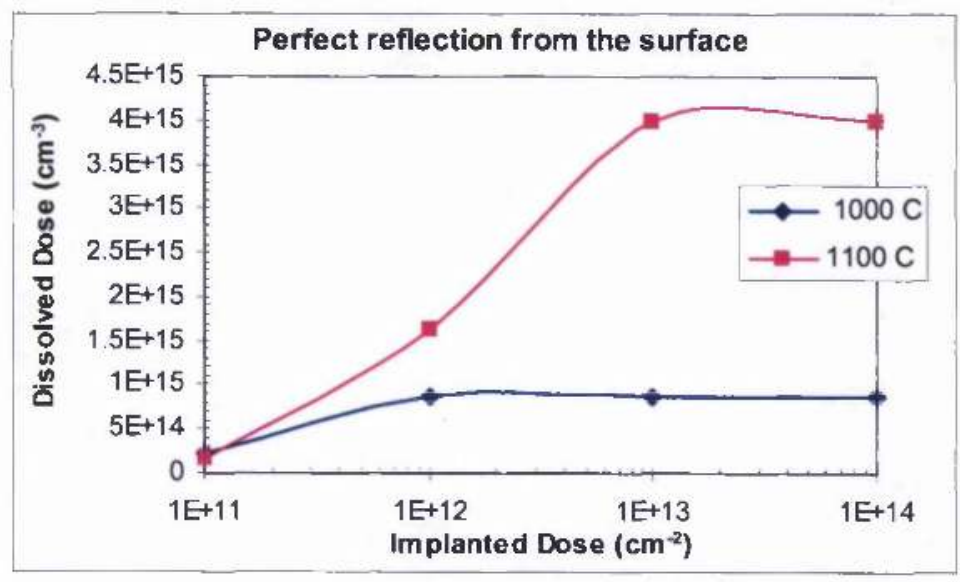

(a)

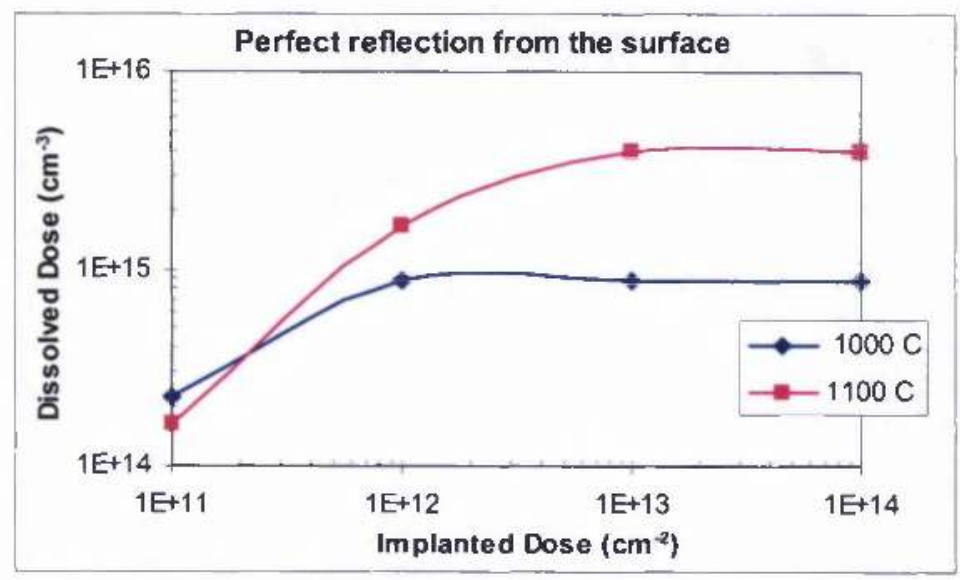

(b)

Figure 6.15 (a) Dependence of the sulphur dissolved dose with the implanted sulphur dose considering the case of perfect reflection from the sample's surface for the two temperature annealing conditions, $1000^{\circ} \mathrm{C}$ and $1100^{\circ} \mathrm{C}$ for $10 \mathrm{~s}$. (b) Log-Log plot of the same data as in (a).

Therefore, from Figure 6.15 ((a) and (b)) we can deduce that the amount of sulphur that is being dissolved increases fast at low implanted sulphur doses and much less, almost being stable, at higher implanted sulphur doses. In addition, the amount of dissolved sulphur is larger at the higher temperature anneal $\left(1100{ }^{\circ} \mathrm{C}\right.$ for $10 \mathrm{~s}$ ), which justifies the higher sulphur integrated intensity values at this temperature anneal, as we have observed in our results (Figure $5.34 \mathrm{~b}$ ). 
For the case that we have total loss from the surface of the samples, the amount of sulphur that is dissolved is increasing linearly with the increase of the implanted sulphur dose (Figure 6.16). Furthermore, the amount of dissolved sulphur is larger at the $1000{ }^{\circ} \mathrm{C}$ temperature anneal, in contrast to the previous results. The linear behaviour of the dissolved sulphur dose is more clearly seen in the log-log scale of Figure $6.16(\mathrm{~b})$.

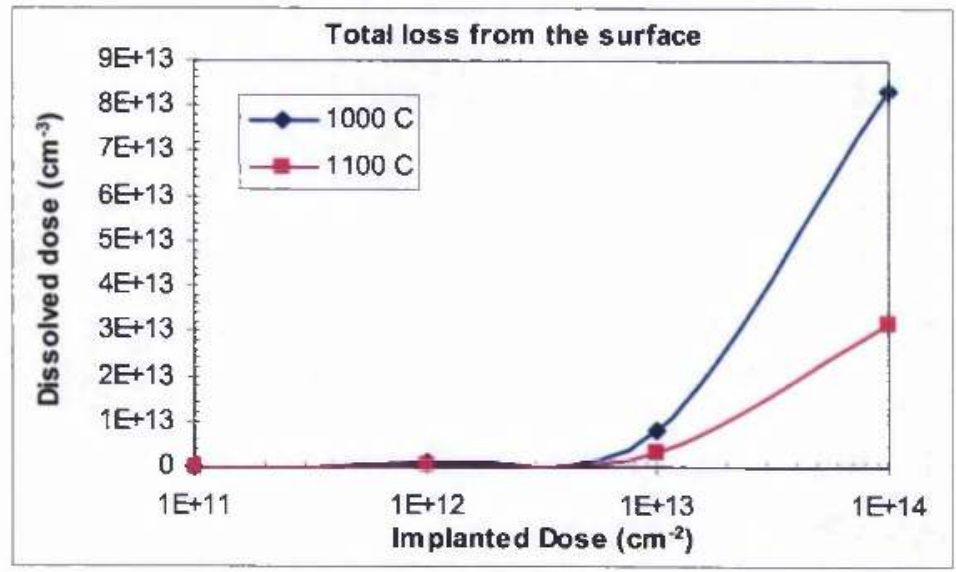

(a)

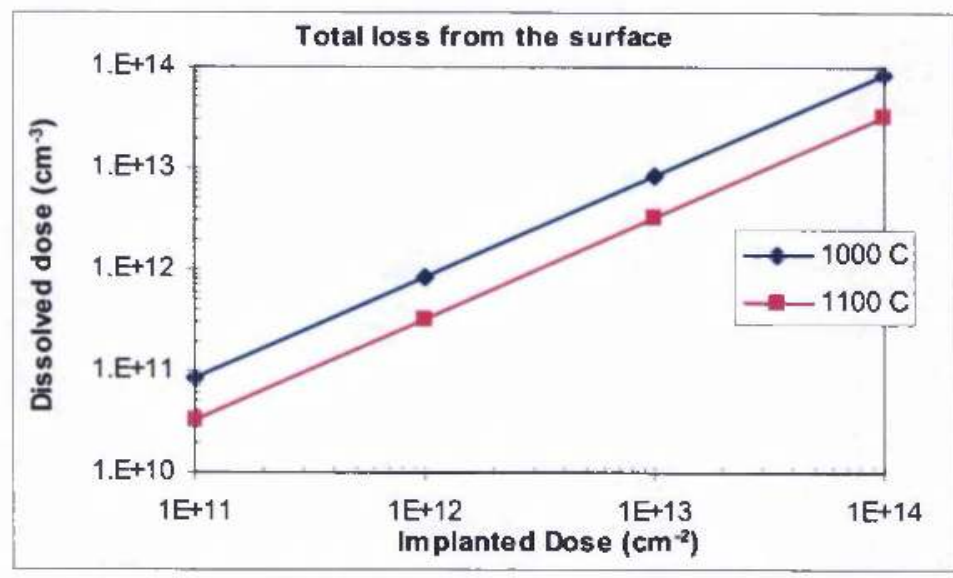

(b)

Figure 6.16 (a) Dependence of the sulphur dissolved dose with the implanted sulphur dose considering the case of total loss from the sample's surface for the two temperature annealing conditions, $1000{ }^{\circ} \mathrm{C}$ and $1100{ }^{\circ} \mathrm{C}$ for $10 \mathrm{~s}$. (b) Log-Log plot of the same data as in (a). 
Finally, an interesting effect is the dependence of the undissolved sulphur dose, i.e. the amount of sulphur that has not been dissolved, with the implanted sulphur dose. The undissolved sulphur is potentially responsible for the production of the non-luminescent centres. The values of the undissolved sulphur dose stem from the profiles (Figures 6.7-6.10), subtracting the values of the solid solubility limits at $1200 \AA$ from the value of sulphur concentration at $1200 \AA$, for the two temperature anneals $\left(1000^{\circ} \mathrm{C}\right.$ and $\left.1100^{\circ} \mathrm{C}\right)$, respectively. For the cases that the subtraction is a negative number the undissolved dose is zero. So for the hypothesis that there is total loss from the sample's surface, all the values of the sulphur concentration are lower than the solid solubility limits, therefore the values in the plot of the sulphur undissolved dose will be zero (Figure 6.17). In contrast, if we consider perfect reflection from the sample's surface, the values of the sulphur concentration are higher than the solid solubility limits, especially for the higher sulphur implant doses $10^{12}, 10^{13}, 10^{14} \mathrm{~S} \mathrm{~cm}^{-2}$, so the plot of the dependence of the undissolved sulphur dose with the implanted sulphur dose can be produced as shown in Figure 6.18.

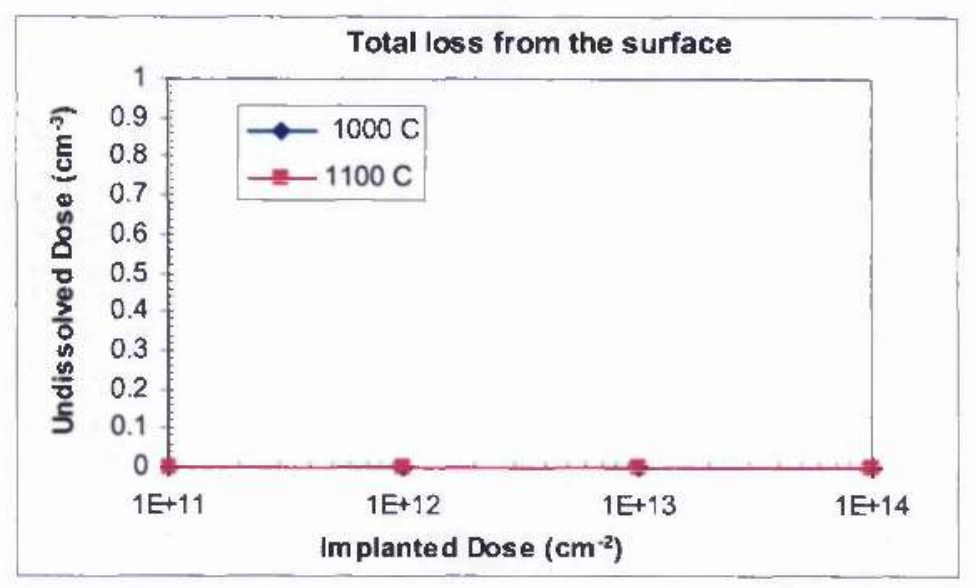

Figure 6.17 Dependence of the sulphur undissolved dose with the implanted sulphur dose considering the case of total loss from the sample's surface for the two temperature annealing conditions, $1000^{\circ} \mathrm{C}$ and $1100{ }^{\circ} \mathrm{C}$ for $10 \mathrm{~s}$. 


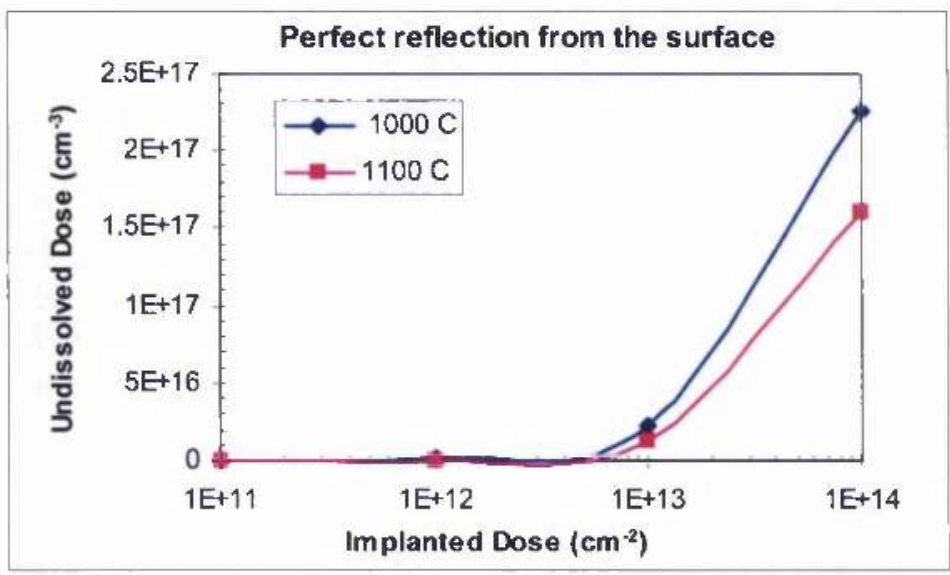

(a)

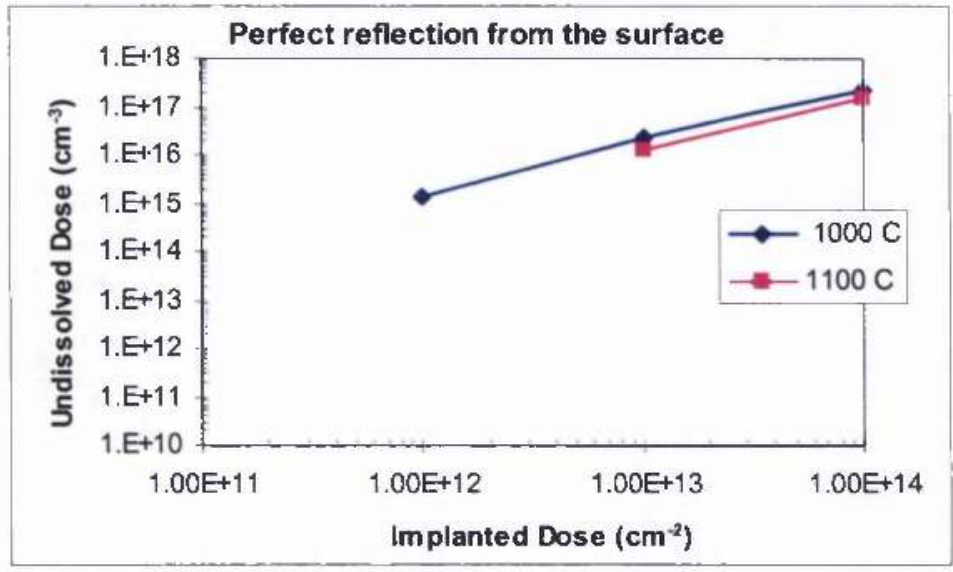

(b)

Figure 6.18 (a) Dependence of the sulphur undissolved dose with the implanted sulphur dose considering the case of perfect reflection from the sample's surface for the two temperature annealing conditions, $1000{ }^{\circ} \mathrm{C}$ and $1100{ }^{\circ} \mathrm{C}$ for $10 \mathrm{~s}$. (b) Log-Log plot of the same data as in (a).

From Figure 6.18 it is observed that the amount of undissolved sulphur is increasing much faster at the higher sulphur implanted doses. Moreover, the amount of the undissolved sulphur is larger for the $1000{ }^{\circ} \mathrm{C}$ temperature anneal.

Comparing Figures 6.15 and 6.18 which illustrate the trends of the dissolved and undissolved sulphur concentration with the implanted sulphur dose, we can deduce that each one of them eliminates the effect of the other one. So if we multiply 
these two trends the total effect would be a flat line. This indicates that the effect of the dissolved sulphur dose, which produces the sulphur luminescent centres may be being minimised by the effect of the undissolved sulphur dose, which is responsible for the non-luminescent centres. This is a possible explanation for our EL results, which show the sulphur integrated intensity not to change very much with the increase of the implanted sulphur dose (Figure $5.34 \mathrm{~b}$ ). Furthermore, considering the two hypotheses, that either there is perfect reflection or total loss from the sample's surface, what is the most likely to happen in reality is to be somewhere in between these two cases.

Furthermore, comparing the diffused profiles as they have derived from our model (Figure 6.10) with the SIMS results (Figure 6.3) we conclude that our model predicts that the sulphur is diffused inside the sample, whereas the SLMS data reveal that there is still a residue of sulphur probably trapped at the surface or at the oxide interface in the sample. The values of the solid solubility limits and the diffusion coefficient of sulphur derive from R.O Carlson et al. $[9,12]$, as has been previously stated. This is the only report about sulphur in silicon. Although it was stated that the values of the solid solubility limits and the diffusion coefficient of sulphur derived from Hall measurements, this is an indirect measurement. In addition, these values have been reported for samples where sulphur was diffused into silicon or from silicon doped with hydrogen sulphide which are different from our samples which were implanted with sulphur and further annealed at high temperatures (1000 $\left.{ }^{0} \mathrm{C} / 1100{ }^{\circ} \mathrm{C}\right)$ for short time $(10 \mathrm{~s})$. Therefore, the values used for the diffusion coefficient of sulphur and the solid solubility limits may not be $100 \%$ applicable to our samples. 


\subsubsection{Model explaining the power and current dependence effects}

The model that can explain our results is similar to the one described by Rosenweig et al. [13] for the recombination via a $\mathrm{Zn}-\mathrm{O}$ complex in $\mathrm{GaP}$. In our model the sulphur forms a radiative recombination centre. As illustrated in the band diagram of Figure 6.19, an electron in the conduction band may recombine radiatively with a hole in the valence band with a help of a phonon (phonon assisted transition since $\mathrm{Si}$ is an indirect band-gap material) with an associated lifetime $\tau_{\mathrm{Si}}$. In addition, an electron trapped in the sulphur related centre may recombine with a hole in the valence band radiatively as a bound electron-hole pair with a lifetime of $\tau_{\mathrm{S}}$, or it may return to the valence band non-radiatevely having a lifetime of $\tau_{\mathrm{NR}}$.

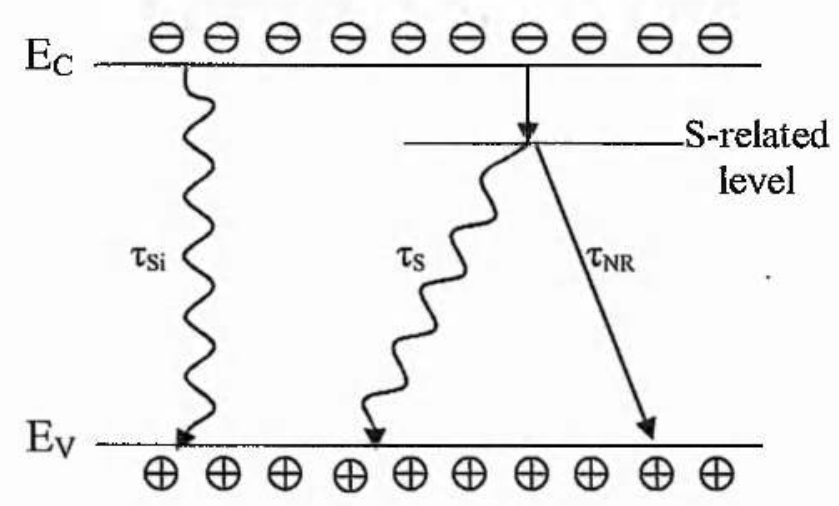

Figure 6.19 Band diagram of recombination via the $\mathrm{S}$ level in $\mathrm{Si} . \tau_{\mathrm{Si}}$ stands for the lifetime of an electron from the conduction band which has recombined radiatively with a hole of the valence band with a help of a phonon, $\tau_{\mathrm{S}}$ stands for the lifetime of an electron from the $\mathrm{S}$ level which has recombined radiatively with a hole of the valence band as a bound electronhole pair and $\tau_{\mathrm{NR}}$ stands for the lifetime of an electron from the $S$ level which returns to the valence band non-radiatively. $\mathrm{E}_{\mathrm{C}}$ and $\mathrm{E}_{\mathrm{V}}$ are the energy of the condution and the valence bands, respectively.

The rate equation description of our model which represents our PL and EL results is illustrated in Figure 6.20. 


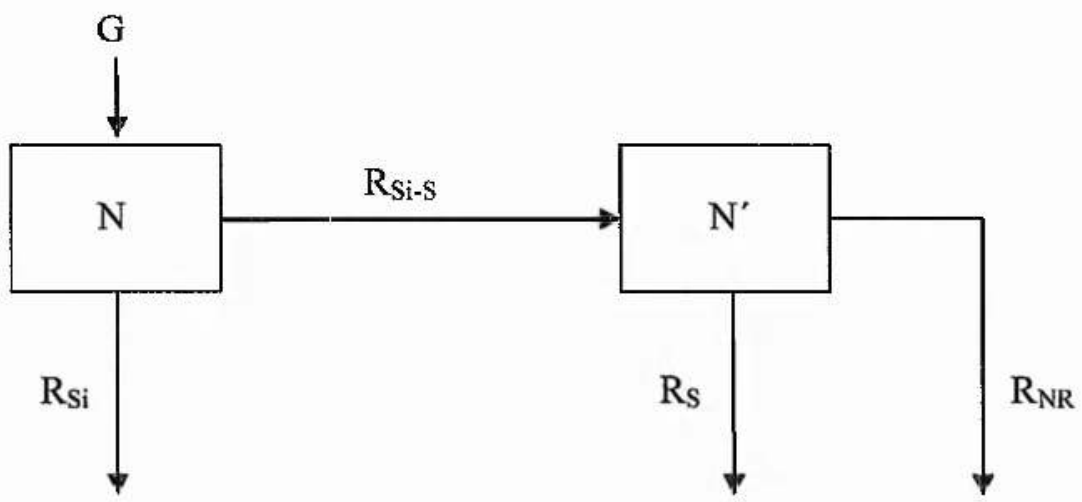

Figure 6.20 Schematic representation of the rate equation description of our model. $G$ is the input generation rate, $R_{S i}$, is the radiative recombination rate from $S i, R_{S}$ is the radiative recombination rate from $S, R_{N R}$ is the non-radiative recombination rate from $S$ and $R_{S i-S}$ is the recombination rate from the conduction band to the S-related level. $\mathrm{N}$ is the density of electrons in the conduction band and $\mathrm{N}^{\prime}$ is the density of electrons trapped in the sulphur related level.

The recombination rate from $\mathrm{Si}, \mathrm{R}_{\mathrm{Si}}$, is equal to the generation rate, $\mathrm{G}$, minus the recombination rate from the conduction band to the $\mathrm{S}$-related level, $\mathrm{R}_{\mathrm{Si}-\mathrm{S}}$, i.e.

$$
R_{S i}=G-R_{S i-S} \Rightarrow R_{S i}=G-B N\left(N_{0}-N^{\prime}\right)
$$

where $\mathrm{N}$ is the density of electrons in the conduction band, $\mathrm{N}^{\prime}$ is the density of electrons trapped in the sulphur related level and $N_{0}$ is the total density of traps due to sulphur. B is a coefficient for conduction band-to-S level recombination. Therefore in equation (6.21), the recombination rate from the conduction band, $\mathrm{R}_{\mathrm{Si}}$, is equal to the generation rate minus the recombination rate from the conduction band to the S-related level, $\mathrm{R}_{\mathrm{Si}-\mathrm{S}}$, which is equal to the product of density of electrons in the conduction band by the total density of traps in the S-related level minus the density of electrons trapped in the S-related level by the coefficient factor $\mathrm{B}$. The recombination rate from $S, R_{S}$, is given by the formula:

$$
R_{S}=R_{S i-S}-R_{N R} \Rightarrow R_{S}=B N\left(N_{0}-N^{\prime}\right)-R_{N R}
$$


where $\mathrm{R}_{\mathrm{Si}-\mathrm{S}}$ is recombination rate from the conduction band to the S-related level as described in equation (6.21) and $R_{N R}$ is the non-radiative rate from $S$. The total recombination rate which is the sum of the recombination rates from $\mathrm{Si}$ and $\mathrm{S}$ is given by the following formula, using also formulas (6.21) and (6.22):

$$
R_{t o t}=R_{S i}+R_{S} \Rightarrow R_{t o t}=G-R_{N R}
$$

The density of electrons in the conduction band, $\mathrm{N}$, and the density of electrons trapped in the sulphur related level, $\mathrm{N}^{\prime}$, are given by the following formulas:

$$
\begin{aligned}
& N=R_{S i} \tau_{S i} \\
& N^{\prime}=R_{S} \tau_{S}
\end{aligned}
$$

where $\tau_{\mathrm{Si}}$ is the lifetime of an electron from the conduction band which has recombined radiatively with a hole of the valence band with a help of a phonon and $\tau_{\mathrm{S}}$ is the lifetime of an electron from the $\mathrm{S}$ level which has recombined radiatively with a hole of the valence band as a bound electron-hole pair. The non-radiative rate from $S, R_{N R}$, is given by

$$
R_{N R}=\frac{N^{\prime}}{\tau_{N R}} \Rightarrow R_{N R}=\frac{R_{S} \tau_{S}}{\tau_{N R}}
$$

where the second formula in equation (6.26) has been derived with the help of equation (6.25). Therefore, the recombination rate from $S, R_{S}$, (equation (6.22)) can be written using formulas (6.24), (6.25) and (6.26) as follows:

$$
R_{S}=\frac{B N_{0} R_{S i} \tau_{S i}}{1+B R_{S i} \tau_{S i} \tau_{s}+\frac{\tau_{s}}{\tau_{N R}}}
$$


In addition, the recombination rate from $\mathrm{Si}, \mathrm{R}_{\mathrm{Si}}$, (equation (6.21)) can be also written using formulas (6.24) and (6.25) as follows:

$$
R_{S i}=\frac{G}{1+B N_{0} \tau_{S i}-B R_{S} \tau_{s} \tau_{S i}}
$$

If we substitute the term of $R_{S}$ in equation (6.28) from its analytical form as shown in equation (6.27), equation (6.28) can be written as:

$$
R_{S i}^{2}\left(B \tau_{S i} \tau_{S}\right)+R_{S i}\left[\left(1+B N_{0} \tau_{S i}\right)\left(1+\frac{\tau_{S}}{\tau_{N R}}\right)-B G \tau_{S i} \tau_{s}\right]-G\left(1+\frac{\tau_{S}}{\tau_{N R}}\right)=0
$$

The above formula is a quadratic equation in terms of $\mathrm{R}_{\mathrm{Si}}$. Solving equation (6.29), we have found that the solution which is accepted is given by

$$
R_{S i}=\frac{-\mathrm{AB}^{\prime}+\Gamma+\sqrt{\mathrm{A}^{2} \mathrm{~B}^{\prime 2}+\Gamma^{2}-2 \Gamma\left[\mathrm{B}^{\prime}(\mathrm{A}-2)\right]}}{2 \Delta^{\prime}}
$$

where

$$
\begin{gathered}
\mathrm{A}=1+B \mathrm{~N}_{0} \tau_{S t} \\
\mathrm{~B}^{\prime}=1+\frac{\tau_{s}}{\tau_{N R}} \\
\Gamma=\mathrm{B} G \tau_{S i} \tau_{S} \\
\Delta^{\prime}=\mathrm{B} \tau_{S i} \tau_{S}
\end{gathered}
$$

derive from equation (6.29).

Substituting the solution $R_{S i}$ from equation 6.28 to equation 6.25 we obtain:

$$
R_{S}=\frac{\left(-\mathrm{AB}^{\prime}+\Gamma+\sqrt{\mathrm{A}^{2} \mathrm{~B}^{\prime 2}+\Gamma^{2}-2 \Gamma\left[\mathrm{B}^{\prime}(\mathrm{A}-2)\right]}\right) \mathrm{A}-2 G \Delta^{\prime}}{\left(-\mathrm{AB}^{\prime}+\Gamma+\sqrt{\mathrm{A}^{2} \mathrm{~B}^{\prime 2}+\Gamma^{2}-2 \Gamma\left[\mathrm{B}^{\prime}(\mathrm{A}-2)\right]}\right] \Delta^{\prime}}
$$


where A, $\mathrm{B}^{\prime}, \Gamma$ and $\Delta^{\prime}$ come from equations (6.31)-(6.34).

The total recombination rate which is the sum of the recombination rates from $\mathrm{Si}$ and $\mathrm{S}$ is given by the sum of equations (6.30) and (6.35):

$$
\begin{aligned}
& R_{\text {tot }}=\frac{-\mathrm{AB}^{\prime}+\Gamma+\sqrt{\mathrm{A}^{2} \mathrm{~B}^{\prime 2}+\Gamma^{2}-2 \Gamma\left[\mathrm{B}^{\prime}(\mathrm{A}-2)\right]}}{2 \Delta^{\prime}}+ \\
& \frac{\left(-\mathrm{AB}^{\prime}+\Gamma+\sqrt{\mathrm{A}^{2} \mathrm{~B}^{\prime 2}+\Gamma^{2}-2 \Gamma\left[\mathrm{B}^{\prime}(\mathrm{A}-2)\right]}\right) \mathrm{A}-2 G \Delta^{\prime}}{\left(-\mathrm{AB}^{\prime}+\Gamma+\sqrt{\mathrm{A}^{2} \mathrm{~B}^{\prime 2}+\Gamma^{2}-2 \Gamma\left[\mathrm{B}^{\prime}(\mathrm{A}-2)\right]}\right] \Delta^{\prime}}
\end{aligned}
$$

In equations (6.30), (6.35) and (6.36) the recombination rates for $\mathrm{Si}, \mathrm{S}$ and total ( $R_{S i}, R_{S}$ and $R_{\text {tot }}$ respectively) are equivalent to the integrated intensities that we have measured in our experimental results in chapter five, and the generation rate $G$ is equivalent to the power that we are providing (applied current or laser power). Therefore, by using arbitrary units for the parameters $\tau_{\mathrm{Si}}, \tau_{\mathrm{S}}, \tau_{\mathrm{NR}}, \mathrm{N}_{0}, \mathrm{~B}$ (Table 6.3) and taking values of $\mathrm{G}$ ranging from $0-0.5$, we can produce the trend lines for the three integrated intensities for $\mathrm{Si}, \mathrm{S}$ and total as follows:

\begin{tabular}{||c|c||}
\hline Parameters & Arbitrary units \\
\hline$\tau_{\mathrm{Si}}$ & 10 \\
\hline$\tau_{\mathrm{S}}$ & 10 \\
\hline$\tau_{\mathrm{NR}}$ & 100 \\
\hline $\mathrm{N}_{0}$ & 0.7 \\
\hline $\mathrm{B}$ & 1 \\
\hline $\mathrm{G}$ & $0-0.5$ \\
\hline
\end{tabular}

Table 6.3 List of arbitrary units for the lifetime due to $\mathrm{Si}$ and $\mathrm{S}, \mathrm{t}_{\mathrm{Si}}, \tau_{\mathrm{S}}$, respectively, for the non-radiative lifetime from $S, \tau_{\mathrm{NR}}$, for the total density of traps due to sulphur, $N_{0}$, for the coefficient for conduction band-to-S level recombination, B, and for the generation rate, G.

Thus, using equations (6.30)-(6.36) and the values from Table 6.3 we can plot the recombination rates for $\mathrm{Si}, \mathrm{S}$ and the total, $\mathrm{R}_{\mathrm{Si}}, \mathrm{R}_{\mathrm{S}}$, and $\mathrm{R}_{\text {tot }}$, respectively, with the 
generation rate $\mathrm{G}$ which is equivalent to the plot of integrated intensities for $\mathrm{Si}, \mathrm{S}$ and total with the applied current or laser power (Figure 6.21).

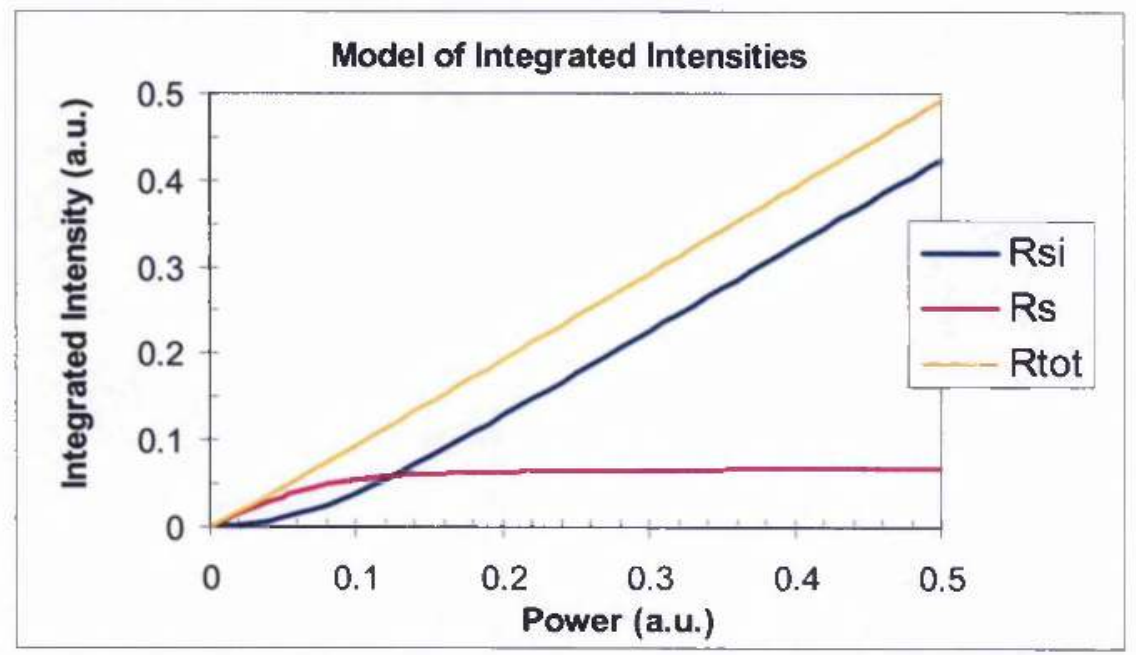

Figure 6.21 Behaviour of the three integrated intensity trends as predicted from the model.

Comparing Figure 6.21 with Figures 5.36-5.43 of chapter 5, we can conclude that our model describes our experimental data. In addition, as was also observed in Figures 5.36-5.43 and is seen in Figure 6.21, at low excitation power, the total integrated intensity trend is closely linear. This is due to the fact that since from low power the sulphur level is filled with electrons and therefore is saturated (sublinear trend), by increasing the power, the rest of incoming electrons are going through the silicon level than via the sulphur level, increasing the possibility of radiative recombinations via the $\mathrm{Si}$ level (superlinear trend). So the total integrated intensity trend which is the sum of $\mathrm{Si}$ and $\mathrm{S}$ integrated intensities becomes linear as observed in the low current injection region. In addition taking into account the values of the slopes of the integrated intensities of $\mathrm{Si}, \mathrm{S}$ and total, listed in Tables 6.1 and 6.2, the sulphur and silicon integrated intensity are increasing sublinear and superlinear, respectively, with the increase of power conditions which agree with our model. From the values of the slopes of the total integrated intensity which are close to one we can conclude that our model predicts better the behaviour of sulphur samples implanted also with the boron. For the case of samples implanted with sulphur only the total integrated intensity trends reveal a superlinear dependence on the power (the 
values of the slopes are above one). For this case our model does not match the total integrated intensity experimental data as well.

The values of the parameters of our model as listed in Table 6.3 are arbitrary units in conjunction with values reported in literature. For instance, the value of the silicon lifetime from experimental data is reported to be in the region of $10 \mu \mathrm{sec}$ [1]. The fact that we see sulphur emission in all samples made us choose the same value for the sulphur lifetime. The number chosen for the lifetime of the non-radiative rate was $100 \mu \mathrm{sec}$. Increasing this value the form of the integrated intensity trend values appear to be relatively insensitive to changes in the parameter. However, reducing this value to e.g. $10 \mu \mathrm{sec}$ we observe that the silicon integrated intensity trend values are becoming smaller and less superlinear than our experimental data. The total integrated intensity trend becomes superlinear. The value of density of traps $\mathrm{N}_{0}$ is set at 0.7 . Increasing this value the crossing point between the sulphur and silicon integrated intensity trends is shifting towards higher power values (Figure 6.21) which does not correlate with our experimental results. Similarly, decreasing this value the crossing point takes place in the lower power regime which again does not comply with our data. Finally, the value of the coefficient B for conduction band-to$\mathrm{S}$ level recombination was chosen to be 1 . Increasing this value above 1 the crossing point of the trends ( $\mathrm{Si}$ and $\mathrm{S}$ ) is shifting towards higher power values and the shapes of the trends are becoming different from the experimental ones at the low power regime. Decreasing $\mathrm{B}$ below 1 the crossing point between the two trends occurs at lower power values, which also does not agree with our experimental data.

An important feature is the energy associated with the quenching of sulphur transition. This can be found from the temperature dependence of the sulphur integrated intensity of the eight studied samples (Figure 5.29 (a) and (b)). By replotting Figure 5.29 ((a) and (b)) in a scale of the natural logarithm of the sulphur integrated intensity versus $1 / \mathrm{T}$, we can find the energy associated with the sulphur quenching by fitting the high temperature fall off. We consider that the sulphur integrated intensity is proportional to the $\exp (-\Delta \mathrm{E} / \mathrm{kT})$; therefore the slope of the fit from the sulphur integrated intensity of each sample multiplied by the Boltzman 
constant, $\mathrm{k}=8.6171 \times 10^{-5} \mathrm{eV} / \mathrm{K}$, can give us an indication of the activation energy of the quenching of the sulphur peak which is thermally activated (Figure 6.22).

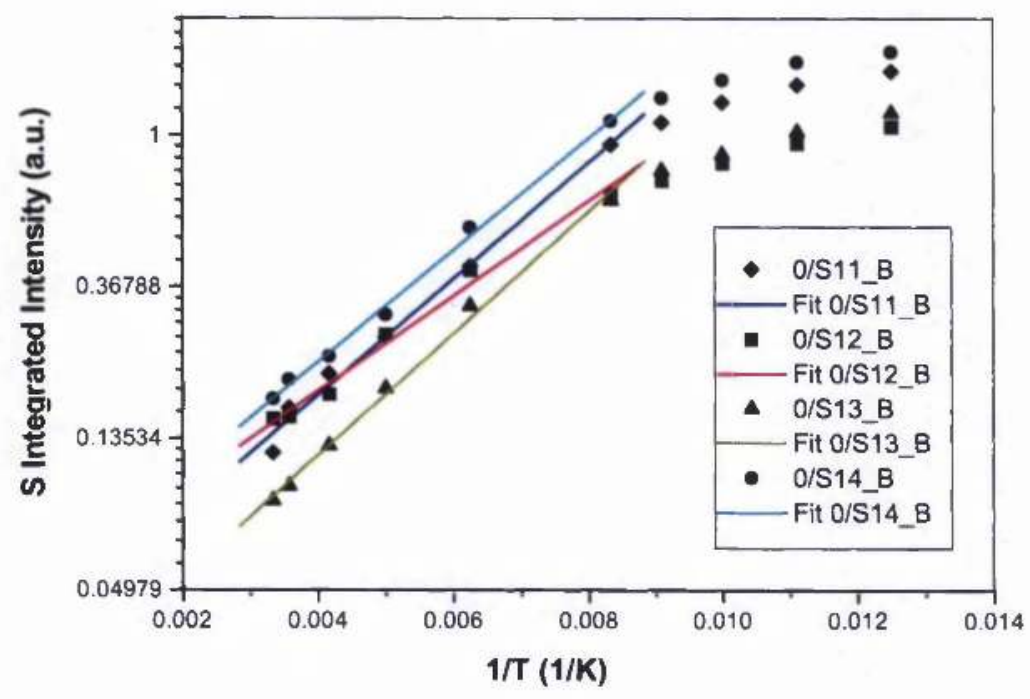

(a)

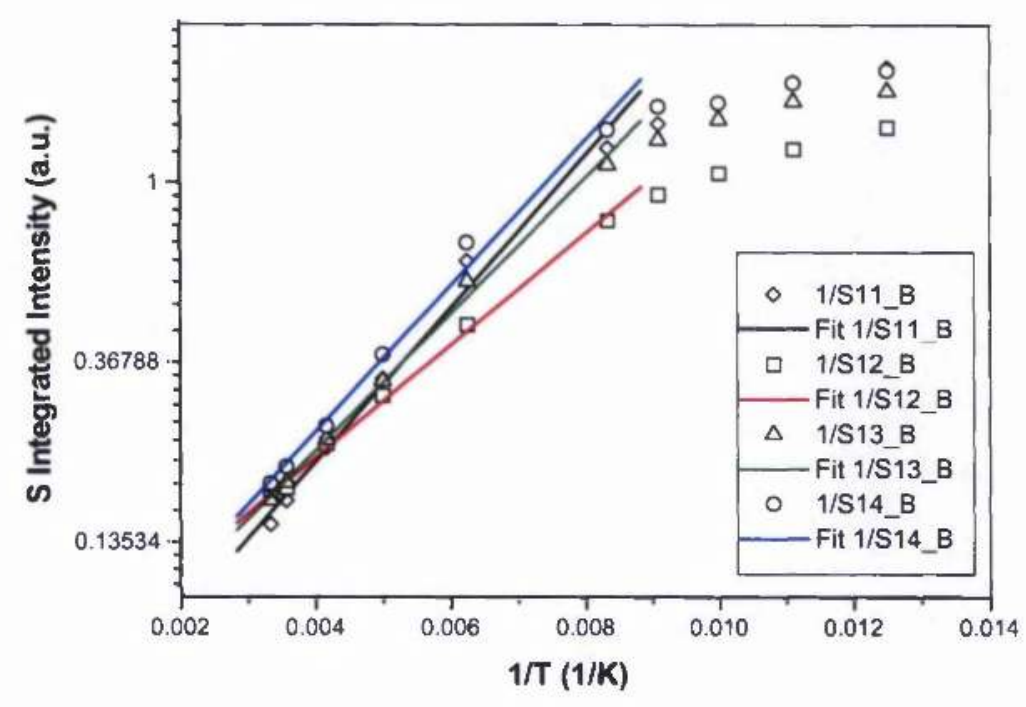

(b)

Figure 6.22 Temperature dependence of the sulphur integrated intensity as taken from the EL spectra of all samples (a) 0/S11_B-0/S14_B, and (b) 1/S11_B-1/S14_B. EL experiments were done at $25 \mathrm{~mA}$ applied drive current. The errors in sulphur integrated intensity and measurement temperature are within the symbol size. The scale in the vertical axis is the natural logarithm of the sulphur integrated intensity. The solid lines are the linear fits at the higher temperature integrated intensity values. 
Therefore, in Table 6.4 are listed the slopes of the linear fits from the sulphur integrated intensity of each sample, the value of the slope multiplied by the Boltzman constant which gives us the activation energy of the sulphur peak quenching, the error in the slope and the error in the energy.

\begin{tabular}{||c|c|c|c|c||}
\hline Samples & Slopes & Energy (eV) & $\begin{array}{c}\text { Error in } \\
\text { slopes }\end{array}$ & $\begin{array}{c}\text { Error in } \\
\text { energy (eV) }\end{array}$ \\
\hline O/S11_B & 382.77 & 0.0329 & 19.8 & 0.0017 \\
\hline 0/S12_B & 313.19 & 0.0269 & 17.8 & 0.0015 \\
\hline 0/S13_B & 401.83 & 0.0346 & 13.9 & 0.0011 \\
\hline 0/S14_B & 368.16 & 0.0317 & 11.1 & 0.0009 \\
\hline 1/S11_B & 427.27 & 0.0368 & 24.1 & 0.0020 \\
\hline 1/S12_B & 312.03 & 0.0268 & 8.8 & 0.0007 \\
\hline 1/S13_B & 380.11 & 0.0327 & 12.7 & 0.0010 \\
\hline 1/S14_B & 405.99 & 0.0349 & 19.8 & 0.0017 \\
\hline Mean Values & 373.92 & 0.0322 & 16.0 & 0.0014 \\
\hline
\end{tabular}

Table 6.4 List of values of the slopes of the eight samples $\left(0 / \mathrm{S} 11 \_\mathrm{B}-1 / \mathrm{S} 14 \_\mathrm{B}\right)$ as taken from the linear fits of their sulphur integrated intensity trends, the energy associated to the sulphur peak quenching which corresponds to each sample, the errors in the slopes and the errors in the energy.

From Table 6.4 and Figure 6.22, taking the mean value of all eight samples, we can conclude that the energy associated with the sulphur quenching is equal to $32.2 \pm 1.4 \mathrm{meV}$. This energy is much less compared to the energy indicated from the value stated in the literature of $139 \mathrm{meV}$ [2]. The reason for the difference in the values may be due to the fact that our samples are implanted with sulphur and boron whereas the value of the energy associated with the $S$ peak quenching from the literature comes from samples which were implanted only with sulphur. This may be related to the effect of the dislocation loop strain barrier in our samples.

In conclusion, in this chapter a discussion about our PL and EL results was given. An interesting effect of the applied laser power on the PL was found, 
revealing an interesting sublinear and superlinear dependence of the sulphur and silicon integrated intensity at low laser power. In accordance to the PL results, the effect of applied current was studied for our EL results. An equivalent sublinear and superlinear behaviour of the sulphur and silicon integrated intensity was found at the low injection conditions. The total integrated intensity was found to be closely linear at the low injection conditions whereas at the higher applied currents it follows the silicon integrated intensity trend. The effect of implanted sulphur dose and the annealing effect were also examined, revealing no significant change of the sulphur emission with the increase of the implanted sulphur dose. This behaviour may be explained from the model which was presented, which revealed that the two main factors which produce the luminescent and non-luminescent sulphur centres may be competing with each other giving a net result of the small change of sulphur integrated intensity with the implanted sulphur dose. Moreover, the diffusion of sulphur atoms after the annealing conditions was thoroughly investigated, presenting the two cases of perfect reflection and perfect loss from the sample's surface. A model that explains our PL and EL power dependence results was provided which described the trends in our experimental data well. Finally, the energy associated with the sulphur peak quenching was calculated from the slopes of the linear fits of the sulphur integrated intensity trends at the higher temperatures of all eight samples. 
Chapter 6-Discussion on Si:S Samples

\section{References}

[1] W. L. Ng, M. A. Lourenço, R. M. Gwilliam, S. Ledain, G. Shao and K. P. Homewood, Nature 410, 192 (2001).

[2] T. G. Brown and D. G. Hall Appl. Phys. Lett., 49, 245 (1986).

[3] T. G. Brown, P. L. Bradfield and D. G. Hall Appl. Phys. Lett., 51, 1585 (1987).

[4] W. L. Ng, PhD thesis, University of Surrey, Spectroscopy of novel light emitting silicon-based diodes, (2000).

[5] M. A. Lourenço, M. Milosavljevic, S. Galata, M. S. A. Siddiqui, G. Shao, R. M. Gwilliam and K. P. Homewood, Vacuum (2004) to be published.

[6] P. L. Bradfield, T. G. Brown and D. G. Hall, J. Appl. Phys. 55, 100 (1989).

[7] H. F. Wolf, Silicon semiconductor data, Pergamon (1969).

[8] S. M. Sze, Physics of semiconductor devices, second edition (1981).

[9] R. O. Carlson, R. N. Hall and E. M. Pell, J. Phys. Chem. Solids 8, 81 (1959).

[10] S. M. Sze, VLSI Technology, first edition (1983).

[11] J. F. Ziegler, Handbook of Ion Implantation Technology, (1992).

[12] F. A. Trumbore, Bell System Tech. J. 39, 205 (1960).

[13] W. Rosenweig, W. H. Hackett and J. S. Jayson, J. Appl. Phys. 40, 4477 (1969). 


\section{CONCLUSIONS AND RECOMMENDATIONS FOR FURTHER WORK}

\subsection{Conclusions}

In the first part of this study, we have demonstrated PL experiments from S doped Si samples. The PL emission consisted of two main peaks at $1129.5 \mathrm{~nm}$ $(1.0997 \mathrm{eV})$ and at $1334 \mathrm{~nm}(0.930 \mathrm{eV})$ which are due to the TO phonon assisted Si transition and due to $\mathrm{S}$. Variable temperature experiments revealed that the two peaks were shifting to longer wavelengths (lower energies) with the increase of temperature. From the three studied samples, the sample which was implanted with sulphur and also implanted with boron, as a means for the introduction of the dislocation loops, the sulphur emission is stronger compared to the silicon one and it remains up to higher temperatures compared to the samples implanted only with sulphur. In addition, of great interest is the effect of laser power on silicon and sulphur emission. It has revealed a sublinear behaviour for the sulphur integrated intensity and a superlinear behaviour for the silicon integrated intensity with the increase of laser power, which can be attributed to the saturation of sulphur related levels responsible for the $1.33 \mu \mathrm{m}$ emission at the high excitation levels.

In the second part of our research, we have presented EL experiments from Si:S LED devices implanted with sulphur at a range of doses and also implanted with boron in order to introduce the dislocation loops. All samples revealed, as for our PL experiments, two major lines at $1129.5 \mathrm{~nm}(01.0997 \mathrm{eV})$ and at $1363.25 \mathrm{~nm}(0.9095$ $\mathrm{eV}$ ) which are due to the TO phonon assisted $\mathrm{Si}$ transition and due to $\mathrm{S}$. From temperature dependence experiments these two emissions were shifting towards longer wavelengths with the increase of temperature. Both silicon and sulphur emission were present at $300 \mathrm{~K}$, with the sulphur emission relatively smaller than the silicon emission. 
The dependence of electrical injection was studied and revealed a behaviour similar to our PL results; a sublinear and a superlinear behaviour for the sulphur and silicon integrated intensity trends respectively was observed. The total integrated intensity which is the sum of the two intensities appeared to be closely linear at low injection conditions and similar to the silicon trend at the higher injection conditions. This behaviour can be attributed to the competing mechanisms between the sulphur and silicon centres, as well as the saturation of sulphur level from low current injection conditions, making the route towards the silicon level more favourable.

The effect of implanted sulphur dose and the annealing effect were also investigated, revealing no significant change of the sulphur emission with the increase of the implanted sulphur dose. In addition, a model of the diffusion of sulphur after the annealing treatments was presented, introducing the two cases of perfect reflection and perfect loss from the sample's surface. Finally a model explaining our PL and EL power dependence experiments was provided which showed that there are two major radiative routes via the silicon and the sulphur that take place, which are competing with each other along with a non-radiative route coming from the sulphur-related level. Our model provides a good match to the behaviour of our experimental data. Finally, the activation energy related to the sulphur peak quenching was calculated to be $32.2 \pm 1.4 \mathrm{meV}$.

\subsection{Recommendations for further work}

There are several ideas which could be implemented in order to improve the sulphur emission

(a) Boron could be implanted first and then sulphur under the same annealing conditions at a variety of implantation doses in order to investigate more their effect in sulphur emission. 
(b) TEM analysis could be performed in our samples to investigate any possible structural changes after the sulphur implantation and after the annealing treatments.

(c) Further engineering of the $\mathrm{Si}: \mathrm{S}$ devices could be made by varying the annealing and dose conditions in order to enhance the sulphur emission at room temperature. 